\title{
Life after survival of a cardiac arrest : the brain is the heart of the matter
}

Citation for published version (APA):

Moulaert, V. R. M. P. (2014). Life after survival of a cardiac arrest : the brain is the heart of the matter. [Doctoral Thesis, Maastricht University]. Maastricht University. https://doi.org/10.26481/dis.20140425vm

Document status and date:

Published: 01/01/2014

DOI:

10.26481/dis.20140425vm

Document Version:

Publisher's PDF, also known as Version of record

\section{Please check the document version of this publication:}

- A submitted manuscript is the version of the article upon submission and before peer-review. There can be important differences between the submitted version and the official published version of record.

People interested in the research are advised to contact the author for the final version of the publication, or visit the DOI to the publisher's website.

- The final author version and the galley proof are versions of the publication after peer review.

- The final published version features the final layout of the paper including the volume, issue and page numbers.

Link to publication

\footnotetext{
General rights rights.

- You may freely distribute the URL identifying the publication in the public portal. please follow below link for the End User Agreement:

www.umlib.nl/taverne-license

Take down policy

If you believe that this document breaches copyright please contact us at:

repository@maastrichtuniversity.nl

providing details and we will investigate your claim.
}

Copyright and moral rights for the publications made accessible in the public portal are retained by the authors and/or other copyright owners and it is a condition of accessing publications that users recognise and abide by the legal requirements associated with these

- Users may download and print one copy of any publication from the public portal for the purpose of private study or research.

- You may not further distribute the material or use it for any profit-making activity or commercial gain

If the publication is distributed under the terms of Article $25 \mathrm{fa}$ of the Dutch Copyright Act, indicated by the "Taverne" license above, 


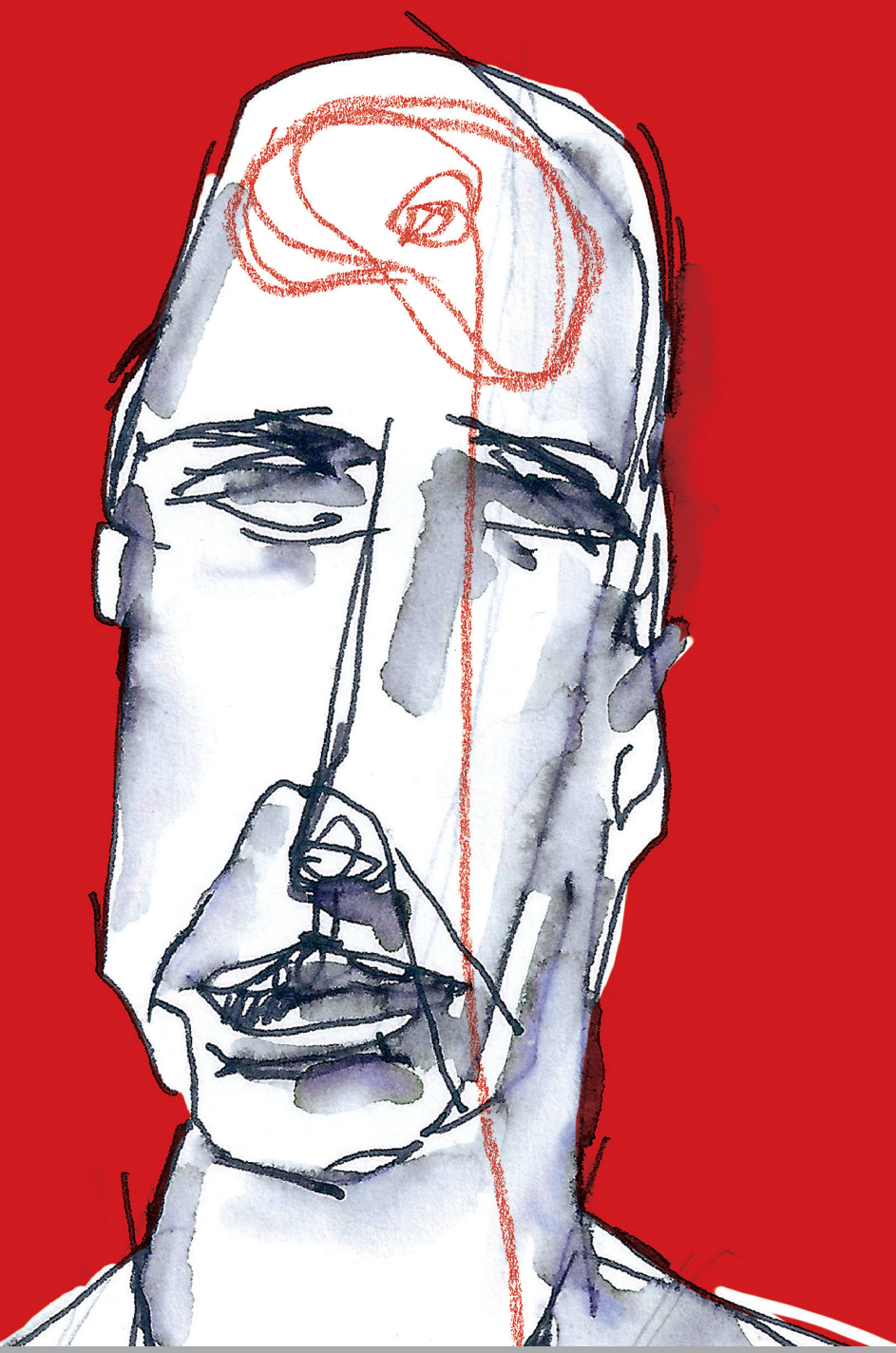

\section{Life after survival of a cardiac arrest The brain is the heart of the matter}

Véronique Moulaert

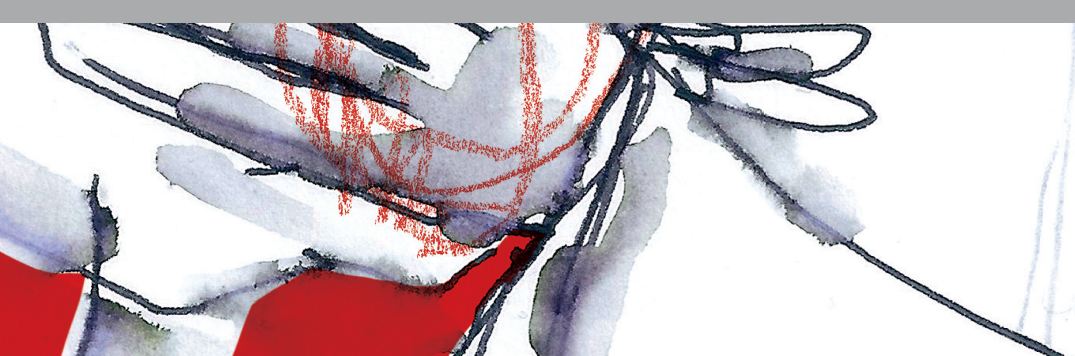





\section{Life after survival of a cardiac arrest The brain is the heart of the matter}

Véronique Moulaert 


\section{Colofon}

ISBN: 978-94-6108-603-7

Omslagontwerp: io_communicatie Omslagillustratie: Miguel Essers / Onesixnorth.com Layout and printed by: Gildeprint 


\section{Life after survival of a cardiac arrest The brain is the heart of the matter}

\section{PROEFSCHRIFT}

Ter verkrijging van de graad van doctor aan de Universiteit Maastricht, op gezag van de Rector Magnificus, prof. dr. L.L.G. Soete, volgens het besluit van het College van Decanen in het openbaar te verdedigen op vrijdag 25 april 2014 om 12.00

door

Véronique Roberte Marie-Paule Moulaert 


\section{Promotores}

Prof. dr. J.A. Verbunt

Prof. dr. C.M. van Heugten

Prof. dr. D.T. Wade, Oxford Centre for Enablement, United Kingdom

\section{Beoordelingscommissie}

Prof. dr. R.J.E.M. Smeets (voorzitter)

Dr. R.W. Koster, AMC Amsterdam

Prof. dr. R.J. van Oostenbrugge

Prof. dr. R.W.H.M. Ponds

Prof. dr. J.M.A. Visser-Meily, UMC Utrecht

The research presented in this thesis was conducted at the School for Public Health and Primary Care: CAPHRI, Department of Rehabilitation Medicine, and School for Mental Health and Neuroscience of Maastricht University. CAPHRI participates in the Netherlands School of Primary Care Research CaRe. CAPHRI was classified as 'excellent' by the external evaluation committee of leading international experts that reviewed CAPHRI in December 2010.

This research was funded by the Netherlands Organisation for Health Research and Development (ZonMw 920-03-373), Fonds Nuts Ohra and Stichting Elisabeth Strouven.

Financial support by Stichting Hartsvrienden Rescar (Maastricht) for the publication of this thesis is gratefully acknowledged. 
"L'essentiel est invisible pour les yeux"

Antoine de Saint-Exupéry, Le Petit Prince 



\section{Table of contents}

Chapter 1

General introduction

\section{Chapter 2}

Life after survival: long-term daily functioning and quality of life after an out-of-hospital cardiac arrest

\section{Chapter 3}

Determinants of quality of life in survivors of a cardiac arrest

\section{Chapter 4}

Cognitive impairments in survivors of out-of-hospital cardiac arrest: a systematic review

\section{Chapter 5}

Activity and Life After Survival of a Cardiac Arrest (ALASCA) and the effectiveness of an early intervention service: design of a randomised controlled trial

\section{Chapter 6}

'Stand still..., and move on', a new early intervention service for cardiac arrest survivors and their caregivers: rationale and description of the intervention

\section{Chapter 7}

'Stand still..., and move on', an early neurologically-focused follow-up for cardiac arrest survivors and their caregivers: a process evaluation

\section{Chapter 8}

Early intervention service 'Stand still ..., and move on' improves quality of life after cardiac arrest: results of a randomised controlled trial

\section{Chapter 9}

General discussion

\section{Summary}

Samenvatting

Information booklet

English version

Dutch version 



\section{Chapter 1}

General introduction 
10 | Chapter 1 
A cardiac arrest is, literally, a life changing event. The cardiac consequences of a cardiac arrest are well-known, but that this dramatic event can also have neurological, psychological and social consequences is less commonly acknowledged, and this confronts survivors, caregivers and healthcare with a challenge. This thesis presents the results of the research project 'Activity and Life After Survival of a Cardiac Arrest' (ALASCA), in which outcome after cardiac arrest was investigated and a new intervention service for cardiac arrest survivors and their caregivers was developed and evaluated.

\section{Definition, causes and incidence of cardiac arrest}

Cardiac arrest is defined as 'the abrupt cessation of cardiac pump function, which may be reversible, but will lead to death in the absence of prompt intervention'. ${ }^{1}$ The cessation of cardiac mechanical activity is confirmed by the absence of signs of circulation. ${ }^{2}$

The most common underlying cause of cardiac arrest is coronary artery disease and its consequences, which accounts for at least $80 \%$ of the cardiac arrests in the Western world. In addition, in 10 to $15 \%$ of the cases cardiomyopathies are the origin of the cardiac arrest. Other less frequent causes include congenital heart disease, arrhythmias, suffocation, intoxication and trauma. ${ }^{1}$

The worldwide incidence of cardiac arrest in the general population is estimated to be around 1-2 /1000 persons per year but differs per country and region. ${ }^{1}$ In the adult population incidence increases with age, and cardiac arrests occur more frequently in men. ${ }^{1}$ In the Netherlands the incidence of cardiac arrest is $0.92 / 1000$ inhabitants per year, which means that each week around 300 persons suffer from a cardiac arrest, resulting in approximately 16.000 cases each year. $^{3,4}$

\section{Survival rates are low, but recent developments are promising}

Around the beginning of the twenty-first century, $9 \%$ to $16 \%$ of patients who were resuscitated after out-of-hospital cardiac arrest were discharged alive from the hospital. ${ }^{5-8}$ Survival rates after in-hospital cardiac arrest ranged from 14 to $37 \% .^{9-12}$

Although survival rates are still relatively low, two promising developments may improve these figures. Firstly, an increasing number of people are trained in cardiopulmonary resuscitation (CPR) and the use of automated external defibrillators (AED's): professionals from police and fire brigade are trained as 'first responders', who can already start resuscitation prior to arrival of the ambulance, and lay people are also encouraged to attend resuscitation courses. Secondly, the number and accessibility of AED's is increasing, due to better equipment of police and fire brigade vehicles and the growing availability of AED's in public spaces, such as airports, train stations, sports facilities and shopping malls. Research by Berdowski et al. in the Dutch province North Holland, has shown that increasing the accessibility of AED's and the number of trained lay people seemed to improve survival, and therefore, the expectation is that survival rates will further improve in the coming years. ${ }^{13}$ This will lead to an increased number of cardiac arrest survivors, and potentially also to an increased number of people having to live with the consequences of a cardiac arrest. 


\section{A cardiac arrest can lead to brain injury}

One of the potential consequences of a cardiac arrest is brain injury, which is caused by the interruption of blood circulation to the brain during the cardiac arrest. The brain has a high metabolic demand, and is therefore very susceptible to deprivation of blood supply. After several minutes of circulatory arrest, irreversible damage to brain tissue may already occur, which is called posthypoxic encephalopathy or hypoxic-ischaemic brain injury. ${ }^{14}$ The pathophysiological mechanisms leading to hypoxic-ischaemic brain injury are complex and include biochemical processes, functional changes in the brain cells, reperfusion injury, and eventually, cell death. ${ }^{14,15}$ As hypoxic-ischaemic brain injury can affect all brain areas, the neurological consequences are diverse and can include disorders of consciousness, movement disorders, cortical visual problems and cognitive impairments. ${ }^{16}$ This shows that a cardiac arrest should not be considered as a cardiac disease only, but that also brain related consequences should be taken into account, and this view forms the basis of this thesis.

\section{A model to describe outcome after cardiac arrest}

In this project, the International Classification of Function, Disability and Health (ICF) of the World Health Organisation (WHO) was used as a framework to describe outcome after cardiac arrest. The ICF model is a holistic bio-psycho-social model of illness and its consequences, which is frequently used in rehabilitation medicine as a framework to report individual health consequences of a disease or disorder. ${ }^{17,18}$

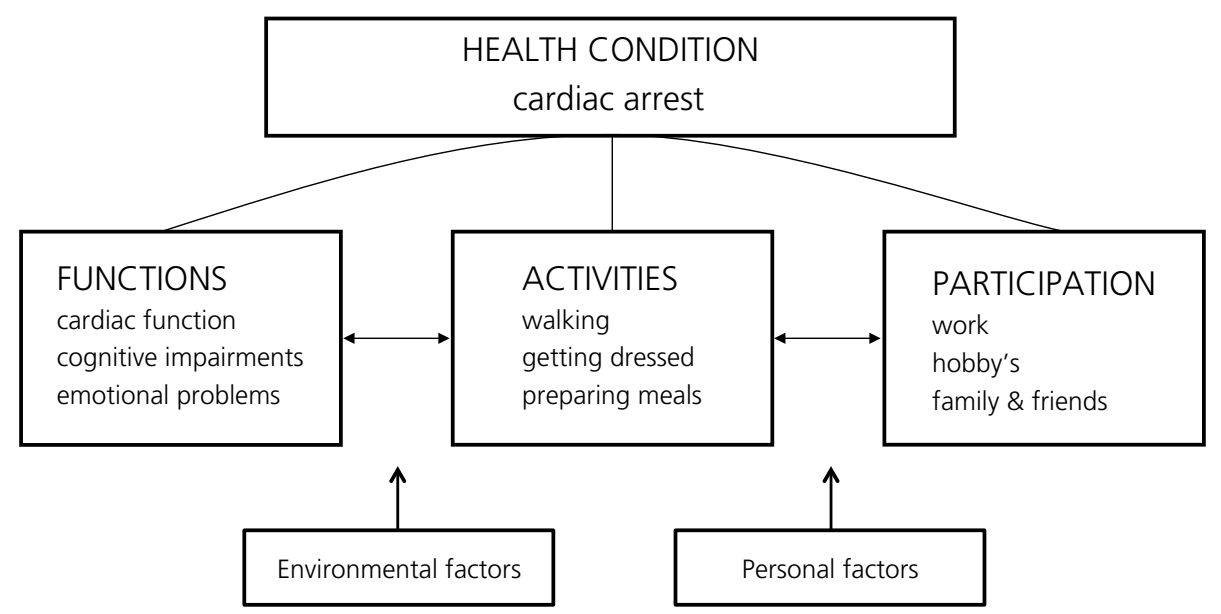

Figure 1. International Classification of Function, Disability and Health (ICF)

Figure 1 presents the ICF model, which describes the impact of a health condition on three levels of functioning: 1) body structures and functions; 2) activities; and 3) societal participation. The first ICF level consists of the bodily structures and functions and includes, for example, cardiac ejection fraction, memory impairments and emotional problems, such as depression. The second ICF level describes the performance of daily activities, which can include walking, getting dressed and preparing meals. The third level of the ICF comprises aspects of societal participation, such as 
work, leisure activities and relationships with family and friends. The three levels of functioning can interact and are also affected by environmental factors, including social support, living conditions and financial resources, as well as by personal factors, such as age, gender and personality.

Quality of life is not incorporated in the original ICF model. The World Health Organisation defined quality of life as: 'individuals' perceptions of their position in life in the context of the culture and value systems in which they live and in relation to their goals expectations, standards and concerns'. ${ }^{19}$ In other words, quality of life can be considered as an overall concept, which can be affected by all levels of the ICF model and which is the persons' own assessment of their situation.

Most previous studies on outcome after cardiac arrest focused exclusively on survival or used very global outcome measures. ${ }^{20}$ One major limitation of such global outcome measures is that they do not provide sufficient information on how people actually function in their daily life. Therefore, in this project outcome after cardiac arrest was measured and described at all three levels of the ICF model, and also in terms of quality of life.

In the next sections, current evidence will be introduced regarding problems cardiac arrest survivors can face on the levels of functions, activities, societal participation and quality of life.

\section{Functions: cognitive and emotional problems seem to be common}

Hypoxic-ischaemic brain injury can lead to cognitive impairments, and especially memory problems seem to be most frequent. ${ }^{21}$ However, the exact frequency of cognitive impairments after cardiac arrest is currently unclear: some studies report that the prevalence of cognitive impairments after cardiac arrest is 'remarkably low', ${ }^{22,23}$ while other studies report that cognitive impairments are present in almost all survivors. ${ }^{24,25}$ This wide variation in prevalence, shows the need for a critical review of the evidence on this topic.

Emotional problems also seem to be common after survival of a cardiac arrest, but again reported frequencies show a wide variation. The reported prevalence of depressive symptoms ranges from $8 \%$ to $45 \% .{ }^{26-29}$ Symptoms of anxiety have been reported in $30 \%$ to $41 \%$ of the survivors, ${ }^{29,30}$ and symptoms of posttraumatic stress were found in $19 \%$ to $27 \%$ of the cases. ${ }^{30,31}$ This variability in prevalence between studies can probably be attributed to variations in patient selection, measurement instruments used, timing of measurements, small samples sizes and other methodological features of the studies. Therefore, further studies using larger epidemiologically defined samples are needed.

\section{Activities and participation: impact on daily life}

With regard to basic activities of daily living ( $A D L)$, studies have shown that most survivors of cardiac arrest are able to regain their independence in self-care. ${ }^{27,32}$ However, more than half of the survivors seem to have difficulties with more extended daily activities. ${ }^{33}$

The concept of participation includes, among other things, living situation and work.

A study performed in Sweden showed that one year after cardiac arrest $68 \%$ of the survivors lived independently in their own home again, while $32 \%$ had moved to sheltered accommodation or needed personal assistance. ${ }^{33}$ In the same study, only $12 \%$ of survivors who had been employed at the time of the cardiac arrest had returned to work one year after the event. ${ }^{33}$ In contrast, a 
study in Switzerland reported that three year after cardiac arrest half of the survivors were back at work. ${ }^{34}$

Living situation and work are only two aspects of participation, and the concept of participation is much broader and includes other roles in society, such as volunteer work, recreational activities and social relationships with family and friends. Therefore, better studies on participation after cardiac arrest are needed using more detailed measurement instruments.

\section{Quality of life after cardiac arrest}

In a study from Saner et al., 49 out of 50 survivors of out-of-hospital cardiac arrest judged their situation after the cardiac arrest worth living. ${ }^{34}$ In addition, de Vos et al. showed that quality of life after cardiac arrest is, in general, considered to be satisfactory and better than after stroke. ${ }^{27}$ Nevertheless, quality of life scores after cardiac arrest are lower compared with healthy reference groups, which indicates that quality of life can be at risk..$^{27,33}$ It is of interest to identify which factors contribute to quality of life, and to investigate how these factors may be affected positively.

\section{A cardiac arrest also affects caregivers}

The caregivers of people who have survived a cardiac arrest also seem to be at risk of healthrelated consequences, which may not only be caused by the burden of having to care for the patient, but also from the stress of living with someone who is, or who is perceived to be at risk of a further cardiac arrest.

There are indeed some studies that indicate that caregivers experience psychosocial problems, lack of support, stress and strain. ${ }^{25,35,36}$ However, these findings were derived from small studies with selected samples, so more evidence on caregiver well-being is indicated.

\section{General aims and outline of this thesis}

The previous sections have shown that a cardiac arrest can lead to problems on all domains of functioning, and also caregiver well-being seems to be negatively affected. However, more information is needed on the exact prevalence of these problems. The frequency, diversity and severity of problems that both patients and caregivers seem to encounter, indicate the need to investigate how current care for this group can be improved.

This thesis consists of two parts: the first part concerns research aimed at gaining more insight into the long-term consequences of a cardiac arrest, with special interest for brain related aspects; the second part concerns research aimed at improving care for cardiac arrest survivors and their caregivers.

\section{Part 1. Outcome after cardiac arrest}

Chapter 2 describes long-term outcome after out-of-hospital cardiac arrest at the levels of cognitive and emotional functioning, daily activities, societal participation and quality of life. In addition, emotional well-being, strain and quality of life of the caregivers are also considered. 
Chapter 3 investigates determinants of quality of life after out-of-hospital cardiac arrest. Chapter $\mathbf{4}$ presents a systematic review on frequency and nature of cognitive impairments after out-of-hospital cardiac arrest.

\section{Part 2: Improving care after survival of a cardiac arrest}

To improve current care, we developed a new early intervention service for survivors of a cardiac arrest and their caregivers called 'Stand still..., and move on'. The effectiveness of this new intervention was examined with a randomised controlled trial. Chapter $\mathbf{5}$ presents the study protocol of this trial. In addition, Chapter 6 gives more detailed information on the content and structure of the new intervention, and also provides the theory and rationale behind it. Chapter $\mathbf{7}$ describes the results of a process evaluation on the feasibility of the intervention, which was performed prior to knowing the effects of the intervention. And Chapter $\mathbf{8}$ reports on the results of the randomised controlled trial and shows the effectiveness of the new intervention.

To conclude, Chapter $\mathbf{9}$ is the general discussion of this thesis, in which overall reflections and implications for clinical practice are discussed, and ideas for future research are presented. 


\section{References}

1. Myerburg RJ, Castellanos A. Cardiac arrest and sudden cardiac death. In: Braunwald E, Zipes DP, Libby P, eds. Heart Disease: A Textbook of Cardiovascular Medicine. Sixth edition ed. Philadelphia: WB Saunders, 2001: 890-931.

2. Jacobs I, Nadkarni V, Bahr J, et al. Cardiac arrest and cardiopulmonary resuscitation outcome reports: update and simplification of the Utstein templates for resuscitation registries. A statement for healthcare professionals from a task force of the international liaison committee on resuscitation (American Heart Association, European Resuscitation Council, Australian Resuscitation Council, New Zealand Resuscitation Council, Heart and Stroke Foundation of Canada, InterAmerican Heart Foundation, Resuscitation Council of Southern Africa). Resuscitation 2004;63(3):233-49.

3. Gorgels AP, Gijsbers C, de Vreede-Swagemakers J, Lousberg A, Wellens HJ. Out-of-hospital cardiac arrest--the relevance of heart failure. The Maastricht Circulatory Arrest Registry. Eur Heart $J$ 2003;24(13):1204-9.

4. Berdowski J, Waalewijn RA, Koster RW. Plotselinge hartstilstand en reanimatie. Hart Bulletin 2007;38(2):56-57.

5. Waalewijn RA, de Vos R, Koster RW. Out-of-hospital cardiac arrests in Amsterdam and its surrounding areas: results from the Amsterdam resuscitation study (ARREST) in 'Utstein' style. Resuscitation 1998;38(3):157-67.

6. Bottiger BW, Grabner C, Bauer H, et al. Long term outcome after out-of-hospital cardiac arrest with physician staffed emergency medical services: the Utstein style applied to a midsized urban/suburban area. Heart 1999;82(6):674-9.

7. Kuisma M, Maatta T. Out-of-hospital cardiac arrests in Helsinki: Utstein style reporting. Heart 1996;76(1):18-23.

8. Fischer M, Fischer NJ, Schuttler J. One-year survival after out-of-hospital cardiac arrest in Bonn city: outcome report according to the 'Utstein style'. Resuscitation 1997;33(3):233-43.

9. Hodgetts TJ, Kenward G, Vlackonikolis I, et al. Incidence, location and reasons for avoidable in-hospital cardiac arrest in a district general hospital. Resuscitation 2002;54(2):115-23.

10. Huang $\mathrm{CH}$, Chen WJ, Ma MH, Chang WT, Lai CL, Lee YT. Factors influencing the outcomes after inhospital resuscitation in Taiwan. Resuscitation 2002;53(3):265-70.

11. Patrick A, Rankin N. The in-hospital Utstein style: use in reporting outcome from cardiac arrest in Middlemore Hospital 1995-1996. Resuscitation 1998;36(2):91-4.

12. Skogvoll E, Isern E, Sangolt GK, Gisvold SE. In-hospital cardiopulmonary resuscitation. 5 years' incidence and survival according to the Utstein template. Acta Anaesthesiol Scand 1999;43(2):177-84.

13. Berdowski RA, Waalewijn RA, Koster RW. Overleving na reanimatie buiten het ziekenhuis is sterk toegenomen: een vergelijkend onderzoek tussen eind 20ste en begin 21ste eeuw. In: Vaartjes I, Peters RJG, van Dis SJ, Bots ML, eds. Hart- en vaatziekten in Nederland najaar 2006, cijfers over ziekte en sterfte. Den Haag: Nederlandse Hartstichting, 2006: 27-34.

14. Busl KM, Greer DM. Hypoxic-ischemic brain injury: pathophysiology, neuropathology and mechanisms. NeuroRehabilitation 2010;26(1):5-13.

15. Muniz AE. Postresuscitation Cerebral Dysfunction. In: Oranto JP, Peberby MA, eds. Contemporary Cardiology: Cardiopulmonary Resuscitation. Totowa, NJ: Humana Press Inc., 2005: 523-547.

16. Khot $\mathrm{S}$, Tirschwell DL. Long-term neurological complications after hypoxic-ischemic encephalopathy Semin Neurol 2006;26(4):422-31. 
17. WHO. International Classification of Functioning, Disability and Health: ICF. Geneva, 2001.

18. Wade DT, Halligan PW. Do biomedical models of illness make for good healthcare systems? Bmj 2004;329(7479):1398-401.

19. WHOQOL-Group. The World Health Organization Quality of Life assessment (WHOQOL): position paper from the World Health Organization. Soc Sci Med 1995;41(10):1403-9.

20. Recommended guidelines for uniform reporting of data from out-of-hospital cardiac arrest: the 'Utstein style'. Prepared by a Task Force of Representatives from the European Resuscitation Council, American Heart Association, Heart and Stroke Foundation of Canada, Australian Resuscitation Council. Resuscitation 1991;22(1):1-26.

21. Grubb NR, O'Carroll R, Cobbe SM, Sirel J, Fox KA. Chronic memory impairment after cardiac arrest outside hospital. Bmj 1996;313(7050):143-6.

22. Bertini G, Giglioli C, Giovannini F, et al. Neuropsychological outcome of survivors of out-of-hospital cardiac arrest. J Emerg Med 1990;8(4):407-12.

23. Horsted TI, Rasmussen LS, Meyhoff CS, Nielsen SL. Long-term prognosis after out-of-hospital cardiac arrest. Resuscitation 2007;72(2):214-8.

24. Kotila M, Kajaste S. Neurological and neuropsychological symptoms after cardiac arrest. Acta Neurologica Scandinavica 1984;69(98):337-338.

25. Pusswald G, Fertl E, Faltl M, Auff E. Neurological rehabilitation of severely disabled cardiac arrest survivors. Part II. Life situation of patients and families after treatment. Resuscitation 2000;47(3):241-8.

26. Sauve MJ, Doolittle N, Walker JA, Paul SM, Scheinman MM. Factors associated with cognitive recovery after cardiopulmonary resuscitation. Am J Crit Care 1996;5(2):127-39.

27. de Vos R, de Haes HC, Koster RW, de Haan RJ. Quality of survival after cardiopulmonary resuscitation. Arch Intern Med 1999;159(3):249-54.

28. Kamphuis HC, De Leeuw JR, Derksen R, Hauer R, Winnubst JA. A 12-month quality of life assessment of cardiac arrest survivors treated with or without an implantable cardioverter defibrillator. Europace 2002;4(4):417-25.

29. Roine RO, Kajaste S, Kaste M. Neuropsychological sequelae of cardiac arrest. Jama 1993;269(2):23742.

30. O'Reilly SM, Grubb N, O'Carroll RE. Long-term emotional consequences of in-hospital cardiac arrest and myocardial infarction. Br J Clin Psychol 2004;43(Pt 1):83-95.

31. Gamper $G$, Willeit M, Sterz F, et al. Life after death: posttraumatic stress disorder in survivors of cardiac arrest--prevalence, associated factors, and the influence of sedation and analgesia. Crit Care Med 2004;32(2):378-83.

32. Hofgren C, Lundgren-Nilsson A, Esbjornsson E, Sunnerhagen KS. Two years after cardiac arrest; cognitive status, ADL function and living situation. Brain Inj 2008;22(12):972-8.

33. Lundgren-Nilsson A, Rosen $H$, Hofgren C, Sunnerhagen KS. The first year after successful cardiac resuscitation: function, activity, participation and quality of life. Resuscitation 2005;66(3):285-9.

34. Saner H, Borner Rodriguez E, Kummer Bangerter A, Schuppel R, von Planta M. Quality of life in longterm survivors of out-of-hospital cardiac arrest. Resuscitation 2002;53(1):7-13.

35. Dougherty CM. Longitudinal recovery following sudden cardiac arrest and internal cardioverter defibrillator implantation: survivors and their families. Am J Crit Care 1994;3(2):145-54.

36. Middelkamp W, Moulaert VR, Verbunt JA, van Heugten CM, Bakx WG, Wade DT. Life after survival: long-term daily life functioning and quality of life of patients with hypoxic brain injury as a result of a cardiac arrest. Clin Rehabil 2007;21(5):425-31. 



\section{Chapter 2}

\section{Life after Survival: long term daily functioning and quality of life after an out-of-hospital cardiac arrest}

Published in Resuscitation as:

Wachelder EM, Moulaert VR, van Heugten C, Verbunt JA, Bekkers SC, Wade DT. Life after survival: long-term daily functioning and quality of life after an out-of-hospital cardiac arrest. 


\begin{abstract}
Background: Information about long-term consequences of cardiac arrest is sparse. Because the survival rate is expected to increase, better knowledge of long-term functioning and quality of survival is essential.

Objectives: To determine the level of functioning of out-of-hospital cardiac arrest survivors 1-6 years later, and to evaluate the predictive value of medical variables on long-term functioning.

Methods: A retrospective cohort study including 63 survivors of an out-of-hospital cardiac arrest, admitted to a Dutch University hospital between 2001 and 2006. Participants received a questionnaire by post. Primary outcome measures were: participation in society (Community Integration Questionnaire) and quality of life (SF-36). Secondary outcome measures were: physical, cognitive and emotional impairment, daily functioning and caregiver strain. Statistical analyses included multiple regression analyses.
\end{abstract}

Results: On average three years post-cardiac arrest, 74\% of the patients experienced a low participation level in society compared with the general population. Over $50 \%$ reported severe fatigue, $38 \%$ feelings of anxiety and/or depression and $24 \%$ a decreased quality of life. Caregivers reported stress related responses, feelings of anxiety and lower quality of life. Seventeen percent of the caregivers reported high caregiver strain, which was associated with the patient's level of functioning. Gender, age, percutaneous coronary Intervention ( $\mathrm{PCI}$ ) and therapeutic hypothermia contributed to outcome on at least one domain of long-term functioning.

Conclusions: After surviving an out-of-hospital cardiac arrest, many patients and partners encounter extensive impairments in their level of functioning and quality of life. Gender, age, $\mathrm{PCl}$ and therapeutic hypothermia are associated with differences in long-term functioning of patients. 


\section{Introduction}

In the Netherlands, the overall incidence of sudden cardiac death is 0.92 per 1000 persons per year. ${ }^{1}$ Reported survival after an out-of-hospital cardiac arrest is between $2 \%-23 \%$ of patients with a bystander-witnessed cardiac arrest surviving to discharge. ${ }^{2}$ However, this number is expected to increase with the increasing availability of automated external defibrillators (AED's). ${ }^{3}$ During a cardiac arrest, the brain suffers hypoxia which may cause diffuse ischaemic-hypoxic injury that may result in cognitive deficits. ${ }^{4}$ Six months after the cardiac arrest, cognitive deficits are still present in up to half of all survivors. ${ }^{5}$ Hypoxic brain injury also has an impact on other important aspects of life. Survivors report symptoms of depression, ${ }^{6}$ dependency on others for daily functioning, ${ }^{6}$ decreased participation in society with only $13 \%-58 \%$ of patients returning to work, ${ }^{7-9}$ and a lower quality of life..$^{6,7}$

Research on prognostic factors for surviving a cardiac arrest showed that among predictors of a poor neurological outcome are older age, unwitnessed arrest, lack of bystander cardiopulmonary resuscitation (CPR), ${ }^{10}$ a non-VTNF initial cardiac rhythm and a long interval between collapse and return of spontaneous circulation. ${ }^{10,11}$ However, little is known concerning prognostic factors of long-term functioning and quality of life of cardiac arrest survivors. This information could help clinicians to inform their patient and family members about future problems and functioning, and possibly guide intervention in the early stages.

In this study we determined the level of participation in society, quality of life, cognitive, emotional and physical impairment, and daily functioning of out-of-hospital cardiac arrest survivors, and strain on, basic functioning and quality of life of their caregivers several years after the event. The hypothesis was that out-of-hospital cardiac arrest survivors have lower levels of functioning on all domains compared with the general population, and that caregiver strain is augmented. Second, we studied prognostic factors for participation in society, quality of life, cognitive impairment and daily functioning after surviving a cardiac arrest. We hypothesized that the interval between collapse and return of spontaneous circulation, ${ }^{10,11}$ application of mild therapeutic hypothermia ${ }^{12,13}$ and implantable cardioverter defibrillator (ICD) placement ${ }^{14,15}$ would all be associated with level of outcome in one or more of these domains.

\section{Methods}

\section{Study population}

Out-of-hospital cardiac arrest survivors who had been admitted to the Department of Cardiology of the University Hospital Maastricht, The Netherlands from January 2001 till December 2006 were asked to participate in this retrospective cohort study. The hospital is the primary referral centre for a catchment area of approximately 200.000 inhabitants covered by a single ambulance service. Participants were survivors aged 18 years or older, still alive at the time of the study, and with sufficient knowledge of the Dutch language to complete questionnaires. 


\section{Data collection}

Patient data were retrieved from two local databases: a recent study in the University Hospital Maastricht, ${ }^{16}$ and the 'Maastricht Sudden Circulatory Arrest Registry'. ${ }^{17}$ Also, the admission registers of the Coronary Care Unit of the University Hospital Maastricht between 2001 and 2006 were hand searched for admission stating 'cardiac arrest' or 'resuscitation'. This combination should identify most of the cardiac arrests, thereby offering a representative sample.

After checking survival status of discharged patients with their general practitioner, potential participants were informed about the study. Both patient and their caregiver were sent a set of questionnaires and were asked for informed consent. One reminder was sent after two weeks. The study protocol was approved by the Medical Ethics Committee of the University Hospital Maastricht.

\section{Measurement instruments}

Socio-demographic variables before the cardiac arrest and current status (as presented in Table 1) were collected by self-report. Main medical variables related to the cardiac arrest (as presented in Table 2) were retrieved from both databases and patient files.

\section{Outcome measures}

The questionnaires for patients encompassed the following domains of the International Classification of Functioning, Disability and Health (ICF): basic functioning, activities in daily life and participation in society. ${ }^{18}$

\section{Basic functioning}

- The New York Heart Association Classification (NYHA), a functional classification of cardiovascular disability. It ranges from Class I (patients without limitation of physical activity) to Class IV (patients unable to carry on physical activity without discomfort). ${ }^{19}$

- The Fatigue Severity Scale (FSS), a 9-item questionnaire assessing the impact of fatigue on patients' functioning. ${ }^{20}$ Scoring is on a 7-point scale. A mean score is calculated (range 1-7) with higher scores reflecting greater fatigue. Construct validity is 0.68 with the visual analogue scale as external criterion, ${ }^{20}$ (Cronbach) alpha is 0.89 in stroke patients. ${ }^{21}$

- The Cognitive Failures Questionnaire (CFQ), a 25-item questionnaire that inquires about failures in perception, memory and executive functioning. ${ }^{22}$ The total score ranges from 0 to 100 , with a higher score indicating more cognitive problems. Construct validity is 0.59 compared with the Short Inventory of memory experiences. ${ }^{22}$ Alpha is 0.88 in a healthy population. ${ }^{23}$ The caregivers were also asked to fill out a CFQ for the patient in order to find out whether the scores correlate with one another.

- The Hospital Anxiety and Depression Scale (HADS), a widely-used questionnaire designed to assess mood disorders in non-psychiatric hospital outpatients, with 14 items divided in two subscales measuring signs of anxiety and depression. ${ }^{24}$ The scale has a concurrent validity of 0.73 compared with the Beck Depression Inventory and alpha is 0.83 (anxiety subscale) and 0.82 (depression subscale). ${ }^{24}$ 
- The Impact of Event Scale (IES), a 15-item questionnaire that assesses stress reactions after traumatic events, focussing on psychological responses of intrusion and avoidance. ${ }^{25}$ The total score ranges from 0 to 75 , with a higher score indicating more stress reactions. The scale has a content validity of 0.63 , moderate construct validity and alpha is 0.86 (intrusion) and 0.82 (avoidance). ${ }^{25}$

\section{Daily functioning}

- The Barthel Index measures basic activities of daily living (ADL) and consists of 10 items, with a total score ranging from 0 (totally $A D L$ dependent) to 20 (independent in basic ADL). ${ }^{26}$ Construct validity is 0.92 compared with the Functional Independence Measure, alpha is 0.84 in stroke patients. $^{26}$

- The Frenchay Activities Index (FAI), a 15-item questionnaire for instrumental ADL referring to the patient's ability to perform more complex activities. ${ }^{27,28}$ Scoring is on a 4-point scale with total score ranging from 0 (low ability) to 45 (high ability). In a stroke population, construct validity is $0.61-0.66$ compared with the Barthel Index, alpha is $0.87 .27,28$

\section{Participation in society (primary outcome measure)}

- The Community Integration Questionnaire (CIQ), a 15-item questionnaire assessing participation in three domains (Home Integration, Social Integration and Productive Activity). ${ }^{29}$ Items are rated from 0 to 2, with 2 representing greater independence and integration. The total score ranges from 0 to 29 . In patients with traumatic brain injury, concurrent validity is 0.47 0.60 compared with the Functional Assessment Measure, test-retest reliability is $0.83-0.97 .{ }^{29}$

\section{Quality of life (primary outcome measure)}

- The 36-item short form health survey (SF-36), a generic health related quality of life measure containing 36 items, covering eight dimensions of health within a Physical and Mental Component subscale. ${ }^{30}$ For each dimension and subscale, scores are transformed to a scale from 0 (worst health) to 100 (best health). Alpha is $0.73-0.96^{30}$ and the scale has good psychometric properties in patients with heart disease. ${ }^{31}$

\section{Caregiver}

- The Caregiver Strain Index (CSI), a 13-item questionnaire that measures strain related to provision of care by asking the patient's caregiver to answer yes/no statements. ${ }^{32}$ Positive responses to seven or more items indicate a greater level of strain. There is moderate evidence for its construct validity, alpha is $0.86 .^{32}$

The caregivers were also asked to fill in the following questionnaires: Hospital Anxiety and Depression Scale, Impact of Event Scale and the 36-item short form health survey. 


\section{Statistical analysis}

Descriptive statistics were used to present demographic and medical characteristics of the participants and their scores on the questionnaires. The percentages of participants with a score below or above the cut-off score of the questionnaire are reported. Cut-off scores were used as presented in the original questionnaires if available, and for the Frenchay Activities Index, Community Integration Questionnaire and the SF-36 a cut-off score was calculated based on mean variable score for the Dutch population (as derived from the literature) +/- one standard deviation. $28,33,34$

In cases with $\geq 15 \%$ missing values within a questionnaire, the total score on the questionnaire was not calculated and the data excluded from the analyses. In cases with $<15 \%$ missing values, the mean score of items per subscale was imputed.

To examine associations between outcome measures and medical variables, Spearman correlation coefficients were calculated. Multiple linear regression analyses with backward elimination were carried out using the variables with the highest bivariate correlation coefficients as independent variables. Dependent variables were cognitive impairment, daily functioning, participation in society and quality of life. Since in previous studies age and gender appeared to be related to the patient's functioning and quality of life, these factors were introduced in the model as potential confounding factors. ${ }^{9,35}$

A limit value for elimination in the regression analyses was set at $p<0.10$ and a $p$-value of $\leq 0.05$ was considered statistically significant.

Statistical analyses were performed using the software package SPSS version 12.0 (SPSS Inc, Chicago, Illinois, USA).

\section{Results}

As shown in Figure 1, 220 persons with a possible out-of-hospital cardiac arrest were identified. Due to exclusion, death and loss-to-follow up, 88 persons were eligible for participation in the study. Sixty-three (72\%) patients, 54 men and 9 women, with a mean age of 60.2 (SD 12.7) years, and forty-two caregivers participated.

The mean time since cardiac arrest was 36 (SD 18.8) months. No statistically significant gender$(t=-0.62, p=0.54)$ or age-related (Chi-square $=0.04, p=0.84$ ) differences between responders and non-responders appeared. Demographic characteristics and medical data of the patients are presented in Tables 1 and 2 respectively. 
$\mathbf{2 2 0}$ cases of hospital admissions after a possible out-of-hospital cardiac arrest

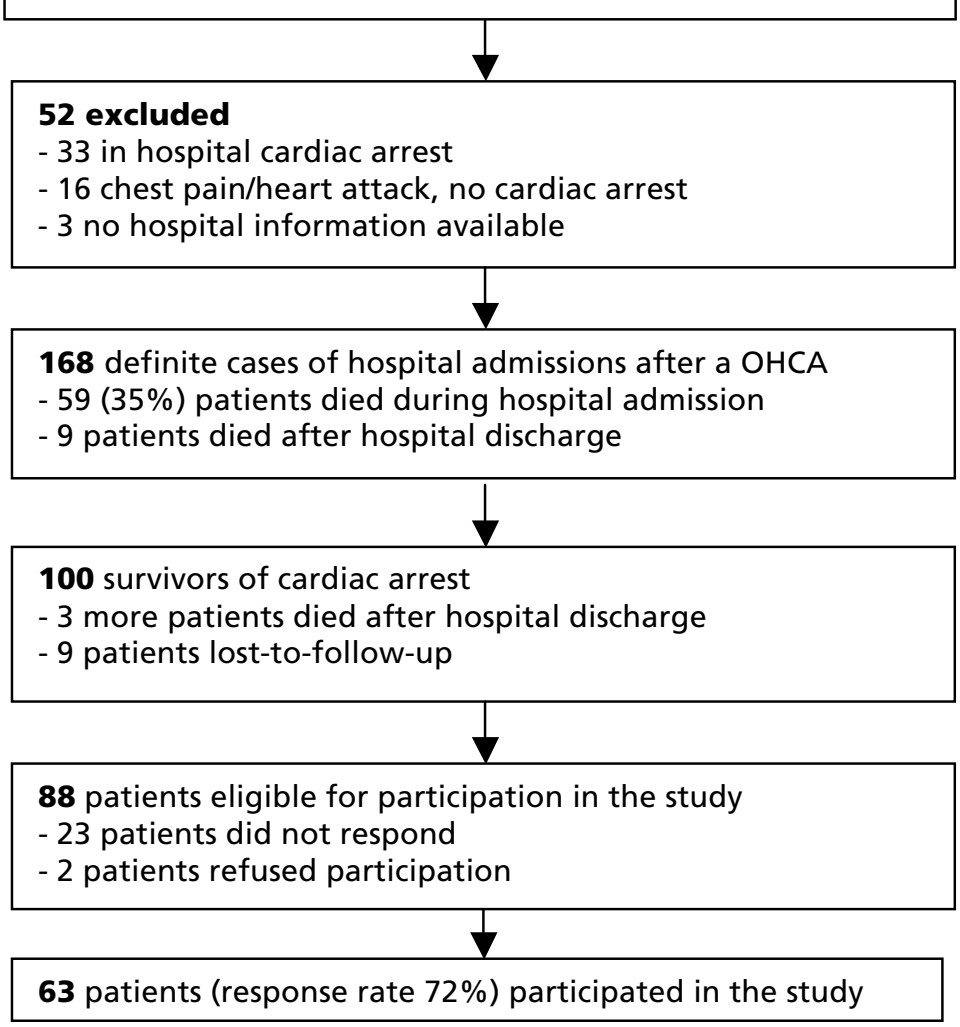

Figure 1. Flow chart of patient inclusion 
Table 1. Demographic characteristics of the patients $(n=63)$

at time of cardiac arrest

current situation

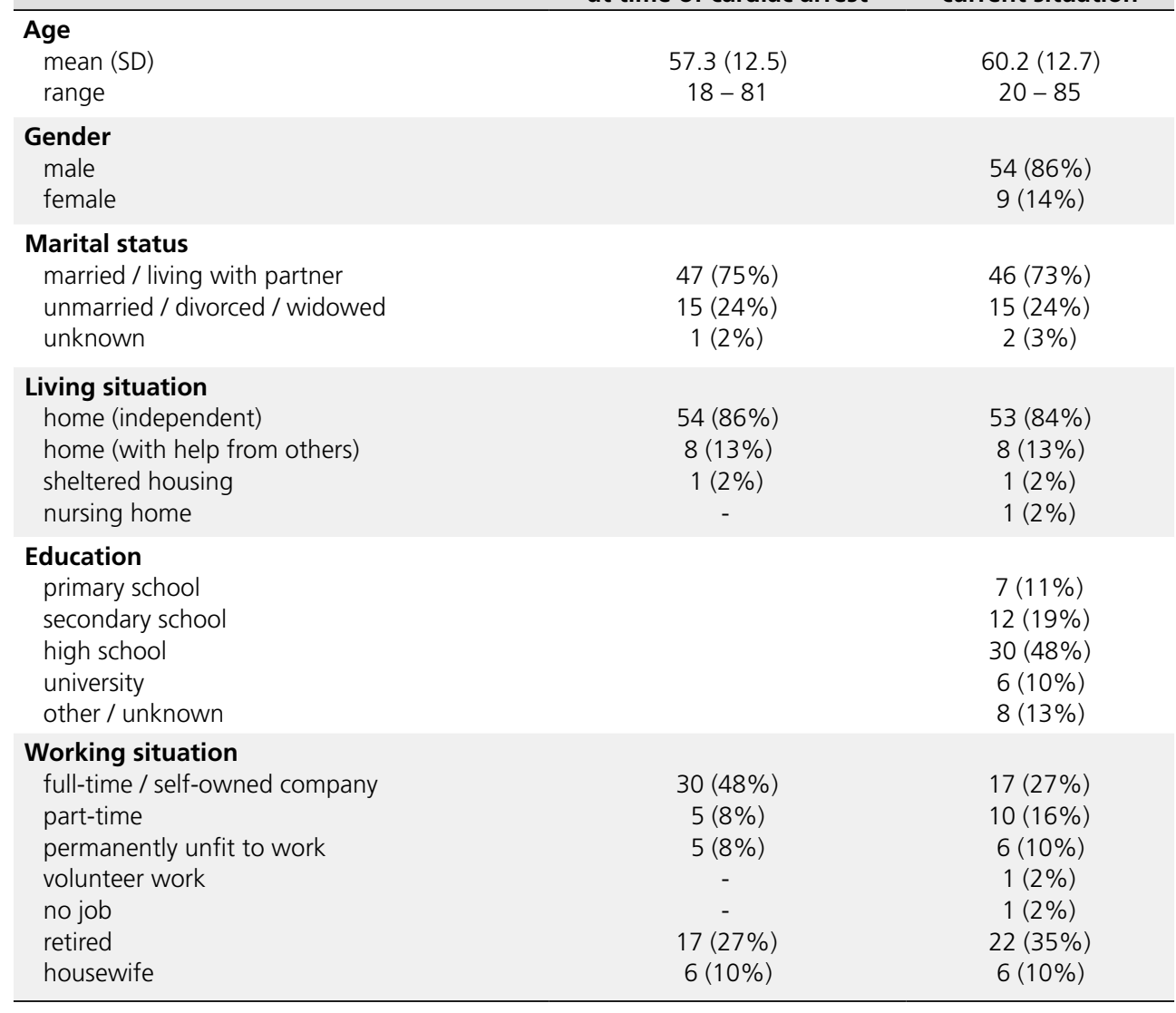

As shown in Table 1, the marital status and living situation did not alter significantly after the cardiac arrest. The majority of the patients remained independent after the cardiac arrest.

Of the 30 patients working full-time before the event, seventeen people still worked full-time and eight worked part-time after the cardiac arrest. Of the five patients working part-time before the cardiac arrest, two persons were working less hours and three persons had retired. This means that 17 out of 35 (49\%) patients were able to return to their previous job. In addition, 10 (29\%) patients were able to return to work, but were working less hours. 
Table 2. Medical data regarding the cardiac arrest

\begin{tabular}{|c|c|c|}
\hline & $\mathrm{N}$ & $\begin{array}{c}\mathrm{N}(\%), \\
\text { mean (SD) or median (range) }\end{array}$ \\
\hline Age at time of cardiac arrest & 63 & $57.3(12.5)$ \\
\hline $\begin{array}{l}\text { Location of cardiac arrest } \\
\text { street / public area } \\
\text { home } \\
\text { in the ambulance } \\
\text { other }\end{array}$ & 63 & $\begin{array}{c}30(48 \%) \\
20(32 \%) \\
4(6 \%) \\
9(14 \%)\end{array}$ \\
\hline Witnessed cardiac arrest & 63 & $56(89 \%)$ \\
\hline $\begin{array}{l}\text { Bystander CPR } \\
\text { yes, by lay person } \\
\text { yes, by trained person } \\
\text { no }\end{array}$ & 63 & $\begin{array}{l}26(41 \%) \\
23(37 \%) \\
14(22 \%)\end{array}$ \\
\hline $\begin{array}{l}\text { Initial cardiac rhythm } \\
\text { VF } \\
\text { VTNF } \\
\text { other rhythm }\end{array}$ & 62 & $\begin{array}{c}55(89 \%) \\
6(10 \%) \\
1(2 \%)\end{array}$ \\
\hline Number of defibrillations & 63 & $2.0(0-12)$ \\
\hline Interval collapse - ROSC (min) & 47 & $10.0(2-35)$ \\
\hline $\begin{array}{l}\text { (Sub)acute interventions } \\
\text { PCI } \\
\text { CABG } \\
\text { ICD } \\
\text { therapeutic hypothermia }\end{array}$ & 63 & $\begin{array}{l}28(44 \%) \\
13(21 \%) \\
25(46 \%) \\
17(27 \%)\end{array}$ \\
\hline LVEF $<1$ week after cardiac arrest & 58 & $47.5(12.7)$ \\
\hline $\begin{array}{l}\text { Cardiovascular history } \\
\text { myocardial infarction } \\
\text { cardiac arrest } \\
\text { cardiac interventions (PCl, CABG) } \\
\text { claudication } \\
\text { stroke } \\
\text { diabetes mellitus }\end{array}$ & 63 & $\begin{array}{l}19(30 \%) \\
2(3 \%) \\
8(13 \%) \\
4(6 \%) \\
2(3 \%) \\
3(5 \%)\end{array}$ \\
\hline
\end{tabular}

$\mathrm{CPR}=$ Cardiopulmonary Resuscitation

$\mathrm{VF}=$ Ventricular Fibrillation

$\mathrm{VT}=$ Ventricular Tachycardia

ROSC $=$ Return Of Spontaneous Circulation

$\mathrm{PCl}=$ Percutaneous Coronary Intervention

$\mathrm{CABG}=$ Coronary Artery Bypass Graft

ICD = Implantable Cardioverter Defibrillator

$\mathrm{LVEF}=$ Left Ventricular Ejection Fraction

\section{Current level of functioning}

The long-term level of functioning of the participants is shown in Table 3. The majority of the patients had a lower participation level in society than the general population and $24 \%$ showed a lower quality of life (SF-36). One in five patients experienced cognitive impairments. Caregivers reported better scores on the Cognitive Failures Questionnaire focussing on the patients' cognitive functioning as compared to the patients themselves, but this difference was not statistically significant $(t=0.95, p=0.34)$. 
Table 3. Basic functioning, activities in daily living and participation in society of the patients ( $n=63$ )

\begin{tabular}{|c|c|c|c|c|}
\hline ICF domain & $\begin{array}{l}\text { cut-off } \\
\text { score }\end{array}$ & $\mathbf{N}$ & $\begin{array}{l}\text { Mean (SD) or } \\
\text { median (range) }\end{array}$ & $\begin{array}{c}N(\%) \\
\text { impaired }\end{array}$ \\
\hline \multicolumn{5}{|l|}{ Basic functioning } \\
\hline New York Heart Association classification (NYHA) & $\geq 3$ & 62 & $1.0(1-4)$ & $8(13 \%)$ \\
\hline Fatigue Severity Scale (FSS) & $\geq 4$ & 61 & $4.3(1.6)$ & $34(56 \%)$ \\
\hline Cognitive Failures Questionnaire (CFQ) & $\geq 44$ & 61 & $29.8(18.4)$ & $13(21 \%)$ \\
\hline Cognitive Failures Questionnaire (CFQ) by caregiver & $\geq 44$ & 42 & $26.5(16.2)$ & $6(14 \%)$ \\
\hline Hospital Anxiety and Depression Scale (HADS) & $\geq 11$ & 63 & $8.5(6.4)$ & $22(35 \%)$ \\
\hline - subscale anxiety & $\geq 9$ & 63 & $4.4(3.4)$ & $8(13 \%)$ \\
\hline - subscale depression & $\geq 9$ & 63 & $4.2(3.6)$ & $9(14 \%)$ \\
\hline Impact of Event Scale (IES) & $\geq 26$ & 63 & $13.0(13.7)$ & $13(21 \%)$ \\
\hline \multicolumn{5}{|l|}{ Activities of daily living } \\
\hline Barthel Index & $\leq 14$ & 63 & $20.0(7-20)$ & $2(3 \%)$ \\
\hline Frenchay Activities Index (FAI) & $\leq 16$ & 61 & $25.7(8.7)$ & $12(20 \%)$ \\
\hline \multicolumn{5}{|l|}{ Participation in society } \\
\hline Community Integration Questionnaire (CIQ) & $\leq 18$ & 61 & $14.7(5.5)$ & $45(74 \%)$ \\
\hline \multicolumn{5}{|l|}{ Quality of life } \\
\hline SF-36 physical component & $\leq 50$ & 58 & $71.8(19.6)$ & $10(17 \%)$ \\
\hline SF-36 mental component & $\leq 55$ & 55 & $73.0(20.5)$ & $13(24 \%)$ \\
\hline
\end{tabular}

The situation of caregivers is presented in Table 4 . Half of the caregivers scored high on the Impact of Event Scale. These scores were significantly higher than scores of patients $(t=-3.84, p<0.00)$. Almost one in five of the caregivers showed a high level of caregiver strain.

Table 4. Basic functioning and quality of life of the caregivers $(n=42)$

\begin{tabular}{lllcc}
\hline ICF domain & $\begin{array}{l}\text { cut-off } \\
\text { score }\end{array}$ & N & $\begin{array}{c}\text { Mean (SD) or } \\
\text { median (range) }\end{array}$ & $\begin{array}{c}\mathbf{N}(\mathbf{\%}) \\
\text { impaired }\end{array}$ \\
\hline Basic functioning & & & & \\
$\quad$ Hospital Anxiety and Depression Scale (HADS) & $\geq 11$ & 42 & $9.1(7.8)$ & $\mathbf{1 6}(\mathbf{3 8 \% )}$ \\
$\quad-\quad$ subscale anxiety & $\geq 9$ & 42 & $5.7(4.8)$ & $\mathbf{1 1 ( 2 6 \% )}$ \\
$\quad$ subscale depression & $\geq 9$ & 42 & $3.0(0-13)$ & $\mathbf{4 ( 1 0 \% )}$ \\
Impact of Event Scale (IES) & $\geq 26$ & 40 & $25.2(16.9)$ & $\mathbf{2 0 ( 5 0 \% )}$ \\
Quality of life & & & & \\
$\quad$ SF-36 physical component & $\leq 50$ & 38 & $85.0(21-100)$ & $\mathbf{9 ( 2 4 \% )}$ \\
$\quad$ SF-36 mental component & $\leq 55$ & 39 & $74.3(20.6)$ & $\mathbf{9 ( 2 3 \% )}$ \\
Caregiver Strain index (CSI) & $\geq 7$ & 41 & $3.0(0-13)$ & $\mathbf{7 ( 1 7 \% )}$ \\
\hline
\end{tabular}

\section{Prognostic variables for current level of functioning}

As shown in Table 5, quality of life, participation in society and daily functioning of patients after surviving a cardiac arrest could be significantly predicted by the regression model, mainly due to the contribution of gender and age.

Gender contributed significantly in the explanation of all dependent variables. Male patients appeared to have a higher quality of life and cognitive functioning, but lower levels of participation in society and instrumental daily activities as compared to females. Age contributed significantly in the explanation of the level of quality of life (physical health), participation in society and instrumental daily activities, indicating lower levels of functioning in older patients. 
$\mathrm{PCl}$ appeared to contribute significantly in the explanation of societal participation, daily functioning and cognitive functioning $(B 0.26 ; p=0.03, B 0.31 ; p=0.01$ and $B-0.32 ; p=$ 0.01 respectively). In addition, mild therapeutic hypothermia appeared to contribute significantly in the explanation of cognitive functioning ( $B 0.40$ and $p<0.01$ ), indicating more cognitive problems in the group treated with hypothermia.

Table 5. Final step in multiple linear regression analyses with backward elimination

\begin{tabular}{|c|c|c|c|c|c|}
\hline Dependent variables & Independent variables & $\mathbf{R}^{2}$ & adjusted $R^{2}$ & Standardized beta & p-value \\
\hline SF-36 physical health & $\begin{array}{l}\text { gender } \\
\text { age } \\
\text { therapeutic hypothermia }\end{array}$ & 0.16 & 0.12 & $\begin{array}{l}-0.26 \\
-0.32 \\
-0.23\end{array}$ & $\begin{array}{l}0.02 \\
\mathbf{0 . 0 4} \\
\mathbf{0 . 0 2} \\
0.08\end{array}$ \\
\hline SF-36 mental health & $\begin{array}{l}\text { gender } \\
\text { therapeutic hypothermia }\end{array}$ & 0.17 & 0.14 & $\begin{array}{l}-0.35 \\
-0.23\end{array}$ & $\begin{array}{l}0.01 \\
\mathbf{0 . 0 1} \\
0.08\end{array}$ \\
\hline CIQ & $\begin{array}{l}\text { gender } \\
\text { age } \\
\text { catheterization with } \mathrm{PCl}\end{array}$ & 0.33 & 0.29 & $\begin{array}{r}0.24 \\
-0.34 \\
0.26\end{array}$ & $\begin{array}{l}0.00 \\
0.04 \\
0.01 \\
\mathbf{0 . 0 3}\end{array}$ \\
\hline FAl & $\begin{array}{l}\text { gender } \\
\text { age } \\
\text { catheterization with } \mathrm{PCl}\end{array}$ & 0.34 & 0.30 & $\begin{array}{r}0.23 \\
-0.31 \\
0.31\end{array}$ & $\begin{array}{l}0.00 \\
0.04 \\
0.01 \\
0.01\end{array}$ \\
\hline CFQ & $\begin{array}{l}\text { gender } \\
\text { catheterization with PCI } \\
\text { therapeutic hypothermia }\end{array}$ & 0.34 & 0.31 & $\begin{array}{r}0.41 \\
-0.32 \\
0.40\end{array}$ & $\begin{array}{l}0.00 \\
0.00 \\
0.01 \\
\mathbf{0 . 0 0}\end{array}$ \\
\hline
\end{tabular}

Independent variables: gender, age, number of defibrillations, catheterization with $\mathrm{PCl}$, therapeutic hypothermia, myocardial infarction in cardiovascular history.

$\mathrm{PCl}=$ Percutaneous Coronary Intervention

SF-36 = Short Form 36

$\mathrm{CIQ}=$ Community Integration Questionnaire

$\mathrm{FAl}=$ Frenchay Activities Index

CFQ $=$ Cognitive Failures Questionnaire

\section{Discussion}

We found that many patients surviving six months to six years after an out-of hospital cardiac arrest experienced severe fatigue, feelings of anxiety and depression, cognitive problems and a decreased quality of life. They also had problems with participation in society. These results can be compared to functioning in the general population, but also to other studies focusing on cardiac arrest survivors or brain injured patients.

In comparison with the general population, patients in this study seem to have lower levels of participation in society. ${ }^{33}$ Their health related quality of life is just below average. ${ }^{34}$ The mean score on the SF-36 appeared to be lower than in previous studies in cardiac arrest survivors but 
higher than in patients with traumatic brain injury, ${ }_{1}^{36,37}$ whereas the level of participation in society seems comparable with that of patients after traumatic brain injury. ${ }^{29}$ However, the mean age of the patients in the current study is higher as compared to the general population, and older age showed to have a negative effect on participation in society. Of the 35 (56\%) patients working before the cardiac arrest, $49 \%$ were able to fully return to work, which is better than presented in earlier studies..$^{7-9}$

Severe fatigue was present in more than half of the patients. This finding is similar to the rate in patients one year post-stroke, where $70 \%$ of patients experienced fatigue. ${ }^{21}$ The scores found on the HADS, with $14 \%$ showing signs of depression, agree with previous studies on cardiac arrest. 6,38 Twenty-two percent of our patients experienced problems with cognitive functioning. In previous studies on cardiac arrest survivors percentages of 11-50\% were reported. ${ }^{5,39}$ However, we used the CFQ to assess cognitive problems and it reflects the perception of the patients, who may be either less aware or overestimate their cognitive problems. Conclusions on cognitive functioning from this study have to be drawn with caution.

The performance of instrumental daily activities found is comparable with the general population and much better than in stroke patients. ${ }^{28}$ Fifty-four (86\%) patients in this study functioned independently which seems better than in earlier studies where $23-32 \%$ of the patients were unable to live at home independently up to one year after the cardiac arrest. 6,8,35

\section{Caregivers}

Little information is available on the strain put on the partner after a cardiac arrest. Based on the results of this study, many caregivers experience stress reactions and feelings of anxiety after their partner's cardiac arrest, even more so than the patients. Almost one in five caregivers showed a high level of caregiver strain. This is less than the $64 \%$ found in a previous study of caregivers to severely brain injured patients. ${ }^{40}$

\section{Prognostic factors for long term functioning}

Looking at prognostic factors for long term daily functioning, gender and age influenced the patient's quality of life, participation in society and daily functioning. $6,7,9$ This confirms findings in previous studies. ${ }^{9,35}$ Patients treated with $\mathrm{PCl}$ after cardiac arrest seemed to have a higher level of cognitive functioning, participation in society and instrumental daily activities than patients without $\mathrm{PCl}$. This may be due to selection bias (only patients with VF, a prognostic favourable initial rhythm, being treated). There were significantly more cognitive problems in patients treated with mild therapeutic hypothermia but this may also reflect selection bias because this treatment is only administered to patients who are comatose upon arrival in the hospital, and coma itself is related to more cognitive impairments. ${ }^{5,11}$ Mild therapeutic hypothermia may improve mortality and neurological outcome, ${ }^{12,13}$ although a recent study did not show a significant difference in Glasgow Outcome Scale between treated and untreated patients. ${ }^{16}$

Several studies have investigated the influence of having an ICD on the quality of life, ${ }^{14,15}$ but we did not find any associations between having an ICD and quality of life. 


\section{Limitations}

This study is limited by its retrospective design. Information in the hospital medical files concerning the resuscitation procedures could be prone to bias. In addition, possible associations between resuscitation variables and long-term outcome retrieved from the questionnaires could be influenced by confounders (e.g. level of functioning before the cardiac arrest and changes in treatment of cardiac arrest) or selection bias through patient participation. This study has a small sample size, but it is larger than many previous studies on this topic.

\section{Future research}

Further research based on prospective studies with larger samples is needed on different domains of long-term functioning of both patients and caregivers, and on prognostic factors for future functioning and quality of survival so that these problems can be discussed more adequately after patients survive a cardiac arrest.

\section{Conclusions}

Our results indicate that after surviving an out-of-hospital cardiac arrest, both patients and partners can experience important impairments in their lives, similar to those seen in patients with other kinds of brain damage. This might suggest that, in order to improve their quality of life, survivors of cardiac arrest should receive additional therapy similar to patients with other brain injuries rather than regarding them as cardiac patients only. It also shows the need and importance of further research in this field.

\section{Acknowledgements}

The authors want to thank Drs. B.J.W. Eikemans, J.P.J.M. de Munter, M. de Munter and J. Partouns for providing the majority of the medical data of the participants, and for the effort they put in the study. We also want to thank the participants for their participation and useful comments. 


\section{References}

1. Straus SM, Bleumink GS, Dieleman JP, van der Lei J, Stricker BH, Sturkenboom MC. The incidence of sudden cardiac death in the general population. J Clin Epidemiol 2004;57(1):98-102.

2. Fredriksson M, Herlitz J, Nichol G. Variation in outcome in studies of out-of-hospital cardiac arrest: a review of studies conforming to the Utstein guidelines. Am J Emerg Med 2003;21(4):276-81.

3. Hallstrom AP, Ornato JP, Weisfeldt M, et al. Public-access defibrillation and survival after out-of-hospital cardiac arrest. N Engl J Med 2004;351(7):637-46.

4. Lim C, Alexander MP, LaFleche G, Schnyer DM, Verfaellie M. The neurological and cognitive sequelae of cardiac arrest. Neurology 2004;63(10):1774-8.

5. Sauve MJ, Doolittle N, Walker JA, Paul SM, Scheinman MM. Factors associated with cognitive recovery after cardiopulmonary resuscitation. Am J Crit Care 1996;5(2):127-39.

6. de Vos R, de Haes HC, Koster RW, de Haan RJ. Quality of survival after cardiopulmonary resuscitation. Arch Intern Med 1999;159(3):249-54.

7. Saner H, Borner Rodriguez E, Kummer Bangerter A, Schuppel R, von Planta M. Quality of life in longterm survivors of out-of-hospital cardiac arrest. Resuscitation 2002;53(1):7-13.

8. Lundgren-Nilsson A, Rosen H, Hofgren C, Sunnerhagen KS. The first year after successful cardiac resuscitation: function, activity, participation and quality of life. Resuscitation 2005;66(3):285-9.

9. Bunch TJ, White RD, Khan AH, Packer DL. Impact of age on long-term survival and quality of life following out-of-hospital cardiac arrest. Crit Care Med 2004;32(4):963-7.

10. Waalewijn RA, de Vos R, Koster RW. Out-of-hospital cardiac arrests in Amsterdam and its surrounding areas: results from the Amsterdam resuscitation study (ARREST) in 'Utstein' style. Resuscitation 1998;38(3):157-67.

11. Wijdicks EF, Hijdra A, Young GB, Bassetti CL, Wiebe S. Practice parameter: prediction of outcome in comatose survivors after cardiopulmonary resuscitation (an evidence-based review): report of the Quality Standards Subcommittee of the American Academy of Neurology. Neurology 2006;67(2):20310.

12. Mild therapeutic hypothermia to improve the neurologic outcome after cardiac arrest. N Engl I Med 2002;346(8):549-56.

13. Bernard SA, Gray TW, Buist MD, et al. Treatment of comatose survivors of out-of-hospital cardiac arrest with induced hypothermia. N Engl J Med 2002;346(8):557-63.

14. Groeneveld PW, Matta MA, Suh JJ, Heidenreich PA, Shea JA. Costs and quality-of-life effects of implantable cardioverter-defibrillators. Am J Cardio/ 2006;98(10):1409-15.

15. Kamphuis HC, De Leeuw JR, Derksen R, Hauer R, Winnubst JA. A 12-month quality of life assessment of cardiac arrest survivors treated with or without an implantable cardioverter defibrillator. Europace 2002;4(4):417-25.

16. Bekkers SC, Eikemans BJ, Tieleman R, et al. Hypothermia for out-of-hospital cardiac arrest survivors: a single-center experience. Am J Emerg Med 2007;25(9):1078-80.

17. Wellens HJ, Gorgels AP, de Munter H. Sudden death in the community. J Cardiovasc Electrophysiol 2003;14(9 Suppl):S104-7.

18. WHO. International Classification of Functioning, Disability and Health: ICF. Geneva, 2001.

19. Bennett JA, Riegel B, Bittner V, Nichols J. Validity and reliability of the NYHA classes for measuring research outcomes in patients with cardiac disease. Heart Lung 2002;31(4):262-70.

20. Krupp LB, LaRocca NG, Muir-Nash J, Steinberg AD. The fatigue severity scale. Application to patients with multiple sclerosis and systemic lupus erythematosus. Arch Neurol 1989;46(10):1121-3. 
21. Schepers VP, Visser-Meily AM, Ketelaar M, Lindeman E. Poststroke fatigue: course and its relation to personal and stroke-related factors. Arch Phys Med Rehabil 2006;87(2):184-8.

22. Broadbent DE, Cooper PF, FitzGerald P, Parkes KR. The Cognitive Failures Questionnaire (CFQ) and its correlates. Br J Clin Psychol 1982;21 (Pt 1):1-16.

23. Ponds R, van Boxtel $M$, Jolles J. De 'Cognitive Failure Questionnaire' als maat voor subjectief cognitief functioneren. Tijdschrift voor Neuropsychologie 2006(1):37-45.

24. Bjelland I, Dahl AA, Haug TT, Neckelmann D. The validity of the Hospital Anxiety and Depression Scale. An updated literature review. J Psychosom Res 2002;52(2):69-77.

25. Sundin EC, Horowitz MJ. Impact of Event Scale: psychometric properties. Br J Psychiatry 2002;180:2059.

26. Hsueh IP, Lin JH, Jeng JS, Hsieh CL. Comparison of the psychometric characteristics of the functional independence measure, 5 item Barthel index, and 10 item Barthel index in patients with stroke. $J$ Neurol Neurosurg Psychiatry 2002;73(2):188-90.

27. Wade DT, Legh-Smith J, Langton Hewer R. Social activities after stroke: measurement and natural history using the Frenchay Activities Index. Int Rehabil Med 1985;7(4):176-81.

28. Schuling J, de Haan R, Limburg M, Groenier KH. The Frenchay Activities Index. Assessment of functional status in stroke patients. Stroke 1993;24(8):1173-7.

29. Sander AM, Fuchs KL, High WM, Jr., Hall KM, Kreutzer JS, Rosenthal M. The Community Integration Questionnaire revisited: an assessment of factor structure and validity. Arch Phys Med Rehabil 1999;80(10):1303-8.

30. Brazier JE, Harper R, Jones NM, et al. Validating the SF-36 health survey questionnaire: new outcome measure for primary care. Bmj 1992;305(6846):160-4.

31. Dempster $\mathrm{M}$, Donnelly $\mathrm{M}$. Measuring the health related quality of life of people with ischaemic heart disease. Heart 2000;83(6):641-4.

32. Robinson BC. Validation of a Caregiver Strain Index. J Gerontol 1983;38(3):344-8.

33. Willer B, Ottenbacher KJ, Coad ML. The community integration questionnaire. A comparative examination. Am J Phys Med Rehabil 1994;73(2):103-11.

34. Aaronson NK, Muller M, Cohen PD, et al. Translation, validation, and norming of the Dutch language version of the SF-36 Health Survey in community and chronic disease populations. I Clin Epidemiol 1998;51(11):1055-68.

35. van Alem AP, Waalewijn RA, Koster RW, de Vos R. Assessment of quality of life and cognitive function after out-of-hospital cardiac arrest with successful resuscitation. Am J Cardiol 2004;93(2):131-5.

36. Horsted TI, Rasmussen LS, Meyhoff CS, Nielsen SL. Long-term prognosis after out-of-hospital cardiac arrest. Resuscitation 2007;72(2):214-8.

37. Lippert-Gruner M, Maegele M, Haverkamp H, Klug N, Wedekind C. Health-related quality of life during the first year after severe brain trauma with and without polytrauma. Brain Inj 2007;21(5):451-5.

38. Ladwig KH, Schoefinius A, Dammann G, Danner R, Gurtler R, Herrmann R. Long-acting psychotraumatic properties of a cardiac arrest experience. Am J Psychiatry 1999;156(6):912-9.

39. van Alem AP, de Vos R, Schmand B, Koster RW. Cognitive impairment in survivors of out-of-hospital cardiac arrest. Am Heart J 2004;148(3):416-21.

40. Middelkamp W, Moulaert VR, Verbunt JA, van Heugten CM, Bakx WG, Wade DT. Life after survival: long-term daily life functioning and quality of life of patients with hypoxic brain injury as a result of a cardiac arrest. Clin Rehabil 2007;21(5):425-31. 



\section{Chapter 3}

\section{Determinants of quality of life in survivors of cardiac arrest}

Published in Journal of Rehabilitation Medicine as:

Moulaert VR, Wachelder EM, Verbunt JA, Wade DT, van Heugten CM. Determinants of quality of life in survivors of cardiac arrest. J Rehabil Med 2010;42(6):553-8. 


\begin{abstract}
Objective: To study factors related to quality of life after a hypoxic period due to cardiac arrest.

Design: Retrospective cohort study.

Subjects: Eighty-eight survivors of out-of-hospital cardiac arrest, admitted to a Dutch academic hospital between 2001 and 2006.

Methods: Patients received a set of questionnaires at home. The main outcome measures were physical and mental quality of life (Medical Outcomes Study 36-item Short Form Health Survey; SF-36). Potential determinants were cognitive complaints, emotional problems (depression/ anxiety), posttraumatic stress, fatigue, daily functioning and participation in society. Multiple linear regression analyses were performed with physical and mental quality of life as dependent variables.
\end{abstract}

Results: Sixty-three (72\%) patients responded. Mean time since cardiac arrest was 36 (SD 19) months. Backward regression analyses showed that physical quality of life was significantly $\left(p<0.001\right.$, adjusted $\left.R^{2}=0.531\right)$ related to cognitive complaints $(\beta=-0.378)$, instrumental daily life activities $(\beta=0.262)$, posttraumatic stress $(\beta=-0.246)$ and fatigue $(\beta=-0.226)$. Mental quality of life was significantly $\left(p<0.001\right.$, adjusted $\left.R^{2}=0.664\right)$ explained by anxiety/depression $(\beta=-0.609)$, fatigue $(\beta=-0.177)$ and cognitive complaints $(\beta=-0.175)$.

Conclusion: Quality of life is related to cognitive complaints, fatigue, anxiety/depression, posttraumatic stress and difficulties in daily activities in survivors of out-of-hospital cardiac arrest. Rehabilitation programmes for this group should specifically address these topics. 


\section{Introduction}

A person's quality of life should be a major outcome measure in studies of survivors of cardiac arrest, since reporting on survival rates alone does not provide all information about the success of resuscitation. ${ }^{1}$ Several prospective studies have reported that the long-term quality of life of cardiac arrest survivors is generally acceptable to good..$^{2-4}$ However, a substantial group of cardiac arrest survivors experience ongoing problems and a decreased quality of life. ${ }^{5}$ Medical variables cannot reliably predict quality of life after cardiac arrest. Although the performance of bystander cardiopulmonary resuscitation (CPR) seems associated with a better quality of life, ${ }^{4}$ longer time delays during resuscitation and the type of emergency cardiac care were not related to post-cardiac arrest quality of life. ${ }^{6-8}$ In order to help the survivors with long-term problems, it is important to investigate which factors influence their quality of life, as this may identify potential targets for rehabilitation treatment.

Survivors of cardiac arrest are often categorized as 'cardiac patients', although they may also be regarded as 'neurological patients' because a cardiac arrest can result in hypoxic brain injury. Indeed, about half of cardiac arrest survivors have enduring cognitive impairments, as was shown in a recent systematic review. ${ }^{9}$ The long-term consequences of hypoxic brain injury secondary to cardiac arrest may therefore be comparable to the long-term consequences of other types of brain damage such as traumatic brain injury.

Studies on patients with varying other causes of brain injury have revealed that reduced quality of life was associated with three important variables, namely cognitive impairments, emotional problems and fatigue. Cognitive impairments were related to the quality of life of stroke patients. ${ }^{10}$ The importance of emotional problems was shown in a study on patients with mild traumatic brain injury in which life satisfaction was related to posttraumatic stress and depression. ${ }^{11}$ Fatigue was associated with quality of life in both stroke patients ${ }^{12}$ and in traumatic brain injured patients. ${ }^{13}$ Similarly, multivariate regression analyses in a cohort of survivors of subarachnoid hemorrhage showed that mood, fatigue, and cognitive complaints were strongly associated with reduced scores on a stroke-specific quality of life scale. ${ }^{14}$

There are few studies that have investigated possible cognitive or psychosocial factors affecting quality of life after cardiac arrest. One study showed that memory complaints were related to quality of life in a study on survivors of out-of-hospital cardiac arrest. ${ }^{15}$ Another study identified that posttraumatic stress was common after cardiac arrest and was negatively related to quality of life. ${ }^{16}$ In addition, anxiety and depression were also reported frequently after cardiac arrest and affected perceived health improvement and social functioning. ${ }^{8}$ However, the amount of information on factors affecting quality of life after cardiac arrest is limited and an integrative multivariate model is currently lacking.

The aim of this study was therefore to investigate potential determinants of quality of life after a hypoxic period due to cardiac arrest. It was hypothesized that quality of life would be affected by the same factors that influence quality of life of other brain injured patients, namely cognitive complaints, emotional problems and fatigue. 


\section{Methods}

Survivors of out-of-hospital cardiac arrest who had been admitted to the Department of Cardiology of Maastricht University Medical Centre (MUMC+), the Netherlands, between January 2001 and December 2006 were invited to participate in this retrospective cohort study. MUMC+ is an academic hospital in the southern part of the Netherlands and is the primary referral centre in a radius of 25 kilometres with a catchment area of approximately 200.000 inhabitants, which is served by a single ambulance service. The incidence of cardiac arrest in this area is 9.2 per 10.000 for people between 20 and 75 years old. ${ }^{17}$ Survival rates until discharge are, in general, low, ${ }^{18}$ being $7.4 \%$ in this specific region. ${ }^{19}$

For inclusion in this study, participants had to be survivors aged 18 years or older, still alive at the time of the study, and with sufficient knowledge of the Dutch language to complete the questionnaires.

Patient data of potential participants for this study were retrieved from two hospital databases containing all out-of-hospital cardiac arrests in Maastricht and the surrounding area. ${ }^{17,20}$ Furthermore, the admission registers from 2001 to 2006 of the Coronary Care Unit were hand searched for admissions stating 'cardiac arrest' or 'resuscitation'. After retrieving potential participants, data were checked for accuracy of the diagnosis and for survival until discharge. Next, the general practitioners of all potential participants were contacted to confirm whether the subjects were currently still alive. People thought to be alive received information about the study by mail, together with the informed consent form and the set of questionnaires. The study protocol was approved by the Medical Ethics Committee of Maastricht University Medical Centre. Other results about the respondents and their caregivers concerning their long-term functioning have been published elsewhere. ${ }^{5}$

\section{Assessment instruments}

\section{Socio-demographic and medical variables}

The following socio-demographic variables were extracted from the notes: age, gender, marital status, living situation, education and work situation. The medical variables extracted were: age at time of cardiac arrest, time since cardiac arrest, location of cardiac arrest, presence of witnesses, performance of bystander cardiopulmonary resuscitation, initial cardiac rhythm, number of defibrillations, interval from collapse to return of spontaneous circulation, (sub)acute interventions, left ventricular ejection fraction and cardiovascular history.

\section{Quality of life}

The Medical Outcomes Study 36-item Short Form Health Survey (SF-36), a 36-item generic quality of life measure distinguishing two domains, namely physical health and mental health. The scores on the two domains range from 0 to 100 . Higher scores represent a better experienced quality of life. Norm values for the Dutch population are a mean of 76.3 (SD 26) for the physical component and 78.0 (SD 23) for mental component. ${ }^{21}$ 


\section{Participation in society}

The Community Integration Questionnaire (CIQ), a 15-item questionnaire that assesses the level of social participation in society in three domains: Home Integration, Social Integration and Productive Activity.22

\section{Basic activities of daily living}

The Barthel Index (BI), a widely used instrument that measures basic (personal) activities of daily living (ADL). The instrument consists of 10 items and measures to what extent a person can perform basic ADL activities independently. High scores indicate a high level of independence. ${ }^{23}$

\section{Instrumental activities of daily living}

The Frenchay Activities Index (FAl), an accepted measure for instrumental (extended) activities of daily living, that reports on the performance of fifteen daily life activities. ${ }^{24}$

\section{Cognitive complaints}

The Cognitive Failures Questionnaire (CFQ), a 25-item questionnaire on self-reported cognitive failures. A higher score represents the experience of more cognitive complaints. ${ }^{25}$

\section{Emotional problems}

The Hospital Anxiety and Depression Scale (HADS), a 14-item questionnaire, designed to detect the presence of mild degrees of mood disorders in non-psychiatric hospital outpatients. ${ }^{26}$ The HADS consists of two sub-scales: depression and anxiety. Higher scores represent more emotional problems.

\section{Posttraumatic stress}

The Impact of Event Scale (IES) which measures psychological reactions that take place after a traumatic event. The IES consists of 15 items and explores the level of posttraumatic stress by asking for intrusive and avoidance symptoms..$^{27,28}$

\section{Fatigue}

The Fatigue Severity Scale (FSS), a 9-item questionnaire that measures the impact of fatigue symptoms in daily activities, with a higher score indicating a more negative impact. ${ }^{29}$

\section{Statistical analysis}

Descriptive statistics were used to present the demographic, medical and resuscitation characteristics of the study population. To investigate possible differences between the responders and the non-responders, the T- test and Chi-square test were used for age and gender respectively. Assessment instruments in which more than $15 \%$ of the items were missing, were not used in our analyses. When there were less than $15 \%$ missing items, the missing data were imputed by dividing the sum of the scale by the number of items answered and then multiplied by the total number of items of that measurement instrument.

Because of the non-parametric distribution of most of the variables, Spearman rank correlations coefficients (2-tailed) were calculated to investigate relationships between the physical and mental quality of life and the potential determinants. A p-value $<0.01$ was considered statistically significant. 
The influence of the potential determinants on quality of life was determined with multiple linear regression analyses (backward method) for the physical and mental domains separately. The independent variables that were introduced were the variables with a significant correlation with quality of life. A limit value for elimination in the regression analyses was set at $p<0.10$. For the regression models a $p$-value of $<0.05$ was considered statistically significant. The regression models were checked for independence of errors and absence of co-linearity and outliers.

Statistical analyses were performed using the software package SPSS version 15.0 and 16.0 (SPSS Inc., Chicago, Illinois, USA).

\section{Results}

From the databases searched, 220 persons with a possible out-of-hospital cardiac arrest were identified. After excluding those who did not fulfill the inclusion criteria, or who had died, or who were lost to follow up, 88 persons remained who were eligible for this study. This group received the set of questionnaires at home. 63 persons responded by returning the questionnaires: a response rate of $72 \%$ (see Figure 1 for flow chart of patient inclusion).

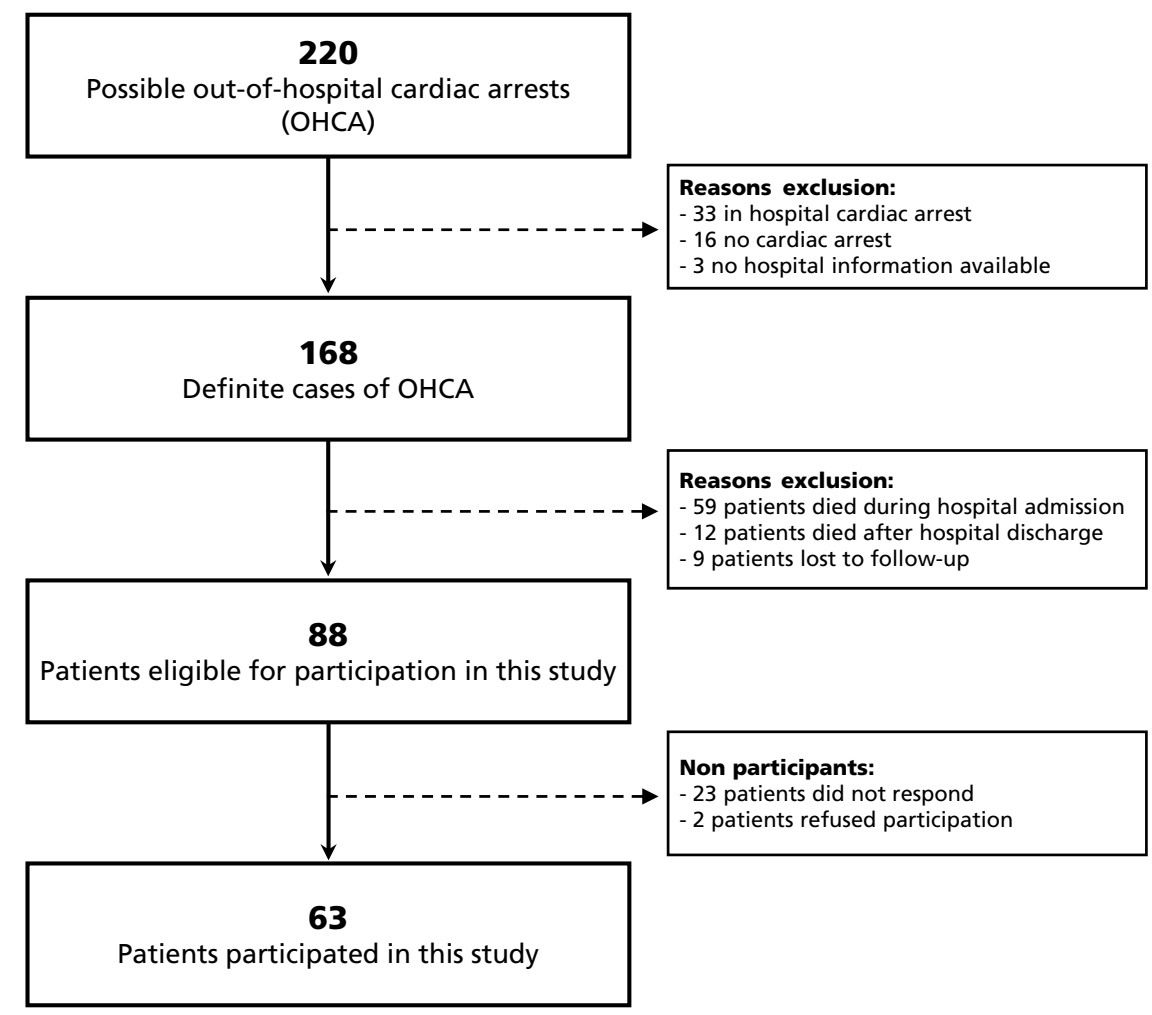

Figure 1. Flow chart of patient inclusion 
There were no significant differences in gender $(t=-0.62, p=0.54)$ or age (Chi-square $=0.04, p=$ 0.84 ) between the responders and the non-responders.

The group of responders consisted of 54 (86\%) men and nine women. Their mean age was 60.0 (SD 12.7) years. The mean time since cardiac arrest was 36.0 (SD 18.8) months. The demographic characteristics of the patients are presented in Table 1. For the marital status, living situation and work situation both the results at the time of cardiac arrest and their current situation are shown.

Table 1. Demographic characteristics of the participants $(n=63)$

\begin{tabular}{lcc}
\hline & At time of cardiac arrest & Current situation \\
\hline Age & & \\
mean (SD) & $57.3($ SD 12.5$)$ & $60.2($ SD 12.7$)$ \\
range & $18-81$ & $20-85$ \\
Gender, $n(\%)$ & & \\
male & & $54(86 \%)$ \\
female & & $9(14 \%)$ \\
Marital status, $n$ (\%) & $47(75 \%)$ & \\
married / living with partner & $15(24 \%)$ & $46(73 \%)$ \\
unmarried / divorced / widowed & $1(2 \%)$ & $15(24 \%)$ \\
unknown & & $2(3 \%)$ \\
Living situation, $n$ (\%) & $54(86 \%)$ & \\
home (independent) & $8(13 \%)$ & $53(84 \%)$ \\
home (with help from others) & $1(2 \%)$ & $8(13 \%)$ \\
sheltered housing & - & $1(2 \%)$ \\
nursing home & & $1(2 \%)$ \\
Education, $n$ (\%) & & \\
primary school & & $7(11 \%)$ \\
secondary school & & $12(19 \%)$ \\
high school & & $30(48 \%)$ \\
university & $6(10 \%)$ \\
other / unknown & & $8(13 \%)$ \\
Working situation, $n$ (\%) & & \\
full-time / self-owned company & & $17(27 \%)$ \\
part-time & & $10(16 \%)$ \\
permanently unfit to work & $6(10 \%)$ \\
volunteer work & $1(27 \%)$ & $1(2 \%)$ \\
no job & & $22(35 \%)$ \\
retired & & $6(10 \%)$ \\
housewife & &
\end{tabular}

$\mathrm{SD}=$ standard deviation 
Table 2 shows information on the cardiac arrest, resuscitation, medical interventions and patient history.

Table 2. Medical data of the participants

\begin{tabular}{|c|c|c|}
\hline & $\mathbf{n}$ & \\
\hline Age at time of cardiac arrest, mean (SD) & 63 & 57.3 (SD 12.5) \\
\hline Time since cardiac arrest (months), mean (SD) & 63 & $60.0(S D 18.8)$ \\
\hline $\begin{array}{l}\text { Location of cardiac arrest, } \mathrm{n}(\%) \\
\text { street / public area } \\
\text { home } \\
\text { in the ambulance } \\
\text { other }\end{array}$ & 63 & $\begin{array}{c}30(48 \%) \\
20(32 \%) \\
4(6 \%) \\
9(14 \%)\end{array}$ \\
\hline Witnessed cardiac arrest, $\mathrm{n}(\%)$ & 63 & $56(89 \%)$ \\
\hline $\begin{array}{l}\text { Bystander CPR, n (\%) } \\
\text { yes, by lay person } \\
\text { yes, by trained person } \\
\text { no }\end{array}$ & 63 & $\begin{array}{l}26(41 \%) \\
23(37 \%) \\
14(22 \%)\end{array}$ \\
\hline $\begin{array}{l}\text { Initial cardiac rhythm, n (\%) } \\
\text { VF } \\
\text { VTNF } \\
\text { other rhythm }\end{array}$ & 62 & $\begin{array}{c}55(89 \%) \\
6(10 \%) \\
1(2 \%)\end{array}$ \\
\hline Number of defibrillations, median (range) & 63 & $2(0-12)$ \\
\hline Interval collapse - ROSC (min), median (range) & 47 & $10(2-35)$ \\
\hline $\begin{array}{l}\text { (Sub)acute interventions, } \mathrm{n}(\%) \\
\text { none / only catheterization } \\
\text { catheterization with } \mathrm{PCI} \\
\text { CABG } \\
\text { ICD } \\
\text { therapeutic hypothermia }\end{array}$ & 63 & $\begin{array}{l}24(38 \%) \\
28(44 \%) \\
13(21 \%) \\
25(46 \%) \\
17(27 \%)\end{array}$ \\
\hline LVEF $<1$ week after cardiac arrest, mean (SD) & 58 & $47.5($ SD 12.7) \\
\hline $\begin{array}{l}\text { Cardiovascular history, } \mathrm{n}(\%) \\
\text { myocardial infarction } \\
\text { cardiac arrest } \\
\text { cardiac interventions (PCI, CABG) } \\
\text { claudicatio intermittens } \\
\text { CVA } \\
\text { diabetes mellitus }\end{array}$ & 63 & $\begin{array}{l}19(30 \%) \\
2(3 \%) \\
8(13 \%) \\
4(6 \%) \\
2(3 \%) \\
3(5 \%)\end{array}$ \\
\hline
\end{tabular}

$C P R=$ Cardiopulmonary Resuscitation

$\mathrm{VF}=$ Ventricular Fibrillation

VT = Ventricular Tachycardia

ROSC = Return Of Spontaneous Circulation

$\mathrm{PCI}=$ Percutaneous Coronary Intervention
CABG $=$ Coronary Artery Bypass Graft

$I C D=$ Implantable Cardioverter Defibrillator

LVEF = Left Ventricular Ejection Fraction

CVA $=$ Cerebrovascular Accident

$\mathrm{SD}=$ standard deviation

Table 3 shows the scores on the assessment instruments. All outcome measures were not normally distributed, except the FSS and the CIQ. When more than 15\% of the items were missing, this person was not taken into account in the analyses; this was the case for two patients on the SF36 per subdomain, CIQ, FAI, CFQ and FSS. In case of less than $15 \%$ missing values, data were imputed; this varied from one patient (1.6\%) on the HADS to eight patients (12.7\%) on the CFQ. 
For six patients this was only one item, for one patient two items, and for one patient three items on the CFQ.

The mean/ median score on the SF-36 in our population was 71.8/ 77.4 (range 28 - 100) on the SF-36 physical domain and 73.0/ 79.5 (range 26 - 100) on the SF-36 mental domain. The scores in our sample are somewhat lower than in the Dutch norm population. ${ }^{21}$

Table 3. Quality of life, participation, basic and instrumental activities of daily living, cognitive complaints, emotional problems, posttraumatic stress and fatigue of the participants

\begin{tabular}{|c|c|c|c|c|}
\hline $\begin{array}{l}\text { Domain } \\
\text { Assessment instrument }\end{array}$ & $\mathbf{n}$ & Cut-off & Mean (SD) & Median (range) \\
\hline $\begin{array}{l}\text { Quality of life } \\
\text { SF-36 physical } \\
\text { SF-36 mental }\end{array}$ & $\begin{array}{l}58 \\
55\end{array}$ & --- & $\begin{array}{l}71.8(\text { SD 19.6) } \\
73.0(\text { SD 20.5) }\end{array}$ & $\begin{array}{l}77.4(28-100) \\
79.5(26-100)\end{array}$ \\
\hline $\begin{array}{l}\text { Participation in society } \\
\text { Community Integration Questionnaire }\end{array}$ & 61 & --- & 14.7 (SD 5.5) & $15.0(4-26)$ \\
\hline $\begin{array}{l}\text { Basic activities of daily living } \\
\text { Barthel Index }\end{array}$ & 63 & $<15$ & 19.4 (SD 2.1) & $20.0(7-20)$ \\
\hline $\begin{array}{l}\text { Instrumental activities of daily living } \\
\text { Frenchay Activities Index }\end{array}$ & 61 & --- & 25.7 (SD 8.7) & $27.0(6-41)$ \\
\hline $\begin{array}{l}\text { Cognitive complaints } \\
\text { Cognitive Failures Questionnaire }\end{array}$ & 61 & $>43$ & 29.8 (SD 18.4) & $30.0(0-73)$ \\
\hline $\begin{array}{l}\text { Emotional problems } \\
\text { Hospital Anxiety and Depression Scale, total } \\
\text { - subscale anxiety } \\
\text { - subscale depression }\end{array}$ & $\begin{array}{l}63 \\
63 \\
63\end{array}$ & $\begin{array}{l}>10 \\
>8 \\
>8\end{array}$ & $\begin{array}{l}8.5(S D \text { 6.4) } \\
4.4(\text { SD 3.4) } \\
4.2(\text { SD 3.6) }\end{array}$ & $\begin{array}{l}7.0(0-25) \\
4.0(0-14) \\
3.0(0-12)\end{array}$ \\
\hline $\begin{array}{l}\text { Posttraumatic stress } \\
\text { Impact of Event Scale }\end{array}$ & 63 & $>25$ & 13.0 (SD 13.7) & $8(0-53)$ \\
\hline $\begin{array}{l}\text { Fatigue } \\
\text { Fatigue Severity Scale }\end{array}$ & 61 & $>3$ & 4.3 (SD 1.6) & $4.3(1-7)$ \\
\hline
\end{tabular}

SF-36 = Medical Outcomes Study 36-item Short Form Health Survey

$\mathrm{SD}=$ standard deviation

Table 4 shows the Spearman rank correlations between the two SF-36 domains and the other variables. No significant correlations were found between the SF-36 domains and the CIQ and the $\mathrm{Bl}$. 
Table 4. Spearman's correlations between quality of life and the potential determinants

\begin{tabular}{lcc}
\hline & SF-36 Physical & SF-36 Mental \\
\hline CIQ & 0.29 & 0.26 \\
BI & 0.22 & 0.10 \\
FAI & $0.44^{* *}$ & $0.41^{*}$ \\
FSS & $-0.61^{* *}$ & $-0.57^{* *}$ \\
CFQ & $-0.55^{* *}$ & $-0.40^{*}$ \\
HADS & $-0.48^{* *}$ & $-0.73^{* *}$ \\
IES & $-0.37^{*}$ & $-0.43^{* *}$ \\
\hline
\end{tabular}

${ }^{*} p \leq 0.01 ;{ }^{* *} p \leq 0.001$

SF-36 = Medical Outcomes Study 36-item Short Form Health Survey

$\mathrm{CIQ}=$ Community Integration Questionnaire

$\mathrm{BI}=$ Barthel Index

FAI = Frenchay Activities Index

FSS = Fatigue Severity Scale

$\mathrm{CFQ}=$ Cognitive Failures Questionnaire

HADS = Hospital Anxiety and Depression Scale

IES = Impact of Event Scale

Figure 2 presents the results of the backward regression analyses. The variables with significant correlations in Table 4 were introduced as independent variables.

For the SF-36 physical domain the model could significantly explain 53\% of the variance ( $p<0.001$, adjusted $R^{2}=0.531$ ). Four variables contributed to the model: in order of impact, the CFQ $(\beta=-0.378, p=0.001)$, FAI $(\beta=0.262, p=0.013)$, IES $(\beta=-0.246, p=0.017)$ and the FSS $(\beta=-0.226, p=0.057)$. The final model for the SF-36 mental domain accounted for $66 \%$ of the variance $\left(p<0.001\right.$, adjusted $\left.R^{2}=0.664\right)$. In this model, mental quality of life was related to the $\operatorname{HADS}(\beta=-0.609, p<0.001)$, the FSS $(\beta=-0.177, p=0.069)$ and the CFQ $(\beta=-0.175, p=0.081)$.

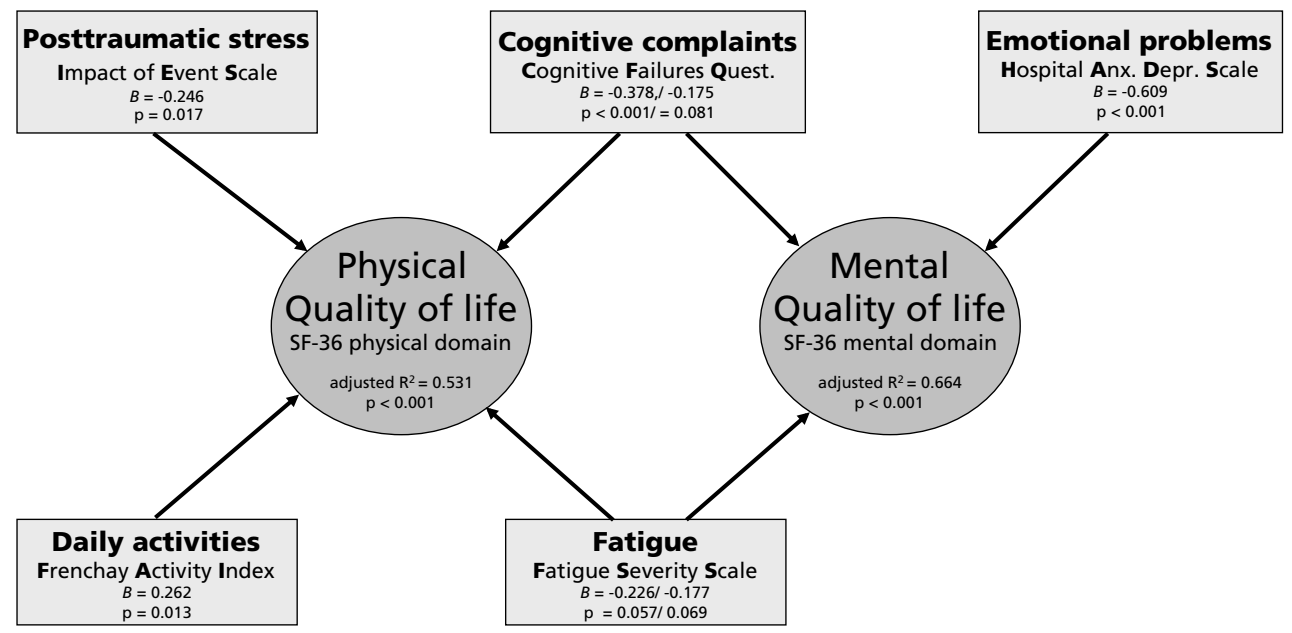

Figure 2. Determinants of physical and mental quality of life 


\section{Discussion}

This retrospective cohort study has shown that quality of life can be at risk after out-of-hospital cardiac arrest. The quality of life scores were slightly below that of the general Dutch population. ${ }^{21}$ This is in line with previous studies on quality of life after cardiac arrest. ${ }^{6,30}$ Mental quality of life could be affected more than physical quality of life, probably because significant motor impairments after cardiac arrest are rare. In addition, both cognitive and emotional functioning contribute to mental quality of life. Both are known to be at risk after hypoxic brain injury. 5,31,32

The correlation matrix showed that quality of life significantly correlated with instrumental daily activities, severity of fatigue, amount of cognitive complaints, level of mood disturbance (anxiety/ depression) and degree of posttraumatic stress. In contrast, quality of life was not related to participation in society and basic (personal) ADL functioning. That social participation was not related to quality of life is surprising. However, this might be explained by the fact that the majority of the participants did not work anymore and were over 60 years old, implying that their participation may already have been limited prior to the cardiac arrest. Basic ADL activities were hardly impaired and showed a clear ceiling effect, which probably explains the lack of any detectable influence.

The regression analyses revealed that physical quality of life was significantly related to cognitive complaints, performance of instrumental daily activities, posttraumatic stress and fatigue. Mental quality of life was primarily affected by anxiety/depression and to a lesser extent to fatigue and cognitive complaints. Both models could explain a substantial amount of the variance, 53\% and $66 \%$ respectively. Instrumental daily activities only contributed to physical quality of life, probably because a minimal level of physical fitness is necessary to perform these daily activities. Posttraumatic stress also contributed to physical quality of life only. In contrast, in a group of subarachnoid hemorrhage patients, comparable in the sense that they also have brain injury without clear physical impairments, posttraumatic stress disorders strongly predicted both mental and physical quality of life after 13 months. ${ }^{33}$ Anxiety and depressive symptoms were strongly related to mental quality of life alone, as would be expected as both are measures of mood disturbance. Cognitive complaints and fatigue were related to both physical and mental health. Fatigue is clearly a concept with both a mental and a physical aspect. That cognitive problems also affect physical health is an interesting finding, and possibly arises because cognitive impairments, for example in memory and planning, reduce the performance of complex physical activities.

There are some limitations to this study. First, the design was retrospective, which may have led to a selection bias and makes it difficult to draw causal relationships between quality of life and the potential determinants. Secondly, not all potential participants actually participated. Although the response was relatively high, this may have led to selection bias. It is possible that some people were in such a poor condition that filling out the questionnaires was not possible for them. On the other hand, it might also be that those without any complaints did not want to participate as they felt that there was 'nothing wrong', or due to the fact that they were too busy with their daily life. Looking at the incidence rates in the region and the number of patients retrieved 
from the hospital files, the sample can however be regarded as highly representative. Thirdly, time since cardiac arrest varied between one and six years and therefore participants may have been in different phases of recovery. Fourthly, we used self-report. The self-reporting of cognitive complaints has to be interpreted with caution, especially in cases of severe hypoxic brain injury. However, self-report of mood and activities are probably valid. To overcome the weaknesses mentioned above, a larger, prospective study would be necessary, in which cognitive impairments should be objectified with neuropsychological tests. Such a study is currently being conducted. ${ }^{34}$ In conclusion, this study has shown that quality of life after cardiac arrest seems to be affected by multiple factors including cognitive complaints, fatigue, emotional problems, posttraumatic stress and difficulties in daily activities. A similar pattern has been shown in patients with stroke ${ }^{10,12,14}$ and traumatic brain injury. ${ }^{11,13}$ This confirms our hypothesis that a survivor of a cardiac arrest should not only be regarded as a 'cardiac patient', but also as a 'brain injured patient'. Furthermore, our finding that quality of life is related to a diversity of factors, suggests that multidisciplinary rehabilitation programmes focussing on these factors, should be developed and evaluated.

\section{Acknowledgements}

We are grateful to B. Eikemans, J. de Munter, M. de Munter and J. Partouns for their help in identifying potential participants and collecting medical data. S. Bekkers and A. Gorgels are thanked for facilitating this study.

The study is funded by the Netherlands Organization for Health Research and Development (Zon/Mw) and Fonds Nuts/Ohra. 


\section{References}

1. Neumar RW, Nolan JP, Adrie C, et al. Post-cardiac arrest syndrome: epidemiology, pathophysiology, treatment, and prognostication. A consensus statement from the International Liaison Committee on Resuscitation (American Heart Association, Australian and New Zealand Council on Resuscitation, European Resuscitation Council, Heart and Stroke Foundation of Canada, InterAmerican Heart Foundation, Resuscitation Council of Asia, and the Resuscitation Council of Southern Africa); the American Heart Association Emergency Cardiovascular Care Committee; the Council on Cardiovascular Surgery and Anesthesia; the Council on Cardiopulmonary, Perioperative, and Critical Care; the Council on Clinical Cardiology; and the Stroke Council. Circulation 2008;118(23):2452-83.

2. Bunch TJ, White RD, Gersh BJ, et al. Long-term outcomes of out-of-hospital cardiac arrest after successful early defibrillation. N Engl J Med 2003;348(26):2626-33.

3. Lundgren-Nilsson A, Rosen $H$, Hofgren C, Sunnerhagen KS. The first year after successful cardiac resuscitation: function, activity, participation and quality of life. Resuscitation 2005;66(3):285-9.

4. Stiell I, Nichol G, Wells G, et al. Health-related quality of life is better for cardiac arrest survivors who received citizen cardiopulmonary resuscitation. Circulation 2003;108(16):1939-44.

5. Wachelder EM, Moulaert VR, van Heugten C, Verbunt JA, Bekkers SC, Wade DT. Life after survival: long-term daily functioning and quality of life after an out-of-hospital cardiac arrest. Resuscitation 2009;80(5):517-22.

6. van Alem AP, Waalewijn RA, Koster RW, de Vos R. Assessment of quality of life and cognitive function after out-of-hospital cardiac arrest with successful resuscitation. Am J Cardiol 2004;93(2):131-5.

7. Eisenburger P, List M, Schorkhuber W, Walker R, Sterz F, Laggner AN. Long-term cardiac arrest survivors of the Vienna emergency medical service. Resuscitation 1998;38(3):137-43.

8. Kamphuis HC, De Leeuw JR, Derksen R, Hauer R, Winnubst JA. A 12-month quality of life assessment of cardiac arrest survivors treated with or without an implantable cardioverter defibrillator. Europace 2002;4(4):417-25.

9. Moulaert VR, Verbunt JA, van Heugten CM, Wade DT. Cognitive impairments in survivors of out-ofhospital cardiac arrest: A systematic review. Resuscitation 2009;80(3):297-305.

10. Hochstenbach JB, Anderson PG, van Limbeek J, Mulder TT. Is there a relation between neuropsychologic variables and quality of life after stroke? Arch Phys Med Rehabil 2001;82(10):1360-6.

11. Stalnacke BM. Community integration, social support and life satisfaction in relation to symptoms 3 years after mild traumatic brain injury. Brain Inj 2007;21(9):933-42.

12. van de Port IG, Kwakkel G, Schepers VP, Heinemans $C T$, Lindeman E. Is fatigue an independent factor associated with activities of daily living, instrumental activities of daily living and health-related quality of life in chronic stroke? Cerebrovasc Dis 2007;23(1):40-5.

13. Cantor JB, Ashman T, Gordon W, et al. Fatigue after traumatic brain injury and its impact on participation and quality of life. J Head Trauma Rehabil 2008;23(1):41-51.

14. Visser-Meily JM, Rhebergen ML, Rinkel GJ, van Zandvoort MJ, Post MW. Long-term health-related quality of life after aneurysmal subarachnoid hemorrhage: relationship with psychological symptoms and personality characteristics. Stroke 2009;40(4):1526-9.

15. Bunch TJ, White RD, Smith GE, et al. Long-term subjective memory function in ventricular fibrillation out-of-hospital cardiac arrest survivors resuscitated by early defibrillation. Resuscitation 2004;60(2):18995.

16. Gamper G, Willeit M, Sterz F, et al. Life after death: posttraumatic stress disorder in survivors of cardiac arrest--prevalence, associated factors, and the influence of sedation and analgesia. Crit Care Med 2004;32(2):378-83. 
17. Gorgels AP, Gijsbers C, de Vreede-Swagemakers J, Lousberg A, Wellens HJ. Out-of-hospital cardiac arrest--the relevance of heart failure. The Maastricht Circulatory Arrest Registry. Eur Heart $J$ 2003;24(13):1204-9.

18. Eisenberg MS, Horwood BT, Cummins RO, Reynolds-Haertle R, Hearne TR. Cardiac arrest and resuscitation: a tale of 29 cities. Ann Emerg Med 1990;19(2):179-86.

19. de Vreede-Swagemakers JJ, Gorgels AP, Dubois-Arbouw WI, et al. Circumstances and causes of out-ofhospital cardiac arrest in sudden death survivors. Heart 1998;79(4):356-61.

20. Bekkers SC, Eikemans BJ, Tieleman R, et al. Hypothermia for out-of-hospital cardiac arrest survivors: a single-center experience. Am J Emerg Med 2007;25(9):1078-80.

21. Aaronson NK, Muller M, Cohen PD, et al. Translation, validation, and norming of the Dutch language version of the SF-36 Health Survey in community and chronic disease populations. I Clin Epidemiol 1998;51(11):1055-68.

22. Sander AM, Fuchs KL, High WM, Jr., Hall KM, Kreutzer JS, Rosenthal M. The Community Integration Questionnaire revisited: an assessment of factor structure and validity. Arch Phys Med Rehabil 1999;80(10):1303-8.

23. de Haan R, Limburg M, Schuling J, Broeshart J, Jonkers L, van Zuylen P. [Clinimetric evaluation of the Barthel Index, a measure of limitations in dailly activities]. Ned Tijdschr Geneeskd 1993;137(18):91721.

24. Turnbull JC, Kersten P, Habib M, McLellan L, Mullee MA, George S. Validation of the Frenchay Activities Index in a general population aged 16 years and older. Arch Phys Med Rehabil 2000;81(8):1034-8.

25. Broadbent DE, Cooper PF, FitzGerald P, Parkes KR. The Cognitive Failures Questionnaire (CFQ) and its correlates. Br J Clin Psychol 1982;21 (Pt 1):1-16.

26. Spinhoven P, Ormel J, Sloekers PP, Kempen GI, Speckens AE, Van Hemert AM. A validation study of the Hospital Anxiety and Depression Scale (HADS) in different groups of Dutch subjects. Psychol Med 1997;27(2):363-70.

27. Sundin EC, Horowitz MJ. Impact of Event Scale: psychometric properties. Br J Psychiatry 2002;180:2059.

28. van der Ploeg E, Mooren TT, Kleber RJ, van der Velden PG, Brom D. Construct validation of the Dutch version of the impact of event scale. Psychol Assess 2004;16(1):16-26.

29. Kleinman L, Zodet MW, Hakim Z, et al. Psychometric evaluation of the fatigue severity scale for use in chronic hepatitis C. Qual Life Res 2000;9(5):499-508.

30. Horsted TI, Rasmussen LS, Meyhoff CS, Nielsen SL. Long-term prognosis after out-of-hospital cardiac arrest. Resuscitation 2007;72(2):214-8.

31. van Alem AP, de Vos R, Schmand B, Koster RW. Cognitive impairment in survivors of out-of-hospital cardiac arrest. Am Heart J 2004;148(3):416-21.

32. de Vos R, de Haes HC, Koster RW, de Haan RJ. Quality of survival after cardiopulmonary resuscitation. Arch Intern Med 1999;159(3):249-54.

33. Noble AJ, Baisch S, Mendelow AD, Allen L, Kane P, Schenk T. Posttraumatic stress disorder explains reduced quality of life in subarachnoid hemorrhage patients in both the short and long term. Neurosurgery 2008;63(6):1095-104; discussion 1004-5.

34. Moulaert VR, Verbunt JA, van Heugten CM, et al. Activity and Life After Survival of a Cardiac Arrest (ALASCA) and the effectiveness of an early intervention service: design of a randomised controlled trial. BMC Cardiovasc Disord 2007;7(1):26. 


\section{Chapter 4}

\section{Cognitive impairments in survivors of out-of-hospital}

cardiac arrest: a systematic review

Published in Resuscitation as:

Moulaert VR, Verbunt JA, van Heugten CM, Wade DT. Cognitive impairments in survivors of out-of-hospital cardiac arrest: a systematic review. Resuscitation 2009;80(3):297-305. 


\section{Summary}

Objective: To describe the current evidence on the frequency and nature of cognitive impairments in survivors of out-of-hospital cardiac arrest.

Design: Systematic review.

Data sources: Pubmed, Embase, PsychInfo and Cinahl (1980-2006). No language restriction was imposed.

Review methods: The following inclusion criteria were used: participants had to be survivors of out-of-hospital cardiac arrest, eighteen years or older, and there had to be least one cognitive outcome measure with a follow-up of three months or more. Case-reports and qualitative studies were excluded. The articles were screened on title, abstract and full-text by two reviewers. All selected articles were reviewed and assessed by two reviewers independently using a quality criteria list.

Results: Out of the 286 articles initially identified, 28 were selected for final evaluation. There was a high heterogeneity between the studies with regard to study design, number of participants, outcome measures and duration of follow-up. In general the quality of the articles appeared low, with a few positive exceptions.

The reported frequency of cognitive impairments in survivors of out-of-hospital cardiac arrest ranged from $6 \%$ to $100 \%$. Memory problems were the most common cognitive impairment, followed by impairments in attention and executive functioning. Three high-quality prospective studies found that cognitive problems occured in about half of the survivors of out-of-hospital cardiac arrest.

Conclusion: There are few good studies on the frequency of cognitive impairments after outof-hospital cardiac arrest. However, cognitive problems, in particular memory problems, seem common in survivors of out-of-hospital cardiac arrest. 


\section{Introduction}

During a cardiac arrest the brain can suffer from a temporary limitation in blood supply, which can lead to hypoxic brain injury. One of the main clinical consequences of hypoxic brain injury is cognitive impairment. Although cognitive impairments may not be directly visible, they can affect a person's life greatly in daily activities, in participation in society and in quality of life..$^{1-3}$ It is currently unclear how often cognitive impairments occur after a cardiac arrest, and what kind of cognitive problems occur most frequently. Existing publications, dedicated to cognitive function after cardiac arrest, vary in study design, research population and outcome measures used. Some studies report that the incidence of neurological sequelae is remarkably low, ${ }^{4,5}$ while others state that survivors of out-hospital cardiac arrest are seriously disabled because of their neuropsychological deficits. ${ }^{6,7}$ To our knowledge, evidence on this topic has not yet been reviewed systematically. The aim of this study is to review systematically current evidence on the frequency and nature of cognitive impairments in survivors of out-of-hospital cardiac arrest.

\section{Methods}

A systematic literature search was performed using the databases Pubmed, Embase, Psychlnfo and Cinahl. Details on the search strategies are presented in Appendix A. The literature search was performed by the first reviewer (VM) in March 2007. The publications for this review were selected based on the inclusion criteria as described in Table 1.

Table 1. Inclusion criteria for the selection of publications

\begin{tabular}{ll}
\hline Participants & $\begin{array}{l}\text { Survivors of out-of-hospital cardiac arrest } \\
\end{array}$ \\
Type of study & No case-reports or qualitative studies \\
Outcome measure & Cognitive functioning \\
Follow-up & $>3$ months after the cardiac arrest \\
Year of publication & $1-1-1980-31-12-2006$ \\
Language & No restriction \\
\hline
\end{tabular}

Two independent reviewers $(\mathrm{VM}+\mathrm{JV}$ ) selected eligible articles (see Figure 1 for flow chart of the selection process). If the two reviewers disagreed and consensus could not be reached, the third reviewer $(\mathrm{CvH})$ made the final decision. An additional hand search was performed in which the references of the articles selected $(n=36)$ were tracked and personal files of the first reviewer were searched.

Of the 43 articles that were read in full-text, all except four were written in English. There were two articles written in German, one in French and one in Hungarian. The Hungarian and French articles were reviewed after translation by native speakers with medical backgrounds.

\section{Data extraction}

The first reviewer (VM) extracted the following data from the articles on a structured form: author, year of publication, study design, in/ exclusion criteria, years of data collection, number of participants, age distribution, characteristics of the control group (if present), outcome measures used, duration of follow-up and the frequency and kind of cognitive impairments. The second reviewer checked the extracted data. 


\section{Quality assessment}

The methodological quality of the selected studies was assessed by the two reviewers independently using an adapted version of the quality criteria scoring list of Hayden. ${ }^{8}$ The original criteria scoring list was adapted for our research: one of the six original domains, 'measurement of prognostic factors', was removed because this was beyond the scope of our review. The final quality criteria scoring list intents to measure the risk of bias on five important methodological domains in prognostic cohort studies, namely study participation, study attrition, outcome measurement, study confounding and statistical analysis/ presentation. The risk of bias per domain was summarised as low, moderate, or high. To compare the quality of the various studies, we combined the scores on the five domains into one overall quality score. Domains with a low risk of bias received two points, domains with moderate risk of bias one point, and in case of high risk of bias no points were given. This resulted in a total score ranging from 0 (indicating very poor quality) to 10 (indicating excellent quality). A copy of the quality criteria list used can be provided on request to the first author.

\section{Results}

The initial literature search resulted in 286 titles, extracted from the four databases. Further selection based on title, abstract, and full-text, resulted in a final selection of 28 articles (see Figure 1). In Table 2, the inter-observer agreement in the different stages of the selection process can be found.

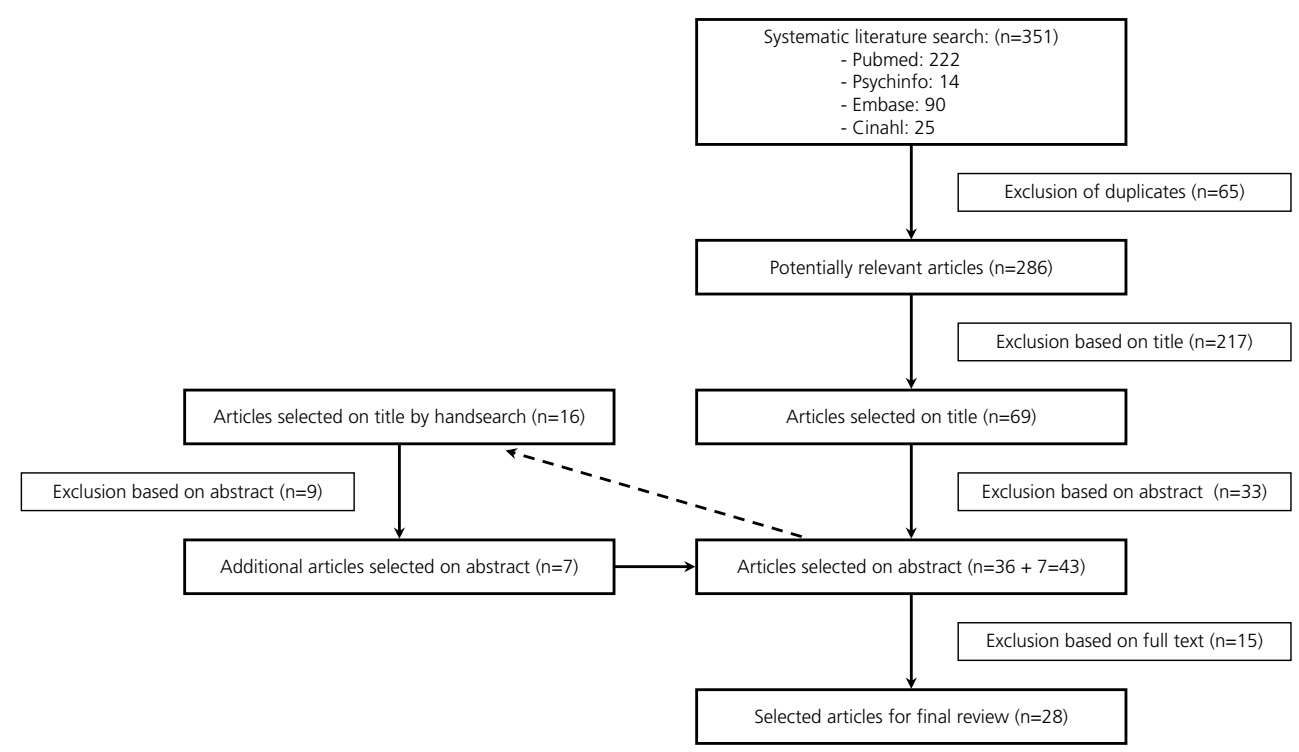

Figure 1. Flow chart of the literature search and selection process 
Table 2. Agreement between the reviewers during selection process of the articles

\begin{tabular}{llll}
\hline $\begin{array}{l}\text { Selection of articles } \\
\text { based on }\end{array}$ & $\begin{array}{l}\text { Direct agreement between } \\
\text { first and second reviewer }\end{array}$ & $\begin{array}{l}\text { Agreement based on } \\
\text { consent }\end{array}$ & $\begin{array}{l}\text { Decision by third } \\
\text { reviewer }\end{array}$ \\
\hline Title & $243(85 \%)$ & $34(12 \%)$ & $9(3 \%)$ \\
Abstract & $47(68 \%)$ & $14(20 \%)$ & $8(12 \%)$ \\
Hand search & $9(56 \%)$ & $7(44 \%)$ & --- \\
Full text & $43(100 \%)$ & --- & --- \\
\hline
\end{tabular}

\section{Quality assessment}

Consensus on quality was reached in all except three articles, for which the third reviewer was consulted. The total quality scores ranged between 0 (very poor) and 10 (excellent). The majority of the articles, 22 (79\%), received a score of 6 or below. Only six studies had a total score higher than $6 .{ }^{9-14}$ The study of van Alem was the only study that received the maximum score of $10 .{ }^{12}$

\section{Study population}

The characteristics and results of the reviewed articles are summarised in Tables 3 and 4 . In Table 3 the studies with a case-control, cross-sectional or retrospective cohort design are described briefly. In Table 4 the eight prospective studies are presented in more detail.

The study populations all included survivors of out-of-hospital cardiac arrest but several studies also contained other groups of survivors, for example survivors of in-hospital cardiac arrest, respiratory arrest or carbon monoxide poisoning. ${ }^{1,15-21}$ Several studies used selected populations. In six studies participants were selected based on the presence of cognitive problems or referral for rehabilitation. 3,7,16,22-24 In four studies participants were excluded if they had severe cognitive impairments. $7,20,25,26$

The number of subjects per study ranged from 10 to 308. In eleven (39\%) of the studies there were less than twenty subjects. In ten (36\%) studies the number of subjects was between 20 and 50. Only the remaining seven (25\%) studies had more than 50 subjects. The mean age of the participants varied between 37 years ${ }^{16}$ and 70 years. ${ }^{22}$

\section{Study design, measurement instruments and follow-up}

Study designs varied considerably: five case control studies, two cross-sectional studies, one combination of a case control and a cross-sectional study, twelve retrospective cohort studies, seven prospective cohort studies and one study reported data from a randomised controlled trial. The outcome measures used to assess cognitive functioning were varied: interviews, questionnaires, the mini-mental state examination (MMSE) and/ or other neuropsychological tests. The cognitive domains that were measured in one or more studies were orientation, attention, memory, perception, executive functioning, apraxia, verbal function and language skills, construction and concept formation/ reasoning. Memory was measured most frequently, in 22 of the studies, and was further classified into episodic long-term, short-term, recall, recognition and/or visual memory. The duration of follow-up from the time of the cardiac arrest to the measurement moment showed a mean or median follow-up from 6 to 59 months, often with a wide range. 


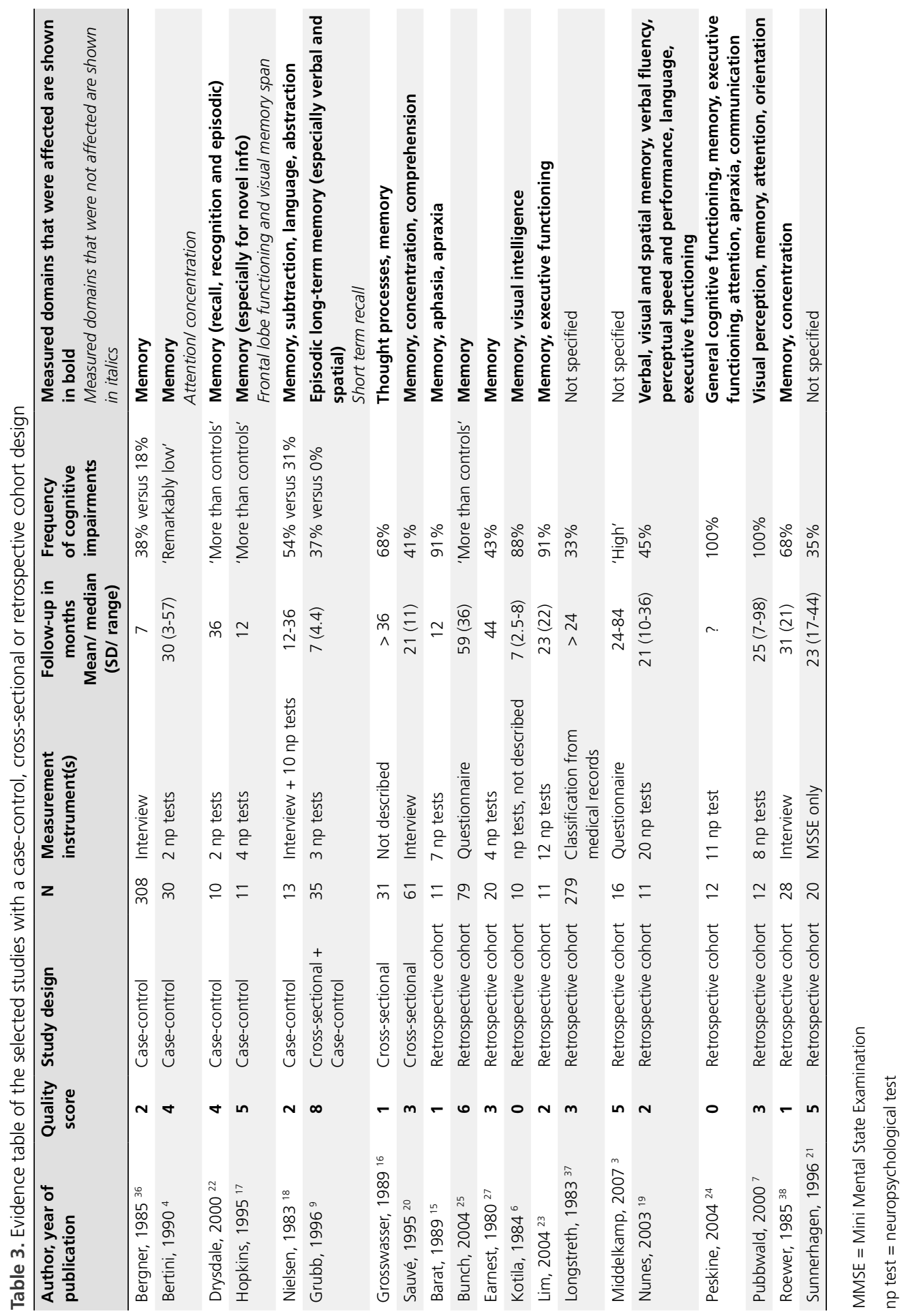




\section{Outcomes of the studies}

All except two studies reported that cognitive problems are common after out-of hospital cardiac arrest. The frequency of cognitive problems ranged from $6 \%$ to $100 \%$. The three prospective studies with the highest quality scores, in which a battery of neuropsychological tests had been administered, reported cognitive problems in $42 \%, 48 \%$ and $50 \%$ of the participants respectively. ${ }^{10,12,14}$

Most of the cognitive domains assessed were affected, and no domain escaped impairment. The most frequently impaired domains were memory, attention and executive functioning. Memory problems were reported to occur in $12 \%$ to $100 \%$ of the participants. Memory for novel information and delayed recall seemed to be affected most frequently. 7,11,17

Five of the prospective studies reported on the changes in cognitive function over time. Two studies showed no significant changes in cognitive functioning during the follow-up period of 1 year. ${ }^{14,26}$ In contrast, two other studies showed a significant improvement in cognitive function (attention, orientation, early retention, delayed recall, reasoning and motor speed) during the first three months, but no further improvements up to six months. ${ }^{10,11}$ Scores on the MMSE showed improvements in the first months only. ${ }^{1,14}$

In some studies possible confounding factors were examined. In two studies a positive relationship was found between better cognitive outcome and several resuscitation variables (fast start of resuscitation, the presence of witnesses, early start of CPR, early defibrillation, no need for and/or no delay of advanced life support, and short time to return of spontaneous circulation). ${ }^{12,13}$ In contrast, four studies did not show any relation between resuscitation variables and cognition. ${ }^{5,9,14,25}$ Co-morbidity, ${ }^{9,13}$ time since the cardiac arrest ${ }^{9,22}$ and sex ${ }^{5,14}$ were not related to cognitive outcome. Younger age was related to better cognitive outcome in one study, ${ }^{16}$ while the opposite was shown in the study of Bunch et al. ${ }^{25}$ In addition, several other studies showed no relationship between cognitive outcome and age at all. 5,9,13,14 The influence of depression was examined in a number of studies. Although four studies reported a relationship between cognitive impairments and depressive symptoms, ${ }^{11,14,17,21}$ this finding was not confirmed in the study of Grubb et al. ${ }^{9}$ Being awake at admission ${ }^{27}$ and a short time to post-arrest awakening (meaning a short duration of coma) were consistently related to better long-term cognitive functioning in three studies. ${ }^{10,11,16}$ 


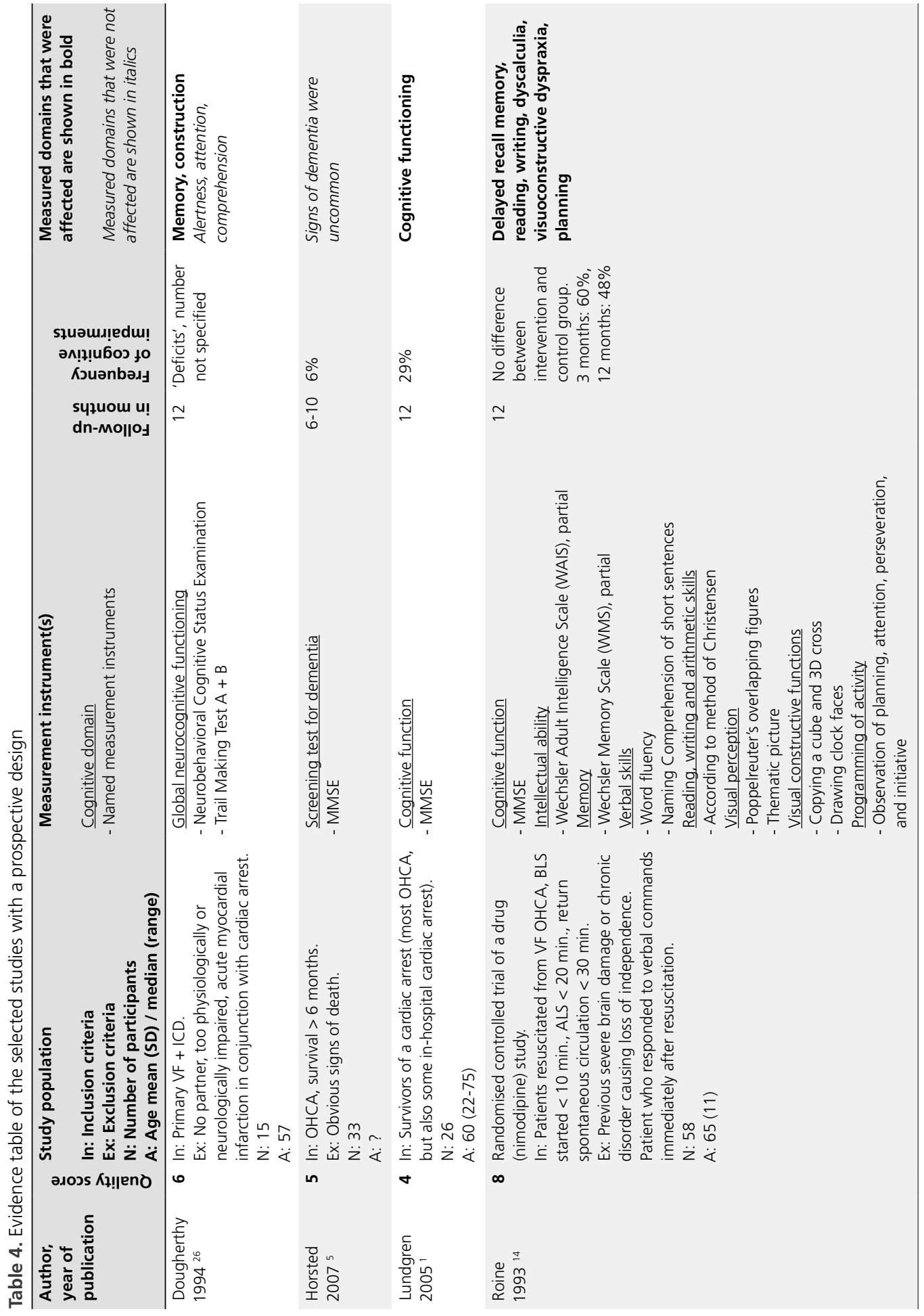




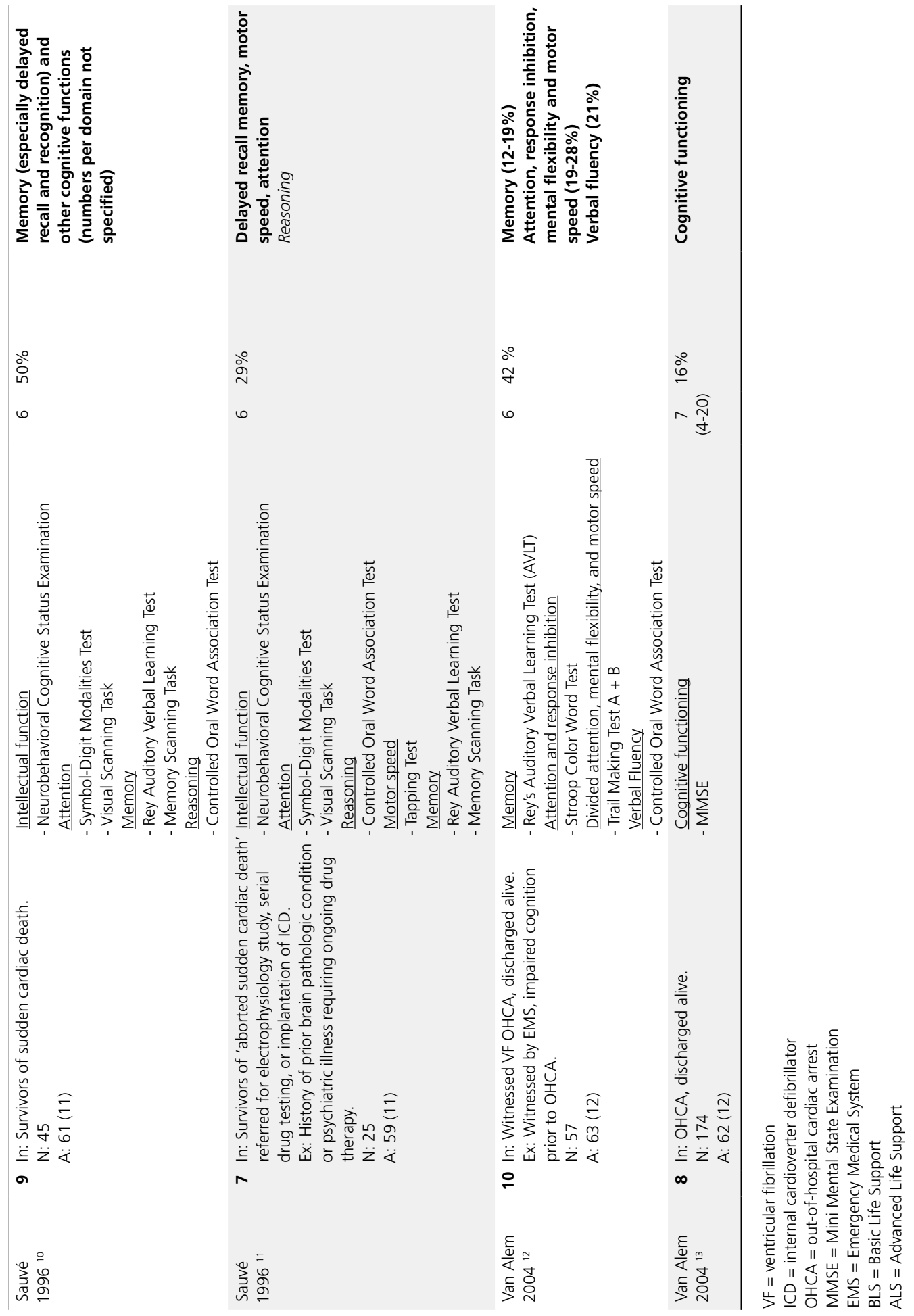




\section{Discussion}

This systematic review revealed only a few high quality studies on the nature and frequency of long-term cognitive impairments after out-of-hospital cardiac arrest. After critically reviewing all selected articles, only three relatively large $(n=45,57$ and 58), qualitatively sound, prospective studies remained in which cognition was measured with a battery of neuropsychological tests. ${ }^{10,12,14}$ The results suggest that cognitive impairments are common after out-of-hospital cardiac arrest and that all cognitive domains can be affected, with memory being the most commonly and severely affected domain, followed by attention and executive functioning. Improvement in cognitive function over time was seen in some of the studies, but during the first three months only, suggesting that recovery of cognitive functioning may be limited to three months. However, the quality of the current evidence is not sufficient to draw final conclusions on this issue.

The quality of the reviewed articles was in general low. Therefore, caution is needed with regard to generalising the results from the reported studies to the whole population of out-of-hospital cardiac arrest survivors. Only six studies had a quality score of $7 / 10$ or above on the quality criteria list which was predominantly influenced by study design: prospective studies scored better while case-control, cross-sectional and retrospective studies tended to receive lower quality scores because they have a higher intrinsic risk of bias.

The low quality of most studies can be attributed to four important methodological weaknesses. First of all, the study populations themselves often showed a high risk of bias. Several studies described a population that did not consist of survivors of out-of-hospital cardiac arrest alone. Other studies had selected populations such as patients already referred for specialised treatment or already having evident cognitive problems; these will probably be more seriously affected patients. On the other hand, there were also studies that excluded severely impaired patients.

Second, the sample size was small in most of the studies. Only seven studies included 50 subjects or more. The small sample sizes coupled with the biases already discussed make it difficult to generalise the results to the whole population of survivors of out-of-hospital cardiac arrest.

Third, cognitive functioning was measured differently in each study, probably because there is no standard protocol for testing cognitive function in hypoxic brain injured patients. Due to the heterogeneity of the studies statistical pooling was not possible. In four studies the assessment of cognitive function was solely based on the mini-mental state examination (MMSE) which has been shown to be insensitive at detecting cognitive impairments. ${ }^{28}$ These studies reported a lower frequency of cognitive impairments than other studies using a battery of neuropsychological tests. Nevertheless, a substantial number of studies did conduct a good battery of neuropsychological tests but still the cut-off scores, used to define cognitive impairment, differed between the studies. Lastly, possible confounding factors were not consistently taken into account. Most of the studies that did consider confounding factors showed contradictory results. It is currently unclear how age, depression, the duration of the cardiac arrest and other variables related to the resuscitation affect cognitive functioning. However, there was agreement between several studies that co-morbidity, time since the cardiac arrest and sex are not related to the severity of cognitive impairment. In addition, being awake at admission and a short duration of coma were consistently related to better long-term cognitive functioning. 
This systematic review also might have been subject to bias. Although we performed an extensive literature search without language restriction, it is possible that we have missed some articles. Furthermore, bias may arise both in abstracting data and in scoring quality. We tried to limit the risk of subjectivity by using a standardised criteria list and by using two people to abstract and check data independently. Lastly, using a quality score makes it easier to compare studies but takes away the detailed information sometimes needed to judge the quality of a study.

One main finding of this systematic review is that cognitive problems seem common in survivors of out-of-hospital cardiac arrest. In the three best prospective studies, cognitive problems were reported in $42 \%, 48 \%$ and $50 \%$ of the participants respectively. $10,12,14$ This indicates that about half of the survivors of out-of-hospital cardiac arrest suffer from cognitive impairments. The cognitive domains that were affected most frequently were memory, attention and executive functioning but these were also the domains that were measured most often. Memory problems were reported most frequently. A possible explanation for this is that the hippocampus, a brain structure important for the storage of information, is very sensitive to decreased cerebral perfusion. ${ }^{29,30}$ Furthermore, memory seems to be affected by the global cerebral atrophy seen after out-of-hospital cardiac arrest. ${ }^{31}$ Global cerebral atrophy may also explain why so many cognitive domains can be impaired after cardiac arrest. The biological mechanisms involved in the development of global ischaemic brain injury are complex and the subject of ongoing research. Hypothermia in comatose cardiac arrest survivors improves so-called neurological outcome. ${ }^{32}$ However, a study by Tiainen et al. could not demonstrate significant positive effects of hypothermia on cognitive functioning. ${ }^{33}$ This discrepancy may arise because neurological outcome is often measured using the Glasgow-Pittsburgh Cerebral Performance Categories (CPC), as is recommended in the 'Utstein' criteria. ${ }^{34}$ Although a CPC score of 1 or 2 is commonly regarded as 'good outcome', it includes subjects with 'mild to moderate' cognitive impairments, such as dysphasia and permanent memory or mental changes. Furthermore, the CPC seems insensitive to more subtle cognitive impairments. Therefore, we advocate the use of neuropsychological testing (including at least tests for memory, attention and executive functioning) in determining outcome after cardiac arrest. A neuropsychologist can be consulted to select and administer an appropriate set of neuropscyhological tests. Suggestions of neuropsychological tests can be found in a design article by Moulaert et al. ${ }^{35}$

For clinicians it is important to be aware that cognitive impairments occur frequently after outof-hospital cardiac arrest. Unfortunately, cognitive impairments can be easily overlooked so that, unless one explicitly screens for them, they can easily be missed. This is of concern because cognitive problems may have a high impact on a person's daily functioning and quality of life. A large prospective trial is now needed to collect reliable data on the prevalence, severity and course of cognitive problems after a cardiac arrest, and to relate the cognitive losses identified to possible limitations in daily life, participation in society and quality of life. 


\section{Ethical approval}

Ethical approval was not required.

\section{Contributions}

V. Moulaert was the first reviewer, performed the literature search and is the guarantor of this study. J. Verbunt acted as second reviewer. Both reviewers read all the selected titles and abstracts and selected the final articles for the review. C. van Heugten was the third reviewer and acted as a mediator in case of disagreement between the two reviewers and then made the final decision. All authors participated in the selection of a quality criteria scoring list and contributed to the protocol and final manuscript.

\section{Funding}

The study is funded by the Netherlands Organisation for Health Research and Development (Zon/Mw) and Fonds Nuts/Ohra.

\section{Acknowledgements}

We would like to thank Jill Hayden for providing us with the original version of her quality criteria list. We kindly acknowledge Daniel Keszthelyi and Ward Vanagt for their help in translating the Hungarian and French articles, respectively. 
Appendix A. Keywords and limits used in the literature search

\begin{tabular}{|c|c|c|c|}
\hline \multirow[t]{2}{*}{ Database } & \multicolumn{2}{|l|}{ Keywords } & \multirow[t]{2}{*}{ LIMITS } \\
\hline & Population & Cognitive outcome & \\
\hline Pubmed & $\begin{array}{l}\text { HEART ARREST } \\
\text { Heart arrest* } \\
\text { Asystole* } \\
\text { Cardiac arrest* } \\
\text { Cardiopulmonary arrest* } \\
\text { Circulatory arrest* } \\
\text { Cardiac sudden death* } \\
\text { Sudden cardiac death* } \\
\text { RESUSCITATION } \\
\text { Resuscitation* } \\
\text { Cardiopulmonary resuscitation* } \\
\text { Cpr }\end{array}$ & $\begin{array}{l}\text { COGNITION DISORDERS } \\
\text { Cognition disorder* } \\
\text { Cognitive } \\
\text { MEMORY DISORDERS } \\
\text { Memory disorder* } \\
\text { Amnesia } \\
\text { NEUROPSYCHOLOGICAL TESTS } \\
\text { Neuropsychological test* }\end{array}$ & $\begin{array}{l}\text { All adults: } 19+ \\
\text { 1980-2006 }\end{array}$ \\
\hline Psychinfo & $\begin{array}{l}\text { Heart arrest* } \\
\text { Asystole* } \\
\text { Cardiac arrest* } \\
\text { Cardiopulmonary arrest* } \\
\text { Circulatory arrest* } \\
\text { Cardiac sudden death* } \\
\text { Sudden cardiac death* } \\
\text { Resuscitation* } \\
\text { Cardiopulmonary resuscitation* } \\
\text { Cpr }\end{array}$ & $\begin{array}{l}\text { COGNITIVE IMPAIRMENT } \\
\text { MEMORY-DISORDERS } \\
\text { NEUROPSYCHOLOGICAL } \\
\text { ASSESSMENT }\end{array}$ & $\begin{array}{l}\text { Adult (18+) } \\
1980-2006\end{array}$ \\
\hline Cinahl & $\begin{array}{l}\text { HEART ARREST } \\
\text { Asystole* } \\
\text { Cardiac arrest* } \\
\text { Cardiopulmonary arrest* } \\
\text { Circulatory arrest* } \\
\text { DEATH-SUDDEN-CARDIAC } \\
\text { RESUSCITATION } \\
\text { Cardiopulmonary resuscitation* } \\
\text { Cpr }\end{array}$ & $\begin{array}{l}\text { COGNTION DISORDERS } \\
\text { MEMORY DISORDERS } \\
\text { NEUROPSYCHOLOGICAL TESTS }\end{array}$ & $\begin{array}{l}\text { AND Adult } \\
1980-2006\end{array}$ \\
\hline Embase & $\begin{array}{l}\text { HEART ARREST } \\
\text { ASYSTOLE } \\
\text { Cardiac arrest } \\
\text { Cardiopulmonary arrest* } \\
\text { Circulatory arrest* } \\
\text { SUDDEN DEATH } \\
\text { RESUSCITATION } \\
\text { Cardiopulmonary resuscitation* } \\
\text { Cpr }\end{array}$ & $\begin{array}{l}\text { COGNITIVE DEFECT } \\
\text { MEMORY DISORDER } \\
\text { NEUROPSYCHOLOGICAL TEST }\end{array}$ & $\begin{array}{l}\text { AND adult } \\
1986-2006\end{array}$ \\
\hline
\end{tabular}

MesH or thesaurus terms are indicated in capital letters.

Text words are indicated in regular letters.

* $=$ truncation 


\section{References}

1. Lundgren-Nilsson A, Rosen $H$, Hofgren C, Sunnerhagen KS. The first year after successful cardiac resuscitation: function, activity, participation and quality of life. Resuscitation 2005;66(3):285-9.

2. de Vos R, de Haes HC, Koster RW, de Haan RJ. Quality of survival after cardiopulmonary resuscitation. Arch Intern Med 1999;159(3):249-54.

3. Middelkamp W, Moulaert VR, Verbunt JA, van Heugten CM, Bakx WG, Wade DT. Life after survival: long-term daily life functioning and quality of life of patients with hypoxic brain injury as a result of a cardiac arrest. Clin Rehabil 2007;21(5):425-31.

4. Bertini G, Giglioli C, Giovannini F, et al. Neuropsychological outcome of survivors of out-of-hospital cardiac arrest. J Emerg Med 1990;8(4):407-12.

5. Horsted TI, Rasmussen LS, Meyhoff CS, Nielsen SL. Long-term prognosis after out-of-hospital cardiac arrest. Resuscitation 2007;72(2):214-8.

6. Kotila M, Kajaste S. Neurological and neuropsychological symptoms after cardiac arrest. Acta Neurologica Scandinavica 1984;69(98):337-338.

7. Pusswald G, Fertl E, Faltl M, Auff E. Neurological rehabilitation of severely disabled cardiac arrest survivors. Part II. Life situation of patients and families after treatment. Resuscitation 2000;47(3):241-8

8. Hayden JA, Cote P, Bombardier C. Evaluation of the quality of prognosis studies in systematic reviews. Ann Intern Med 2006;144(6):427-37.

9. Grubb NR, O'Carroll R, Cobbe SM, Sirel J, Fox KA. Chronic memory impairment after cardiac arrest outside hospital. Bmj 1996;313(7050):143-6.

10. Sauve MJ, Doolittle N, Walker JA, Paul SM, Scheinman MM. Factors associated with cognitive recovery after cardiopulmonary resuscitation. Am J Crit Care 1996;5(2):127-39.

11. Sauve MJ, Walker JA, Massa SM, Winkle RA, Scheinman MM. Patterns of cognitive recovery in sudden cardiac arrest survivors: the pilot study. Heart Lung 1996;25(3):172-81.

12. van Alem AP, de Vos R, Schmand B, Koster RW. Cognitive impairment in survivors of out-of-hospital cardiac arrest. Am Heart J 2004;148(3):416-21.

13. van Alem AP, Waalewijn RA, Koster RW, de Vos R. Assessment of quality of life and cognitive function after out-of-hospital cardiac arrest with successful resuscitation. Am J Cardiol 2004;93(2):131-5.

14. Roine RO, Kajaste S, Kaste M. Neuropsychological sequelae of cardiac arrest. Jama 1993;269(2):23742.

15. Barat M, Blanchard JY, Darriet D, Giroire JM, Daverat P, Mazaux JM. Long-term cognitive impairments following prolonged cerebral anoxia. Influence on subsequent functional ability. Annales de Readaptation et de Medecine Physique 1989;32(5):657-668.

16. Groswasser Z, Cohen M, Costeff H. Rehabilitation outcome after anoxic brain damage. Arch Phys Med Rehabil 1989;70(3):186-8.

17. Hopkins RO, Kesner RP, Goldstein M. Memory for novel and familiar spatial and linguistic temporal distance information in hypoxic subjects. J Int Neuropsychol Soc 1995;1(5):454-68.

18. Nielsen JR, Gram L, Rasmussen LP, et al. Intellectual and social function of patients surviving cardiac arrest outside the hospital. Acta Med Scand 1983;213(1):37-9.

19. Nunes B, Pais J, Garcia R, Magalhaes Z, Granja C, Silva MC. Cardiac arrest: long-term cognitive and imaging analysis. Resuscitation 2003;57(3):287-97.

20. Sauve MJ. Long-term physical functioning and psychosocial adjustment in survivors of sudden cardiac death. Heart Lung 1995;24(2):133-44. 
21. Sunnerhagen KS, Johansson O, Herlitz J, Grimby G. Life after cardiac arrest; a retrospective study. Resuscitation 1996;31(2):135-40.

22. Drysdale EE, Grubb NR, Fox KA, O'Carroll RE. Chronicity of memory impairment in long-term out-ofhospital cardiac arrest survivors. Resuscitation 2000;47(1):27-32.

23. Lim C, Alexander MP, LaFleche G, Schnyer DM, Verfaellie M. The neurological and cognitive sequelae of cardiac arrest. Neurology 2004;63(10):1774-8.

24. Peskine A, Picq C, Pradat-Diehl P. Cerebral anoxia and disability. Brain Inj 2004;18(12):1243-54.

25. Bunch TJ, White RD, Smith GE, et al. Long-term subjective memory function in ventricular fibrillation out-of-hospital cardiac arrest survivors resuscitated by early defibrillation. Resuscitation 2004;60(2):18995.

26. Dougherty $\mathrm{CM}$. Longitudinal recovery following sudden cardiac arrest and internal cardioverter defibrillator implantation: survivors and their families. Am J Crit Care 1994;3(2):145-54.

27. Earnest MP, Yarnell PR, Merrill SL, Knapp GL. Long-term survival and neurologic status after resuscitation from out-of-hospital cardiac arrest. Neurology 1980;30(12):1298-1302.

28. Nys GM, van Zandvoort MJ, de Kort PL, Jansen BP, Kappelle LJ, de Haan EH. Restrictions of the MiniMental State Examination in acute stroke. Arch Clin Neuropsychol 2005;20(5):623-9.

29. Back T, Hemmen T, Schuler OG. Lesion evolution in cerebral ischemia. J Neuro/ 2004;251(4):388-97.

30. Harukuni I, Bhardwaj A. Mechanisms of brain injury after global cerebral ischemia. Neurol Clin 2006;24(1):1-21.

31. Grubb NR, Fox KA, Smith K, et al. Memory impairment in out-of-hospital cardiac arrest survivors is associated with global reduction in brain volume, not focal hippocampal injury. Stroke 2000;31(7):150914.

32. Cheung KW, Green RS, Magee KD. Systematic review of randomized controlled trials of therapeutic hypothermia as a neuroprotectant in post cardiac arrest patients. Cjem 2006;8(5):329-37.

33. Tiainen M, Poutiainen E, Kovala T, Takkunen O, Happola O, Roine RO. Cognitive and neurophysiological outcome of cardiac arrest survivors treated with therapeutic hypothermia. Stroke 2007;38(8):2303-8.

34. Recommended guidelines for uniform reporting of data from out-of-hospital cardiac arrest: the 'Utstein style'. Prepared by a Task Force of Representatives from the European Resuscitation Council, American Heart Association, Heart and Stroke Foundation of Canada, Australian Resuscitation Council. Resuscitation 1991;22(1):1-26.

35. Moulaert VR, Verbunt JA, van Heugten CM, et al. Activity and Life After Survival of a Cardiac Arrest (ALASCA) and the effectiveness of an early intervention service: design of a randomised controlled trial. BMC Cardiovasc Disord 2007;7(1):26.

36. Bergner L, Hallstrom AP, Bergner M, Eisenberg MS, Cobb LA. Health status of survivors of cardiac arrest and of myocardial infarction controls. Am J Public Health 1985;75(11):1321-3.

37. Longstreth WT, Jr., Inui TS, Cobb LA, Copass MK. Neurologic recovery after out-of-hospital cardiac arrest. Ann Intern Med 1983;98(5 Pt 1):588-92.

38. Roewer N, Kloss T, Puschel K. [Long-term result and quality of life following preclinical cardiopulmonary resuscitation]. Anasth Intensivther Notfallmed 1985;20(5):244-50. 



\section{Chapter 5}

\section{Activity and Life After Survival of a Cardiac Arrest (ALASCA) and the effectiveness of an early intervention service: design of a randomised controlled trial [ISRCTN74835019]}

Published in BMC Cardiovascular Disorders as:

Moulaert VR, Verbunt JA, van Heugten CM, Bakx WG, Gorgels AP, Bekkers SC, de Krom MC, Wade DT. Activity and Life After Survival of a Cardiac Arrest (ALASCA) and the effectiveness of an early intervention service: design of a randomised controlled trial. BMC Cardiovascular 


\begin{abstract}
Background: Cardiac arrest survivors may experience hypoxic brain injury that results in cognitive impairments which frequently remain unrecognised. This may lead to limitations in daily activities and participation in society, a decreased quality of life for the patient, and a high strain for the caregiver. Publications about interventions directed at improving quality of life after survival of a cardiac arrest are scarce. Therefore, evidence about effective rehabilitation programmes for cardiac arrest survivors is urgently needed. This paper presents the design of the ALASCA (Activity and Life After Survival of a Cardiac Arrest) trial, a randomised, controlled clinical trial to evaluate the effects of a new early intervention service for survivors of a cardiac arrest and their caregivers.
\end{abstract}

Methods / design: The study population comprises all people who survive two weeks after a cardiac arrest and are admitted to one of the participating hospitals in the Southern part of the Netherlands. In a two-group randomised, controlled clinical trial, half of the participants will receive an early intervention service.

The early intervention service consists of several consultations with a specialised nurse for the patient and their caregiver during the first three months after the cardiac arrest. The intervention is directed at screening for cognitive problems, provision of informational, emotional and practical support, and stimulating self-management. If necessary, referral to specialised care can take place. Persons in the control group will receive the care as usual.

The primary outcome measures are the extent of participation in society and quality of life of the patient one year after a cardiac arrest. Secondary outcome measures are the level of cognitive, emotional and cardiovascular impairment and daily functioning of the patient, as well as the strain for and quality of life of the caregiver. Participants and their caregivers will be followed for twelve months after the cardiac arrest.

A process evaluation will be performed to gain insight into factors that might have contributed to the effectiveness of the intervention and to gather information about the feasibility of the programme. Furthermore, an economic evaluation will be carried out to determine the costeffectiveness and cost-utility of the intervention.

Discussion: The results of this study will provide evidence on the effectiveness of this early intervention service, as well as the cost-effectiveness and its feasibility.

Trial registration: Current Controlled Trials [ISRCTN74835019] 


\section{Background}

The incidence of cardiac arrest is 1 - 2 per 1000 inhabitants a year but differs according to country and region. ${ }^{1}$ In the Netherlands, the incidence of cardiac arrests lies between 0.6 - 0.9 per 1000 inhabitants per year, resulting in approximately 16,000 cases of cardiac arrests each year. ${ }^{2,3}$ Resuscitation is attempted in $30-50 \%$ of the cases. ${ }^{4}$ The survival rate at discharge from the hospital after attempted resuscitations is only 9 to $16 \%$ for out-of-hospital resuscitations $s^{2,5-7}$ and between 14 and $37 \%$ for in-hospital resuscitations. ${ }^{8-11}$

Faster access to external automated defibrillators (AED's) outside the hospital will probably raise survival rates. ${ }^{4,12}$ This will lead to an increased number of cardiac arrest survivors and, thus, to more patients having to live with the consequences of surviving a cardiac arrest.

A cardiac arrest may lead to irreversible brain damage, called posthypoxic encephalopathy or hypoxic brain injury. Hypoxic brain injury often leads to cognitive or emotional impairments, with memory disorders and depressive symptoms being the most common complaints. ${ }^{13-15}$ As a result of this, the performance of daily activities can be limited even six to twelve months later, with almost a quarter of the people needing some form of assistance in daily life. ${ }^{13,16-19}$ Furthermore, participation in society often decreases after a cardiac arrest. For example, of the people who were working prior to a cardiac arrest only $20 \%$ were able to resume their job. ${ }^{20,21}$ This all seems to result in a reduced quality of life for both the patient and their caregiver and leads to a high strain on the carer. ${ }^{18,20-22}$

Unfortunately, although the number of problems is substantial, a large percentage of these problems, especially the cognitive impairments, are not recognised or treated.

Currently, there exist no specific follow-up programmes or nursing interventions for cardiac arrest survivors in the Netherlands. In the international literature, only a few programmes for cardiac arrest survivors were found. In a study by Cowan et al., psychosocial nursing therapy reduced twoyear mortality in a group of cardiac arrest survivors. ${ }^{23}$ This intervention consisted of physiological relaxation (biofeedback), cognitive behavioral therapy aimed at self-management and health education. Dougherthy et al. showed that an intervention, based on the principles of social cognitive theory and the concerns of patients and their partners, reduced physical symptoms and anxiety and enhanced knowledge in persons who had received an internal cardioverter defibrillator (ICD) implantation. ${ }^{24-26}$ However, this intervention had no effect on health care use. ${ }^{25,26}$

The diffuse brain injury and cognitive loss after a cardiac arrest seems in many ways similar to that seen after traumatic brain injury. In a study on traumatic brain injury patients, a routine follow-up service resulted in a reduction in social morbidity and severity of post concussion symptoms six months later. ${ }^{27}$ Given that cognitive impairment is a major problem in both hypoxic brain injury and moderate head injury, a comparable type of treatment could prove beneficial for patients after a cardiac arrest. 


\section{Aims and hypotheses}

The primary goal of the present study is to evaluate the effectiveness of a new, early intervention service for survivors of a cardiac arrest and their caregivers. Secondly, a process evaluation will be performed to gain insight into factors that might have contributed to the effectiveness of the intervention and to gather information about the feasibility of the programme. Finally, an economic evaluation will determine the cost-effectiveness and cost-utility of the intervention.

We anticipate that the prospective follow-up and support provided by a specialised nurse will reduce the negative consequences of a cardiac arrest and will result in a higher level of participation in society and quality of life of the cardiac arrest survivor. Furthermore, we expect that this intervention will be cost-effective.

\section{Methods/ Design}

\section{Study design}

The study presented in this paper is a randomised, controlled clinical trial in which the effect of an early intervention service will be investigated. Participants will be followed over one year. During this year, three measurements will take place, namely two weeks, three months and twelve months after the cardiac arrest (see flow diagram, Figure 1). The Medical Ethics Committee of Maastricht University Medical Centre approved the study protocol. The study is registered in a public trial registry [ISRCTN74835019]. This study is part of a larger research project, which also comprises a prospective and prognostic cohort study.

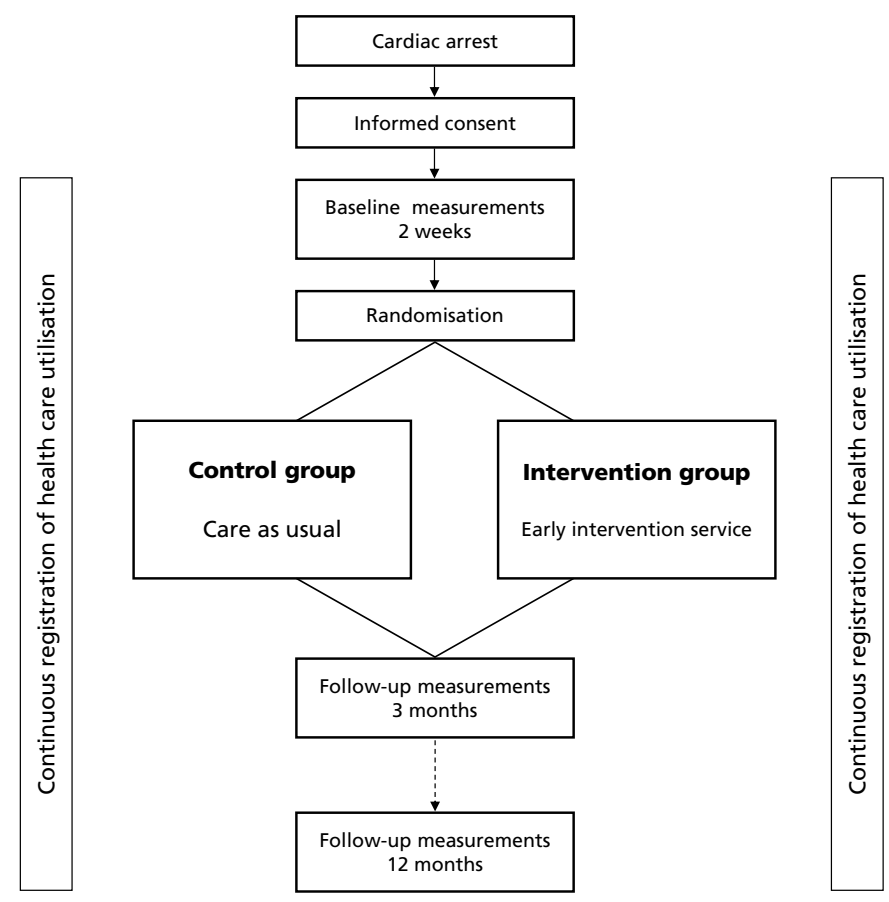

Figure 1. Study design 


\section{Setting}

Participants will be recruited from the coronary care units and intensive care units of four hospitals in the Southern part of the Netherlands, starting in April 2007. One of the participating hospitals is a university hospital.

\section{Study population}

The population of this study consists of cardiac arrest survivors admitted to one of the participating hospitals, including both survivors of out-of-hospital and in-hospital cardiac arrests (for in- and exclusion criteria, see Table 1) and their caregivers. In this study caregiver is defined as partner, spouse, or significant other that is most closely related to the patient.

The sample size calculation (two groups and one-sided testing) results from research on traumatic brain injured patients with regard to their participation in society assessed using the Community Integration Questionnaire (CIQ, described in more detail later). The mean (SD) total score on the CIQ was 16.09 (SD 4.20). ${ }^{28}$ An assumed clinical relevant difference between groups of at least $10 \%$, an alpha of 0.05 and a power (1- $\beta$ ) of 0.8 would necessitate 84 patients in each group. With an estimated loss to follow-up of $15 \%$, based on earlier research in cardiac arrest survivors, 200 participants are thought to be necessary for the clinical trial. 19,21,29 This should be achievable within three years, as the area served by the participating hospitals covers approximately $1,000,000$ inhabitants.

Table 1. Inclusion and exclusion criteria

\section{Inclusion criteria}

- All people who survive two weeks after a cardiac arrest

- Admitted in or to one of the participating hospitals

- Living within $50 \mathrm{~km}$ of one of the participating hospitals

- 18 years or older

- Sufficient knowledge of Dutch language

\section{Exclusion criteria}

- Life expectancy lower than 3 months (as assessed by the treating physician)

- Living in residential or institutional care prior to the cardiac arrest

\section{Recruitment and randomisation}

Between three and ten days after the cardiac arrest the patient and caregiver will be approached to participate in the study by their treating physician. Standard procedures concerning informed consent will be used. Both patients and caregivers sign an informed consent form if they decide to participate in the study. In case the patient is still unconscious or incapacitated at the moment that informed consent is needed, the caregiver will be asked to give provisional informed consent. When the patient regains consciousness, definitive informed consent will be sought.

Participants will be randomly allocated to either the intervention group or the control group. The randomisation will take place after the baseline measurements ( 2 weeks after the cardiac arrest) and will be performed centrally by the project leader using a computerised block randomisation. The randomisation scheme includes prestratification on two variables, namely hospital site and 
location of the cardiac arrest (in-hospital versus out-of hospital). Two series of opaque numbered envelopes will be prepared for each hospital site (one for in-hospital and one for out-of-hospital cardiac arrests), filled with a card indicating the allocated group. After registration, the envelope will be opened and the specialised nurse will be informed about the patients that are allocated to the intervention group.

\section{Group allocation and intervention}

The intervention group will receive an early intervention service delivered by a specialised nurse in addition to usual health care available to all patients, whereas the control group will only receive usual health care. The intervention period will extend up to three months after the cardiac arrest. During this period a specialised nurse will provide one to six consultations for the patient together with his or her caregiver (if present). The number of consultations will be tailored for each individual participant and will depend on the severity of the problems and the needs and wished of the patient and their caregiver. The consultations will take place in the hospital or at the participants' home. In between the consultations the participants have the opportunity to contact the nurses by phone or email. During the intervention period the specialised nurse will screen for cognitive and emotional problems. Next to that, information will be provided by means of an information booklet and by discussing questions that the participants may have. Furthermore, emotional and practical support will be offered and self-management will be explained and promoted. A consultant in rehabilitation medicine supervises the specialised nurses. If necessary, referral to additional diagnostics or specialised rehabilitation care can take place.

There will be no restrictions on possible co-interventions. Participants assigned to the intervention group who do not want treatment will still be approached for all the follow-up measurements.

\section{Data collection}

Baseline measurements will be administered two weeks (=T1) after the cardiac arrest, with further assessments at three $(=\mathrm{T} 2)$ and twelve months $(=\mathrm{T} 3)$. The measurements will be administered wherever the patient is at that time. A research assistant, who will be blinded to the group allocation, will perform the assessments.

To check for the effectiveness of blinding, the research assistants will be asked after the last measurement to indicate whether they think the participant belonged to the intervention group or the control group.

\section{Socio-demographical and medical variables}

The following socio-demographical variables will be recorded: Age, gender, nationality, marital status, living condition, educational level, and work situation. The variables related to the resuscitation and medical situation of the patient that will be recorded are presented in Table 2 . 
Table 2. Variables related to the resuscitation and the medical condition of the patient

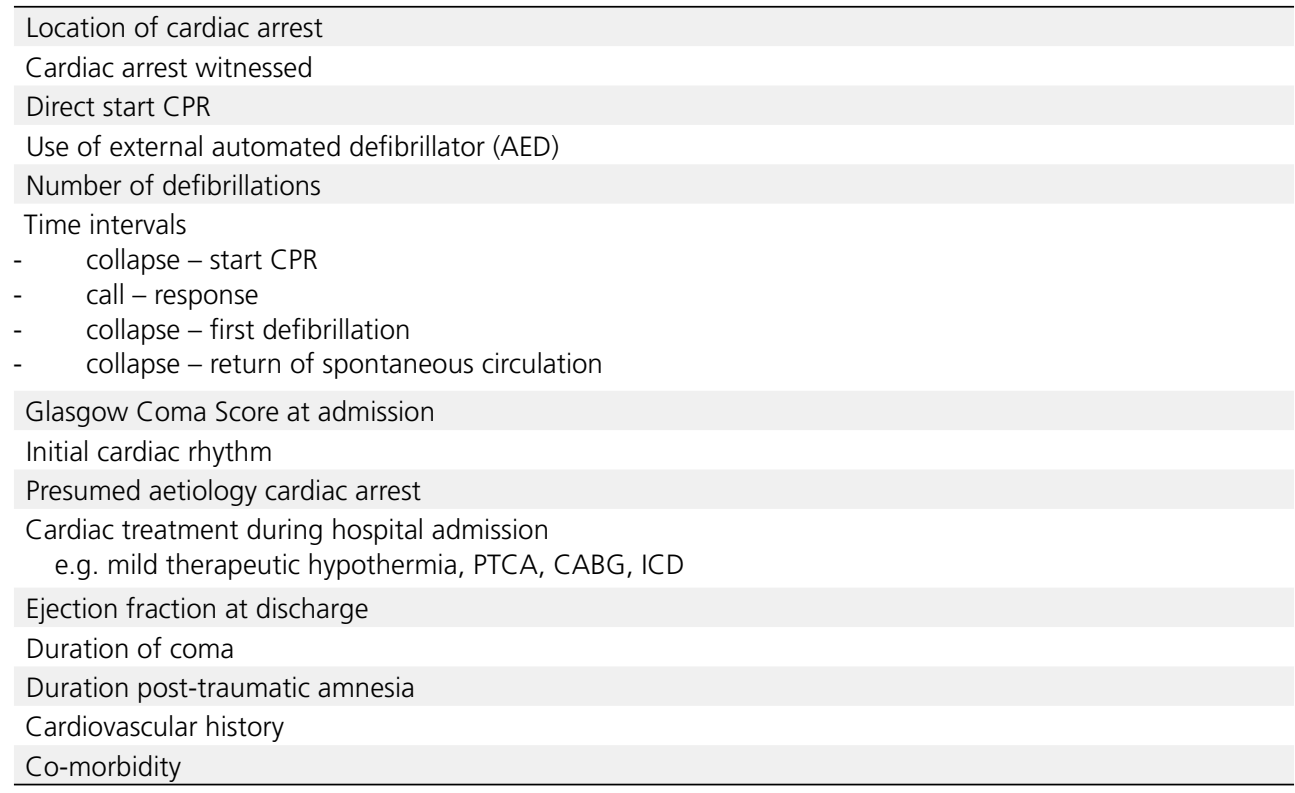

\section{Outcome measures for the effect evaluation}

The primary outcome measures of this trial are participation in society and quality of life of the cardiac arrest survivor. The secondary outcome measures are cognitive, emotional and cardiovascular impairment and daily functioning of the cardiac arrest survivor, as well as the strain, emotional functioning and quality of life of the caregiver. The instruments that will be used to measure these domains are presented in Table 3 and Table 4 and are described in the next sections.

\section{Primary outcome measures}

Community Integration Questionnaire

The Community Integration Questionnaire (CIQ) is a 15-item questionnaire that assesses the level of participation in society. ${ }^{30}$ The CIQ comprises three scales, namely home integration, productive activity, and social integration.

\section{Impact on Participation and Autonomy}

The Impact on Participation and Autonomy (IPA) is a 39-item questionnaire that focuses on two aspects of participation, namely perceived participation and the experience of problems. ${ }^{31}$

\section{EuroQo/ 6D}

The EuroQol 6D (EQ-6D) is a generic quality of life measure consisting of 6 items (mobility, selfcare, usual activities, pain/discomfort, anxiety/depression and cognition) each with three answer possibilities..$^{32}$ In addition, participants are asked to give a general rating of their current health state on a visual analogue scale, ranging from 0 to 100. 
Table 3. Outcome domains, measurement instruments and measurement moments for the cardiac arrest survivors

\begin{tabular}{|c|c|c|c|c|c|c|}
\hline Domain & Measurement instrument & Abbr. & T0 & T1 & $\mathrm{T} 2$ & T3 \\
\hline Participation in society & $\begin{array}{l}\text { Community Integration Questionnaire } \\
\text { Impact on Participation and Autonomy }\end{array}$ & $\begin{array}{l}\text { CIQ } \\
\text { IPA }\end{array}$ & $x$ & & $x$ & $\begin{array}{l}x \\
x\end{array}$ \\
\hline Quality of life & $\begin{array}{l}\text { Short-Form-36 (RAND 36-item Health Survey) } \\
\text { EuroQol 6D } \\
\text { Quality Of Life after Brain Injury }\end{array}$ & $\begin{array}{l}\text { SF-36 } \\
\text { EQ-6D } \\
\text { QOLIBRI }\end{array}$ & & $\begin{array}{l}x \\
x\end{array}$ & $\begin{array}{l}x \\
x \\
x\end{array}$ & $\begin{array}{l}x \\
x \\
x\end{array}$ \\
\hline Cognitive functioning & $\begin{array}{l}\text { Cognitive Failures Questionnaire } \\
\text { Cognitive Log } \\
\text { Adult Memory and Information Processing Battery } \\
\text { Paragraph Recall } \\
\text { Trail Making Test, part A + B } \\
\text { Verbal Fluency Test }\end{array}$ & $\begin{array}{l}\text { CFQ } \\
\text { Cog-log } \\
\text { AMIPB } \\
\text { PR } \\
\text { TMT } \\
\text { VFT }\end{array}$ & & $\begin{array}{l}x \\
x \\
x \\
x \\
X \\
x\end{array}$ & $\begin{array}{l}x \\
x \\
x \\
x \\
x \\
x\end{array}$ & $\begin{array}{l}x \\
x \\
x \\
x \\
X \\
x\end{array}$ \\
\hline Emotional functioning & $\begin{array}{l}\text { Hospital Anxiety and Depression Scale } \\
\text { Impact of Event Scale }\end{array}$ & $\begin{array}{l}\text { HADS } \\
\text { IES }\end{array}$ & & $\begin{array}{l}x \\
x\end{array}$ & $\begin{array}{l}x \\
x\end{array}$ & $\begin{array}{l}x \\
x\end{array}$ \\
\hline Cardiorespiratory functioning & New York Heart Association Classification & NYHA & & $x$ & $x$ & $x$ \\
\hline Fatigue & Fatigue Severity Scale & FSS & & & $x$ & $x$ \\
\hline Basic daily activities & Barthel Index & $\mathrm{BI}$ & & $x$ & & \\
\hline Instrumental daily activities & Frenchay Activity Index & FAl & $x$ & & $x$ & \\
\hline
\end{tabular}

$\mathrm{T} 0=$ situation prior to cardiac arrest (asked retrospectively at T1)

$\mathrm{T} 1=2$ weeks after cardiac arrest

$\mathrm{T} 2=3$ months after cardiac arrest

$\mathrm{T} 3=1$ year after cardiac arrest

Table 4. Outcome domains, measurement instruments and measurement moments for the caregivers

\begin{tabular}{|c|c|c|c|c|c|}
\hline Domain & Measurement instrument & Abbr. & T1 & $\mathrm{T} 2$ & T3 \\
\hline \multirow[t]{2}{*}{ Quality of life } & Short-Form-36 (RAND 36-item Health Survey) & SF-36 & $x$ & $x$ & $x$ \\
\hline & EuroQol 6D & EQ-6D & $x$ & $x$ & $x$ \\
\hline \multirow[t]{2}{*}{ Emotional functioning } & Hospital Anxiety and Depression Scale & HADS & $x$ & $x$ & $x$ \\
\hline & Impact of Event Scale & IES & $x$ & $x$ & $x$ \\
\hline Fatigue & Fatigue Severity Scale & FSS & & $x$ & $x$ \\
\hline Caregiver Strain & Caregiver Strain Index & CSI & $\mathrm{x}$ & $x$ & $x$ \\
\hline
\end{tabular}

$\mathrm{T} 1=2$ weeks after cardiac arrest

$\mathrm{T} 2=3$ months after cardiac arrest

$\mathrm{T} 3=1$ year after cardiac arrest

\section{Medical Outcomes Study 36-item Short Form Health Survey}

The Medical Outcomes Study 36-item Short Form Health Survey (SF-36 / RAND 36-item Health Survey) is a 36-item generic quality of life questionnaire that measures several domains of perceived health. ${ }^{33}$

\section{Quality Of Life after Brain Injury}

The Quality Of Life after Brain Injury questionnaire (QOLIBRI) is a brain injury specific quality of life measure. The QOLIBRI consists of 49 questions that measure health related quality of life within six domains (physical condition, thinking activities, feelings and emotions, functioning in daily life, relationships and social/leisure activities, current situation and future prospects). ${ }^{34}$ 


\section{Secondary outcome measures}

Cognitive Failures Questionnaire

The Cognitive Failures Questionnaire (CFQ) is a 25-item questionnaire on self-reported cognitive failures. ${ }^{35}$ Both the patient as well as his or her caregiver will be asked to fill out this questionnaire to evaluate the cognitive status of the patient.

\section{Cognitive Log}

The Cognitive Log (Cog-log) is a 10-item cognitive screening instrument. ${ }^{36}$ It measures higher neurocognitive processes including orientation, memory, concentration and executive skills.

\section{Adult Memory and Information Processing Battery Task A}

The Adult Memory and Information Processing Battery (AMIPB) Task A is a measure for information processing speed. ${ }^{37}$ In this test, the subject is asked to select the second highest number in each row of five. The final score is the number of correct choices made in two minutes.

\section{Paragraph Recall}

The Paragraph Recall (PR) is a test for immediate and delayed verbal memory. ${ }^{38}$ The subject is asked to recall as much as possible from a paragraph, which is read to the subject aloud. This will be performed both directly, and, without warning, again 20 minutes later. To prevent interference with the paragraph from the previous measurement, a different paragraph will be used each time.

\section{Trail Making Test}

The Trail Making Test (TMT) measures scanning, visuomotor tracking, divided attention and cognitive flexibility. ${ }^{39}$ The test is divided into two parts, part A and B. In part A, the subject is asked to connect consecutively numbered circles on one work sheet as fast as possible. In part $B$, the subject is asked to connect consequently numbered and lettered circles. The time needed to complete part A and part B is recorded.

\section{Verbal Fluency Test}

During the Verbal Fluency Test (VFT), the subject is asked to name as many words from one semantic category, in this case animals, in one minute. ${ }^{40}$

\section{Hospital Anxiety and Depression Scale}

The Hospital Anxiety and Depression Scale (HADS) is a commonly used questionnaire, which was designed to detect the presence of mild degrees of mood disorders in non-psychiatric hospital outpatients. ${ }^{41}$ The HADS consists of 14 items, and has two sub-scales, namely depression and anxiety.

\section{Impact of Event Scale}

The Impact of Event Scale (IES) measures psychological reactions that can take place after a traumatic event. The IES has 15 items and explores the level of posttraumatic stress by asking for intrusive and avoidance symptoms. ${ }^{42,43}$ 


\section{New York Heart Association Classification}

The New York Heart Association Classification (NYHA-classification) is a functional classification system that divides cardiac patients into four classes depending on their limitation in physical activities. $^{44}$

\section{Fatigue Severity Scale}

The Fatigue Severity Scale (FSS) is a 9-item questionnaire that measures experienced severity of fatigue symptoms in daily activities. ${ }^{45}$

\section{Barthel Index}

The Barthel Index (BI) is a widely used instrument that measures basic (personal) activities of daily living (ADL). The instrument consists of 10 items and measures to what extent a person can perform basic ADL activities independently. ${ }^{46}$

\section{Frenchay Activities Index}

The Frenchay Activities Index (FAI) is an accepted measure for instrumental ADL that reports on fifteen daily life activities. ${ }^{47}$ Compared to the Barthel Index, the measured activities are of a higher level, for example the preparation of meals, doing groceries, making trips and performing paid labour.

\section{Caregiver Strain Index}

The Caregiver Strain Index (CSI) is a 13-item, dichotomous scale that has to be filled out by a partner, caregiver or significant other. ${ }^{48}$ The CSI measures strain related to the provision of care.

\section{Parameters for process evaluation}

The intervention will be evaluated based on information from the specialised nurses and the participants. First, the intervention process will be evaluated based on information provided by the specialised nurse. He/she will record the following items: the actual number of consultations (face-to-face, by telephone and by email), the direct time related to each consultation, the indirect time related to each consultation (administration, travel time), the provision of information per consultation, the use of the screening tools, the kind of problems presented, number of referrals, completion of the intervention according to protocol and, in case of non-compliance, reason for non-compliance. Second, after completion of the intervention the participant and his/her caregiver will be asked to fill out a questionnaire to evaluate the intervention.

\section{Determination of costs}

Data concerning costs will be gathered prospectively using monthly cost-diaries. ${ }^{49}$ All the participants receive cost-diaries in which they are asked to note all their health care utilisation during that month. To prevent non-compliance, the research assistant will give a phone call at the end of each month and will record the health care utilisation of that month. For the calculation of the total costs, three categories can be distinguished, namely direct health care costs, direct non-health care costs and indirect costs. For the determination of the direct health care costs the following variables will be recorded: duration admission in health care facility, visits physicians 
and other health care providers and amount of prescribed medication. Direct non-health care costs that will be measured, are the costs of informal health care, over-the-counter medication, costs of health activities, hours of paid or unpaid household help and special aids. The indirect costs comprise loss of paid and unpaid work productivity of the patient.

\section{Statistical analysis}

\section{Effect evaluation}

Descriptive techniques will be used to present data concerning the participants, number of dropouts, losses-to-follow up and the scores on the outcome measures.

To determine whether the patients participating in this trial are representative for the population of cardiac arrest survivors, the baseline characteristics between compliant and non-compliant participants, as well as dropouts and losses-to-follow up will be compared.

Before examining the effectiveness of the intervention, the comparability of the two groups will be checked. Baseline characteristics will be compared using independent sample T-test (normal distribution) or Mann Whitney U-test (non-normal distribution), in case of a continuous variable. In case of a dichotomous variable a chi-square test will be used.

The data from the evaluation study will be analysed according to the intention-to-treatment principle. If either T1 or T2 data are missing the 'last-observation-carried-forward' principle will be used.

Multiple regression analysis, adjusted for possible differences in baseline characteristics or baseline scores, will be applied to examine differences between the intervention and the control group on the primary outcome measures at T3 (one year after the cardiac arrest). If there is a difference between the groups, the effect size will be calculated. Subgroup analysis will be performed for potential effect modifiers.

To assess whether protocol deviations or care provided outside the intervention have caused biases, the results of the intention-to-treatment analysis will be compared to the on-treatment analysis.

\section{Process evaluation}

The outcomes of the process evaluation will be reported using descriptive techniques.

\section{Economic evaluation}

To determine the cost-effectiveness of the intervention a statistical analysis of costs will be performed. The total costs are calculated by adding up direct health care costs, direct non-health care costs and indirect costs. Health care costs are estimated using the Dutch guideline for cost analysis in health care research. ${ }^{50}$ The Friction Cost Approach will be used to evaluate production losses, necessary to determine indirect costs. ${ }^{50}$ Discounting of costs will take place if significant changes in health care costs take place during the study period. As the distribution of costs might be skewed, differences in costs between the intervention and care-as-usual will be calculated by means of bootstrapping, a method appropriate for any distribution of data. A multi-way sensitivity analysis will be performed to gain insight into the generalisability of the economic evaluation. A cost-utility analysis will relate the difference in between the intervention and careas-usual to changes in utility. This will result in costs per quality-adjusted-life-years (QALY's). 


\section{Discussion}

The main goal of the ALASCA trial is to evaluate a new early intervention service for cardiac arrest survivors and their caregivers. This is a relevant topic because evidence on effective rehabilitation programmes for cardiac arrest survivors is urgently needed. During the design of this study many choices and selections were made, and four of the more important ones will be discussed.

First, the intervention was designed especially for this study. There are very few studies describing programmes for people with hypoxic brain injury due to a cardiac arrest. Consequently, we chose to model the intervention upon evidence of effective interventions for people who had traumatic brain injury, as there are many similarities between hypoxic and traumatic brain injuries. ${ }^{27}$ This intervention designed for this study is a combination of a psychosocial intervention and a process intervention. The psychosocial aspects of the intervention are directed at providing informational, emotional and practical support and simulating self-management. The intervention is also process intervention because it is directed at providing the care needed fast and efficiently to each individual patient.

Second, the selection of our primary outcome measures, participation in society and quality of life, may differ from common primary outcome measures in cardiology research. However, this is a common approach in rehabilitation medicine, where maximisation of participation in society is one of the main goals. ${ }^{51}$ We expect that through the care provided in the new intervention, patients will be able to reach a higher level of participation, as well as a higher quality of life.

Third, it may need some clarification why three quality of life measures will be administered. The EQ-6D and the SF-36 were chosen because they measure generic quality of life and can be used in the cost-effectiveness analyses. Next to that, these questionnaires have been used in many other patient groups, which makes it possible to compare the quality of life of cardiac arrest survivors to that of other patient groups. The third quality of life measure is the QOLIBRI, which is a brain injury specific questionnaire. This questionnaire was included because it may have a higher sensitivity to change in case of hypoxic brain injury than both general quality of life measures.

Fourth, we explicitly chose to include the strain for and quality of life of the caregiver in the secondary outcome measures. Our impression is that being the partner of a cardiac arrest survivor can imply a heavy burden. These caregivers are at risk for developing stress and emotional problems and this definitely needs more attention. Therefore, the intervention is directed at both the patient and their caregiver, who is expected to benefit from the early intervention service as well.

To conclude, this paper describes the design of a randomised, controlled clinical trial that will investigate the effectiveness of a new early intervention service for cardiac arrest survivors and their caregivers. The inclusion of the participants started in April 2007 and will continue until April 2010. The results of this study will provide evidence on the effectiveness of this early intervention service, as well as the cost-effectiveness and its feasibility. This will give insight into the question whether it would be useful to implement this early intervention service in the Dutch health care system. 


\section{Competing interests}

The authors declare that they have no competing interests.

\section{Authors' contributions}

V. Moulaert is the main researcher and is responsible for writing the protocol. J. Verbunt and W. Bakx originated the idea for the study. J. Verbunt is project-leader of the study. J. Verbunt and C. van Heugten are the supervisors of V. Moulaert. D. Wade is the promotor of V. Moulaert.

J. Verbunt, C. van Heugten, W. Bakx, A. Gorgels, S. Bekkers, M. de Krom and D. Wade participated in the design of the study and research protocol. All authors read and corrected draft versions of the manuscript and approved the final manuscript.

\section{Acknowledgments}

The study is funded by the Netherlands Organisation for Health Research and Development (Zon/Mw) and Stichting Nuts Ohra.

We would like to thank Brigitte Cobben and Peter Heuts for their contribution to the design of the intervention. Jolanda van Haastregt gave useful advice about the process evaluation. Mariëlle Goossens is thanked for her help with regard to the design of the economic evaluation of this study. 


\section{References}

1. Myerburg RJ, Castellanos A. Cardiac arrest and sudden cardiac death. In: Braunwald E, Zipes DP, Libby P, eds. Heart Disease: A Textbook of Cardiovascular Medicine. Sixth edition ed. Philadelphia: WB Saunders, 2001: 890-931.

2. Waalewijn RA, de Vos R, Koster RW. Out-of-hospital cardiac arrests in Amsterdam and its surrounding areas: results from the Amsterdam resuscitation study (ARREST) in 'Utstein' style. Resuscitation 1998;38(3):157-67.

3. Gorgels AP, Gijsbers C, de Vreede-Swagemakers J, Lousberg A, Wellens HJ. Out-of-hospital cardiac arrest--the relevance of heart failure. The Maastricht Circulatory Arrest Registry. Eur Heart $J$ 2003;24(13):1204-9.

4. Berdowski RA, Waalewijn RA, Koster RW. Overleving na reanimatie buiten het ziekenhuis is sterk toegenomen: een vergelijkend onderzoek tussen eind 20ste en begin 21ste eeuw. In: Vaartjes I, Peters RJG, van Dis SJ, Bots ML, eds. Hart- en vaatziekten in Nederland najaar 2006, cijfers over ziekte en sterfte. Den Haag: Nederlandse Hartstichting, 2006: 27-34.

5. Bottiger BW, Grabner C, Bauer H, et al. Long term outcome after out-of-hospital cardiac arrest with physician staffed emergency medical services: the Utstein style applied to a midsized urban/suburban area. Heart 1999;82(6):674-9.

6. Kuisma M, Maatta T. Out-of-hospital cardiac arrests in Helsinki: Utstein style reporting. Heart 1996;76(1):18-23.

7. Fischer M, Fischer NJ, Schuttler J. One-year survival after out-of-hospital cardiac arrest in Bonn city: outcome report according to the 'Utstein style'. Resuscitation 1997;33(3):233-43.

8. Hodgetts TJ, Kenward G, Vlackonikolis I, et al. Incidence, location and reasons for avoidable in-hospital cardiac arrest in a district general hospital. Resuscitation 2002;54(2):115-23.

9. Huang $\mathrm{CH}$, Chen WJ, Ma MH, Chang WT, Lai CL, Lee YT. Factors influencing the outcomes after inhospital resuscitation in Taiwan. Resuscitation 2002;53(3):265-70.

10. Patrick A, Rankin N. The in-hospital Utstein style: use in reporting outcome from cardiac arrest in Middlemore Hospital 1995-1996. Resuscitation 1998;36(2):91-4.

11. Skogvoll E, Isern E, Sangolt GK, Gisvold SE. In-hospital cardiopulmonary resuscitation. 5 years' incidence and survival according to the Utstein template. Acta Anaesthesiol Scand 1999;43(2):177-84.

12. Valenzuela TD, Roe DJ, Nichol G, Clark LL, Spaite DW, Hardman RG. Outcomes of rapid defibrillation by security officers after cardiac arrest in casinos. N Engl J Med 2000;343(17):1206-9.

13. Sauve MJ, Doolittle N, Walker JA, Paul SM, Scheinman MM. Factors associated with cognitive recovery after cardiopulmonary resuscitation. Am J Crit Care 1996;5(2):127-39.

14. Roine RO, Kajaste S, Kaste M. Neuropsychological sequelae of cardiac arrest. Jama 1993;269(2):23742.

15. Grubb NR, O'Carroll R, Cobbe SM, Sirel J, Fox KA. Chronic memory impairment after cardiac arrest outside hospital. Bmj 1996;313(7050):143-6.

16. Fertl E, Vass K, Sterz F, Gabriel H, Auff E. Neurological rehabilitation of severely disabled cardiac arrest survivors. Part I. Course of post-acute inpatient treatment. Resuscitation 2000;47(3):231-9.

17. Lim C, Alexander MP, LaFleche G, Schnyer DM, Verfaellie M. The neurological and cognitive sequelae of cardiac arrest. Neurology 2004;63(10):1774-8.

18. Pusswald G, Fertl E, Faltl M, Auff E. Neurological rehabilitation of severely disabled cardiac arrest survivors. Part II. Life situation of patients and families after treatment. Resuscitation 2000;47(3):241-8. 
19. van Alem AP, de Vos R, Schmand B, Koster RW. Cognitive impairment in survivors of out-of-hospital cardiac arrest. Am Heart J 2004;148(3):416-21.

20. de Vos R, de Haes HC, Koster RW, de Haan RJ. Quality of survival after cardiopulmonary resuscitation. Arch Intern Med 1999;159(3):249-54.

21. Lundgren-Nilsson A, Rosen $H$, Hofgren $C$, Sunnerhagen KS. The first year after successful cardiac resuscitation: function, activity, participation and quality of life. Resuscitation 2005;66(3):285-9.

22. Middelkamp W, Moulaert VR, Verbunt JA, van Heugten CM, Bakx WG, Wade DT. Life after survival: long-term daily life functioning and quality of life of patients with hypoxic brain injury as a result of a cardiac arrest. Clin Rehabil 2007;21(5):425-31.

23. Cowan MJ, Pike KC, Budzynski HK. Psychosocial nursing therapy following sudden cardiac arrest: impact on two-year survival. Nurs Res 2001;50(2):68-76.

24. Dougherty CM, Johnson-Crowley NR, Lewis FM, Thompson EA. Theoretical development of nursing interventions for sudden cardiac arrest survivors using social cognitive theory. ANS Adv Nurs Sci 2001;24(1):78-86.

25. Dougherty CM, Lewis FM, Thompson EA, Baer JD, Kim W. Short-term efficacy of a telephone intervention by expert nurses after an implantable cardioverter defibrillator. Pacing Clin Electrophysiol 2004;27(12):1594-602.

26. Dougherty $C M$, Thompson EA, Lewis FM. Long-term outcomes of a telephone intervention after an ICD. Pacing Clin Electrophysiol 2005;28(11):1157-67.

27. Wade DT, King NS, Wenden FJ, Crawford S, Caldwell FE. Routine follow up after head injury: a second randomised controlled trial. J Neurol Neurosurg Psychiatry 1998;65(2):177-83.

28. Corrigan JD, Smith-Knapp K, Granger CV. Outcomes in the first 5 years after traumatic brain injury. Arch Phys Med Rehabil 1998;79(3):298-305.

29. Sunnerhagen KS, Johansson O, Herlitz J, Grimby G. Life after cardiac arrest; a retrospective study. Resuscitation 1996;31(2):135-40.

30. Sander AM, Fuchs KL, High WM, Jr., Hall KM, Kreutzer JS, Rosenthal M. The Community Integration Questionnaire revisited: an assessment of factor structure and validity. Arch Phys Med Rehabil 1999;80(10):1303-8.

31. Cardol M, Beelen A, van den Bos GA, de Jong BA, de Groot IJ, de Haan RJ. Responsiveness of the Impact on Participation and Autonomy questionnaire. Arch Phys Med Rehabil 2002;83(11):1524-9.

32. Hoeymans $\mathrm{N}$, van Lindert $\mathrm{H}$, Westert GP. The health status of the Dutch population as assessed by the EQ-6D. Qual Life Res 2005;14(3):655-63.

33. Aaronson NK, Muller M, Cohen PD, et al. Translation, validation, and norming of the Dutch language version of the SF-36 Health Survey in community and chronic disease populations. J Clin Epidemiol 1998;51(11):1055-68.

34. von Steinbuechel N, Petersen C, Bullinger M. Assessment of health-related quality of life in persons after traumatic brain injury--development of the Qolibri, a specific measure. Acta Neurochir Suppl 2005;93:43-9.

35. Broadbent DE, Cooper PF, FitzGerald P, Parkes KR. The Cognitive Failures Questionnaire (CFQ) and its correlates. Br J Clin Psychol 1982;21 (Pt 1):1-16.

36. Alderson AL, Novack TA. Reliable serial measurement of cognitive processes in rehabilitation: the Cognitive Log. Arch Phys Med Rehabil 2003;84(5):668-72.

37. Vlaar AM, Wade DT. The Adult Memory and Information Processing Battery (AMIPB) test of informationprocessing speed: a study of its reliability and feasibility in patients with multiple sclerosis. Clin Rehabil 2003;17(4):386-93. 
38. Sunderland A, Watts K, Baddeley AD, Harris JE. Subjective memory assessment and test performance in elderly adults. J Gerontol 1986;41(3):376-84.

39. O'Donnell WE, Reynolds DM, De Soto CB. Neuropsychological impairment scale (NIS): initial validation study using trailmaking test (A \& B) and WAIS digit symbol (scaled score) in a mixed grouping of psychiatric, neurological, and normal patients. J Clin Psychol 1983;39(5):746-8.

40. Vlaar AM, Wade DT. Verbal fluency assessment of patients with multiple sclerosis: test-retest and interobserver reliability. Clin Rehabil 2003;17(7):756-64.

41. Spinhoven P, Ormel J, Sloekers PP, Kempen GI, Speckens AE, Van Hemert AM. A validation study of the Hospital Anxiety and Depression Scale (HADS) in different groups of Dutch subjects. Psychol Med 1997;27(2):363-70.

42. Sundin EC, Horowitz MJ. Impact of Event Scale: psychometric properties. Br J Psychiatry 2002;180:2059.

43. van der Ploeg E, Mooren TT, Kleber RJ, van der Velden PG, Brom D. Construct validation of the Dutch version of the impact of event scale. Psychol Assess 2004;16(1):16-26.

44. Bennett JA, Riegel B, Bittner V, Nichols J. Validity and reliability of the NYHA classes for measuring research outcomes in patients with cardiac disease. Heart Lung 2002;31(4):262-70.

45. Kleinman L, Zodet MW, Hakim Z, et al. Psychometric evaluation of the fatigue severity scale for use in chronic hepatitis C. Qual Life Res 2000;9(5):499-508.

46. de Haan R, Limburg M, Schuling J, Broeshart J, Jonkers L, van Zuylen P. [Clinimetric evaluation of the Barthel Index, a measure of limitations in dailly activities]. Ned Tijdschr Geneeskd 1993;137(18):91721.

47. Turnbull JC, Kersten P, Habib M, McLellan L, Mullee MA, George S. Validation of the Frenchay Activities Index in a general population aged 16 years and older. Arch Phys Med Rehabil 2000;81(8):1034-8.

48. Thornton M, Travis SS. Analysis of the reliability of the modified caregiver strain index. J Gerontol $B$ Psychol Sci Soc Sci 2003;58(2):S127-32.

49. Goossens ME, Rutten-van Molken MP, Vlaeyen JW, van der Linden SM. The cost diary: a method to measure direct and indirect costs in cost-effectiveness research. J Clin Epidemiol 2000;53(7):688-95.

50. Oostenbrink JB, Bouwmans CAM, Koopmanschap MA, Rutten FFH. Handleiding voor Kostenonderzoek: Methoden en standaard kostprijzen voor economische evaluaties in de gezondheidszorg. Geactualiseerde versie ed: College voor zorgverzekeringen, 2004.

51. Ustun TB, Chatterji S, Bickenbach J, Kostanjsek N, Schneider M. The International Classification of Functioning, Disability and Health: a new tool for understanding disability and health. Disabil Rehabil 2003;25(11-12):565-71. 


\section{Chapter 6}

'Stand still ..., and move on', a new early intervention

service for cardiac arrest survivors and their caregivers:

rationale and description of the intervention

Published in Clinical Rehabilitation as:

Moulaert VR, Verbunt JA, Bakx WG, Gorgels AP, de Krom MC, Heuts PH, Wade DT, van Heugten CM. 'Stand still ..., and move on', a new early intervention service for cardiac arrest survivors and their caregivers: rationale and description of the intervention.

Clinical Rehabilitation 2011;25(10):867-79. 


\begin{abstract}
Objective: To describe a new early intervention service for survivors of cardiac arrest and their caregivers, and to explain the evidence and rationale behind it.

Rationale: A cardiac arrest may cause hypoxic-ischaemic brain injury, which often results in cognitive impairments. Survivors of cardiac arrest can also encounter emotional problems, limitations in daily life, reduced participation in society and a decreased quality of life. A new early intervention service was designed based on literature study, expert opinion and patient experiences.
\end{abstract}

Description of the intervention: The early intervention service is an individualised programme, consisting of one to six consultations by a specialised nurse for the patient and their caregiver. The intervention starts soon after discharge from the hospital and can last up to three months. The intervention consists of screening for cognitive and emotional problems, provision of information and support, promotion of self-management strategies and can include referral to further specialised care if indicated.

Discussion: This intervention is assumed to reduce future problems related to hypoxic-ischaemic brain injury in the patient and caregiver, and its effectiveness is currently being investigated in a randomised controlled multi-centre trial. 


\section{Introduction}

The overall incidence of cardiac arrest in the Netherlands is 0.92/1000 inhabitants per year, resulting in approximately 16.000 cases each year. ${ }^{1,2}$ Despite continuous attempts to improve resuscitation techniques and acute medical care, the world wide survival rates have remained stable over the last 25 years, with a survival rate to discharge from the hospital in attempted resuscitations of only $7.6 \% .^{3}$ However, the expectation is that the numbers of survivors will increase due to the growing availability of automated external defibrillators in public places and use by both professionals and lay people. ${ }^{4,5}$

Survivors of cardiac arrest are at risk of hypoxic-ischaemic brain injury, which can arise after a few minutes without cardiac output and leads to cognitive impairments in about half of the survivors of out-of-hospital cardiac arrest. ${ }^{6}$ In addition, survivors of cardiac arrest can also experience other consequences, such as problems in emotional functioning, limitations in daily life activities, reduced participation in society and a decreased quality of life. ${ }^{7,8}$ The partners of the cardiac arrest survivors, or other informal caregivers, also may experience negative effects, such as a high caregiver strain and symptoms of depression or posttraumatic stress. ${ }^{9,10}$

Although sometimes the problems after a cardiac arrest are obvious, in many cases the exact nature of the consequences can be hard to define and will remain hidden. Moreover, the detection of cognitive and emotional impairments can be especially difficult and should preferably be performed by someone who is trained and experienced in screening for these health problems and who recognises their effect on daily living. Currently, this is not common practice yet and as a result the negative consequences of hypoxic-ischaemic brain injury may be under diagnosed and under treated. We therefore decided to design a new early intervention service for survivors of cardiac arrest and their caregivers, and subject it to a formal trial.

Up to now, only two studies have addressed a psychosocial intervention for patients after cardiac arrest. ${ }^{11,12}$ However, for patients with other cardiac diseases many more studies describing the effect of psychosocial interventions have been published. ${ }^{13-15}$ Although these interventions often consider emotional aspects in patients with cardiac disease, they mostly do not address possible cognitive problems. Therefore, we additionally searched for evidence on effective interventions in a patient group with cognitive impairments after acquired brain injury. We focused on patients with traumatic brain injury, as the negative health consequences of hypoxic-ischaemic brain injury due to cardiac arrest may resemble those after traumatic brain injury: Both are a result of diffuse brain injury and, in general, result mainly in cognitive impairments without evident physical impairments. In the design of our intervention for survivors of cardiac arrest we integrated evidence on psychosocial interventions for cardiac patients with evidence on effective interventions after traumatic brain injury. ${ }^{16-18}$

This paper describes the new early intervention service for survivors of cardiac arrest called 'Stand still ..., and move on', and will present the evidence and rationale behind this programme. We chose to describe the background and design of this intervention separately from the results on its effectiveness, as we can provide more detailed information on the actual content of the intervention here. This may facilitate interpretation, reproduction and possible implementation of the intervention in clinical practice. The effectiveness of the intervention is currently being investigated in a randomised controlled trial and will be reported on in the future. ${ }^{19}$ 
To give an overview, first the design process of the intervention will be described. Second, the evidence currently available on the effectiveness of existing psychosocial interventions for both cardiac patients and patients with traumatic brain injury is presented. Finally, the characteristics and content of the intervention itself will be provided.

\section{Design of the early intervention service - overview}

We reviewed articles presenting results of controlled studies of psychosocial interventions in people with cardiac arrest, other cardiac diseases and traumatic brain injury. In order to do this, a literature search was performed in the database PubMed using keywords such as 'heart arrest', 'coronary artery disease', 'traumatic brain injury', 'aftercare', 'nursing care', 'follow-up programme', 'psychosocial intervention' and 'psycho-educational intervention'. We excluded several studies on patients who had received an implantable cardioverter defibrillator (ICD), but in which it was unclear whether they had also had a cardiac arrest.

The literature study resulted in a framework for the new intervention which was then discussed during an expert meeting with three consultants in rehabilitation medicine, a trainee in rehabilitation medicine, a psychologist and a nurse from a neurology department. Next, this group designed a preliminary protocol for the intervention and, in addition, an information booklet. The protocol and the information booklet were reviewed by an advisory board consisting of another consultant in rehabilitation medicine, a cardiologist, a neurologist and several experts working in a brain injury department. In addition, patient opinion was derived from interviews with three cardiac arrest survivors and their family and they were asked to give feedback on the preliminary outline of the intervention and the information booklet. Finally, the intervention was tested on four subjects during a pilot study. All patient feedback was integrated in the final protocol.

We used a holistic biopsychomedical model of illness based on the International Classification of Function, Disability and Health as a framework to guide our study and intervention. ${ }^{20,21}$ This model is commonly used in rehabilitation medicine practice and research and it distinguishes three levels of functioning, namely basic function, activities and social participation. The following are examples of the three levels in a survivor of a cardiac arrest. First, a person can have limitations in function, such as a reduced cardiac ejection fraction, memory impairments or a depressed mood. Second, at the level of activities, a person may be limited in leisure activities or in performing household activities. With regard to participation, this may affect someone's role as a parent or partner and can result in difficulties in return to work. Moreover, the three levels of functioning can interact and are also affected by personal and environmental factors.

\section{Review of the literature}

\section{Evidence on psychosocial interventions in patients with cardiac disease}

We identified two studies on psychosocial interventions after cardiac arrest. Cowan et al. performed a controlled study that examined the effect of individual psychosocial nursing therapy after a cardiac arrest. ${ }^{11}$ The intervention consisted of eleven ninety-minute sessions given by an experienced cardiovascular nurse. During the sessions physiological relaxation was practised, 
self-management and coping strategies were taught and health education was given. This intervention led to a reduced risk of cardiovascular mortality and depressive symptoms two years later.

Dougherty et al. designed a telephone-based nursing intervention for survivors of cardiac arrest, who had received an implantable cardioverter defibrillator (ICD). ${ }^{22}$ The intervention was directed at improving self-efficacy, outcome efficacy expectations and enhancing self-management behavioural skills. ${ }^{23}$ The content of the intervention was based on the patients' and partners' concerns that were identified through multiple interviews during the first year after the cardiac arrest. In this study the following topics were considered most essential and became part of the intervention: physical changes and symptoms, activities of daily living, emotional reactions, shocks from ICD, partner relationships, safety and prevention, and dealing with health care providers. ${ }^{24}$ The intervention was given by specialised cardiovascular nurses and started after the ICD implantation. During eight consecutive weeks, there were weekly fifteen to twenty minute telephone contacts. Moreover, all participants could use a nurse pager system to contact a nurse at any time and an information booklet was supplied in which the experiences and successful strategies of other survivors were described. This information booklet was highly appreciated by the participants. ${ }^{22}$ The effectiveness of this intervention was examined in a randomised clinical trial, which showed that the intervention group showed less physical symptoms, lower levels of anxiety and enhanced knowledge about cardiac arrest and living with an ICD, both in the shortterm and long-term. ${ }^{12,25}$ The long-term results also showed an improvement in self-confidence. There was no effect on health care use.

In contrast to the limited number of studies on intervention services for survivors of cardiac arrest, there are numerous studies on psychosocial interventions for patients with other cardiovascular diseases, such as coronary artery disease or heart failure. Two meta-analyses summarizing results up to 1995 and 1998 respectively, studied the additional effect of psychosocial/ psychoeducational interventions in standard rehabilitation programmes for patients with coronary artery disease. ${ }^{13,14}$ Both reviews showed that the addition of psychosocial interventions led to a decrease in cardiac mortality and lowered the recurrence of nonfatal cardiac events. Moreover, beneficial effects were found on cardiovascular risk factors, such as systolic blood pressure, heart rate, cholesterol, weight and smoking habits. In addition, the review by Linden et al. reported a positive effect on the levels of anxiety and depression, ${ }^{13}$ but this finding was not replicated in the review by Dusseldorp et al. ${ }^{14}$

A recent third systematic review by Allen et al. summarised 55 randomised trials of nursing interventions in patients with coronary artery disease or heart failure published between 2000 and 2008. ${ }^{15}$ The majority of the interventions consisted of combinations of education, behavioural counselling and support. This review showed that a small majority of the trials demonstrated a beneficial impact on at least one of the following outcome measures: blood pressure, lipids, physical activity, dietary intake, cigarette smoking, weight loss, health care utilisation, mortality, quality of life or psychosocial outcomes. Three out of ten studies showed a significant effect on psychosocial factors such as anxiety, depression, adjustment or self-efficacy. ${ }^{15}$ 
All three systematic reviews described above recommend the inclusion of psychosocial treatment in cardiac rehabilitation programmes. However, none of them could identify the specific components that make the interventions effective.

A fourth systematic review by Jovicic et al. did investigate the specific effect of the promotion of self-management in patients with heart failure. ${ }^{26}$ Self-management was defined as 'enabling patients to assume a primary role in managing and improving their condition and health', implicating that an active attitude towards dealing with their problems is promoted. Selfmanagement can, for example, be improved by acquiring several self-management skills such as problem solving, decision making, resource utilisation and action planning. ${ }^{27}$ This review showed that self-management programmes for patients with heart failure resulted in improvements in health behaviour and a decrease in hospital readmissions in patients with heart failure, but did not affect quality of life scores or mortality.

To conclude, the literature reviewed above has shown some positive effects of psychosocial interventions for survivors of cardiac arrest and other cardiac diseases. However, all reviewed studies focused mainly on the cardiac disease and emotional problems and did not address possible neurological or cognitive problems. However, cognitive impairments, especially problems with memory, attention and planning, are common after cardiac arrest and affect half of the survivors. ${ }^{6}$ In the next paragraph, we will therefore report on an additional literature search on psychosocial interventions in patients with traumatic brain injury, as they may have comparable symptoms as patients with hypoxic-ischaemic brain injury after cardiac arrest.

\section{Evidence on psychosocial interventions in patients with traumatic brain injury}

Although patients with severe traumatic brain injury often require inpatient rehabilitation treatment, this is not always necessary for patients with mild or moderate traumatic brain injury. In fact, the study of Salazar et al. compared an eight week in-patient rehabilitation programme with a limited eight week home rehabilitation programme for military patients with moderateto-severe closed head injury and showed that there were no differences with regard to return to work, quality of life and cognitive or psychiatric function up to one year. ${ }^{28}$

Next, a study by Bell et al. showed that a telephone-based intervention for traumatic brain injured patients, consisting of seven calls in nine months, appeared to be effective one year later on functional status and quality of well-being. ${ }^{29}$ The telephone consultations consisted of brief motivational interviewing, counselling, education and, if necessary, follow-up appointments or therapy prescriptions.

Moreover, three controlled studies showed that even more concise, mostly one-session outpatient interventions, can be equally effective in patients with traumatic brain injury. ${ }^{16-18}$ In the first study, Paniak et al. compared one-session educational intervention and providing a folder on head injury with a more intensive outpatient treatment including several consultations, neuropsychological assessment and additional therapy if indicated. ${ }^{16,30}$ The concise intervention was equally effective after three and twelve months on measures of participation, quality of life and vocational status, and also patient appreciation was comparable. In the second study by Wade et al. an early intervention was offered to patients who had been admitted to the hospital after any kind of traumatic brain injury. Participating patients were approached at 7-10 days after injury by an 
occupational therapist or psychologist. They were offered additional information, standardised information leaflets, advice, support and further assessment or interventions as needed. ${ }^{31}$ This individually tailored intervention resulted in improvements six months after the injury in social participation and everyday activities and decreased the severity of post-concussion symptoms, such as concentration difficulties, headaches, fatigue, sleep disturbance and irritability. ${ }^{17}$

The third study by Ponsford et al. reported on an early intervention for patients with mild traumatic brain injury who had not been admitted to the hospital. ${ }^{18}$ In this intervention patients were contacted within 48 hours and seen 5-7 days after their injury. An information booklet was handed out concerning common symptoms and course after traumatic brain injury and possible coping strategies. This intervention led to a reduction in post-concussion symptoms and psychological distress three months later.

Summarising the evidence on psychosocial interventions after traumatic brain injury reveals that even concise outpatient interventions, consisting of at least oral and written information, support and sometimes further referral at indication, are effective up to one year after the event.

To conclude, based on the literature available, there is evidence that interventions that focus on psychosocial aspects and self-management may be effective in patients after cardiac arrest and other cardiac diseases. In addition, there is also evidence that concise and early intervention services for patients with mild to moderate traumatic brain injury can be useful and effective. Our patient group of interest, survivors of cardiac arrest, is at risk for brain injury due to a cardiac cause. Currently, we are not aware of any studies that have evaluated the effect of an early psychosocial intervention or rehabilitation programme for the consequences of hypoxic-ischaemic brain injury due to cardiac arrest. Therefore, we have developed a new intervention service for survivors of cardiac arrest, based on the combined evidence on effective interventions in the fields of cardiac disease and traumatic brain injury.

\section{The intervention 'Stand still ..., and move on' \\ Assumptions and goals}

The early intervention service 'Stand still ..., and move on' is designed for all patients who have suffered and survived a cardiac arrest and their caregivers. It is based on the following assumptions:

- $\quad$ Any person who had a cardiac arrest may suffer hypoxic-ischaemic brain injury

- Cognitive and emotional problems are common after cardiac arrest

- Cognitive and emotional problems are often not recognised by health care professionals

- Partners or other informal caregivers may also be affected significantly

- Patients and caregivers may be helped by a relatively brief psychosocial intervention that screens for cognitive or emotional problems and offers information, advice and support

The intervention has the following main goals:

1. Early detection of cognitive and emotional problems

2. Providing appropriate information and emotional and practical support

3. Promotion of self-management techniques

4. Referral to specialised services if necessary 


\section{Structure of the intervention}

The intervention is an individualised, semi-structured programme, provided by a specialised nurse, which is offered during the first months after discharge from the hospital. Main characteristics of the intervention are described in Table 1.

Table 1. Characteristics of the early intervention service

\begin{tabular}{|c|c|}
\hline \multirow{2}{*}{$\begin{array}{l}\text { Target group } \\
\text { Provider of intervention }\end{array}$} & Survivors of cardiac arrest and their caregiver \\
\hline & $\begin{array}{l}\text { Specialised nurses with experience in the field of cardiology, neurology } \\
\text { or rehabilitation medicine }\end{array}$ \\
\hline $\begin{array}{l}\text { Required competences of the } \\
\text { nurses }\end{array}$ & $\begin{array}{l}\text { Basic knowledge about pathophysiology and treatment of cardiac } \\
\text { arrest and cardiac disease } \\
\text { Knowledge of and the ability to detect possible cognitive and } \\
\quad \text { emotional impairments } \\
\text { Skills to give relevant information and provide support } \\
\text { Skills to teach and stimulate the use of self-management techniques } \\
\text { and action plans }\end{array}$ \\
\hline \multirow{2}{*}{$\begin{array}{l}\text { Start intervention } \\
\text { Duration intervention }\end{array}$} & Soon after discharge from the hospital, preferably within one month \\
\hline & Approximately three months \\
\hline Frequency & Between one and six face-to face consultations \\
\hline Duration of consultations & $\begin{array}{l}\text { First session: } 1 \text { hour } \\
\text { Follow-up sessions: } 30 \text { minutes } \\
\text { Telephone consultations are optional extra sessions }\end{array}$ \\
\hline Location & Home visits or out-patient clinic \\
\hline Content & $\begin{array}{l}\text { Compulsory topics and additional optional topics at request or } \\
\text { indication (see Table 3) }\end{array}$ \\
\hline Additional information supply & $\begin{array}{l}\text { A special information booklet is provided to all participants during the } \\
\text { first session } \\
\text { Several pre-existing folders about cardiologic and neurologic topics are } \\
\text { available as needed }\end{array}$ \\
\hline $\begin{array}{cc}\text { Cognitive screening } \\
-\quad & \text { subjective } \\
-\quad & \text { objective }\end{array}$ & $\begin{array}{l}\text { Checklist or interview } \\
\text { Short cognitive screening instrument }\end{array}$ \\
\hline $\begin{array}{l}\text { Optional domains of further } \\
\text { screening }\end{array}$ & Anxiety/ depression, posttraumatic stress and caregiver strain \\
\hline
\end{tabular}

The intervention is focused on the neurological sequelae of hypoxic-ischaemic brain and to emotional or other problems that may arise after the cardiac arrest. This intervention does not attend any specific cardiac or physical rehabilitation goals, although we do not exclude the possibility to combine the content of this intervention with more physically oriented cardiac rehabilitation programmes.

This early intervention service is given on an individual basis. Sometimes, psychosocial or selfmanagement programmes are offered as a group programme, but the low numbers of possible participants per hospital per month implied that it would take several months to form a new group. Thus, because the intervention is meant to start soon after discharge from the hospital, we designed an individualised programme. This makes it also possible to offer a more individually tailored intervention that can be adapted to the needs and wishes of the participants. 


\section{Specialised nurses}

The early intervention service can be provided by nurses with a background in cardiology, neurology or rehabilitation medicine. The nurses participating in the trial received a twelve hour training programme focussed on acquiring the necessary competences (see Table 1). In the training special attention was directed at acquiring skills to detect cognitive and emotional impairments and skills to teach and promote self-management techniques. We prefer nurses as providers of the intervention since having a medical background is, to our opinion, important as patients may still have medical questions after discharge from the hospital. Next to that, nurses are trained in dealing with a diverse spectrum of problems and in giving practical support and advice. We also expected that a nurse-based intervention will have a higher cost-effectiveness compared with screening by a physician. However, we do not rule out that persons with another background or profession could deliver this intervention as well, provided that they have had suitable experience and training. In our trial the nurses worked under supervision of a consultant in rehabilitation medicine, with whom they also discussed potential referrals.

\section{Content of the intervention}

A suggestion for a schedule for the first three sessions is provided in Table 2. In case there are less than three consultations, what is possible as this is a flexible intervention, the topics mentioned in session 2 or 3 should be addressed earlier. During the intervention there are several topics that need to be discussed. In addition, there is room to pay attention to any other current problem or concern. Table 3 shows the 'compulsory topics', and gives some examples of potential additional topics.

Table 2. Suggested content of the sessions

Session 1
Explanation of content and structure of the intervention
Getting to know each other
First exploration of current problems or concerns
Hand out special information booklet

\section{Session 2}

Explore current problems

Administer Checklist Cognition and Emotion (CLCE-24)

Provide information about possible cognitive and emotional problems

Explain principles self-management and action plans

\section{Session $\mathbf{3}$ and potential further sessions}

Explore current problems

Explore the strain on the caregiver

Provide information if there are questions

Practise self-management techniques and action plans at indication

Determine together if referral to specialised care is necessary 
Table 3. Obligatory and optional topics of the intervention

\author{
Obligatory topics \\ 1. Cognitive changes and challenges \\ Relation cardiac arrest and hypoxic-ischaemic brain injury \\ Possible cognitive changes \\ Fatigue and irritability \\ Forgetfulness, reduced concentration, loosing the thread of things \\ Slowness, difficulty in following conversation (especially in noisy places) \\ Advices on how to deal with cognitive problems

\section{Emotional changes and challenges} \\ Information on normal process of emotional recovery for patient and caregiver \\ Possible emotional changes (e.g. anxiety, depression) and changes in character \\ Fear of recurrence, dealing with death, fear of ICD shocks (if relevant) \\ Social isolation, loneliness and loss \\ Caregiver strain \\ Advices on how to deal with emotional problems
}

\title{
3. Principles self-management
}

Explanation of the principles of self-management

Practising self-management techniques and action plans

\section{Optional topics}

Cardiologic topics

Physical changes and challenges

Activities of daily living

Changes and challenges for the caregiver

Partner relationships and sexuality

Dealing with healthcare providers

Caregivers, usually a partner or spouse and occasionally another informal carer, are also invited to participate because they often have difficulties such as feelings of depression or posttraumatic stress and can experience a high burden., ${ }^{9,10,32}$ Information, reassurance and support might be also useful for them. In addition, caregivers can help the patient to remember the information provided during the consultations and they can provide insight about the actual functioning of the cardiac arrest survivor. The nurse will proactively investigate caregiver strain and may suggest coping strategies. This is usually deferred to session three but can be started earlier if there is need to do so.

The nurse also discusses with the participants whether further referral is necessary, usually during the last session, but earlier if needed. Depending on the current problems, referrals can be made, for example to a consultant in rehabilitation medicine in order to evaluate the necessity of a multidisciplinary rehabilitation treatment, to a neuropsychologist for further cognitive testing or to a cardiologist in case of cardiac symptoms or concerns.

\section{Self-management}

Teaching self-management is an important part of the programme. The goal of self-management is to stimulate patients to take responsibility in striving for the best quality of life with their condition. Acquisition of self-management techniques includes acquiring problem solving skills and making action plans. ${ }^{27}$ Controlled studies in several chronic patient groups in primary care 
have shown that patient education programmes that include the teaching of self-management skills are more effective compared with information-only education programmes. ${ }^{33}$ It has also been shown that the inclusion of action plans, in which patients make a plan how to gradually work towards a short-term achievable goal, makes self-management interventions even more effective. ${ }^{33}$ During the intervention, the nurse explains the background of self-management, teaches self-management skills and stimulates the patient to make action plans, which are evaluated in the next session.

\section{Information booklet}

As part of the intervention, a special information booklet was written, that is handed out during the first session. In this booklet information concerning the mechanism and possible consequences of hypoxic-ischaemic brain injury due to cardiac arrest is presented. It highlights the most frequently reported cognitive and emotional problems encountered by patients after cardiac arrest and provides information about possible coping strategies. In addition, the potential negative impact upon the caregivers is addressed.

Furthermore, the nurses also have access to several pre-existing folders that can be handed out at indication and focus on related topics in the field of cardiology (e.g. cardiac medication, cardiac treatments and implantation of an ICD), neurology (e.g. stroke, coma, memory problems and fatigue) or driving restrictions. These folders are largely freely available.

\section{Screening instruments}

The detection of possible cognitive or emotional problems is one of the most important goals of this intervention and can be supported by both subjective and objective screening instruments. An example of a subjective instrument is the Checklist Cognition and Emotion (CLCE-24). Originally, the CLCE-24 was designed to detect cognitive and emotional problems in stroke patients. ${ }^{34}$ This checklist describes more than twenty common cognitive and emotional problems and during a semi-structured interview the patient and caregiver are asked whether they recognize any of these problems. Alternatively or additionally, an objective cognitive screening instrument may be used. We recommend the use of an instrument that includes at least a minimum set of assessments on memory, attention and executive functioning, as these cognitive domains are most often impaired after cardiac arrest. ${ }^{6}$ In our study the Cognitive Log (Cog-log) was used for this purpose, ${ }^{35}$ but our experience so far suggests that it may not be sensitive enough to detect cognitive impairments in this patient group. Another potential cognitive screening instrument is the Montreal Cognitive Assessment (MoCA). ${ }^{36}$ The MoCA is a brief cognitive screening instrument with a good sensitivity and specificity for the detection of mild cognitive impairments and includes items measuring executive functioning and attention, but it has not yet been studied in patients with hypoxic-ischaemic brain injury. The Mini-Mental State Examination (MMSE) has been shown to be an invalid and insensitive instrument without an appropriate cut-off point for the detection of cognitive problems in both acute and chronic stroke, and is probably not particularly useful in our patient group. ${ }^{37,38}$ 
The specialised nurse can also use additional instruments for the screening of symptoms of anxiety/depression, posttraumatic stress and caregiver strain, if this seems clinically relevant. In our protocol we used the Hospital Anxiety and Depression Scale, ${ }^{39}$ Impact of Event Scale ${ }^{40}$ and the Caregiver Strain Index ${ }^{41}$ for this purpose respectively, but several other good instruments are available.

\section{Discussion}

Survivors of cardiac arrest are at risk for cognitive or emotional problems, which can lead to limitations in daily activities, social participation and quality of life and may also affect the caregivers. In this article we have described a new early intervention service consisting of four components, namely 1 . early screening on cognitive and emotional problems, 2. supply of information and support, 3. promotion of self-management techniques and 4. referral to specialised care if necessary. These four components are all expected to contribute to the effectiveness of the intervention and will now be discussed respectively.

Our first assumption is that, especially in case of the 'hidden' cognitive and emotional problems, an active screening method is indicated. Patients may not anticipate on a link between their cardiac arrest and, for example, the memory problems or depressive mood they experience, and therefore will not actively seek for support themselves. A study on stroke patients already showed that formal screening resulted in the detection of a much higher number of cognitive and emotional impairments compared with information obtained from the patient's chart at discharge. ${ }^{42}$

Second, we assume that the provision of information and support may have a positive effect on both the patient and the caregiver. Information about the cardiac arrest and common symptoms in patients and caregivers can reduce stress, as it may stop the vicious circle of symptoms and worries. Next to that, the nurse can promote an active coping style and suggest compensation strategies. ${ }^{17}$

Third, the intervention promotes the use self-management techniques. The use of selfmanagement has previously been shown to be effective in heart failure ${ }^{26}$ and several other chronic illnesses. ${ }^{27}$

Fourth, if during the intervention severe or disabling problems are detected, this should lead to a referral for further assessment and treatment. We expect that early detection and early treatment may prevent or reduce future problems.

To conclude, the design of this early intervention service for survivors of cardiac arrest was based on current evidence, expert opinion and patient experiences and has a clear rationale behind it. The next step is to determine its effectiveness objectively, taking also the cost-effectiveness into account. This is currently being investigated in a randomised controlled multi-centre trial with a one year follow-up in which the new intervention is compared with care-as usual. ${ }^{19}$ In addition, a process evaluation will be performed in which we will monitor the actual implementation of the intervention, determine whether the intervention was delivered according to protocol and evaluate the experiences of the participants and the nurses. 


\section{Clinical messages}

- Survivors of cardiac arrest may have cognitive and emotional impairments due to hypoxicischaemic brain injury, leading to limitations in daily activities, a decreased level of participation in society and a lower quality of life.

- In current care these problems are probably under diagnosed and under treated.

- A new early intervention service designed to detect and manage these problems is described.

\section{Acknowledgements}

We would like to thank Brigitte Cobben for her help in the design and testing of the intervention. We also thank the patients and caregivers for their valuable contributions and feedback on the intervention and the information booklet.

\section{Funding}

This study is funded by the Netherlands Organisation for Health Research and Development (Zon/Mw) and Fonds Nuts Ohra.

\section{Conflict of interest statement}

The authors declare that there is no conflict of interest. 


\section{References}

1. Gorgels AP, Gijsbers C, de Vreede-Swagemakers J, Lousberg A, Wellens HJ. Out-of-hospital cardiac arrest--the relevance of heart failure. The Maastricht Circulatory Arrest Registry. Eur Heart $J$ 2003;24(13):1204-9.

2. Straus SM, Bleumink GS, Dieleman JP, van der Lei J, Stricker BH, Sturkenboom MC. The incidence of sudden cardiac death in the general population. J Clin Epidemio/ 2004;57(1):98-102.

3. Sasson C, Rogers MA, Dahl J, Kellermann AL. Predictors of survival from out-of-hospital cardiac arrest: a systematic review and meta-analysis. Circ Cardiovasc Qual Outcomes 2010;3(1):63-81.

4. Valenzuela TD, Roe DJ, Nichol G, Clark LL, Spaite DW, Hardman RG. Outcomes of rapid defibrillation by security officers after cardiac arrest in casinos. N Engl J Med 2000;343(17):1206-9.

5. Koster RW, Berdowski J. Overleving na reanimatie buiten het ziekenhuis in Noord-Holland: resultaten Arrest 7 over 2006-2008. Betere overleving dankzij de Automatische Externe Defibrillator? In: Vaartjes I, van Dis I, Visseren FLJ, Bots ML, eds. Hart- en vaatziekten in Nederland 2009. Den Haag: Nederlandse Hartstichting, 2009: 49-59.

6. Moulaert VR, Verbunt JA, van Heugten CM, Wade DT. Cognitive impairments in survivors of out-ofhospital cardiac arrest: A systematic review. Resuscitation 2009;80(3):297-305.

7. Lundgren-Nilsson A, Rosen $H$, Hofgren $C$, Sunnerhagen KS. The first year after successful cardiac resuscitation: function, activity, participation and quality of life. Resuscitation 2005;66(3):285-9.

8. de Vos R, de Haes HC, Koster RW, de Haan RJ. Quality of survival after cardiopulmonary resuscitation. Arch Intern Med 1999;159(3):249-54.

9. Pusswald G, Fertl E, Faltl M, Auff E. Neurological rehabilitation of severely disabled cardiac arrest survivors. Part II. Life situation of patients and families after treatment. Resuscitation 2000;47(3):241-8.

10. Wachelder EM, Moulaert VR, van Heugten C, Verbunt JA, Bekkers SC, Wade DT. Life after survival: long-term daily functioning and quality of life after an out-of-hospital cardiac arrest. Resuscitation 2009;80(5):517-22.

11. Cowan MJ, Pike KC, Budzynski HK. Psychosocial nursing therapy following sudden cardiac arrest: impact on two-year survival. Nurs Res 2001;50(2):68-76.

12. Dougherty CM, Thompson EA, Lewis FM. Long-term outcomes of a telephone intervention after an ICD. Pacing Clin Electrophysiol 2005;28(11):1157-67.

13. Linden W, Stossel C, Maurice J. Psychosocial interventions for patients with coronary artery disease: a meta-analysis. Arch Intern Med 1996;156(7):745-52.

14. Dusseldorp E, van Elderen T, Maes S, Meulman J, Kraaij V. A meta-analysis of psychoeduational programs for coronary heart disease patients. Health Psychol 1999;18(5):506-19.

15. Allen JK, Dennison CR. Randomized trials of nursing interventions for secondary prevention in patients with coronary artery disease and heart failure: systematic review. J Cardiovasc Nurs 2010;25(3):207-20

16. Paniak C, Toller-Lobe G, Reynolds S, Melnyk A, Nagy J. A randomized trial of two treatments for mild traumatic brain injury: 1 year follow-up. Brain Inj 2000;14(3):219-26.

17. Wade DT, King NS, Wenden FJ, Crawford S, Caldwell FE. Routine follow up after head injury: a second randomised controlled trial. J Neurol Neurosurg Psychiatry 1998;65(2):177-83.

18. Ponsford J, Willmott C, Rothwell A, et al. Impact of early intervention on outcome following mild head injury in adults. J Neurol Neurosurg Psychiatry 2002;73(3):330-2.

19. Moulaert VR, Verbunt JA, van Heugten CM, et al. Activity and Life After Survival of a Cardiac Arrest (ALASCA) and the effectiveness of an early intervention service: design of a randomised controlled trial. BMC Cardiovasc Disord 2007;7(1):26. 
20. WHO. International Classification of Functioning, Disability and Health: ICF. Geneva, 2001.

21. Wade DT, Halligan PW. Do biomedical models of illness make for good healthcare systems? Bmj 2004;329(7479):1398-401.

22. Dougherty $C M$, Pyper GP, Frasz HA. Description of a nursing intervention program after an implantable cardioverter defibrillator. Heart Lung 2004;33(3):183-90.

23. Dougherty CM, Johnson-Crowley NR, Lewis FM, Thompson EA. Theoretical development of nursing interventions for sudden cardiac arrest survivors using social cognitive theory. ANS Adv Nurs Sci 2001;24(1):78-86.

24. Dougherty CM, Benoliel JQ, Bellin C. Domains of nursing intervention after sudden cardiac arrest and automatic internal cardioverter defibrillator implantation. Heart Lung 2000;29(2):79-86.

25. Dougherty CM, Lewis FM, Thompson EA, Baer JD, Kim W. Short-term efficacy of a telephone intervention by expert nurses after an implantable cardioverter defibrillator. Pacing Clin Electrophysiol 2004;27(12):1594-602.

26. Jovicic A, Holroyd-Leduc JM, Straus SE. Effects of self-management intervention on health outcomes of patients with heart failure: a systematic review of randomized controlled trials. BMC Cardiovasc Disord 2006;6:43.

27. Lorig KR, Holman H. Self-management education: history, definition, outcomes, and mechanisms. Ann Behav Med 2003;26(1):1-7.

28. Salazar AM, Warden DL, Schwab K, et al. Cognitive rehabilitation for traumatic brain injury: A randomized trial. Defense and Veterans Head Injury Program (DVHIP) Study Group. Jama 2000;283(23):3075-81.

29. Bell KR, Temkin NR, Esselman PC, et al. The effect of a scheduled telephone intervention on outcome after moderate to severe traumatic brain injury: a randomized trial. Arch Phys Med Rehabil 2005;86(5):851-6.

30. Paniak C, Toller-Lobe G, Durand A, Nagy J. A randomized trial of two treatments for mild traumatic brain injury. Brain Inj 1998;12(12):1011-23.

31. King NS, Crawford S, Wenden FJ, Moss NE, Wade DT. Interventions and service need following mild and moderate head injury: the Oxford Head Injury Service. Clin Rehabil 1997;11(1):13-27.

32. Dougherty CM, Pyper GP, Benoliel JQ. Domains of concern of intimate partners of sudden cardiac arrest survivors after ICD implantation. J Cardiovasc Nurs 2004;19(1):21-31.

33. Bodenheimer $\mathrm{T}$, Lorig $\mathrm{K}$, Holman $\mathrm{H}$, Grumbach $\mathrm{K}$. Patient self-management of chronic disease in primary care. Jama 2002;288(19):2469-75.

34. van Heugten C, Rasquin S, Winkens I, Beusmans G, Verhey F. Checklist for cognitive and emotional consequences following stroke (CLCE-24): development, usability and quality of the self-report version. Clin Neurol Neurosurg 2007;109(3):257-62.

35. Alderson AL, Novack TA. Reliable serial measurement of cognitive processes in rehabilitation: the Cognitive Log. Arch Phys Med Rehabil 2003;84(5):668-72.

36. Nasreddine ZS, Phillips NA, Bedirian V, et al. The Montreal Cognitive Assessment, MoCA: a brief screening tool for mild cognitive impairment. J Am Geriatr Soc 2005;53(4):695-9.

37. Nys GM, van Zandvoort MJ, de Kort PL, Jansen BP, Kappelle LJ, de Haan EH. Restrictions of the MiniMental State Examination in acute stroke. Arch Clin Neuropsychol 2005;20(5):623-9.

38. Pendlebury ST, Cuthbertson FC, Welch SJ, Mehta Z, Rothwell PM. Underestimation of cognitive impairment by mini-mental state examination versus the montreal cognitive assessment in patients with transient ischemic attack and stroke: a population-based study. Stroke 2010;41(6):1290-3. 
39. Spinhoven P, Ormel J, Sloekers PP, Kempen GI, Speckens AE, Van Hemert AM. A validation study of the Hospital Anxiety and Depression Scale (HADS) in different groups of Dutch subjects. Psychol Med 1997;27(2):363-70.

40. Sundin EC, Horowitz MJ. Impact of Event Scale: psychometric properties. Br J Psychiatry 2002;180:2059.

41. Thornton M, Travis SS. Analysis of the reliability of the modified caregiver strain index. J Gerontol $B$ Psychol Sci Soc Sci 2003;58(2):S127-32.

42. Edwards DF, Hahn MG, Baum CM, Perlmutter MS, Sheedy C, Dromerick AW. Screening patients with stroke for rehabilitation needs: validation of the post-stroke rehabilitation guidelines. Neurorehabil Neural Repair 2006;20(1):42-8. 


\section{Chapter 7}

'Stand still ..., and move on', an early neurologically-focused follow-up for cardiac arrest survivors and their caregivers:

a process evaluation

Published in BMC Health Services Research as:

Moulaert VR, van Haastregt JCM, Wade DT, van Heugten CM, Verbunt JA. 'Stand still ..., and move on', an early neurologically-focused follow-up for cardiac arrest survivors and their caregivers: a process evaluation. BMC Health Services Research 2014;14:34. 


\begin{abstract}
Background: A cardiac arrest can lead to hypoxic-ischaemic brain injury which can result in cognitive and emotional impairments and may negatively affect daily functioning, participation in society and quality of life. Furthermore, the impact on the family of the patient can be high. We designed an intervention called 'Stand still..., and move on', which is a concise, individualised, semi-structured intervention for survivors of cardiac arrest and their caregivers, consisting of between one and six face-to-face consultations provided by a trained nurse. The intervention is directed at early detection of cognitive and emotional problems, provision of information, promotion of self-management and referral to specialised care if necessary. The effectiveness of the intervention is being examined in a randomised controlled trial [ISRCTN74835019]. Alongside this trial we performed a process evaluation which aims to investigate the feasibility of the intervention by assessing: 1) the attendance and dose delivered; 2) performance according to protocol; and 3) the opinion of patients, caregivers and nurses on the intervention.
\end{abstract}

Methods: Participants of this process evaluation were 97 patients allocated to the intervention group of the RCT, their 91 caregivers, and six nurses who conducted the intervention. Measurement instruments used were evaluation forms for patients and caregivers, registration and evaluation forms for nurses, and semi-structured interviews with nurses.

Results: Seventy-nine of the patients (81\%) allocated to the intervention group and 65 caregivers (71\%) participated in the intervention. The mean (SD) number of consultations per patient was 1.8 (1.0), and most consultations were conducted at the patients' home. The intervention was performed largely according to protocol, except that the intervention usually started later than intended, consultations were longer than expected, and the topic of self-management was not regularly addressed. Patients marked the quality of the intervention with a mean score of 7.5 and the performance of the nurse with an 8.0 out of ten. Overall, the intervention was positively evaluated by patients, caregivers and nurses.

Conclusions: The intervention 'Stand still..., and move on' is a promising intervention which was performed largely according to protocol and seems feasible for implementation after some adaptations, if it is found to be effective. 


\section{Background}

Surviving a cardiac arrest is a major life event. Persons who survive a cardiac arrest may suffer from hypoxic-ischaemic brain injury due to the temporary cessation of blood circulation in the brain. ${ }^{1}$ This can lead to cognitive and emotional impairments, and may affect daily functioning, participation in society and quality of life..$^{2-4}$ Furthermore, a cardiac arrest can have considerable impact on the family and caregivers in terms of psychosocial problems and high perceived care burden. ${ }^{4}$

In literature only a few aftercare interventions for survivors of cardiac arrest have been described. ${ }^{5}$ We identified two psychosocial interventions that resulted in improved knowledge and reduced physical and emotional symptoms. ${ }^{6,7}$ Although these interventions addressed psychosocial topics, they did not include screening for possible cognitive impairments. We have previously shown that cognitive impairments occur in almost fifty percent of the survivors of cardiac arrest and are related to a reduced quality of life, which suggests that early detection of cognitive impairments may be important. 8,9 We therefore developed an early intervention service called 'Stand still ..., and move on', which is directed at early detection of cognitive and emotional problems, provision of information on possible consequences of a cardiac arrest, promotion of self-management and referral to specialised care if necessary. ${ }^{5}$ The main goal of this intervention was to improve societal participation and quality of life, and the effect of this intervention is examined in a randomised controlled trial (RCT): 'Activity and Life After Survival of a Cardiac Arrest' (ALASCA) [ISRCTN74835019]. ${ }^{10}$ In this RCT the intervention group received the new intervention, while the control group received care as usual.

In the current paper we present the results of the process evaluation of this intervention, which was performed alongside the trial. A process evaluation is a systematic way to monitor the delivery of an intervention and can provide insight into factors that may have influenced the effectiveness of the intervention and can help to understand why an intervention was effective or not. ${ }^{11}$ We performed this process evaluation prior to analysing the results of the trial, in order to prevent possible bias related to already knowing the effectiveness of the intervention. ${ }^{12}$

The aim of this process evaluation was to evaluate the feasibility of the intervention by assessing: 1) the attendance and dose delivered; 2) performance according to protocol; and 3) the opinion of patients, caregivers and nurses on the intervention.

\section{Methods}

\section{Intervention}

The intervention 'Stand still..., and move on' is a concise, individualised, semi-structured intervention, for survivors of cardiac arrest and their caregivers. ${ }^{5}$ The intervention is conducted by trained nurses and consists of between one and six face-to-face consultations, depending on the individual needs of patient and caregiver. The first consultation is planned soon after discharge from hospital, preferably within one month. Both patient and caregiver are invited to the consultations. If the patient has a caregiver who decides to participate, patient and caregiver attend the consultations together. The first consultation has an intended duration of approximately 
60 minutes and follow-up sessions are intended to last about 30 minutes. The consultations take place in hospital or at the patients' home. Additional consultation by telephone is possible.

The intervention is designed for the early detection of cognitive and emotional consequences of cardiac arrest and consists of four elements: 1) screening for cognitive and emotional problems; 2) provision of information and support; 3) promotion of self-management strategies; and 4) referral to specialised care if indicated. Below, each element will be described in more detail.

First, the nurse screens for signs of cognitive impairments in the patient and for possible emotional problems in patient and caregiver by conversation and observation. In addition, the nurse can use one of the following screening instruments: Checklist Cognition and Emotion (CLCE-24), ${ }^{13}$ Cognitive Log (Cog-log) ${ }_{1}^{14}$ Hospital Anxiety and Depression Scale, ${ }^{15}$ Impact of Event Scale ${ }^{16}$ and the Caregiver Strain Index. ${ }^{17}$

Second, the nurse provides information about possible consequences of cardiac arrest. She also hands out an information booklet that was developed for this intervention. In this information booklet, which is added to this thesis, frequently occurring cognitive and emotional problems after cardiac arrest are described, and suggestions for effective coping strategies are provided. In addition, the nurse has a set of brochures from patient organisations on topics such as medication, cardiac treatments, memory problems, fatigue or driving restrictions, which she can offer at indication.

Third, self-management strategies are promoted. The goal of self-management is to stimulate patients to take responsibility for actions that should give the best quality of life given their possibilities. ${ }^{18}$ Self-management interventions have shown to be effective in several chronic illnesses, including in heart failure. ${ }^{19,20}$ To promote self-management, self-management skills such as problem solving and making action plans can be practiced with the participants if needed. ${ }^{19}$ Finally, the nurse discusses whether referral to specialised care is indicated. Referrals can be made, for example, to a cardiologist in case of cardiac symptoms or concerns, to a neuropsychologist for further cognitive testing and treatment, or to a consultant in rehabilitation medicine to evaluate the need for multi-disciplinary rehabilitation treatment. More details on the rationale and description of the intervention have been published elsewhere. ${ }^{5}$

\section{Participants}

\section{Patients}

The 97 patients eligible for this process evaluation were all survivors of a cardiac arrest who were allocated to the intervention group of the ALASCA trial. Inclusion for the ALASCA trial took place between April 2007 and November 2010. During this period 185 patients were included for the trial at the coronary care units and intensive care units of five hospitals in the Netherlands. Inclusion criteria for the ALASCA study were: survival more than two weeks after in-hospital or out-of-hospital cardiac arrest, living within $50 \mathrm{~km}$ of one of the participating hospitals, age 18 years or older and sufficient knowledge of the Dutch language. Exclusion criteria were a life expectancy lower than 3 months (as evaluated by the treating physician) and living in residential or institutional care prior to the cardiac arrest. 


\section{Caregivers}

Ninety-one of the 97 patients in the intervention group had a caregiver. Caregiver was defined as partner, spouse, or other informal caregiver closely related to the patient. There were no additional in- or exclusion criteria for the caregivers.

\section{Nurses}

Six nurses undertook the intervention. Prior to the start of the interventions, training was offered to the nurses directed at acquiring skills to detect cognitive and emotional problems and promoting self-management among survivors of cardiac arrest. In addition, once a year a booster session was organised, and throughout the intervention period the nurses could contact a consultant in rehabilitation medicine (JV) for advice.

\section{Data collection}

Table 1 describes the measurement instruments used in this process evaluation. All patients allocated to the intervention group, who had participated in at least one consultation, received an evaluation form after the last consultation. Also all caregivers who had been present in at least one of the consultations received an evaluation form. Evaluation forms were sent by mail and non-responders received one reminder. The nurses registered the course and contents of the intervention after each consultation on a registration form, and after the last consultation of each patient the nurses filled out an evaluation form. Finally, after completion of the trial the nurses were invited for interviews.

Table 1. Outcome measures and measurement instruments of the process evaluation

\begin{tabular}{|c|c|c|c|c|c|}
\hline & $\begin{array}{l}\text { Evaluation } \\
\text { form patient }\end{array}$ & $\begin{array}{c}\text { Evaluation } \\
\text { form caregiver }\end{array}$ & $\begin{array}{l}\text { Registration } \\
\text { form nurse }\end{array}$ & $\begin{array}{l}\text { Evaluation } \\
\text { form nurse }\end{array}$ & $\begin{array}{c}\text { Interview } \\
\text { nurses }\end{array}$ \\
\hline \multicolumn{6}{|l|}{ 1. Attendance and dose delivered } \\
\hline - Attendance patients and caregivers & & & $x$ & & \\
\hline - Frequency and duration consultations & & & $x$ & & \\
\hline \multicolumn{6}{|l|}{ 2. Performance according to protocol } \\
\hline - Characteristics consultations & & & $x$ & & \\
\hline - Course and contents consultations & $x$ & $x$ & $x$ & $x$ & $x$ \\
\hline \multicolumn{6}{|l|}{ 3. Opinion on the intervention } \\
\hline - Opinion patients & $x$ & & & & \\
\hline - Opinion caregivers & & $x$ & & & \\
\hline - Opinion nurses & & & & $x$ & $x$ \\
\hline
\end{tabular}

\section{Evaluation form patient}

The evaluation form for the patient consisted of thirteen multiple choice questions and statements regarding the course, contents and quality of the intervention. In addition, patients were asked to give a grade (10-point scale, ranging from 1 to 10) for the perceived quality of the intervention and the performance of the nurse. In three open questions the patients were asked to mention strong and weak points of the intervention and to provide suggestions for improvements. 


\section{Evaluation form caregiver}

The evaluation form for the caregiver was the same as the evaluation form for the patients, except that questions were formulated from the perspective of the caregiver.

\section{Registration form nurse}

The registration form for the nurses included questions concerning characteristics of the intervention, including frequency, duration, start and location of the consultations, and the presence of the caregiver. Furthermore, the nurses registered the course and contents of the intervention, including the topics discussed, use of screening instruments, delivery of the information booklets and the extent to which self-management techniques had been practised with the patients.

\section{Evaluation form nurse}

After the last consultation with each patient, the nurses filled out an evaluation form on which they registered their perceived usefulness of the intervention for patient and caregiver. In addition, there were three open questions concerning strong and weak points of the intervention and suggestions for improvements.

\section{Interview nurses}

After completion of the trial, the two nurses that had conducted most interventions were invited to participate in an individual semi-structured interview by a researcher who had not been involved in the intervention process $(\mathrm{JvH})$. During this interview, the nurses were invited to evaluate the intervention. In addition, two other nurses were invited to participate in a more concise telephone interview by the principal researcher (VM). The remaining two nurses were not approached for an interview as they both had stopped working on the project prior to the end of the trial, and one of the nurses had seen one patient only.

\section{Data analysis}

The quantitative data from the registration and evaluation forms were analysed with descriptive statistics using SPSS, version 20. Qualitative data, resulting from the open questions on the evaluation forms and the interviews with the nurses, was classified into categories based on the contents of the answers.

\section{Ethical considerations}

The Medical Ethics Committee of Maastricht University Medical Centre approved the ALASCA study. The study is registered in a public trial registry [ISRCTN74835019]. Patients and caregivers participating in this process evaluation had signed an informed consent form at the start of the ALASCA study. 


\section{Results}

\section{Characteristics participants}

The mean age of the 97 patients allocated to the intervention group was 60 years (SD 12) at the moment of their cardiac arrest and $80(82 \%)$ were male. The majority of the cardiac arrests $(n=77$, $79 \%)$ had occurred outside the hospital.

The caregivers of the patients had a mean age of 57 years (SD 11) and $77(88 \%)$ were female. Caregivers were spouses/partners $(n=82,92 \%)$, children $(n=4,5 \%)$ or other family members $(n=3,3 \%)$.

The six nurses were all women with an age ranging from 40 to 57 years. They were experienced nurses who had been working for more than 15 years in the field of neurology $(n=2)$, cardiology $(n=3)$ or intensive care medicine $(n=1)$. Three nurses followed a 12 -hour group training and three nurses that started later received a more compact and personal training.

\section{Attendance patients and caregivers}

Of the 97 patients allocated to the intervention group, 79 patients (81\%) actually received the intervention. Ten patients (10\%) did not receive the intervention because they stopped their participation in the ALASCA study prior to the start of the intervention because of death $(n=2)$, medical problems $(n=3)$, high burden/ lack of time $(n=3)$ or lack of interest $(n=2)$. Six persons $(6 \%)$ refused the intervention while they continued their participation in the ALASCA study. Reasons for refusal were medical problems $(n=1)$, being already in rehabilitation treatment $(n=2)$ or lack of interest $(n=3)$. Furthermore, one patient did not receive the intervention due to logistical problems and for one person the reason was unknown.

Ninety-one of the 97 patients allocated to the intervention group had a caregiver. Of the 79 patients who actually received the intervention, 75 patients had a caregiver. Ten of these caregivers did not participate in the intervention, because of divorce $(n=2)$ or because they could not be present at the moment of the consultation $(n=8)$. Overall, $65(71 \%)$ of the 91 caregivers have received the intervention.

\section{Response}

The patient evaluation form was returned by 58 (73\%) of the 79 patients who had received the intervention. The caregiver evaluation form was returned by $49(75 \%)$ of the 65 caregivers who had participated in the intervention. The nurses filled out 136 registration forms (96\%) about the 141 consultations they had conducted, and we received 75 evaluation forms (94\%). The two nurses who were invited for the semi-structured interview and the two nurses who were invited for the telephone interview, all agreed to participate in the interviews.

\section{Frequency and duration consultations}

Patients that participated in the intervention received a mean number of 1.8 consultations (SD 1.0 , range $1-5$ ). The majority of patients ( $n=41,52 \%$ ) received one consultation. The duration of the face-to-face consultations did not change over time, and was as follows: six consultations (5\%) were shorter than 30 minutes, a quarter $(n=30)$ lasted 30 to 60 minutes, two thirds $(n=81)$ had a duration of 60 to 90 minutes, and 4 consultations (3\%) lasted more than 90 minutes. The 
telephone consultations had a mean duration of 16 minutes (SD 8, range 5 - 30). Nurses spent on average 18 minutes on preparation and administration per consultation.

\section{Characteristics consultations}

On average the first consultation was conducted 90 days after the cardiac arrest (SD 59, range 19 - 344). Consultations were most frequently performed at the patients' home $(n=80,68 \%)$. The remaining consultations were performed in hospital, of which $25(21 \%)$ at an outpatient clinic and thirteen (11\%) at a clinical ward. Of the 141 consultations, nineteen consultations (13\%) were conducted by telephone. Three patients received an intervention that consisted of telephone consultations only.

\section{Course and contents consultations}

The nurses registered whether the four elements of the intervention had been addressed during the consultations.

\section{Screening for cognitive and emotional problems}

The topics 'cognition' and 'emotion' were discussed or addressed in at least one of the consultations in $62(83 \%)$ and 61 (82\%) patients respectively. In addition, the nurses used the following screening instruments during the consultations: Checklist Cognition and Emotion $(n=32)$, Hospital Anxiety and Depression Scale $(n=2)$, Impact of Event Scale $(n=20)$ and Caregiver Strain Index $(n=22)$.

\section{Provision of information and support}

Table 2 shows the topics that have been discussed during the consultations. Topics that were addressed most frequently were: daily activities, cognitive changes, emotional changes, physical changes, caregiver strain and fatigue.

The information booklet was offered to 68 of the patients (92\%). Of the participants who had received the booklet, 47 patients (83\%) and 41 caregivers $(87 \%)$ reported that they had read it. In addition, the nurses presented 26 other brochures to 19 patients on the following topics: medication for heart diseases $(n=13)$, implantable cardioverter defibrillator $(n=3)$, percutaneous coronary intervention $(n=3)$, myocardial infarction $(n=2)$, fatigue $(n=2)$, driving restrictions $(n=2)$, smoking $(n=2)$, heart failure $(n=1)$, sport $(n=1)$ and information about the hospital $(n=1)$.

\section{Promotion of self-management strategies}

The topic of self-management was addressed during at least one of the consultations in 14 patients (19\%), and self-management techniques were practiced with 4 patients (5\%).

\section{Referral to specialised care}

During the intervention, 13 patients $(18 \%)$ were referred to specialised care. Patients were referred to a consultant in rehabilitation medicine $(n=7)$, psychologist $(n=2)$, neurologist $(n=1)$, social worker $(n=1)$, general practitioner $(n=1)$ and physiotherapist $(n=1)$. 
Table 2. Number of patients with whom a topic was discussed during the intervention $(n=75)$

\begin{tabular}{lll}
\hline Topic & $\mathbf{n}(\mathbf{})$ \\
\hline Daily activities & $67(89 \%)$ \\
Cognitive changes & $62(83 \%)$ \\
Emotional changes & $61(81 \%)$ \\
Physical changes & $56(75 \%)$ \\
Caregiver strain & $55(73 \%)$ \\
Fatigue & $53(71 \%)$ \\
Driving & $43(57 \%)$ \\
Family and children & $40(53 \%)$ \\
Participation in society (including work) & $40(53 \%)$ \\
Behavioural changes & $38(51 \%)$ \\
Cardiologic questions & $35(47 \%)$ \\
Contacts with friends & $26(35 \%)$ \\
Implantable cardioverter defibrillator & $15(20 \%)$ \\
Partner relationships and sexuality & $15(20 \%)$ \\
Self-management & $14(19 \%)$ \\
Dealing with health care providers & $12(16 \%)$ \\
\hline
\end{tabular}

\section{Opinion patients and caregivers}

Table 3 shows that most patients and caregivers found the intervention useful and reported that they received enough information, advice and support. The quality and timing of the information booklet were evaluated positively, although eight patients (16\%) and eight caregivers (19\%) would have preferred to receive the booklet earlier. After the intervention, most patients and caregivers felt capable of dealing with the consequences of the cardiac arrest and stated that they would recommend the intervention to others.

Patients graded the perceived quality of the intervention with a mean score of 7.5 (SD 1.7, range $1-10$ ) and caregivers gave a 7.4 (SD 1.6, range $3-10$ ). Both patients and caregivers marked the performance of the nurse with an 8.0 (SD 1.1, range 3 - 10). Patients and caregivers that had received more than one consultation reported, on average, higher scores for the quality of the intervention and the performance of the nurse.

Strong aspects of the intervention, as reported by the patients and caregivers, were the opportunity to ask questions, the information provided and, most of all, the personal attention of the nurses, not only for the patient, but also for the caregiver. The most frequently reported weakness was the late start of intervention. A suggestion made by several participants was to add a group session with other patients who survived a cardiac arrest and their caregivers. 
Table 3. Opinion of patients and caregivers on the intervention

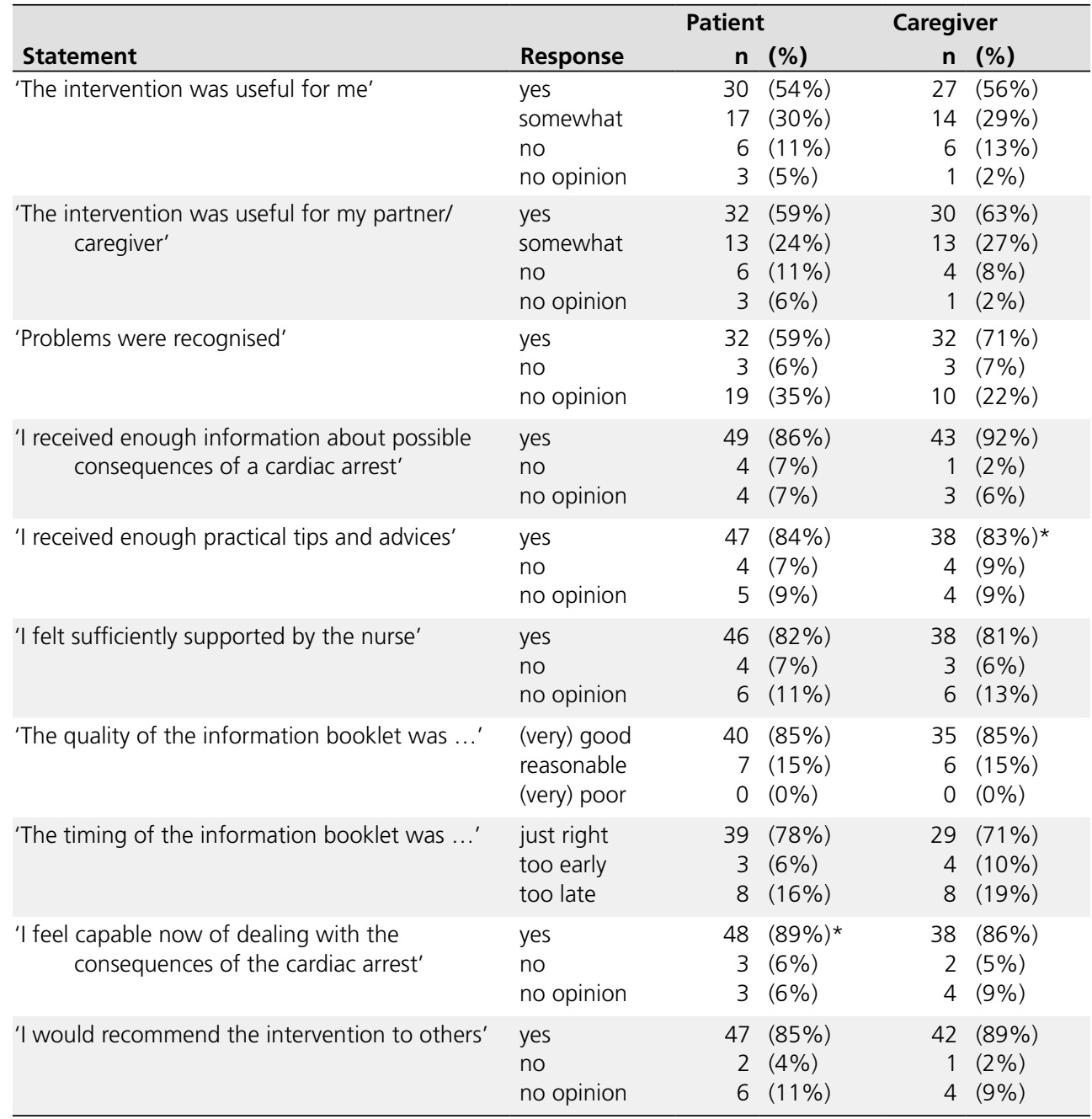

* Percentages have been rounded off to whole numbers and therefore do not always add up to 100 percent

\section{Opinion nurses}

The nurses considered the intervention useful for most patients $(n=71,95 \%)$ and also for most caregivers ( $n=61,95 \%)$. All nurses recommended implementation of the intervention into regular health care.

The interviews showed that nurses had different opinions on the optimal number of consultations per patient. Two nurses regarded one consultation sufficient for most patients, while the other two nurses considered it important to see patient and caregiver more frequently. All nurses reported that face-to-face contact was essential and could not be replaced by telephone calls. 
According to the nurses, home visits were highly appreciated by the patients, but were more time consuming for them due to travel time.

The three nurses who had used the Checklist Cognition and Emotion, considered it to be a valuable screening instrument, mainly because it helped to structure the conversation.

All nurses mentioned that the information booklet provided useful information for patients and caregivers, which is not present in regular brochures.

During the interviews, the nurses explained that they regarded self-management not particularly useful for this patient group on this moment after their cardiac arrest. They considered selfmanagement more suitable for more extensive interventions provided during the chronic phase.

The main strong aspects of the intervention reported by the nurses were the time, attention and open conversations they had with patients and caregivers. In addition, they valued that the well-being and burden of the caregiver was specifically addressed. The nurses reported that the information they could provide was highly appreciated. According to the nurses, the protocol provided sufficient structure to conduct the intervention and was feasible in most cases. Also, the semi-structured format of the intervention was positively evaluated as this enabled them to tailor the intervention to the individual needs and wishes of patient and caregiver.

The nurses also reported some weaknesses. Their main comment was that the intervention started too late. Besides, the nurses considered the intervention to be less useful for two groups of patients, namely for patients who experienced no problems at all and for patients that had already started a rehabilitation treatment. A suggestion made by one nurse was to introduce the intervention to patient and family already during hospital admission. As such, patients and family know what they can expect and rely on after discharge from hospital.

\section{Differences between nurses}

Table 4 shows how the six nurses performed several aspects of the intervention. Differences can be noticed concerning number of consultations they conducted per patient, use of screening instruments and referral to specialised care. Next to that, table 4 also shows that the scores given by patients and caregivers for perceived quality of intervention and performance of the nurse varied between the nurses. 
Table 4. Differences in performance of the intervention across the nurses

\begin{tabular}{|c|c|c|c|c|c|c|}
\hline & Nurse A & Nurse B & Nurse C & Nurse D & Nurse E & Nurse F \\
\hline Number of patients & 28 & 25 & 14 & 7 & 4 & 1 \\
\hline $\begin{array}{l}\text { Consultations per patient } \\
\text { mean (SD) }\end{array}$ & $2.4(1.1)$ & $1.2(0.6)$ & $1.4(0.6)$ & $2.3(1.0)$ & $1.8(0.5)$ & 1.0 (n.a.) \\
\hline \multicolumn{7}{|l|}{ Screening instruments } \\
\hline$\quad$ CLCE-24 & 23 & 0 & 0 & 6 & 3 & 0 \\
\hline Cognitive Log & 0 & 0 & 0 & 0 & 0 & 0 \\
\hline HADS & 0 & 0 & 2 & 0 & 0 & 0 \\
\hline IES & 19 & 0 & 0 & 0 & 0 & 0 \\
\hline$-\quad \mathrm{CSI}$ & 20 & 0 & 1 & 0 & 0 & 0 \\
\hline $\begin{array}{l}\text { Patients referred to } \\
\text { specialised care }\end{array}$ & 6 & 5 & 1 & 1 & 0 & 0 \\
\hline \multicolumn{7}{|l|}{$\begin{array}{l}\text { Quality intervention } \\
\text { grades mean }(S D)\end{array}$} \\
\hline According to patient & $8.0(1.1)$ & $7.2(2.0)$ & $7.0(1.9)$ & $8.0(1.4)$ & $6.0(2.0)$ & 9.0 (n.a.) \\
\hline - According to caregiver & $7.8(1.0)$ & $7.0(2.2)$ & $6.7(1.9)$ & $7.6(1.5)$ & 8.0 (n.a.) & 8.0 (n.a.) \\
\hline \multicolumn{7}{|l|}{$\begin{array}{l}\text { Performance nurse } \\
\text { grades mean }(S D)\end{array}$} \\
\hline - According to patient & $8.3(0.8)$ & $8.0(1.1)$ & $7.1(2.0)$ & $7.7(1.1)$ & $7.7(0.6)$ & 9.0 (n.a.) \\
\hline - According to caregiver & $8.2(0.9)$ & $8.2(1.2)$ & $7.0(2.1)$ & $8.3(0.5)$ & 8.0 (n.a.) & 8.0 (n.a.) \\
\hline
\end{tabular}

CLCE-24 = Checklist Cognition and Emotion

HADS = Hospital Anxiety and Depression Scale

$\mathrm{IES}=$ Impact of Event Scale

$\mathrm{CSI}=$ Caregiver Strain Index

n.a. $=$ not applicable

\section{Discussion}

We have studied the feasibility of an intervention by nurses for people who have survived a cardiac arrest and we found that most patients and caregivers participated and received on average 1.8 consultations. Nurses followed the protocol in most aspects, but the intervention started later after the event than intended, consultations were longer than expected, and selfmanagement was rarely discussed. Overall, the intervention was positively evaluated by patients, caregivers and nurses.

The late start of the intervention, on average 90 days after cardiac arrest instead of the intended one month after discharge, can be mainly contributed to the design and organisational aspects of the ALASCA trial as, prior to randomisation, patients had to be informed about the trial, give their consent and perform the first measurements for the study. One can question whether the delayed start of the intervention may have influenced its effectiveness. We think that performing the first consultation earlier, that is more according to protocol, will probably increase the effectiveness because potential problems are addressed earlier, which may prevent some of the future negative consequences. Also the evaluations from patients, caregivers and nurses have shown that it is important to reduce this delay, which seems feasible in case of implementation of this intervention outside a scientific trial. 
The duration of most consultations was longer than intended, namely 60 - 90 minutes, instead of the intended 60 minutes for first consultations and 30 minutes for subsequent consultations. However, as the number of consultations per patient was lower than we had expected, the total time spent on face-to-face contact was not exceeded.

The most unexpected deviation from protocol was that the topic of self-management was not frequently addressed: only in $19 \%$ of the patients was this topic discussed. Interviews with the nurses revealed that they considered self-management not suitable for this patient group in this phase, which explains why they did not promote it. According to the nurses, the topic of selfmanagement is more appropriate for a later phase, and can be better practised during more extensive interventions. Indeed, most previous studies on self-management have been performed in chronic conditions, ${ }^{19}$ and the two effective self-management interventions for survivors of cardiac arrest were much more elaborate and consisted of eight and eleven sessions respectively. ${ }^{6,7}$ We therefore conclude that it is not feasible to address self-management properly in the current intervention and propose to eliminate it as one of the obligatory elements.

\section{Limitations of the process evaluation}

A risk in evaluation studies is that participants may tend to give socially desirable answers. We tried to prevent this by providing anonymous evaluations forms to patients and caregivers, and by sending out these forms after the intervention had finished.

The interviews and evaluation forms for the nurses were not anonymous. To limit the risk that the nurses would provide socially desirable answers, the interviews were administered by a researcher who was not involved in the trial. Moreover, the nurses did not have any formal or personal relationships with the researchers before or after the trial.

\section{Suggestions for implementation}

This process evaluation has shown that the intervention is sufficiently feasible. However, there can be some tension between 'a flexible intervention' and guaranteeing that certain content is sufficiently addressed. The advantage of a flexible intervention is that it can be tailored to the actual needs of the participants and, in case there are no problems or questions, the number of consultations remains limited, which will positively affect the cost-effectiveness. We have noticed structural differences between the nurses with regard to their performance of the intervention, and believe that the feasibility and reproducibility of the intervention can be improved on some aspects by making several of the optional elements of the intervention more obligatory.

First of all, we suggest offering at least two consultations to all patients. When not taking into account the nurse who had only consulted one patient, the two nurses who consulted patients most frequently also received the highest grades for the intervention and their performance. This suggests that conducting several consultations improves the perceived quality of the intervention. Secondly, we advise administering a formal screening instrument to all patients. The nurses that used the Checklist Cognition and Emotion were very positive about it, and previous research in stroke patients also showed that formal screening significantly contributed to the detection of cognitive and emotional problems. ${ }^{21}$ We think that making such a screening instrument obligatory will secure that 'screening for cognitive and emotional problems' is effectuated in all patients. 
During the trial, most consultations were conducted as home visits. This seemed to be appreciated by the patients, but also demonstrated the disadvantage that it is more time consuming for the nurse. We recommend that home visits should remain possible but suggest combining the consultation with the nurse with regular out-patient consultations with the cardiologist. As such, the extra effort for the patient is limited while it can improve efficiency for the nurse.

\section{Conclusions}

In conclusion, the intervention 'Stand still..., and move on' is a promising intervention, which seems to be feasible and was positively evaluated by patients, caregivers and nurses. Although the intervention was performed according to protocol on most aspects, we have reported a few deviations and we have made recommendations how to address this in future implementation. If the intervention turns out to be (cost-) effective we recommend implementation in regular health care.

\section{Competing interests}

The authors declare that they have no competing interests.

\section{Authors' contributions}

VM was the principle investigator on this project. She was involved in the design of the intervention, the design of the process evaluation, data collection, data analysis and wrote the drafts of the manuscript. JvH contributed to the design of the process evaluation, performed the semi-structured interviews and supervised data analysis. DW was involved in the design of the intervention and the ALASCA trial. JV was the consultant in rehabilitation medicine that the nurses could contact throughout the intervention period. CVH and JV supervised the project and were involved in the design of the intervention, the design of the process evaluation and interpretation of the results. All authors read, critically reviewed and approved the final manuscript.

\section{Acknowledgments}

We would like to acknowledge all patients and caregivers for their participation in this process evaluation and for their valuable suggestions. The nurses are thanked for their efforts, enthusiasm, and their useful feedback. This study was funded by the Netherlands Organization for Health Research and Development (ZON/MW), Fonds Nuts Ohra and Stichting Elisabeth Strouven. The funding agencies were not involved in the design, performance or interpretation of the study. 


\section{References}

1. BusI KM, Greer DM. Hypoxic-ischemic brain injury: pathophysiology, neuropathology and mechanisms. NeuroRehabilitation 2010;26(1):5-13.

2. de Vos R, de Haes HC, Koster RW, de Haan RJ. Quality of survival after cardiopulmonary resuscitation. Arch Intern Med 1999;159(3):249-54.

3. Lundgren-Nilsson A, Rosen H, Hofgren C, Sunnerhagen KS. The first year after successful cardiac resuscitation: function, activity, participation and quality of life. Resuscitation 2005;66(3):285-9.

4. Wachelder EM, Moulaert VR, van Heugten C, Verbunt JA, Bekkers SC, Wade DT. Life after survival: long-term daily functioning and quality of life after an out-of-hospital cardiac arrest. Resuscitation 2009;80(5):517-22.

5. Moulaert VR, Verbunt JA, Bakx WG, et al. 'Stand still ..., and move on', a new early intervention service for cardiac arrest survivors and their caregivers: rationale and description of the intervention. Clin Rehabil 2011;25(10):867-79.

6. Cowan MJ, Pike KC, Budzynski HK. Psychosocial nursing therapy following sudden cardiac arrest: impact on two-year survival. Nurs Res 2001;50(2):68-76.

7. Dougherty $C M$, Thompson EA, Lewis FM. Long-term outcomes of a telephone intervention after an ICD. Pacing Clin Electrophysiol 2005;28(11):1157-67.

8. Moulaert VR, Verbunt JA, van Heugten CM, Wade DT. Cognitive impairments in survivors of out-ofhospital cardiac arrest: A systematic review. Resuscitation 2009;80(3):297-305.

9. Moulaert VR, Wachelder EM, Verbunt JA, Wade DT, van Heugten CM. Determinants of quality of life in survivors of cardiac arrest. J Rehabil Med 2010;42(6):553-8.

10. Moulaert VR, Verbunt JA, van Heugten CM, et al. Activity and Life After Survival of a Cardiac Arrest (ALASCA) and the effectiveness of an early intervention service: design of a randomised controlled trial. BMC Cardiovasc Disord 2007;7(1):26.

11. Saunders RP, Evans MH, Joshi P. Developing a process-evaluation plan for assessing health promotion program implementation: a how-to guide. Health Promot Pract 2005;6(2):134-47.

12. Oakley A, Strange V, Bonell C, Allen E, Stephenson J. Process evaluation in randomised controlled trials of complex interventions. Bmj 2006;332(7538):413-6.

13. van Heugten $C$, Rasquin S, Winkens I, Beusmans G, Verhey F. Checklist for cognitive and emotional consequences following stroke (CLCE-24): development, usability and quality of the self-report version. Clin Neurol Neurosurg 2007;109(3):257-62.

14. Alderson AL, Novack TA. Reliable serial measurement of cognitive processes in rehabilitation: the Cognitive Log. Arch Phys Med Rehabil 2003;84(5):668-72.

15. Spinhoven P, Ormel J, Sloekers PP, Kempen GI, Speckens AE, Van Hemert AM. A validation study of the Hospital Anxiety and Depression Scale (HADS) in different groups of Dutch subjects. Psychol Med 1997;27(2):363-70.

16. Sundin EC, Horowitz MJ. Impact of Event Scale: psychometric properties. Br J Psychiatry 2002;180:2059.

17. Thornton M, Travis SS. Analysis of the reliability of the modified caregiver strain index. J Gerontol $B$ Psychol Sci Soc Sci 2003;58(2):S127-32.

18. Bodenheimer T, Lorig K, Holman H, Grumbach K. Patient self-management of chronic disease in primary care. Jama 2002;288(19):2469-75. 
19. Lorig KR, Holman H. Self-management education: history, definition, outcomes, and mechanisms. Ann Behav Med 2003;26(1):1-7.

20. Jovicic A, Holroyd-Leduc JM, Straus SE. Effects of self-management intervention on health outcomes of patients with heart failure: a systematic review of randomized controlled trials. BMC Cardiovasc Disord 2006;6:43.

21. Edwards DF, Hahn MG, Baum CM, Perlmutter MS, Sheedy C, Dromerick AW. Screening patients with stroke for rehabilitation needs: validation of the post-stroke rehabilitation guidelines. Neurorehabil Neural Repair 2006;20(1):42-8. 


\section{Chapter 8}

\section{Early intervention service 'Stand still ..., and move on' improves quality of life after cardiac arrest: results of a randomised controlled trial}

Submitted as:

Moulaert VR, van Heugten CM, Winkens B, Bakx WGM, de Krom MCFTM, Gorgels APM, Wade DT, Verbunt JA. Early intervention service 'Stand still ..., and move on' improves quality of life after cardiac arrest: results of a randomised controlled trial 


\begin{abstract}
Objective: To investigate the effectiveness of adding a new early intervention service to usual care for survivors of a cardiac arrest and their caregivers.

Design: Multicentre single blind randomised controlled trial with baseline measurements two weeks after the cardiac arrest and follow up measurements at three and twelve months.

Setting: Five hospitals in the Netherlands.

Participants: 185 adult survivors of out-of-hospital or in-hospital cardiac arrest, along with 155 caregivers.

Intervention: The intervention service 'Stand still ..., and move on' was directed at early detection of cognitive and emotional problems, providing information and support, promoting self-management, and referring to specialised care if necessary. The intervention consisted of one to six face-to-face consultations with a trained nurse after hospital discharge. Patients in the control group received usual care.
\end{abstract}

Main outcome measures: Primary outcome measures were the extent of participation in society (Community Integration Questionnaire) and quality of life (SF-36 and EuroQol VAS) of the patient one year after a cardiac arrest. Secondary outcome measures were the level of cognitive functioning, emotional state, extended daily activities and return of work of the patient, as well as quality of life, caregiver strain and emotional state of the caregiver. The effect of the intervention was analysed using 'intention to treat' linear mixed model analyses, with estimated mean differences (EMD) as effect size.

Results: On the primary outcome measures, patients in the intervention group had a significantly better quality of life one year after the cardiac arrest compared with control group patients on the following SF-36 domains: Role Emotional $(E M D=16.38, p=0.006)$, Mental Health (EMD=6.87, $p=0.003)$ and General Health $(E M D=8.07, p=0.010)$, but there was no difference on the level of participation in society. On the secondary outcome measures, patients in the intervention group scored significantly better on overall emotional state (HADS total, EMD=-3.25, $p=0.002$ ) and symptoms of anxiety (HADS anxiety, EMD $=-1.79, p=0.001$ ). Also, three months after the cardiac arrest, 24 people (50\%) in the intervention group were already back at work, compared with 8 people $(21 \%)$ in the control group ( $p=0.006)$, but at 12 months the difference was not significant $(p=0.734)$. No significant differences on caregiver outcomes were found.

Conclusion: This early intervention service resulted in statistically significant and clinically relevant improvements in quality of life and emotional state of survivors of a cardiac arrest, suggesting that quality of care for cardiac arrest survivors can be improved by a service focused on detecting and managing the cognitive and emotional consequences of a cardiac arrest.

Trial registration: Current Controlled Trials ISRCTN74835019. 


\section{What this paper adds}

\section{What is already known on this topic}

- A cardiac arrest can lead to hypoxic-ischaemic brain injury and half of the survivors have some kind of cognitive impairment, but these cognitive impairments are frequently not recognised

- Cardiac arrest survivors can also have emotional problems, decreased participation in society and a lower quality of life, and their caregivers are at risk for high burden and emotional problems

- $\quad$ Up to now, interventions for cardiac arrest survivors have not focused on possible cognitive impairments, but studies on patients with traumatic brain injury suggest that such an approach may have added value

\section{What this study adds}

- A brief early intervention service, which addressed possible cognitive and emotional problems, improved quality of life and emotional state in survivors of cardiac arrest

- After survival of a cardiac arrest, not only cardiac consequences should be monitored, but also possible brain injury related consequences should be screened for

- $\quad$ The intervention did not result in better outcomes for the caregivers

\section{Introduction}

After survival of a cardiac arrest, cognitive impairments are present in about half of the survivors and quality of life can be at risk. ${ }^{1-3}$ Cognitive impairments after cardiac arrest arise from the temporary cessation of blood circulation to the brain leading to hypoxic-ischaemic brain injury. ${ }^{4}$ The most commonly affected cognitive domains are memory, attention and executive functioning. ${ }^{1}$ Emotional problems, such as anxiety and depression, also occur frequently, and a reduced level of participation in society, including low return to work, has been reported. 5,6 Furthermore, caregivers may also experience a high burden and they often have emotional problems, including symptoms of posttraumatic stress. 7,8 Because a cardiac arrest can negatively affect patients and caregivers on all these domains, there is an urgent need for effective interventions that guide patient and caregiver after survival of a cardiac arrest.

Up to now, two psychosocial interventions for cardiac arrest survivors have shown positive effects on mortality, physical and emotional symptoms and knowledge about cardiac arrest and implantable cardioverter defibrillators (ICD's). ${ }^{9,10}$ However, in these studies quality of life was not taken into account and cognitive impairments were not specifically addressed. We take the view that cognitive impairments deserve specific attention, as they are common after cardiac arrest and affect quality of life, but are often not identified by health care professionals. ${ }^{11,12} \mathrm{We}$ therefore developed a new early intervention service for survivors of a cardiac arrest and their caregivers called 'Stand still ..., and move on'. This brief intervention does not only comprise psychosocial and educational aspects, but also includes a screening for cognitive impairments. ${ }^{13}$ 
The goal of the present study was to evaluate the effectiveness of this new intervention service. We expected that the intervention would result in a higher level of participation in society and better quality of life of the cardiac arrest survivors, compared with those who had received usual care only.

\section{Methods}

\section{Study design}

This study, called 'Activity and Life after Survival of a Cardiac Arrest' (ALASCA), was a multicentre single blind randomised controlled trial in which the effect of receiving the new intervention service was compared with care as usual only. The study was registered in a trial register [ISRCTN74835019], and the protocol has been published. ${ }^{14}$

We made some minor changes to protocol. We replaced multiple regression analysis with a more advanced and powerful statistical technique, linear mixed models, which has the following advantages: it is more suitable for repeated measures as it takes baseline level into account, and it can handle missing items. As a consequence, it was not necessary anymore to impute any missing items.

\section{Participants}

Inclusion criteria for the study were: survival more than two weeks after an in-hospital or out-ofhospital cardiac arrest, living within $50 \mathrm{~km}$ of one of the participating hospitals, age 18 years or older, and sufficient knowledge of the Dutch language. Exclusion criteria were a life expectancy less than three months, as estimated by the treating physician, and living in residential or institutional care prior to the cardiac arrest.

In this study, caregiver was defined as partner, spouse, or significant other who was closely related to the patient. There were no additional in- or exclusion criteria for the caregivers. If a patient had a partner or a spouse, this person was asked to participate in the trial together with the patient. If the patient did not have partner or a spouse, we asked the patient to assign another person as caregiver, but this was not obligatory.

\section{Setting}

Participants were recruited from the coronary care units and intensive care units of five hospitals in the Southern part of the Netherlands, from April 2007 to December 2010. The adherence area of the participating hospitals covers approximately one million inhabitants. All hospitals had protocols for care of resuscitation patients in line with international guidelines and performed therapeutic hypothermia and pacemaker implantations. ${ }^{15}$ In addition, two of the hospitals undertook percutaneous coronary interventions, ICD implantations, catheter ablations, and coronary artery bypass grafts. Throughout the study period, medical care for cardiac arrest patients in the participating hospitals remained unchanged.

\section{Intervention}

Patients in the intervention group received the early intervention service called 'Stand still ..., and move on' in addition to usual health care. This intervention is a short duration, individualised, semi-structured intervention for survivors of cardiac arrest and their caregivers, which consists 
of four elements: 1) screening for cognitive and emotional problems; 2) provision of support and information on cardiac arrest and possible neurological consequences; 3) promotion of selfmanagement strategies and 4) referral to specialised care if indicated..$^{13}$ The intervention was conducted by trained nurses, started after discharge from the hospital and comprised face-toface consultations at the patients' home or at an outpatient clinic. The number of consultations could vary from one to six, depending on the individual needs of patient and caregiver, and additional consultation by telephone was possible.

In the design of the intervention, current evidence on effective interventions for related patients groups, including patients with coronary artery disease, heart failure and traumatic brain injury, was incorporated. More details on the rationale and content of the intervention, as well as training of the nurses, have been published earlier. ${ }^{13}$ Furthermore, we have conducted a process evaluation to investigate actual delivery of the intervention, which showed that the intervention was performed largely according to protocol, except that the intervention usually started later than intended, consultations were longer than expected, and the topic of self-management was not regularly addressed. ${ }^{16}$

\section{Care as usual}

This new service was set in the context of and added to standard care. All participating hospitals had general outpatient cardiac rehabilitation programmes, in which patients could enrol at indication of their cardiologist. ${ }^{17}$ However, no specific programmes for cardiac arrest survivors were present, and specific attention for cognitive impairments was not included.

\section{Procedure}

Newly admitted survivors of cardiac arrest were assessed for their eligibility in the study and potential participants were approached between three and ten days after their cardiac arrest. Patients and caregivers signed an informed consent form if they decided to participate. In case of unconsciousness or incapacity of the patient, the caregiver was asked for provisional informed consent, which had to be confirmed by the patient when capacity was regained.

Baseline measurements were planned two weeks after the cardiac arrest, with follow up measurements at three and twelve months. At baseline, the level of daily functioning and participation in society prior to the cardiac arrest were assessed. Research assistants visited the patients at their residence to perform the measurements. The Medical Ethics Committee of Maastricht University Medical Centre approved the study protocol.

\section{Outcome measures}

Primary outcome measures were participation in society and quality of life of the cardiac arrest survivor one year after the cardiac arrest. 
Participation in society was measured with the Community Integration Questionnaire (CIQ), a 15 -item questionnaire with scores ranging from 0 to 29 , with higher scores reflecting a better participation. ${ }^{18}$

Quality of life was measured with the Medical Outcomes Study 36-item Short Form Health Survey (SF-36 / RAND-36) and the EuroQol VAS. The SF-36 is a 36-item generic quality of life questionnaire which measures eight domains of perceived health: Physical Functioning, Social Functioning, Role Physical, Role Emotional, Mental Health, Vitality, Bodily Pain and General Health. Domain scores range from 0 to $100 .{ }^{19}$ The EuroQol VAS is a visual analogue scale which asks for a personal rating of current general health state on a scale ranging from 0 to $100 .{ }^{20}$ For both quality of life measures, higher scores indicate a better quality of life.

Secondary outcome measures were the level of cognitive functioning, emotional state, extended daily activities and return to work of the patient, as well as quality of life, caregiver strain and emotional state of the caregiver.

Cognitive functioning was measured on the following domains: overall cognitive status (Cognitive Log), ${ }^{21}$ information processing speed (Adult Memory and Information Processing Battery Task A), ${ }^{22}$ verbal fluency (Verbal Fluency Test), ${ }^{23}$ attention (Trail Making Test A and B) ${ }^{24}$ and memory (Paragraph Recall, immediate and delayed). ${ }^{25}$ Cognitive complaints were measured with the Cognitive Failures Questionnaire (CFQ), a 25-item questionnaire on self-reported cognitive failures, with scores ranging from 0 to 100 . Higher scores on the CFQ indicate more perceived cognitive failures. ${ }^{26}$

Emotional state was measured with the Hospital Anxiety and Depression Scale (HADS), a 14 item questionnaire with subscales Anxiety and Depression. Total scores range from 0 to 42 , and both subscales range from 0 to 21 . Higher scores reflect more emotional problems. ${ }^{27}$ Furthermore, symptoms of posttraumatic stress were measured with the Impact of Event Scale (IES), with scores ranging from 0 to 75, higher scores indicating more symptoms of posttraumatic stress. ${ }^{28}$

Basic personal activities of daily living ( $A D L$ ) were measured, only at baseline, with the Barthel Index (BI), a scale ranging from 0 to 20, with higher scores reflecting a higher level of independence. ${ }^{29}$ Extended daily activities were measured with the Frenchay Activities Index (FAI), scores range from 0 to 45, with higher scores representing a higher level of activities. ${ }^{30}$

Work status was monitored at 3 and 12 months, and return to work was defined as partial or complete return to a paid job.

Socio-demographical and medical variables were recorded at baseline.

Caregiver strain was measured with the Caregiver Strain Index (CSI), a 13-item scale with dichotomous items. Scores range from 0 to 13, with higher scores reflecting a higher caregiver strain. ${ }^{31}$ For measurement of quality of life and emotional state of the caregivers the same instruments were as used for the patients. More details on the measurement instruments can be found in the study protocol. ${ }^{14}$

\section{Sample size and power calculation}

The Community Integration Questionnaire (CIQ) was used to perform a power calculation and determine sample size. Since no studies on survivors of cardiac arrest using this outcome measure 
were available at the start of the study, CIQ scores of patients with traumatic brain injury were used as a reference value (mean 16.09 (SD 4.20).32 Sample size calculation (independent-samples t-test, one-sided testing), with an assumed clinical relevant difference between groups of at least $10 \%$, an alpha of 0.05 and a power $(1-\beta)$ of 0.8 , showed that 84 patients were necessary in each group, resulting in a target sample size of 168 patients. With an estimated loss to follow-up of $15 \%$, we aimed to include 200 participants.

\section{Randomisation and blinding}

Participants were randomly allocated to either the intervention group or the control group, with a 1:1 allocation ratio. Randomisation took place after the baseline measurements. The randomisation procedure was performed centrally by the project leader using a computerised block randomisation containing blocks of 15. The randomisation scheme included stratification on two variables, namely hospital site and location of the cardiac arrest (in-hospital versus out-of hospital). For each hospital site, two series of numbered opaque envelopes were prepared, filled with cards indicating group allocation. After completion of baseline measurements, the next consecutive envelope in a series was opened and the patient was informed by postal mail about group allocation.

Research assistants administered the assessments and were blinded for group allocation. To check success of blinding, they were asked to indicate group allocation for all participants who completed the trial, choosing one of the following options: 'Intervention group', 'Control group' or 'I don't know'.

\section{Statistical analysis}

Baseline characteristics were presented by mean (SD) or median (range, i.e. minimum - maximum) for numerical variables, and number (\%) for categorical variables. No imputation of missing data was performed.

To check for selection bias, baseline characteristics (age and gender) of compliant and noncompliant patients were compared. To check for selective dropout of participants, differences between participants who completed the trial and dropouts were examined on the following baseline characteristics: age, gender, initial overall cognitive status, basic ADL and caregiver strain. Group differences were studied using independent-samples t-test (continuous variables with normal distribution), Mann Whitney U-test (continuous variables with non-normal distribution) or Chi-square test (dichotomous variables).

To assess the longitudinal effect of the intervention, we performed linear mixed model analyses, according to the intention to treat principle, with the primary and secondary outcome measures as dependent variables. The following variables were entered as fixed terms: Hospital, Location of cardiac arrest, Time and the interaction term Group*Time. An unstructured covariance structure for the repeated measures was assumed, restricted maximum likelihood estimation was used and significance was based on likelihood ratio tests. Differences in proportions of persons who had returned to work at 3 and 12 months were analysed separately using Chi-square test.

Additionally, per protocol analyses were performed, incorporating only those patients in the intervention group who had received the intervention, and results were compared with intention to treat analyses. 
As multiple primary and secondary outcome measures were tested, $\mathrm{p} \leq 0.01$ (two-sided) were considered statistically significant. Effect sizes were reported as estimated mean differences (EMD). Effects were considered clinically relevant only if the estimated mean difference indicated an improvement of $10 \%$ or more compared with the observed mean in the control group.

Statistical analyses were performed using IBM SPSS Statistics for Windows, version 21.0.

\section{Results}

\section{Participants}

Figure 1 presents the flow of participants through the study. Overall, 185 patients were included in the study, of whom 143 (77\%) completed the trial. Patient recruitment took longer than expected, for which the recruitment period was prolonged from April 2010 to December 2010. In December 2010 patient recruitment was stopped for logistical and financial reasons.

The group of patients who refused to participate were significantly older (mean 67 (SD 12) years versus 60 (SD 12) years, $\mathrm{p}<0.001$ ), and consisted of a significantly lower percentage of males (69\% versus $83 \%, p=0.007)$.

Participants who dropped out during the trial had a small but significantly lower overall cognitive status at baseline compared with those who completed the trial: median score 26 (range 7 - 30) versus 27 (range 17 - 30) $(p=0.012)$.

Baseline assessments were performed after a median of 24 days after the cardiac arrest (range 9 - 70 days), with 3- and 12-months follow up assessments at a median of 96 days (range 74 162) and 369 days (range 353 - 471), respectively. Table 1 shows the baseline characteristics of the patients.

In addition to the 185 patients, 155 caregivers participated in the study. Their relation to the patient was spouse/ partner $(n=138,89 \%)$, child $(n=8,5 \%)$, parent $(n=2,1 \%)$, sibling $n=4,3 \%)$, or friend/other $(n=3,2 \%)$. Caregivers had a mean age of 55 years (SD 12), and 134 (87\%) were female.

The percentage of missing items on the questionnaires was less than $3 \%$. 


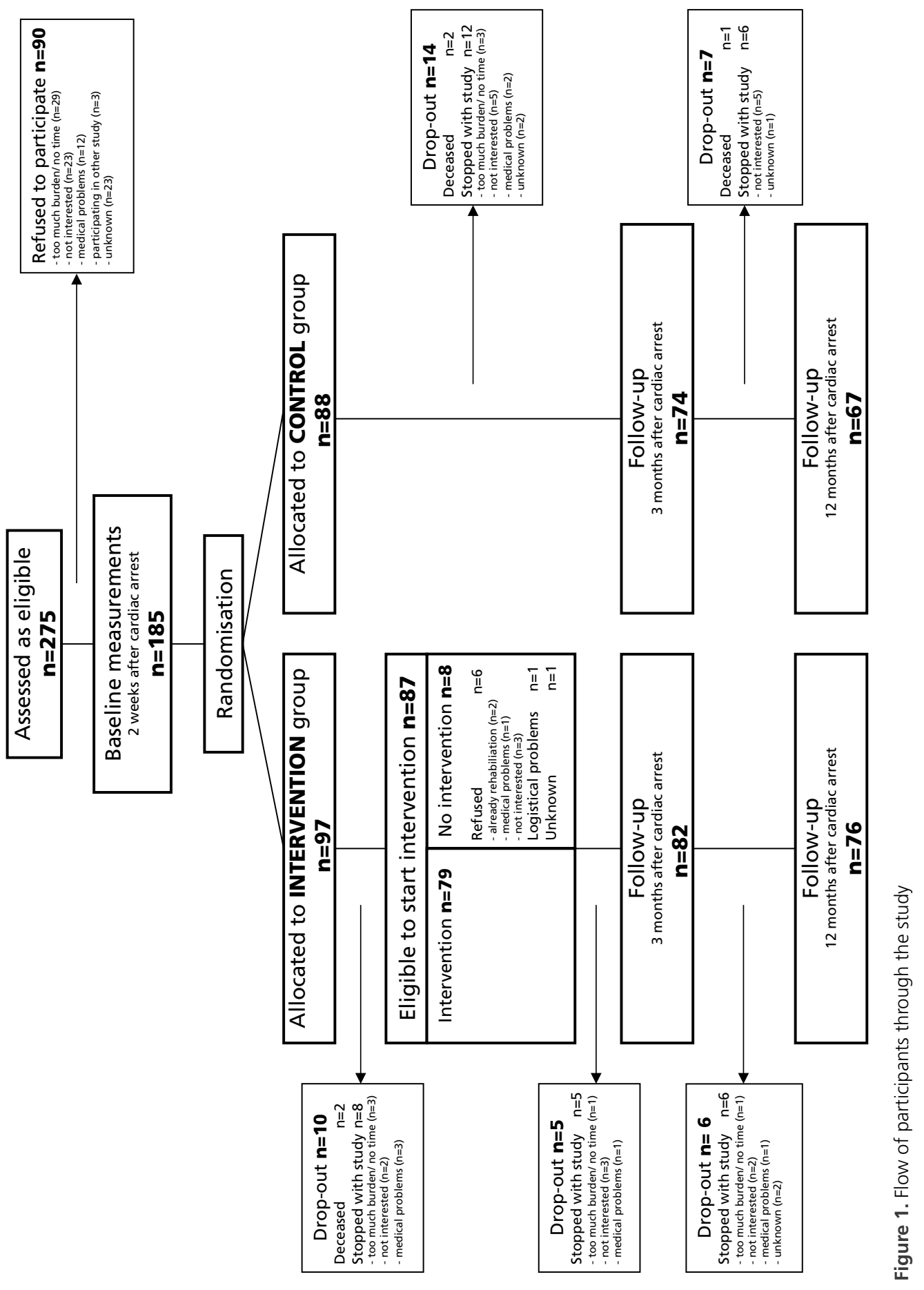


Table 1. Baseline characteristics patients

\begin{tabular}{|c|c|c|c|c|}
\hline & & INTERVENTION $\mathrm{n}=97$ & & CONTROL $n=88$ \\
\hline Socio-demographical variables & $\mathbf{n}$ & & & \\
\hline Male, $\mathrm{n}(\%)$ & 97 & $80(83 \%)$ & 88 & $74(84 \%)$ \\
\hline Age in years, mean (SD) & 97 & 60 (SD 12) & 88 & $60($ SD 12) \\
\hline Marital status, $\mathrm{n}(\%)$ & 90 & & 88 & \\
\hline married / living with partner & & $78(87 \%)$ & & $71(84 \%)$ \\
\hline single/ divorced/ widowed & & $12(13 \%)$ & & $14(16 \%)$ \\
\hline Highest level of education, $\mathrm{n}(\%)$ & 91 & & 85 & \\
\hline basic education & & $37(41 \%)$ & & $35(41 \%)$ \\
\hline further education & & $29(32 \%)$ & & $29(34 \%)$ \\
\hline higher education & & $25(27 \%)$ & & $21(25 \%)$ \\
\hline Employment status, premorbid, $\mathrm{n}(\%)$ & 91 & & 84 & \\
\hline paid job & & $44(48 \%)$ & & $45(54 \%)$ \\
\hline retired/ disability pension & & $36(40 \%)$ & & $32(38 \%)$ \\
\hline sick leave & & $3(3 \%)$ & & $1(1 \%)$ \\
\hline Medical history, n (\%) & 91 & & 82 & \\
\hline no cardiovascular history & & $37(41 \%)$ & & $29(35 \%)$ \\
\hline hypertension & & $27(30 \%)$ & & $23(28 \%)$ \\
\hline myocardial infarction & & $21(23 \%)$ & & $28(34 \%)$ \\
\hline heart failure & & $3(3 \%)$ & & $7(9 \%)$ \\
\hline cardiac arrest & & $1(1 \%)$ & & $1(1 \%)$ \\
\hline CABG & & $8(8 \%)$ & & $6(7 \%)$ \\
\hline arrhythmia & & $8(8 \%)$ & & $9(10 \%)$ \\
\hline diabetes mellitus & & $14(15 \%)$ & & $10(12 \%)$ \\
\hline neurological history & & $8(9 \%)$ & & $10(12 \%)$ \\
\hline \multicolumn{5}{|l|}{ Characteristics cardiac arrest, n (\%) } \\
\hline cardiac cause & 79 & $77(98 \%)$ & 81 & $77(95 \%)$ \\
\hline location out-of-hospital & 97 & $77(79 \%)$ & 88 & $70(80 \%)$ \\
\hline witnessed cardiac arrest & 95 & $89(94 \%)$ & 86 & $83(97 \%)$ \\
\hline bystander CPR & 92 & $83(90 \%)$ & 85 & $76(89 \%)$ \\
\hline initial cardiac rhythm VFNT & 82 & $80(98 \%)$ & 77 & $71(92 \%)$ \\
\hline time collapse - ROSC, minutes & 41 & $10(0-70)$ & 44 & $10(0-60)$ \\
\hline duration coma, in days & 63 & $1(0-17)$ & 58 & $2(0-19)$ \\
\hline Medical interventions, $\mathrm{n}(\%)$ & 92 & & 85 & \\
\hline therapeutic hypothermia & & $44(48 \%)$ & & $38(45 \%)$ \\
\hline catheterisation with $\mathrm{PCl}$ & & $41(44 \%)$ & & $37(44 \%)$ \\
\hline CABG & & $10(11 \%)$ & & $13(15 \%)$ \\
\hline ICD/pacemaker & & $21(23 \%)$ & & $24(22 \%)$ \\
\hline Location of discharge, $\mathrm{n}(\%)$ & 92 & & 80 & \\
\hline home & & $80(87 \%)$ & & $71(89 \%)$ \\
\hline rehabilitation centre & & $7(8 \%)$ & & $8(10 \%)$ \\
\hline nursing home & & $5(5 \%)$ & & $1(1 \%)$ \\
\hline \multicolumn{5}{|l|}{ Baseline functioning, n (\%) } \\
\hline LVEF \% at discharge, median (range) & 31 & $44(10-67)$ & 32 & $44(20-60)$ \\
\hline NYHA classification, $\mathrm{n}(\%)$ & 83 & & 84 & \\
\hline 1 & & $35(42 \%)$ & & $34(41 \%)$ \\
\hline 2 & & $31(37 \%)$ & & $38(45 \%)$ \\
\hline 3 & & $9(11 \%)$ & & $7(8 \%)$ \\
\hline 4 & & $8(10 \%)$ & & $5(6 \%)$ \\
\hline Barthel Index, mean (SD) & 84 & $18.12(S D 3.61)$ & 82 & $18.63(\mathrm{SD} 3.02)$ \\
\hline
\end{tabular}

CABG $=$ Coronary Artery Bypass Graft

$\mathrm{CPR}=$ Cardiopulmonary Resuscitation

$\mathrm{VF}=$ Ventricular Fibrillation

$\mathrm{VT}=$ Ventricular Tachycardia

ROSC = Return Of Spontaneous Circulation

$\mathrm{PCl}=$ Percutaneous Coronary Intervention

$I C D=$ Implantable Cardioverter Defibrillator

LVEF = Left Ventricular Ejection Fraction

NYHA $=$ New York Heart Association 


\section{Effect of the intervention}

Table 2 presents the effects of the intervention and reports observed means of the primary and secondary outcome measures prior to the cardiac arrest or at baseline and after 3 and 12 months, as well as the estimated mean differences between the intervention and control group at 3 and 12 months, obtained from the linear mixed model. At baseline, there were no significant differences between the intervention and control group.

The effect analyses of the primary outcome measures showed no significant differences with regard to participation in society, but there were significant differences in estimated means at 12 months in favour of the intervention group on quality of life on three domains of the SF36, namely Role Emotional ( $p=0.006)$, Mental Health $(p=0.003)$, and General Health $(p=0.010)$. Estimated mean differences showed improvements of $24 \%$ on Role Emotional, $9 \%$ on Mental Health and $13 \%$ on General Health, compared with observed means in the control group.

On the secondary outcome measures, significant improvements were seen at 12 months on HADS total score $(p=0.002)$ and HADS anxiety subscale $(p=0.001)$, with estimated mean differences being $40 \%$ and $43 \%$ higher compared with observed means in the control group. Return to work was, at three months, significantly higher in the intervention group: in the intervention group 24 people (50\%) had already returned to work, compared with 8 people (21\%) in the control group ( $p=0.006)$. But at twelve months there was no significant difference in employment status, with return to work of 32 people $(74 \%)$ in the intervention group, and 27 people $(71 \%)$ in the control group $(p=0.734)$.

No significant effects were found on the outcome measures of the caregivers (Table 3 ).

Per protocol analyses showed similar results as intention to treat analyses.

\section{Success of blinding}

Research assistants filled out the question about group allocation for 134 of the 143 patients who had completed the trial. In seventy-one cases (53\%) group allocation was indicated correctly, in 33 cases $(25 \%)$ incorrectly, and in 29 cases $(22 \%)$ the research assistants indicated that they 'did not know'. 
Table 2. Patient outcomes and effect of the intervention

\begin{tabular}{|c|c|c|c|c|c|c|}
\hline & INTERVENTION & CONTROL & & & & \\
\hline & $\begin{array}{l}\text { Observed } \\
\text { mean (SD) }\end{array}$ & $\begin{array}{l}\text { Observed } \\
\text { mean (SD) }\end{array}$ & $\begin{array}{l}\text { Estimated mean } \\
\text { difference }\end{array}$ & $\begin{array}{l}\text { Lower } \\
95 \% \mathrm{Cl}\end{array}$ & $\begin{array}{l}\text { Upper } \\
95 \% \mathrm{Cl}\end{array}$ & p-value \\
\hline \multicolumn{7}{|c|}{ PRIMARY OUTCOMES } \\
\hline \multicolumn{7}{|c|}{ Participation } \\
\hline \multicolumn{7}{|c|}{ Community Integration Questionnaire } \\
\hline - premorbid & $15.59(4.77)$ & $16.17(4.34)$ & & & & \\
\hline-3 months & $13.99(4.79)$ & $13.70(5.47)$ & 0.21 & -1.24 & 1.67 & 0.770 \\
\hline - 12 months & $16.16(4.68)$ & $14.60(5.16)$ & 1.19 & -0.06 & 2.45 & 0.062 \\
\hline \multicolumn{7}{|c|}{ Quality of life } \\
\hline \multicolumn{7}{|c|}{ SF-36 Physical Functioning } \\
\hline - baseline & $59.16(28.44)$ & $54.11(26.00)$ & & & & \\
\hline - 3 months & $73.44(25.69)$ & $69.71(25.46)$ & 1.87 & -4.54 & 8.29 & 0.565 \\
\hline - 12 months & $78.47(25.03)$ & $73.05(27.37)$ & 4.59 & -2.74 & 11.93 & 0.218 \\
\hline \multicolumn{7}{|c|}{ SF-36 Social Functioning } \\
\hline - baseline & $54.55(28.31)$ & $52.56(28.37)$ & & & & \\
\hline - 3 months & 71.05 (25.18) & $70.96(24.67)$ & -0.58 & -8.46 & 7.31 & 0.885 \\
\hline - 12 months & $81.77(21.08)$ & $79.88(23.21)$ & 2.95 & -4.19 & 10.09 & 0.416 \\
\hline \multicolumn{7}{|c|}{ SF-36 Role Physical } \\
\hline - baseline & $23.46(33.85)$ & $23.77(34.21)$ & & & & \\
\hline - 3 months & $42.67(41.26)$ & 33.09 (40.39) & 9.76 & -3.06 & 22.59 & 0.135 \\
\hline - 12 months & $66.90(41.36)$ & $59.61(43.23)$ & 7.95 & -5.75 & 21.65 & 0.253 \\
\hline \multicolumn{7}{|c|}{ SF-36 Role Emotional } \\
\hline - baseline & $52.19(44.00)$ & $56.91(42.39)$ & & & & \\
\hline-3 months & $69.66(42.02)$ & $62.75(44.06)$ & 8.26 & -5.03 & 21.56 & 0.221 \\
\hline - 12 months & $84.04(32.30)$ & $69.27(41.70)$ & 16.38 & 4.82 & 27.93 & 0.006 \\
\hline \multicolumn{7}{|c|}{ SF-36 Mental Health } \\
\hline - baseline & $71.51(22.13)$ & $73.90(19.29)$ & & & & \\
\hline-3 months & $76.21(19.26)$ & $76.81(18.68)$ & 0.59 & -4.11 & 5.29 & 0.805 \\
\hline - 12 months & $81.35(14.78)$ & $76.06(17.27)$ & 6.87 & 2.41 & 11.33 & 0.003 \\
\hline \multicolumn{7}{|c|}{ SF-36 Vitality } \\
\hline - baseline & $56.65(24.48)$ & $56.95(23.08)$ & & & & \\
\hline-3 months & $64.04(19.87)$ & $64.42(19.66)$ & 0.54 & -4.49 & 5.59 & 0.831 \\
\hline - 12 months & $65.83(19.41)$ & $62.23(19.94)$ & 5.07 & -0.28 & 10.41 & 0.063 \\
\hline \multicolumn{7}{|c|}{ SF-36 Bodily Pain } \\
\hline - baseline & $58.55(27.74)$ & $57.77(29.97)$ & & & & \\
\hline-3 months & $76.45(24.38)$ & $71.13(26.46)$ & 6.58 & -0.89 & 14.05 & 0.084 \\
\hline - 12 months & $86.03(21.29)$ & $76.69(26.16)$ & 9.46 & 1.81 & 17.10 & 0.016 \\
\hline \multicolumn{7}{|c|}{ SF-36 General Health } \\
\hline - baseline & $56.95(20.93)$ & $61.22(19.68)$ & & & & \\
\hline-3 months & $60.06(23.36)$ & $61.32(20.44)$ & 2.63 & -2.42 & 7.68 & 0.305 \\
\hline - 12 months & $64.79(22.35)$ & $60.00(22.04)$ & 8.07 & 1.99 & 14.15 & 0.010 \\
\hline \multicolumn{7}{|c|}{ EuroQol VAS } \\
\hline - baseline & $61.01(18.91)$ & $61.18(18.62)$ & & & & \\
\hline - 3 months & $70.95(17.06)$ & $71.30(15.95)$ & -0.25 & -4.85 & 4.35 & 0.915 \\
\hline - 12 months & $75.90(16.50)$ & $74.32(14.45)$ & 1.76 & -2.80 & 6.32 & 0.447 \\
\hline \multicolumn{7}{|c|}{ SECONDARY OUTCOMES } \\
\hline \multicolumn{7}{|c|}{ Cognitive functioning } \\
\hline \multicolumn{7}{|c|}{ Cognitive Log } \\
\hline - baseline & $26.39(3.43)$ & $26.04(3.28)$ & & & & \\
\hline-3 months & $26.81(3.06)$ & $27.18(2.43)$ & -0.53 & -1.28 & 0.22 & 0.167 \\
\hline - 12 months & $27.24(2.58)$ & $27.27(2.64)$ & -0.08 & -0.81 & 0.66 & 0.833 \\
\hline
\end{tabular}




\begin{tabular}{|c|c|c|c|c|c|c|}
\hline \multicolumn{7}{|c|}{ AMIPB task A } \\
\hline - baseline & $27.44(10.70)$ & $28.30(9.65)$ & & & & \\
\hline-3 months & $30.47(9.84)$ & 30.97 (9.49) & -0.15 & -1.96 & 1.67 & 0.874 \\
\hline - 12 months & $31.61(10.07)$ & $32.48(9.84)$ & 0.05 & -2.03 & 2.14 & 0.961 \\
\hline \multicolumn{7}{|c|}{ Verbal fluency } \\
\hline - baseline & $19.41(6.56)$ & $18.86(6.35)$ & & & & \\
\hline - 3 months & $21.05(7.67)$ & $21.81(6.34)$ & -1.40 & -2.97 & 0.18 & 0.082 \\
\hline - 12 months & $22.50(7.49)$ & $23.33(6.99)$ & -1.28 & -3.13 & 0.58 & 0.175 \\
\hline \multicolumn{7}{|c|}{ Trail Making Test $A^{*}$} \\
\hline - baseline & $46.51(32.63)$ & $47.23(21.60)$ & & & & \\
\hline - 3 months & $41.89(24.60)$ & $45.75(26.38)$ & 0.38 & -4.29 & 5.05 & 0.873 \\
\hline - 12 months & $44.96(32.75)$ & $41.97(24.84)$ & 5.13 & -1.23 & 11.49 & 0.113 \\
\hline \multicolumn{7}{|c|}{ Trail Making Test B* } \\
\hline - baseline & $123.83(104.52)$ & $129.48(93.49)$ & & & & \\
\hline - 3 months & $112.71(89.62)$ & $111.11(65.56)$ & 0.35 & -14.10 & 14.80 & 0.962 \\
\hline - 12 months & $103.26(92.75)$ & $109.08(73.28)$ & -10.53 & -23.97 & 2.92 & 0.124 \\
\hline \multicolumn{7}{|c|}{ Paragraph recall direct } \\
\hline - baseline & $6.61(3.37)$ & $6.34(2.72)$ & & & & \\
\hline-3 months & $7.01(3.46)$ & $7.49(2.95)$ & -0.64 & -1.48 & 0.19 & 0.132 \\
\hline - 12 months & $6.84(3.02)$ & $7.03(2.96)$ & -0.19 & -0.99 & 0.61 & 0.633 \\
\hline \multicolumn{7}{|c|}{ Paragraph recall delayed } \\
\hline - baseline & $4.88(3.14)$ & $4.39(2.56)$ & & & & \\
\hline-3 months & $5.99(3.79)$ & $6.41(3.10)$ & -0.82 & -1.70 & 0.06 & 0.069 \\
\hline - 12 months & $5.27(3.17)$ & $5.70(2.81)$ & -0.61 & -1.41 & 0.18 & 0.130 \\
\hline \multicolumn{7}{|c|}{ Cognitive Failures Questionnaire* } \\
\hline - baseline & $24.70(15.38)$ & $22.55(13.94)$ & & & & \\
\hline-3 months & $26.25(16.32)$ & $22.66(14.68)$ & 2.28 & -1.26 & 5.81 & 0.205 \\
\hline - 12 months & $25.20(15.14)$ & $26.48(15.57)$ & -1.31 & -5.25 & 2.64 & 0.513 \\
\hline \multicolumn{7}{|c|}{ Emotional state } \\
\hline \multicolumn{7}{|c|}{ HADS Total* } \\
\hline - baseline & $10.13(8.79)$ & $9.27(7.87)$ & & & & \\
\hline-3 months & $8.32(7.11)$ & $7.42(6.73)$ & 0.20 & -1.62 & 2.02 & 0.827 \\
\hline - 12 months & $5.74(6.02)$ & $8.22(7.50)$ & -3.25 & -5.26 & -1.24 & 0.002 \\
\hline \multicolumn{7}{|c|}{ HADS Anxiety* } \\
\hline - baseline & $5.33(5.09)$ & $4.62(4.14)$ & & & & \\
\hline - 3 months & $3.99(3.53)$ & $4.25(3.80)$ & -0.69 & -1.65 & 0.27 & 0.157 \\
\hline - 12 months & $2.83(3.06)$ & $4.18(4.06)$ & -1.79 & -2.85 & -0.72 & 0.001 \\
\hline \multicolumn{7}{|c|}{ HADS Depression* } \\
\hline - baseline & $4.83(4.34)$ & $4.64(4.45)$ & & & & \\
\hline-3 months & $4.33(4.13)$ & $3.27(3.40)$ & 0.87 & -0.18 & 1.91 & 0.103 \\
\hline - 12 months & $2.90(3.46)$ & $4.03(4.07)$ & -1.36 & -2.50 & -0.22 & 0.020 \\
\hline \multicolumn{7}{|c|}{ Impact of Event Scale* } \\
\hline - baseline & $18.39(18.07)$ & $19.11(15.28)$ & & & & \\
\hline-3 months & $19.21(18.39)$ & $15.17(15.40)$ & 3.83 & -0.26 & 7.92 & 0.066 \\
\hline - 12 months & $11.81(14.56)$ & $16.78(16.31)$ & -4.18 & -8.66 & 0.31 & 0.068 \\
\hline \multicolumn{7}{|c|}{ Extended daily activities } \\
\hline \multicolumn{7}{|c|}{ Frenchay Activity Index } \\
\hline - premorbid & $26.48(7.51)$ & $26.35(7.44)$ & & & & \\
\hline-3 months & $23.15(9.63)$ & $22.71(9.70)$ & 0.32 & -2.09 & 2.73 & 0.794 \\
\hline - 12 months & $26.02(8.60)$ & $25.89(8.47)$ & -0.76 & -2.84 & 1.32 & 0.472 \\
\hline $\begin{array}{l}\text { * Outcome } \\
\text { SD = standar } \\
\mathrm{CI}=\text { confider } \\
\text { AMIPB = Adu } \\
\text { HADS = HosI }\end{array}$ & $\begin{array}{l}\text { Processing Batt } \\
\text { Scale }\end{array}$ & tter functioning & & & & \\
\hline
\end{tabular}


Table 3. Caregiver outcomes and effect of the intervention

\begin{tabular}{|c|c|c|c|c|c|c|}
\hline & INTERVENTION & CONTROL & & & & \\
\hline & $\begin{array}{l}\text { Observed } \\
\text { mean (SD) }\end{array}$ & $\begin{array}{l}\text { Observed } \\
\text { mean (SD) }\end{array}$ & $\begin{array}{l}\text { Estimated mean } \\
\text { difference }\end{array}$ & $\begin{array}{l}\text { Lower } \\
95 \% \mathrm{Cl}\end{array}$ & $\begin{array}{l}\text { Upper } \\
95 \% \mathrm{Cl}\end{array}$ & p-value \\
\hline Quality of I & & & & & & \\
\hline SF-36 Physi & & & & & & \\
\hline - baseline & $82.63(23.06)$ & $81.11(21.55)$ & & & & \\
\hline - 3 months & $84.39(22.27)$ & $84.91(18.67)$ & -2.45 & -6.36 & 1.45 & 0.216 \\
\hline - 12 months & $85.00(19.46)$ & $82.84(21.27)$ & 1.96 & -2.38 & 6.30 & 0.372 \\
\hline SF-36 Socia & & & & & & \\
\hline - baseline & $64.10(28.37)$ & $64.29(28.50)$ & & & & \\
\hline - 3 months & $78.86(23.88)$ & 79.09 (21.79) & -0.33 & -7.88 & 7.23 & 0.932 \\
\hline - 12 months & $87.30(17.60)$ & $83.00(21.69)$ & 2.81 & -4.00 & 9.61 & 0.416 \\
\hline SF-36 Role & & & & & & \\
\hline - baseline & $63.61(40.79)$ & $60.21(44.03)$ & & & & \\
\hline - 3 months & $72.79(40.23)$ & 76.79 (34.99) & -8.33 & -19.77 & 3.10 & 0.152 \\
\hline - 12 months & $79.84(35.60)$ & 77.55 (36.17) & 1.48 & -10.66 & 13.62 & 0.809 \\
\hline SF-36 Role & & & & & & \\
\hline - baseline & $52.50(44.93)$ & $50.00(47.14)$ & & & & \\
\hline - 3 months & $67.65(42.70)$ & $67.86(41.18)$ & -3.38 & -17.13 & 10.38 & 0.628 \\
\hline - 12 months & $86.02(31.68)$ & 79.74 (33.39) & 3.28 & -8.01 & 14.56 & 0.567 \\
\hline SF-36 Ment & & & & & & \\
\hline - baseline & $60.68(19.42)$ & $57.63(24.77)$ & & & & \\
\hline - 3 months & $72.46(17.92)$ & $74.57(19.79)$ & -2.59 & -8.12 & 2.95 & 0.357 \\
\hline - 12 months & $80.06(14.48)$ & $75.92(17.50)$ & 2.16 & -2.98 & 7.31 & 0.406 \\
\hline SF-36 Vitali & & & & & & \\
\hline - baseline & $54.81(21.92)$ & $53.59(22.57)$ & & & & \\
\hline - 3 months & $65.80(19.19)$ & $63.30(22.79)$ & 2.03 & -3.82 & 7.89 & 0.493 \\
\hline - 12 months & $70.97(17.10)$ & $64.61(21.70)$ & 4.66 & -1.25 & 10.57 & 0.121 \\
\hline SF-36 Bodil & & & & & & \\
\hline - baseline & $79.46(23.14)$ & 77.13 (23.94) & & & & \\
\hline - 3 months & $77.23(22.17)$ & 77.69 (20.93) & -1.89 & -7.97 & 4.19 & 0.539 \\
\hline - 12 months & $82.19(21.20)$ & $79.67(24.07)$ & 2.06 & -5.40 & 9.53 & 0.585 \\
\hline SF-36 Gene & & & & & & \\
\hline - baseline & $64.81(18.66)$ & 67.07 (20.95) & & & & \\
\hline - 3 months & $69.93(17.85)$ & $68.48(20.04)$ & 3.76 & -0.86 & 8.37 & 0.110 \\
\hline - 12 months & $69.35(18.34)$ & $68.27(22.40)$ & 2.91 & -2.82 & 8.65 & 0.317 \\
\hline EuroQol VA & & & & & & \\
\hline - baseline & $76.03(15.22)$ & $75.83(16.01)$ & & & & \\
\hline - 3 months & 78.76 (13.39) & 76.70 (18.19) & 2.59 & -1.95 & 7.12 & 0.261 \\
\hline - 12 months & $81.69(15.02)$ & $77.12(16.70)$ & 4.56 & -0.58 & 9.71 & 0.082 \\
\hline Caregiver $\mathbf{s}$ & & & & & & \\
\hline Caregiver $\mathbf{S}$ & & & & & & \\
\hline - baseline & $5.15(3.55)$ & $4.87(3.37)$ & & & & \\
\hline - 3 months & $3.32(2.85)$ & $4.21(3.53)$ & -0.43 & -1.32 & 0.47 & 0.348 \\
\hline - 12 months & $2.74(3.01)$ & $3.25(2.97)$ & -0.12 & -1.01 & 0.77 & 0.786 \\
\hline Emotional s & & & & & & \\
\hline HADS Total & & & & & & \\
\hline - baseline & $14.99(9.57)$ & $15.26(10.49)$ & & & & \\
\hline - 3 months & $10.25(8.80)$ & $9.79(8.70)$ & 0.56 & -1.98 & 3.10 & 0.664 \\
\hline - 12 months & $8.11(7.18)$ & $7.59(6.62)$ & 0.98 & -1.18 & 3.14 & 0.372 \\
\hline
\end{tabular}




\begin{tabular}{|c|c|c|c|c|c|c|}
\hline \multicolumn{7}{|c|}{ HADS Anxiety* } \\
\hline - baseline & $8.55(5.05)$ & $8.79(5.48)$ & & & & \\
\hline - 3 months & $6.29(4.84)$ & $5.86(4.47)$ & 0.43 & -0.93 & 1.80 & 0.530 \\
\hline - 12 months & $5.02(4.05)$ & $4.83(4.20)$ & 0.68 & -0.56 & 1.91 & 0.280 \\
\hline \multicolumn{7}{|c|}{ HADS Depression* } \\
\hline - baseline & $6.50(4.97)$ & $6.43(5.45)$ & & & & \\
\hline - 3 months & $3.91(4.32)$ & $3.89(4.74)$ & 0.12 & -1.19 & 1.43 & 0.860 \\
\hline - 12 months & $3.10(3.62)$ & $3.04(3.30)$ & 0.20 & -0.94 & 1.35 & 0.723 \\
\hline \multicolumn{7}{|c|}{ Impact of Event Scale* } \\
\hline - baseline & $32.39(15.62)$ & $32.59(16.14)$ & & & & \\
\hline-3 months & $24.92(17.55)$ & $22.08(16.19)$ & 2.49 & -2.14 & 7.12 & 0.288 \\
\hline - 12 months & $21.20(17.07)$ & $19.87(17.82)$ & 2.42 & -1.99 & 6.84 & 0.279 \\
\hline
\end{tabular}

* Outcome measures on which lower scores indicate better functioning

$\mathrm{SD}=$ standard deviation

$\mathrm{Cl}=$ confidence interval

HADS = Hospital Anxiety and Depression Scale

\section{Discussion}

Cardiac arrest survivors who received our new early intervention service had an improved quality of life, a better overall emotional state and less anxiety compared with those receiving usual care only. Next to that, there seemed to be a more rapid return to work in the group receiving the intervention, a finding which can also have high socio-economic importance. Improvements were both statistically significant and clinically relevant, indicating that our compact intervention has indeed the potency to increase functional outcome and quality of life of survivors of a cardiac arrest, and we are the first to present this.

What distinguishes our intervention from existing interventions is the specific attention given to possible cognitive impairments. Although cognitive impairments are common after a cardiac arrest, patients are often unaware of these brain injury related consequences, and also health care professionals often do not recognize these so-called 'invisible' problems. ${ }^{12}$ This is the first intervention, to our knowledge, in which active screening for possible cognitive problems was integrated in a psychosocial and on evidence based intervention for survivors of a cardiac arrest and their caregivers.

\section{Comparison with other studies}

Although two previous studies reported positive effects of a psychosocial intervention for survivors of a cardiac arrest on mortality, knowledge about cardiac arrest, physical symptoms and emotional state, this is the first study showing also improvements in quality of life. ${ }^{9,10}$ Special is also that our effective intervention was so brief, in the majority of the cases it consisted of only one or two consultations, while these previous interventions needed eight and eleven consultations respectively. 9,10,16 Furthermore, our findings are in line with evidence on effective interventions for related patients groups, with coronary artery disease, heart failure or traumatic brain injury. ${ }^{33-35}$ 


\section{Strengths and limitations}

We performed a randomised multicentre trial according to current methodological standards with a high number of participants, showing a consistent pattern of strong positive results for patients who had received the new intervention. The validity of these results are further strengthened by the fact that the objective improvements on emotional well-being and quality of life are in line with subjective evaluations by patients, caregivers and nurses as reported in the process evaluation, which was performed prior to knowing the effects of this intervention. ${ }^{16}$

Most previous studies focused on specific subgroups of cardiac arrest survivors, by including only patients after out-of-hospital cardiac arrest or patients who had also received an ICD implantation. ${ }^{9,10}$ In contrast, we had a broad target population, including patients of all ages, after both out-of-hospital and in-hospital cardiac arrest, and with or without ICD. This underscores the generalisability of our results, as well as the feasibility of our intervention in daily care practice of a hospital setting.

Some limitations are, however, worth noting. The first limitation is that the target sample size of 168 participants was not reached, as only 143 of the 185 participants enrolled in the trial, completed it. Nevertheless, we consider the study as sufficiently powered, as more advanced and efficient statistical techniques were used compared with the independent-samples t-test on which the sample size calculation was based.

A second limitation may be that patients refusing study participation were somewhat older and more often female. Next to that, dropouts of the study had a statistically significant lower overall cognitive status at baseline. However, this difference was so small that we consider this to be not clinically relevant and assume that this has not resulted in selection bias. A third limitation is that blinding of the research assistants has not been successful in all cases. Although we had instructed the research assistants to do their best not to reveal group allocation, this was sometimes spontaneously reported by the participants during their home visits. However, as the research assistants were not involved in the data analyses and did not have any other conflict of interests, we do not expect that this has biased the results of this study.

\section{Explanations and implications}

This intervention consisted of four elements and we estimate that, in fact, three elements have contributed to the effectiveness of this intervention. First, active screening for cognitive and emotional impairments was important as these problems are 'invisible' and can be easily missed by health care professionals, as was previously shown in stroke patients. ${ }^{36}$ The second element, provision of adequate information and support, was highly appreciated. Patients and caregivers were very positive about the information they had received from the nurse, and also about the information booklet, which described possible consequences of a cardiac arrest and was developed specifically for this intervention. ${ }^{16}$ This finding is fully in line with two Cochrane reviews which also reported the importance of active information supply and patient education for patients with coronary heart disease and stroke patients. ${ }^{37,38}$ The third important element was referral to specialised care if necessary, which occurred in $18 \%$ of the cases. This shows that indeed in a substantial number of patients referral to specialised care was indicated. ${ }^{16}$ The early and proactive approach of this intervention will probably have improved and hastened these referrals. The one 
element that probably did not contribute to the effectiveness of this intervention is promotion of self-management, since our process evaluation showed that this technique was not regularly practiced during the consultations. ${ }^{16}$ Apparently, practicing and promoting of self-management was not achievable in this concise intervention, and we concluded that self-management probably fits better in more elaborate interventions in a later phase.

The strong positive effects of this intervention seem to rule out the effect of attention alone, as it is unlikely that a few hours of attention alone would result in such large improvements up to one year after the cardiac arrest. Furthermore, as six different nurses have conducted the intervention, effects cannot be contributed to capacities of one specific person, which further improves generalisability of our results.

The feasibility of this intervention was already shown in the process evaluation of this intervention, and implementation in regular health care seems possible. ${ }^{16}$ The fact that our intervention is much briefer than previous interventions for survivors of cardiac arrest, makes it even more attractive for future implementation, as costs will probably be lower.

\section{Future directions}

Anxiety and depression are acknowledged risk factors for new cardiac events and mortality in patients after myocardial infarction. ${ }^{39,40}$ The finding that this intervention improved overall emotional state and lowered anxiety may therefore also have an additional positive effect on cardiovascular prognosis. To investigate this, long-term follow up would be indicated.

Another important finding in this study was that caregivers had even more symptoms of anxiety, depression and posttraumatic stress than the patients, which confirms that caregivers are at high risk for emotional problems. However, this intervention did not result in significant improvements for the caregivers. Therefore, it is essential to investigate what additional needs caregivers have, so that care for the caregivers can also be improved.

The costs of this intervention are relatively low, and societal gain is expected, as long-term quality of life is improved and return to work seems to be accelerated. However, cost effectiveness analyses are a further goal for study.

To conclude, this study described an effective and feasible early intervention service, which improved quality of life and emotional state after cardiac arrest, and resulted in a more rapid return to work. Our findings indicate that not only cardiac consequences should be monitored after survival of a cardiac arrest, but also possible brain related consequences need to be taken into account. Future efforts should therefore focus on making this additional care available for all cardiac arrest survivors. 


\section{Acknowledgments}

We would like to acknowledge all patients and caregivers for their participation in this study. All participating hospitals and involved staff members are thanked for their cooperation. We are grateful to the nurses who conducted the intervention and thank the research assistants who performed the measurements.

\section{Contributors}

VM was the principle investigator on this project, working under supervision of $\mathrm{CVH}$, JV and DW. VM, CVH, WB, MdK, AG, DW and JV were involved in the design of the intervention. VM performed data analyses, with help from BW, who acted as statistical consultant. All authors take responsibility for the integrity of the data and the accuracy of the data analysis. VM wrote the drafts of the manuscript. All authors read, critically reviewed and approved the final manuscript. JV is the guarantor.

\section{Funding}

This study was funded by the Netherlands Organization for Health Research and Development (ZonMw 92003-373), Fonds Nuts Ohra and Stichting Elisabeth Strouven. The funding agencies were not involved in the design, performance or interpretation of the study.

\section{Ethical approval}

This study was approved by the Medical Ethics Committee of Maastricht University Medical Centre, the Netherlands. All participants gave written informed consent. 


\section{References}

1. Moulaert VR, Verbunt JA, van Heugten CM, Wade DT. Cognitive impairments in survivors of out-ofhospital cardiac arrest: A systematic review. Resuscitation 2009;80(3):297-305.

2. de Vos R, de Haes HC, Koster RW, de Haan RJ. Quality of survival after cardiopulmonary resuscitation. Arch Intern Med 1999;159(3):249-54.

3. Saner H, Borner Rodriguez E, Kummer Bangerter A, Schuppel R, von Planta M. Quality of life in longterm survivors of out-of-hospital cardiac arrest. Resuscitation 2002;53(1):7-13.

4. BusI KM, Greer DM. Hypoxic-ischemic brain injury: pathophysiology, neuropathology and mechanisms. NeuroRehabilitation 2010;26(1):5-13.

5. Roine RO, Kajaste S, Kaste M. Neuropsychological sequelae of cardiac arrest. Jama 1993;269(2):23742.

6. Lundgren-Nilsson A, Rosen $H$, Hofgren C, Sunnerhagen KS. The first year after successful cardiac resuscitation: function, activity, participation and quality of life. Resuscitation 2005;66(3):285-9.

7. Pusswald G, Fertl E, Faltl M, Auff E. Neurological rehabilitation of severely disabled cardiac arrest survivors. Part II. Life situation of patients and families after treatment. Resuscitation 2000;47(3):241-8.

8. Wachelder EM, Moulaert VR, van Heugten C, Verbunt JA, Bekkers SC, Wade DT. Life after survival: long-term daily functioning and quality of life after an out-of-hospital cardiac arrest. Resuscitation 2009;80(5):517-22.

9. Cowan MJ, Pike KC, Budzynski HK. Psychosocial nursing therapy following sudden cardiac arrest: impact on two-year survival. Nurs Res 2001;50(2):68-76.

10. Dougherty CM, Thompson EA, Lewis FM. Long-term outcomes of a telephone intervention after an ICD. Pacing Clin Electrophysio/ 2005;28(11):1157-67.

11. Moulaert VR, Wachelder EM, Verbunt JA, Wade DT, van Heugten CM. Determinants of quality of life in survivors of cardiac arrest. J Rehabil Med 2010;42(6):553-8.

12. Cobbe SM, Dalziel K, Ford I, Marsden AK. Survival of 1476 patients initially resuscitated from out of hospital cardiac arrest. Bmj 1996;312(7047):1633-7.

13. Moulaert VR, Verbunt JA, Bakx WG, et al. 'Stand still ..., and move on', a new early intervention service for cardiac arrest survivors and their caregivers: rationale and description of the intervention. Clin Rehabil 2011;25(10):867-79.

14. Moulaert VR, Verbunt JA, van Heugten CM, et al. Activity and Life After Survival of a Cardiac Arrest (ALASCA) and the effectiveness of an early intervention service: design of a randomised controlled trial. BMC Cardiovasc Disord 2007;7(1):26.

15. Nolan JP, Deakin CD, Soar J, Bottiger BW, Smith G. European Resuscitation Council guidelines for resuscitation 2005. Section 4. Adult advanced life support. Resuscitation 2005;67 Suppl 1:S39-86.

16. Moulaert VR, van Haastregt JCM, Wade DT, van Heugten CM, Verbunt JA. 'Stand still ..., and move on', a new early intervention service for cardiac arrest survivors and their caregivers: A process evaluation Submitted 2013.

17. NHS/NVVC. Richtlijn Hartrevalidatie 2004. Den Haag: Nederlandse Hartstichting, 2004.

18. Sander AM, Fuchs KL, High WM, Jr., Hall KM, Kreutzer JS, Rosenthal M. The Community Integration Questionnaire revisited: an assessment of factor structure and validity. Arch Phys Med Rehabil 1999;80(10):1303-8.

19. Aaronson NK, Muller M, Cohen PD, et al. Translation, validation, and norming of the Dutch language version of the SF-36 Health Survey in community and chronic disease populations. I Clin Epidemiol 1998;51(11):1055-68. 
20. Schweikert B, Hahmann H, Leidl R. Validation of the EuroQol questionnaire in cardiac rehabilitation. Heart 2006;92(1):62-7.

21. Alderson AL, Novack TA. Reliable serial measurement of cognitive processes in rehabilitation: the Cognitive Log. Arch Phys Med Rehabil 2003;84(5):668-72.

22. Vlaar AM, Wade DT. The Adult Memory and Information Processing Battery (AMIPB) test of informationprocessing speed: a study of its reliability and feasibility in patients with multiple sclerosis. Clin Rehabil 2003;17(4):386-93.

23. Vlaar AM, Wade DT. Verbal fluency assessment of patients with multiple sclerosis: test-retest and interobserver reliability. Clin Rehabil 2003;17(7):756-64.

24. O'Donnell WE, Reynolds DM, De Soto CB. Neuropsychological impairment scale (NIS): initial validation study using trailmaking test (A \& B) and WAIS digit symbol (scaled score) in a mixed grouping of psychiatric, neurological, and normal patients. J Clin Psychol 1983;39(5):746-8.

25. Sunderland $A$, Watts $K$, Baddeley AD, Harris JE. Subjective memory assessment and test performance in elderly adults. J Gerontol 1986;41(3):376-84.

26. Broadbent DE, Cooper PF, FitzGerald P, Parkes KR. The Cognitive Failures Questionnaire (CFQ) and its correlates. Br J Clin Psychol 1982;21 (Pt 1):1-16.

27. Spinhoven P, Ormel J, Sloekers PP, Kempen GI, Speckens AE, Van Hemert AM. A validation study of the Hospital Anxiety and Depression Scale (HADS) in different groups of Dutch subjects. Psychol Med 1997;27(2):363-70.

28. van der Ploeg E, Mooren TT, Kleber RJ, van der Velden PG, Brom D. Construct validation of the Dutch version of the impact of event scale. Psychol Assess 2004;16(1):16-26.

29. de Haan R, Limburg M, Schuling J, Broeshart J, Jonkers L, van Zuylen P. [Clinimetric evaluation of the Barthel Index, a measure of limitations in dailly activities]. Ned Tijdschr Geneeskd 1993;137(18):91721.

30. Turnbull JC, Kersten P, Habib M, McLellan L, Mullee MA, George S. Validation of the Frenchay Activities Index in a general population aged 16 years and older. Arch Phys Med Rehabil 2000;81(8):1034-8.

31. Thornton M, Travis SS. Analysis of the reliability of the modified caregiver strain index. J Gerontol $B$ Psychol Sci Soc Sci 2003;58(2):S127-32.

32. Corrigan JD, Smith-Knapp K, Granger CV. Outcomes in the first 5 years after traumatic brain injury. Arch Phys Med Rehabil 1998;79(3):298-305.

33. Linden W, Stossel C, Maurice J. Psychosocial interventions for patients with coronary artery disease: a meta-analysis. Arch Intern Med 1996;156(7):745-52.

34. Allen JK, Dennison CR. Randomized trials of nursing interventions for secondary prevention in patients with coronary artery disease and heart failure: systematic review. J Cardiovasc Nurs 2010;25(3):207-20.

35. Wade DT, King NS, Wenden FJ, Crawford S, Caldwell FE. Routine follow up after head injury: a second randomised controlled trial. J Neurol Neurosurg Psychiatry 1998;65(2):177-83.

36. Edwards DF, Hahn MG, Baum CM, Perlmutter MS, Sheedy C, Dromerick AW. Screening patients with stroke for rehabilitation needs: validation of the post-stroke rehabilitation guidelines. Neurorehabil Neural Repair 2006;20(1):42-8.

37. Brown JP, Clark AM, Dalal H, Welch K, Taylor RS. Patient education in the management of coronary heart disease. Cochrane Database Syst Rev 2011(12):CD008895.

38. Forster A, Brown L, Smith J, et al. Information provision for stroke patients and their caregivers. Cochrane Database Syst Rev 2012;11:CD001919. 
39. Roest AM, Martens EJ, Denollet J, de Jonge P. Prognostic association of anxiety post myocardial infarction with mortality and new cardiac events: a meta-analysis. Psychosom Med 2010;72(6):563-9.

40. van Melle JP, de Jonge P, Spijkerman TA, et al. Prognostic association of depression following myocardial infarction with mortality and cardiovascular events: a meta-analysis. Psychosom Med 2004;66(6):81422. 



\title{
Chapter 9
}

\author{
General discussion
}


136 | Chapter 9 
The main goals of the research project 'Activity and Life After Survival of a Cardiac Arrest' (ALASCA) were to investigate functional outcome after surviving a cardiac arrest, and to improve current care for survivors and their caregivers. The studies presented in this thesis have shown that survivors of a cardiac arrest face problems in multiple domains: cognitive impairments, emotional problems and fatigue are common, the level of participation in society is frequently reduced, and quality of life can be at risk. In addition, the effect upon the well-being of the caregivers was also investigated, which revealed that many caregivers experience difficulties, with an especially high prevalence of emotional problems.

These findings inspired us to explore how care for cardiac arrest survivors and their caregivers could be improved, which has resulted in the development of a new early intervention service called 'Stand still..., and move on'. This intervention had an innovative approach, as it included active screening for cognitive impairments and emotional problems, and provided also important information on potential non-cardiac consequences of a cardiac arrest to patient and caregiver. Furthermore, the intervention used a stepped-care approach: patients with additional care needs could be referred to further specialised (rehabilitation) care.

After the development of this new intervention service, we have undertaken a process evaluation and a randomised controlled evaluation, which showed that the intervention is feasible and effective: survivors who had received the new intervention showed important improvements in quality of life and emotional state, and were able to return to work earlier compared with those who had received usual care only.

In the next sections, the main findings of this thesis will be reviewed and specific topics are discussed in more detail, including their clinical implications and suggestions for future research. The discussion will start at the level of the brain itself, and will move on to societal participation, quality of life and caregiver well-being. This will be followed by a critical reflection on current and future methods for measuring of outcome after cardiac arrest, and will be completed with my view on implementation of the intervention in clinical practice.

\section{What is the matter with the brain?}

One important focus of this project was to investigate the brain related consequences of a cardiac arrest. We have shown that cognitive impairments appear to be present in about half of the cardiac arrest survivors, and that memory function is most frequently affected, followed by attention and executive functioning, findings which are in line with two recently published studies. ${ }^{1,2}$

The cognitive domains which are most frequently affected after cardiac arrest can be related to brain areas that rely on high metabolic activity, which are known to be especially vulnerable in case of distortion of circulation. These include the hippocampus and the cortical grey matter, in particular the vascular border zones and the fronto-parietal cortex. 3,4 Furthermore, a recent study using diffusion tensor imaging indicated that widespread white matter damage also arises after

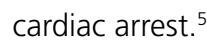


Although the pathophysiological mechanisms leading to hypoxic-ischaemic brain injury are distinct from the underlying mechanisms of mild traumatic brain injury, the clinical pattern seems, to some extent, comparable. In both cases, various kinds of cognitive impairments can occur, but especially problems in memory and executive functioning are frequently present. Furthermore, severe motor disorders, in general, seem to be absent, while emotional and behavioural changes are common.

\section{Assessing brain function in the future}

Our studies have shown the importance of giving explicit attention to cognitive impairments after cardiac arrest, especially as cognitive impairments are 'invisible', and are frequently not recognised by health care professionals., ${ }^{6,7}$ For clinical practice it would thus be of additional value to have a short cognitive screening, which provides an accurate first impression of cognitive functioning. Further research might identify which of the many existing tests is best in terms of time involved, simplicity, sensitivity and specificity, but we recommend against developing yet another new cognitive assessment. Future studies should investigate how these early cognitive assessments relate to long-term cognitive functioning and functional outcome, in order to gain more insight into early predictors of future functioning.

Another interesting topic to study is the course of brain functioning over time after cardiac arrest. One question which deserves further clarification is whether the pattern of recovery after hypoxic-ischaemic brain injury is comparable to that of other types of acquired brain injury such as stroke or traumatic brain injury. It would be relevant to explore how long recovery continues, in order to determine the best time for a final evaluation of the extent of cognitive impairments. In addition, the long-term effects of acute hypoxia on later cognitive decline also need further study. The global ischemia which occurs during a cardiac arrest can affect all brain areas, and this may lead to a higher overall vulnerability of brain. It would thus be of be interest to investigate the pattern of age-related cognitive decline after hypoxic-ischaemic brain injury, and to relate findings to a healthy comparison group and to patients with other types of brain injuries.

To investigate these topics, a long-term prospective cohort study should be set up in which brain function of cardiac arrest survivors would be followed over a long period of time, preferably using a combination of periodic neuropsychological assessments and brain imaging techniques.

\section{Mysteries of the mind: cognitive complaints versus cognitive impairments}

The conclusion of our systematic review, as presented in Chapter 4, was that cognitive impairments seem to be present in about half of the survivors. However, in our retrospective study (Chapter 2 ), only $21 \%$ of the survivors reported cognitive complaints. Although, these numbers have been derived from different sources, it seems to indicate a discrepancy between the subjective experience of cognitive complaints and the prevalence of cognitive impairments as objectified with neuropsychological examination.

This discrepancy is intriguing, especially since there seems to be an underestimation of cognitive problems by cardiac arrest survivors, while in patients with mild traumatic brain injury cognitive complaints are, in general, much more prominent than the objectified cognitive impairments. ${ }^{8}$ One possible explanation is that cardiac arrest survivors are not aware that cognitive problems 
can be one of the consequences of a cardiac arrest, and therefore do not recognise it as such. As a consequence, they may attribute the problems they experience differently, for example to aging or fatigue rather than to the cardiac arrest. The hypothesis that survivors label their cognitive problems as fatigue seems to be supported by the results presented in Chapter 2, in which fatigue was reported much more frequently than cognitive complaints. Another explanation could be that, after a certain amount of time, cardiac arrest survivors adapt their activities to their decreased mental capacities, and therefore do not experience their cognitive impairments as a problem anymore. As cardiac arrest survivors are, on average, older than patients with traumatic brain injury, it may be more commonly accepted that they indeed do reduce their activities.

The finding of a discrepancy between cognitive complaints and cognitive impairments implies that, in future research, measures of self-reported cognitive complaints cannot replace neuropsychological examinations. Clinically, careful differentiation between cognitive complaints and cognitive impairments is also recommended, as treatment approach should probably differ depending on which aspect is most prominent.

\section{Back to life, back to work?}

This thesis has shown that with regard to basic daily activities most cardiac arrest survivors regain their independence. However, as activities become more complex, more difficulties seem to be experienced. Return to work can be considered as an ultimate proof for regaining one's highest levels of functioning again.

Our studies showed that about three quarters of the patients who had been employed at the time of their cardiac arrest were able to return to work, although some had reduced their working hours. This percentage within our Dutch population is relatively high compared with figures from other countries. Studies which were also conducted after the introduction of therapeutic hypothermia showed that return to work in Sweden and Denmark was $42 \%$ and $65 \%$ respectively. ${ }^{1,9}$ These differences between countries are difficult to interpret, but may reflect variations in definitions used and national welfare systems.

More attention on return to work seems indicated, not only because of its high socio-economic impact, but also because employment can contribute to life satisfaction, as was previously shown in a study on patients with aneurysmal subarachnoid haemorrhage. ${ }^{10}$ With regard to future studies, it would be interesting to investigate which factors facilitate return to work and how the process of vocational reintegration can be optimally supported.

\section{Quality of life is more than the absence of problems}

The studies as presented in this thesis, and also previous studies from other researchers, have shown that, although quality of life after cardiac arrest is lower than in the general population, it is still relatively good. ${ }^{11,12}$ This finding may be surprising, especially since our studies have revealed that survivors of a cardiac arrest frequently experience problems on multiple domains, and therefore this topic requires some further reflection.

On the one hand, we have found several factors which are negatively related to quality of life, including cognitive complaints, emotional problems and fatigue, findings which seems to be in line with a study on patients with aneurysmal subarachnoid haemorrhage. ${ }^{13}$ On the other hand, 
there are indications that surviving a cardiac arrest can also have positive effects on quality of life. Many survivors reported that they were grateful for the fact that they had survived this life-threatening event, and some even regarded their survival as 'a second chance'. In some cases the experience of surviving a cardiac arrest also changed their vision and priorities in life. Although these impressions were mainly derived from spontaneous report of patients and clinical experience of professionals, it seems to be in line with results of studies on patients who had survived a myocardial infarction, coronary artery bypass graft (CABG) or had received an implantable cardioverter defibrillator (ICD). ${ }^{14,15}$

However, there are large individual differences in the ways patients react to such a dramatic life event. It may therefore be interesting to study the influence of personal characteristics such as coping style, especially since in patients with aneurysmal subarachnoid haemorrhage coping style was identified as a factor which was also related to quality of life. ${ }^{16}$ Therefore, future studies on determinants of quality of life after cardiac arrest, should also take concepts such meaning and coping into account, and focus on identification of factors which can be influenced positively.

\section{Who cares about the caregivers?}

In this project, we investigated caregiver well-being in several of the studies, which revealed that caregivers can also face a range of difficulties. Although Chapter 8 showed that there was a gradual improvement in caregiver functioning on all domains during the first year, Chapter 2 reported that, even several years after the cardiac arrest, emotional problems were still very common in the caregivers: one third of the caregivers reported symptoms of anxiety or depression, and half experienced symptoms of posttraumatic stress. Interestingly, caregivers faced even more problems on these domains than the patients.

Unfortunately, the intervention 'Stand still ..., and move on', was not able to improve caregiver outcome. This indicates that caregivers have needs that were not sufficiently met with this intervention, and it is important to investigate this gap in future research. Improving care for the caregivers probably requires a more individual approach, as caregivers often find it hard to discuss their own difficulties in the presence of their partner. In addition, several caregivers indicated that they felt a need to get in touch with other caregivers of cardiac arrest survivors.

Recently, a potential innovation in caregiver care was presented. Dougherty et al. developed an intervention for partners of patients who had received an ICD implantation for primary or secondary prevention. ${ }^{17}$ This partner intervention is a nursing intervention which consists of an information booklet, psycho-education and counselling, a continuously accessible nurse pager system, and a partner group, and is provided alongside a patient programme. The effectiveness of this partner intervention is currently being investigated. ${ }^{17}$

An interesting aspect of this recently developed partner intervention is that the counselling sessions and the partner group are both conducted by telephone, an approach which may increase flexibility, feasibility and reduce costs. ${ }^{17}$ In addition, the Internet may also provide new possibilities: a recent qualitative review on patient and partner experiences after ICD implantation described how Internet can be used for mutual exchange and easy access to information. ${ }^{15}$ In order to tailor caregiver care in the future, it is important to gain more insight into which caregivers are at high risk for problems. Studies on caregivers of patients with other types 
of acquired brain injury showed that caregiver burden was not only affected by medical and psychological features of the patients, but also by psychological characteristics of the caregiver and the presence of social support. ${ }^{18,19}$ Future research on risk factors for caregiver strain after cardiac arrest should therefore include variables related to resuscitation, patient, caregiver and environment.

\section{Measuring outcome after cardiac arrest}

In this project the bio-psycho-social perspective of the International Classification of Function, Disability and Health (ICF) model was used as a framework to describe outcome after cardiac arrest. Such a framework helps to structure data, and it provides a model to investigate how different levels of functioning may interact. Such a concept is frequently lacking in studies on outcome after cardiac arrest. As an example, in a systematic review on quality of life after cardiac arrest a wide range of assessment instruments were considered as measures of quality of life, including the New York Heart Association Classification (NYHA) classification, neuropsychological assessments, measures of depression and the Cerebral Performance Categories (CPC), all measures which were originally designed to measure other aspects of functioning, but not specifically quality of life. ${ }^{20}$

Many studies on outcome after cardiac arrest used the Cerebral Performance Categories (CPC), as was recommended in the 'Utstein' criteria. ${ }^{21}$ However, the CPC is a very general scale for neurological outcome, which classifies outcome after cardiac arrest in the following five groups: good cerebral performance (CPC 1), moderate cerebral disability (CPC 2), severe cerebral disability (CPC 3), coma/ vegetative state (CPC 4), and death (CPC 5)..$^{21}$ In most studies a CPC score of either 1 or 2 is reported as so called 'good outcome'.

Recent studies which used the CPC as a main outcome measure reported 'good outcome' in $85 \%$ to $95 \%$ of the survivors. ${ }^{22-24}$ These extremely positive results are not in line with findings described in this thesis, which have shown that survivors frequently face problems on cognitive and functional levels. This indicates that the CPC is probably not valid nor sensitive enough to accurately measure functional outcome after cardiac arrest. Nevertheless, even in clinical trials, the CPC is still the most commonly used 'functional' outcome measure to establish the effect of new medical interventions after cardiac arrest. ${ }^{25}$ Using invalid or insensitive instruments as main outcome measures in clinical trials, may lead to incorrect conclusions on effectiveness of new medical interventions, and this shows the urgent need to establish an adequate core set of outcome measures for future clinical trials in the field of resuscitation.

\section{Towards implementation}

We have shown that the intervention 'Stand still..., and move on' is feasible and effective. Further study is needed to investigate the cost-effectiveness of this intervention, and we anticipate doing this using data on health care costs that we have collected prospectively alongside the trial. We expect that the gains of the intervention will outweigh its costs, since we have already shown that this relatively compact intervention improved quality of life and resulted in an earlier return to work. If the intervention indeed turns out to be cost-effective, implementation into the Dutch health care seems indicated. In the next section, several practical and organisational aspects concerning implementation will be addressed. 
The quality of the intervention depends to a large extent on the quality of the nurses, and therefore, it is essential that the nurses have, or acquire, a range of specific skills. First of all, the nurses must have an interdisciplinary approach, and they must be able to assess, address and support both the cardiac and the non-cardiac consequences of a cardiac arrest, as well as possible problems that caregivers may encounter. Furthermore, they must also have a flexible attitude in order to tailor the intervention to the needs of patient and caregiver.

Although, the nurses conduct the intervention 'Stand still..., and move on' independently, their position should be organised in such a way that they have easy access to medical specialists in the hospital and supervision of an expert in the field of rehabilitation. With regard to implementation, the intervention may be combined with or integrated into existing cardiac rehabilitation programmes.

The early intervention service should preferably be implemented as part of care pathway. On the one side of this pathway, the hospital side, health care professionals must become aware of the multi-factorial problems cardiac arrest survivors can face. Especially in highly specialised hospitals it can be a challenge to retain such a holistic view on a patient. Therefore, hospitals may consider organising a multidisciplinary post-resuscitation team, which visits cardiac arrest survivors throughout the hospital and ensures that all important aspects of this special patient group are sufficiently addressed. Special attention is needed to trace the cardiac arrest survivors who are admitted to other wards besides the cardiology or intensive care units, for example because they had an in-hospital cardiac arrest, and to ensure that these patients can also benefit from the early intervention service. On the other side of the pathway, which is outside the hospital, there must be specialised services to refer to, such as rehabilitation programmes, (neuro) psychological treatments, or social services, so that in case severe problems are detected in a patient or caregiver during the intervention, appropriate follow-up care can be arranged directly. Finally, all health care professionals involved should, in some way, be connected and cooperate in order to establish a real clinical pathway.

To conclude, this thesis has confirmed our hypothesis that the brain related consequences of a cardiac arrest are important. We have shown that cognitive and emotional problems are common, and also affect quality of life. Our finding that the early intervention service 'Stand still..., and move on', which specifically addressed these cognitive and emotional problems, was able to improve quality of life of the patients further supports our view that after cardiac arrest 'the brain is the heart of the matter'. But there is more that needs be pressed to the heart: in the follow-up of survivors of a cardiac arrest it is essential not only to keep an overall view on the patients, but also on their caregivers and families. Therefore, both in clinical practice and research outcome after cardiac arrest should be assessed carefully with valid, reliable and sensitive measures. This will result into a better insight into actual functioning, which can provide directions for further improvement of life after survival of a cardiac arrest. 


\section{References}

1. Cronberg T, Lilja G, Rundgren M, Friberg $\mathrm{H}$, Widner $\mathrm{H}$. Long-term neurological outcome after cardiac arrest and therapeutic hypothermia. Resuscitation 2009;80(10):1119-23.

2. Torgersen J, Strand K, Bjelland TW, et al. Cognitive dysfunction and health-related quality of life after a cardiac arrest and therapeutic hypothermia. Acta Anaesthesio/ Scand 2010;54(6):721-8.

3. Busl KM, Greer DM. Hypoxic-ischemic brain injury: pathophysiology, neuropathology and mechanisms. NeuroRehabilitation 2010;26(1):5-13.

4. Freeman WD, Biewend ML, Barrett KM. Hypoxic-ischaemic brain injury (HIBI) after cardiopulmonary arrest. Current Anaesthesia \& Critical Care 2007;18(5-6):261-276.

5. Luyt CE, Galanaud D, Perlbarg V, et al. Diffusion Tensor Imaging to Predict Long-term Outcome after Cardiac Arrest: A Bicentric Pilot Study. Anesthesiology 2012;117(6):1311-1321.

6. Cobbe SM, Dalziel K, Ford I, Marsden AK. Survival of 1476 patients initially resuscitated from out of hospital cardiac arrest. Bmj 1996;312(7047):1633-7.

7. Edwards DF, Hahn MG, Baum CM, Perlmutter MS, Sheedy C, Dromerick AW. Screening patients with stroke for rehabilitation needs: validation of the post-stroke rehabilitation guidelines. Neurorehabil Neural Repair 2006;20(1):42-8.

8. Stulemeijer M, Vos PE, Bleijenberg G, van der Werf SP. Cognitive complaints after mild traumatic brain injury: things are not always what they seem. J Psychosom Res 2007;63(6):637-45.

9. Kragholm K, Skovmoeller M, Christensen AL, et al. Employment status 1 year after out-of-hospital cardiac arrest in comatose patients treated with therapeutic hypothermia. Acta Anaesthesiol Scand 2013;57(7):936-43.

10. Passier PE, Visser-Meily JM, Rinkel GJ, Lindeman E, Post MW. Life satisfaction and return to work after aneurysmal subarachnoid hemorrhage. J Stroke Cerebrovasc Dis 2011;20(4):324-9.

11. de Vos R, de Haes HC, Koster RW, de Haan RJ. Quality of survival after cardiopulmonary resuscitation. Arch Intern Med 1999;159(3):249-54.

12. Lundgren-Nilsson A, Rosen H, Hofgren C, Sunnerhagen KS. The first year after successful cardiac resuscitation: function, activity, participation and quality of life. Resuscitation 2005;66(3):285-9.

13. Visser-Meily JM, Rhebergen ML, Rinkel GJ, van Zandvoort MJ, Post MW. Long-term health-related quality of life after aneurysmal subarachnoid hemorrhage: relationship with psychological symptoms and personality characteristics. Stroke 2009;40(4):1526-9.

14. Bluvstein I, Moravchick L, Sheps D, Schreiber S, Bloch M. Posttraumatic growth, posttraumatic stress symptoms and mental health among coronary heart disease survivors. I Clin Psychol Med Settings 2013;20(2):164-72.

15. Palacios-Cena D, Losa-Iglesias ME, Alvarez-Lopez $C$, et al. Patients, intimate partners and family experiences of implantable cardioverter defibrillators: qualitative systematic review. J Adv Nurs 2011;67(12):2537-50.

16. Passier PE, Visser-Meily JM, van Zandvoort MJ, Rinkel GJ, Lindeman E, Post MW. Predictors of long-term health-related quality of life in patients with aneurysmal subarachnoid hemorrhage. NeuroRehabilitation 2012;30(2):137-45.

17. Dougherty CM, Thompson EA, Kudenchuk PJ. Development and testing of an intervention to improve outcomes for partners following receipt of an implantable cardioverter defibrillator in the patient. ANS Adv Nurs Sci 2012;35(4):359-77.

18. McCullagh E, Brigstocke G, Donaldson N, Kalra L. Determinants of caregiving burden and quality of life in caregivers of stroke patients. Stroke 2005;36(10):2181-6. 
19. Smeets SM, van Heugten CM, Geboers JF, Visser-Meily JM, Schepers VP. Respite care after acquired brain injury: the well-being of caregivers and patients. Arch Phys Med Rehabil 2012;93(5):834-41.

20. Elliott VJ, Rodgers DL, Brett SJ. Systematic review of quality of life and other patient-centred outcomes after cardiac arrest survival. Resuscitation 2011;82(3):247-56.

21. Recommended guidelines for uniform reporting of data from out-of-hospital cardiac arrest: the 'Utstein style'. Prepared by a Task Force of Representatives from the European Resuscitation Council, American Heart Association, Heart and Stroke Foundation of Canada, Australian Resuscitation Council. Resuscitation 1991;22(1):1-26.

22. Phelps R, Dumas F, Maynard C, Silver J, Rea T. Cerebral Performance Category and long-term prognosis following out-of-hospital cardiac arrest. Crit Care Med 2013;41(5):1252-7.

23. Nielsen N, Hovdenes J, Nilsson F, et al. Outcome, timing and adverse events in therapeutic hypothermia after out-of-hospital cardiac arrest. Acta Anaesthesio/ Scand 2009;53(7):926-34.

24. Bouwes A, Binnekade JM, Kuiper MA, et al. Prognosis of coma after therapeutic hypothermia: a prospective cohort study. Ann Neurol 2012;71(2):206-12.

25. Trzeciak $\mathrm{S}$, Jones $\mathrm{AE}$, Kilgannon $\mathrm{JH}$, et al. Outcome measures utilized in clinical trials of interventions for post-cardiac arrest syndrome: a systematic review. Resuscitation 2009;80(6):617-23. 
Summary 
Chapter 1 provides a general introduction to the topic of this thesis, and starts with the definition, incidence and survival rates of a cardiac arrest. Although currently survival rates after cardiac arrest are still relatively low, the expectation is that survival rates are going to improve the coming years, primarily because more people are trained in resuscitation and the growing availability of automated external defibrillators (AED's) in the community. As a result, the percentage of survivors is likely to rise, which may lead to an increase in the number of people living with the potential consequences of a cardiac arrest.

One important potential consequence of a cardiac arrest is hypoxic-ischaemic brain injury, which is caused by the interruption of blood circulation during the cardiac arrest, and these brain related consequences are the main focus of this thesis.

We used the International Classification of Function, Disability and Health (ICF) of the World Health Organisation (WHO) as a framework to describe outcome after cardiac arrest, which distinguishes three levels of functioning: bodily structures and functions, activities and participation. At the start of this project, evidence started to arise that a cardiac arrest can negatively affect all three levels of functioning and also quality of life. Furthermore, there were signs that also caregiver well-being may be at risk. However, the exact prevalence of problems in patients and caregivers was not clear.

This thesis presents the results of the research project 'Activity and Life After Survival of a Cardiac Arrest' (ALASCA). The main aims of this project as presented in this thesis were:

1. To investigate outcome after cardiac arrest

2. To improve current care after survival of cardiac arrest

\section{Part 1. Outcome after cardiac arrest}

Chapter 2 presents a study on long-term functioning of survivors of an out-of-hospital cardiac arrest and their caregivers. In this retrospective cohort study 63 survivors were included together with 42 caregivers. This study showed that, at an average time of three years after cardiac arrest, $21 \%$ of the survivors experienced cognitive complaints, $35 \%$ had feelings of anxiety and/ or depression, $21 \%$ had symptoms of posttraumatic stress and $50 \%$ reported severe fatigue. Performance of extended daily activities was affected in $20 \%$ of the survivors, and $74 \%$ had a decreased level of societal participation. Of the 35 people who were employed at the time of the cardiac arrest 17 (49\%) were able to return completely to their previous job, and 10 (29\%) more people were able to return to work, but at a reduced number of working hours. Physical quality of life was reduced in $17 \%$ of the survivors, and $24 \%$ had a decreased mental quality of life. The caregivers were also affected: $38 \%$ of the caregivers experienced symptoms of anxiety and/or depression, 50\% showed symptoms of posttraumatic stress, caregiver strain was high in $17 \%$, and $24 \%$ of the caregivers had a reduced quality of life. Altogether, this study revealed that a cardiac arrest can have drastic consequences on many domains of functioning of the cardiac arrest survivors and their caregivers. 
Chapter $\mathbf{3}$ describes a study aimed at identifying determinants of quality of life after cardiac arrest. Multiple regression analyses were conducted using the dataset from our retrospective cohort study described in Chapter 2. This study found that physical quality of life was significantly related to cognitive complaints, instrumental daily life activities, posttraumatic stress and fatigue. Mental quality of life was significantly explained by anxiety/depression, fatigue and cognitive complaints. This was the first study to show that quality of life after cardiac arrest is, to such a large extent, affected by cognitive complaints and emotional problems, which highlights the need to address these factors when caring for these patients.

Chapter 4 is a systematic review summarising all evidence on the frequency and nature of cognitive impairments in survivors of out-of-hospital cardiac arrest. For this study, articles published between 1-1-1980 and 31-12-2006 were screened on title, abstract and full-text by two reviewers, using the databases Pubmed, Embase, Psychlnfo and Cinahl. Finally, 28 articles were selected and these articles were reviewed and assessed by two reviewers independently using a quality criteria list. Overall, there was a high heterogeneity between the studies with regard to study design, number of participants, outcome measures and duration of follow-up, and the methodological quality of the most articles was relatively low. Taking methodological quality into account, we concluded that, six to twelve months after cardiac arrest, cognitive impairments seem to be present in about half of the survivors of out-of-hospital cardiac arrest. Memory problems were the most common cognitive impairment, followed by impairments in attention and executive functioning.

\section{Part 2: Improving care after survival of a cardiac arrest}

The previous chapters showed that after survival of a cardiac arrest problems can occur in all domains of functioning. In particular, the prevalence of cognitive and emotional problems was high, and these factors affected quality of life adversely. This inspired us to develop a new early intervention service for survivors of a cardiac arrest and their caregivers called 'Stand Still ..., and move on', which was then evaluated in a process evaluation and a randomised controlled trial.

Chapter 5 provides a detailed description of the study protocol of this trial, which was a multicentre single blind randomised controlled trial. Baseline measurements were administered two weeks after the cardiac arrest, with follow up measurements at three and twelve months. The study population comprised survivors of in-hospital or out-of-hospital cardiac arrest, who had been admitted to one of five participating hospitals in the Southern part of the Netherlands. Half of the participants received the new intervention, which was added to standard care, while the other half received usual care only. Primary outcome measures were the extent of participation in society and quality of life of the patient one year after a cardiac arrest. Secondary outcome measures were the level of cognitive and emotional functioning and extended daily activities of the patients, as well as quality of life, emotional functioning and strain of the caregivers. 
Chapter 6 gives more information on the background and rationale of the early intervention service 'Stand Still ..., and move on', by presenting the evidence underlying its development, and providing a detailed description of its content and organisation. The intervention was based on a literature review concerning effective interventions for patients with cardiac diseases and patients with traumatic brain injury, and also on expert opinion and reported patient experiences. In short, the intervention is an individualised programme, consisting of one to six consultations by a specialised nurse with the patient and their caregiver, which started soon after discharge from the hospital. The intervention consisted of four elements: 1) screening for cognitive and emotional problems; 2) provision of information and support; 3) promotion of self-management strategies; and 4) referral to further specialised care if indicated.

Chapter $\mathbf{7}$ presents the results of a process evaluation, in which the actual delivery and feasibility of the intervention service was investigated. This process evaluation was performed prior to the analysis of the results concerning the effectiveness of the intervention and consisted of: 1) structured written evaluations from patients and caregivers; 2) registration of content and duration of all the consultations; and 3) evaluations from nurses with evaluation forms and semistructured interviews. Results of this process evaluation indicated that of the total number of 97 patients who had been allocated to the intervention group, 79 patients $(81 \%)$ participated in the intervention, together with 65 of the 91 caregivers (71\%). The mean number of consultations per patient was 1.8 (SD 1.0), and most consultations were conducted at the patients' homes. The intervention was performed according to protocol on most aspects, except that the intervention usually started later than intended, consultations were longer than expected, and the topic of self-management was not regularly addressed. Overall, the intervention was positively evaluated by patients, caregivers and nurses. Patients marked the quality of the intervention with a mean score of 7.5 out of ten and the performance of the nurse with an 8.0. We concluded that the intervention 'Stand still..., and move on' had been performed largely according to protocol and seemed feasible for implementation after some minor adaptations, provided that it was found to be effective.

Chapter 8 presents the effectiveness of the early intervention service 'Stand still..., and move on' for survivors of a cardiac arrest and their caregivers. In the trial, 185 adult survivors of cardiac arrest participated, along with 155 caregivers. Participants who received the new intervention were compared with controls receiving usual care only. This study showed that patients in the intervention group had a significantly higher quality of life on following SF-36 domains: Role Emotional, Mental Health and General Health. In addition, they also scored significantly better on overall emotional state and symptoms of anxiety. These effects were not only statistically significant, but the effect sizes were also clinically relevant. Furthermore, three months after the cardiac arrest significantly more persons were already back at work in the intervention group, namely 24 persons (50\%) compared with 8 persons (21\%) in the control group. But at 12 months the difference in employment rates was not significant anymore. There were no significant improvements in caregiver outcomes. Altogether, the results of this study showed that the new intervention resulted in important improvements in emotional well-being and quality 
of life of the cardiac arrest survivors, and therefore implementation into regular health care was recommended.

Chapter 9 is the general discussion in which the main findings of this thesis are discussed and reflected on; furthermore implications for clinical practice and future research are presented.

The clinical symptoms that occur after hypoxic-ischaemic brain injury are to some extent comparable to symptoms after mild traumatic brain injury, and can be related to brain areas with high metabolic activity, which are especially vulnerable to distortion of blood circulation.

Cognitive impairments are a frequent consequence of hypoxic-ischaemic brain injury, but these 'invisible' problems are frequently missed by health care professionals, and cardiac arrest survivors seem to underestimate their own cognitive problems. Therefore, cognitive screening seems indicated, and cognitive complaints and cognitive impairments should be differentiated.

It may be surprising that although the prevalence of problems after cardiac arrest is high, quality of life appeared to be relatively good. Therefore, potential positively contributing factors were discussed, including coping style and changes in vision and meaning of life that can occur after such an intense life event.

Our studies have identified that caregiver well-being is at risk and that caregivers frequently have emotional problems. As our intervention did not improve caregiver outcome, more research on caregiver needs is urgently needed.

For clinical practice and future research in the field of resuscitation the development of a core set of outcome measures was recommended, which will contribute to better insight into actual functioning and a more adequate evaluation of new (medical) interventions.

Further study is needed to investigate the cost-effectiveness of this intervention, and our hypothesis is that the gains will outweigh its costs.

With regard to implementation, integration of the early intervention service within a care pathway for survivors of a cardiac arrest was recommended.

To conclude, this thesis has confirmed our view that after cardiac arrest 'the brain is the heart of the matter', and it has shown the importance to develop and retain an overall view on survivors, caregivers and their lives after survival of cardiac arrest. 
Samenvatting 
leder jaar krijgen in Nederland 16.000 mensen een hartstilstand. Hoofdstuk 1 beschrijft de achtergrond van dit proefschrift. De kans om een hartstilstand te overleven is met ongeveer $15 \%$ nog altijd relatief klein. De verwachting is dat de komende jaren de overlevingskans zal stijgen, mede dankzij het toenemend aantal mensen dat kan reanimeren en de grotere beschikbaarheid van automatische externe defibrillatoren (AED's). Dit betekent tegelijkertijd dat er meer mensen komen die moeten leven met de gevolgen van een hartstilstand.

Het is bekend dat een hartstilstand gevolgen voor het hart kan hebben. Een minder bekend gevolg van een hartstilstand is dat het ook kan leiden tot schade aan de hersenen. Dit wordt veroorzaakt door de tijdelijke verstoring van de bloedcirculatie. Aangezien het hersenweefsel daar niet goed tegen bestand is, kan er op die manier hersenletsel ontstaan. Dit wordt ook wel hypoxisch-ischemisch hersenletsel genoemd. De focus van dit proefschrift ligt op de gevolgen van dit hersenletsel.

Bij de start van dit onderzoeksproject waren er aanwijzingen dat een hartstilstand op meerdere gebieden invloed kan hebben zoals op het denken, de emoties, dagelijkse activiteiten en ook op de kwaliteit van leven. Ook waren er aanwijzingen dat de impact op de partner of mantelzorger groot kan zijn. Het was echter niet duidelijk hoe vaak er problemen waren bij patiënten en hun mantelzorgers en welke problemen nu de meeste impact hadden.

Dit proefschrift presenteert de resultaten van het ALASCA onderzoek wat staat voor 'Activity and Life After Survival of a Cardiac Arrest'.

Het onderzoek dat beschreven wordt in dit proefschrift had twee belangrijke doelen:

1. Het in kaart brengen van de gevolgen van een hartstilstand.

2. Het verbeteren van de nazorg na een hartstilstand.

\section{Deel 1. Gevolgen van een hartstilstand}

Hoofdstuk 2 beschrijft een studie over het lange termijn functioneren van mensen die een hartstilstand buiten het ziekenhuis overleefd hebben. Aan deze retrospectieve studie hebben 63 overlevenden en 42 mantelzorgers meegedaan. De hartstilstand van deze groep had gemiddeld drie jaar geleden plaats gevonden. Uit deze studie bleek dat bij overlevenden van een hartstilstand vaak problemen voor kwamen: $21 \%$ had cognitieve klachten (dat zijn klachten in het denken, zoals een verminderd geheugen), $21 \%$ had symptomen van posttraumatische stress, $35 \%$ had emotionele klachten (angst en/of depressie) en maar liefst 50\% had last van ernstige vermoeidheid. Daarnaast had $20 \%$ moeite met het uitvoeren van dagelijkse activiteiten (zoals wandelen en boodschappen doen) en had $74 \%$ een verminderde participatie. Van de 35 mensen die op het moment van de hartstilstand nog aan het werk waren, zijn er 17 (49\%) weer volledig aan het werk gegaan. Daarnaast zijn er tien mensen (29\%) wel weer gaan werken, maar dan met minder werkuren. Ook bleek de kwaliteit van leven bij ongeveer een kwart van de mensen verminderd. 
Bij de mantelzorgers kwamen de volgende problemen voor: 38\% had emotionele problemen (angst en/of depressie), 50\% had symptomen van posttraumatische stress, 17\% was overbelast en $24 \%$ had een verminderde kwaliteit van leven.

Samenvattend heeft deze eerste studie laten zien dat een hartstilstand forse consequenties kan hebben op verschillende domeinen van functioneren van zowel patiënt als mantelzorger.

Hoofdstuk 3 beschrijft een studie waarin gezocht werd naar factoren die invloed hebben op de kwaliteit van leven na een hartstilstand. Voor deze studie werd dezelfde patiëntengroep bestudeerd als in Hoofdstuk 2. Het bleek dat de fysieke kwaliteit van leven vooral bepaald werd door cognitieve klachten, het kunnen uitvoeren van dagelijkse activiteiten, posttraumatische stress en vermoeidheid. De mentale kwaliteit van leven werd met name bepaald door emotionele problemen (angst/depressie), vermoeidheid en cognitieve klachten. Deze studie heeft hiermee voor het eerst laten zien dat kwaliteit van leven na een hartstilstand in grote mate bepaald wordt door cognitieve en emotionele problemen. Het is daarom van belang om aan deze gevolgen meer aandacht aan te besteden.

Hoofdstuk $\mathbf{4}$ beschrijft een systematisch literatuuronderzoek over hoe vaak cognitieve stoornissen voorkomen bij mensen die een reanimatie buiten het ziekenhuis overleefd hebben. Hiervoor werden 28 artikelen geselecteerd. Het bleek dat er veel verschillen waren tussen de gevonden studies wat betreft onderzoeksopzet, aantal deelnemers, en de gebruikte meetinstrumenten. De methodologische kwaliteit van de meeste studies was matig. Kijkend naar de drie beste studies werd geconcludeerd dat na een hartstilstand bijna de helft van de mensen op lange termijn nog cognitieve stoornissen heeft. Geheugenproblemen komen daarbij het meeste voor, gevolgd door problemen met aandacht en plannen.

\section{Deel 2. Verbeteren van de nazorg na een hartstilstand}

De vorige hoofdstukken hebben laten zien dat een hartstilstand kan leiden tot problemen op verschillende domeinen van functioneren. Met name cognitieve en emotionele problemen bleken veel voor te komen en hadden een negatieve invloed op de kwaliteit van leven. Dit was voor ons aanleiding om een nieuw nazorgtraject te ontwikkelen voor overlevenden van een hartstilstand en hun naasten genaamd: 'Stilstaan ..., en doorgaan'.

In hoofdstuk 5 wordt een gedetailleerde beschrijving gegeven van het studieprotocol van de gerandomiseerde studie naar het effect van het nieuwe nazorgtraject 'Stilstaan..., en doorgaan'. Dit onderzoek werd uitgevoerd in samenwerking met vijf ziekenhuizen in Limburg en Noord Brabant. Deelnemers aan deze studie waren patiënten die een hartstilstand in of buiten het ziekenhuis overleefd hadden.

De helft van de deelnemers kreeg het nieuwe nazorgtraject aangeboden als aanvulling op de gebruikelijke zorg. De andere helft kreeg alleen de gebruikelijke zorg.

Er werden metingen verricht op drie momenten na de hartstilstand: 2 weken, 3 maanden en 1 jaar. De belangrijkste uitkomstmaten waren de mate van participatie in de maatschappij en kwaliteit van leven van de patiënt één jaar na de harststilstand. Secundaire uitkomstmaten waren 
cognitief en emotioneel functioneren en de mate van dagelijkse activiteiten van de patiënt. Van de mantelzorgers werd emotioneel functioneren, mate van belasting en de kwaliteit van leven gemeten.

Hoofdstuk 6 geeft meer informatie over de achtergrond van het nieuwe nazorgtraject 'Stilstaan ..., en doorgaan'. Ook wordt een gedetailleerde beschrijving van de inhoud van de interventie beschreven. De inhoud van de interventie is gebaseerd op kennis uit de literatuur over effectieve interventies bij patiënten met hartziekten en traumatisch hersenletsel. Daarnaast werd gebruikt gemaakt van de kennis van experts en ervaringsdeskundigen. Kort samengevat is de interventie een individueel programma waarbij patiënten samen met hun eventuele mantelzorger één tot zes gesprekken hebben met een gespecialiseerde verpleegkundige. De interventie begint kort na ontslag uit het ziekenhuis en bestaat uit vier belangrijke elementen: 1) opsporen van cognitieve en emotionele problemen; 2) verschaffen van informatie en steun; 3) bevorderen van zelfmanagement; en 4) indien nodig, doorverwijzing naar meer gespecialiseerde zorg.

Hoofdstuk 7 beschrijft de resultaten van een procesevaluatie waarin gekeken is naar de daadwerkelijke uitvoer en haalbaarheid van het nieuwe nazorgtraject. Deze procesevaluatie is uitgevoerd voordat de effecten van de nieuwe interventie bekend waren. De procesevaluatie bestond uit: 1) schriftelijk evaluaties van de patiënten en mantelzorgers; 2) registraties van de inhoud en duur van alle gesprekken; 3) evaluaties van de verpleegkundigen door middel van vragenlijsten en semi-gestructureerde interviews.

Deze studie liet zien dat 79 van de 97 patiënten (81\%) in de interventiegroep daadwerkelijk heeft meegedaan aan de interventie, samen met 65 van de 91 mantelzorgers (71\%). Gemiddeld hadden deelnemers 1.8 gesprekken met de verpleegkundige (SD 1.0) en de meeste gesprekken vonden bij de mensen thuis plaats. Het bleek dat de interventie grotendeels volgens protocol was uitgevoerd. Op een aantal aspecten werden afwijkingen gevonden: de interventie begon vaak later dan bedoeld, gesprekken waren langer dan verwacht en het onderwerp zelfmanagement werd niet vaak behandeld. De interventie werd positief beoordeeld door de patiënten, mantelzorgers en verpleegkundigen. Patiënten beoordeelden de kwaliteit van de interventie met een 7.5 op een tien-puntschaal en de uitvoering door de verpleegkundige met een 8.0. De conclusie van deze procesevaluatie was dat de interventie grotendeels volgens protocol was uitgevoerd en dat implementatie ervan, na een aantal kleine aanpassingen, haalbaar moet zijn.

In hoofdstuk 8 worden vervolgens de effecten van het nieuwe nazorgtraject gepresenteerd. Aan deze studie deden 185 overlevenden van een hartstilstand mee samen met 155 mantelzorgers. De patiënten die het nieuwe nazorgtraject kregen, hadden één jaar na de hartstilstand een duidelijk betere kwaliteit van leven dan de mensen die alleen de gebruikelijke zorg ontvangen hadden. Ook hadden ze minder emotionele problemen en hervatten ze eerder hun werk. De interventie had geen effect op de mantelzorgers. Samenvattend heeft deze studie laten zien dat de nieuwe interventie leidt tot een belangrijke verbetering van kwaliteit van overleven na een hartstilstand. Implementatie van dit programma in de gezondheidszorg wordt daarom aangeraden. 
Hoofdstuk 9 is de algemene discussie van dit proefschrift waarin wordt gereflecteerd over de belangrijkste bevindingen en deze in perspectief worden geplaatst. Ook worden praktische toepassingen besproken en ideeën voor toekomstig onderzoek gepresenteerd.

De klinische symptomen die voorkomen bij hersenletsel door een hartstilstand kunnen gerelateerd worden aan hersengebieden met een hoge stofwisseling waarvan bekend is dat ze niet goed tegen verstoringen in de bloedcirculatie kunnen. Opvallend is dat het klachtenpatroon na een hartstilstand overeenkomsten vertoont met symptomen die voorkomen na traumatisch hersenletsel.

Cognitieve stoornissen komen vaak voor na hersenletsel na een hartstilstand, maar deze 'onzichtbare' gevolgen worden vaak niet opgemerkt door hulpverleners. Ook lijken overlevenden van een hartstilstand hun cognitieve stoornissen te onderschatten. Daarom is het van belang om actief te screenen of er cognitieve problemen zijn. Daarbij moeten cognitieve klachten en cognitieve stoornissen zorgvuldig van elkaar onderscheiden worden.

Ondanks dat we hebben laten zien dat er relatief vaak problemen zijn na een hartstilstand, blijkt de kwaliteit van leven op lange termijn vrij goed te zijn. Het zou kunnen zijn dat een hartstilstand naast negatieve ook positieve gevolgen heeft en mogelijk spelen veranderingen in levensvisie, zingeving en copingstijl daarbij een rol.

Onze studies hebben laten zien dat er ook vaak problemen zijn bij de mantelzorgers. De nieuwe nazorginterventie had op de mantelzorgers geen effect. Daarom is verder onderzoek naar de behoeften van de mantelzorgers nodig.

Voor de klinische praktijk en toekomstig onderzoek op het gebied van reanimatie wordt aangeraden om een basisset van uitkomstmaten te bepalen, zodat uitkomst na een reanimatie beter in kaart gebracht wordt en nieuwe (medische) interventies beter geëvalueerd kunnen worden.

Het is van belang om ook de kosten-effectiviteit van de nieuwe nazorginterventie in kaart te brengen. Gegevens hiervoor zijn tijdens de studie al verzameld en gaan nog geanalyseerd worden. We verwachten dat de winst op zal wegen tegen de kosten.

Met betrekking tot de implementatie van de nieuwe nazorginterventie wordt geadviseerd om dit in te bedden in een zorgpad, waarbij goede afstemming zowel tijdens de ziekenhuisfase als na ontslag van belang is.

Tot slot, dit proefschrift laat zien dat de neurologische gevolgen van een hartstilstand eigenlijk de kern van de zaak zijn. Daarom werd de Engelse titel van dit proefschrift:

'Life after survival of a cardiac arrest. The brain is the heart of the matter'. 


\section{Information booklet}

English version

Dutch version 



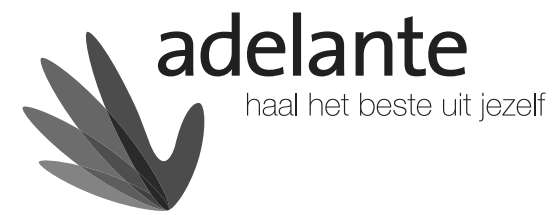

\title{
STAND STILL... AND MOVE ON
}

\author{
Life after survival of a cardiac arrest
}

This booklet is intended for all survivors of a cardiac arrest, their family members and other caregivers. It provides information on the possible consequences of a cardiac arrest and describes potential changes in cognition, emotion and behaviour and how this can affect your daily living. This booklet will give you information and advice, which can help you to get your life back on track. Maybe not all information is applicable to you, we advise to use what is relevant for you.

\section{A shock in different areas}

A cardiac arrest is a shock from several perspectives. The cardiac arrest can be a shock to your heart, a shock to you or your family, and a shock to your brain.

\section{Shock to the heart}

Our heart is the motor of our body. The heart pumps the blood through the whole body, from head to toes, including the brain. The blood supplies the body with oxygen and nutrients and takes away waste material.

During a cardiac arrest, the heart does not pump and the blood circulation stands still for a while. Thanks to resuscitation, your heart has started working again. During resuscitation chest compressions and ventilation are performed. In many

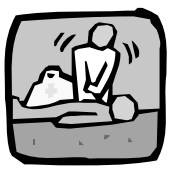
cases, an electrical shock is given via a special apparatus, called an external defibrillator. After that, the heart started beating again, and blood circulation was restored.

\section{Emotional shock to you and your family}

A cardiac arrest is not only an emotional shock to the person who actually has the cardiac arrest, but it is also a shock to family members. Surviving a cardiac arrest means that you almost died. In addition, sometimes family members or friends have been present during the resuscitation. In many cases there has been a period of uncertainty whether you would survive. This can lead to feelings of insecurity and fear. Questions arise, such as 'Why did this happen to me?' and 'How can we move on?'.

\section{Shock to the brain}

The brain is the centre that regulates our body, our thinking and our personality. The brain is sometimes compared to a computer: it regulates all processes in our body such as moving, seeing, hearing, feeling and thinking. Blood supply is essential for functioning of the brain. During a cardiac arrest the blood circulation to the brain has been interrupted. This is a shock to the brain because the supply of blood and oxygen was not sufficient. If a cardiac arrest lasts longer than 5-6 minutes without resuscitation, some damage occurs and some brain tissue dies. This is how brain damage occurs.

\section{Brain damage}

The consequences of brain damage can be very varied, and are different for every person. Changes may occur in movements, sensation and perceptions, feelings and thinking. Below you will read information possible changes in

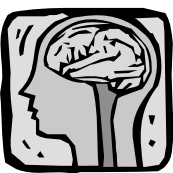
thinking, feeling and behaviour that occur after a cardiac arrest. These changes are often also called the 'invisible consequences' of brain damage because these can not be seen from the outside. These 'invisible consequences' can, however, have a negative impact on your own life and that of your family and friends.

During the first few months after the cardiac arrest, most of the recovery of your brain will occur. You will notice these improvements. However, some consequences will not improve and will remain permanently.

It is important to consider whether you experience these 'invisible consequences' yourself. This is not always easy to recognize. Your partner, other family members or a health care professional can help you to find out which changes have occurred in your functioning. 


\section{Changes in thinking}

When the brain has suffered damage during the cardiac arrest, its function may change. The total capacity of the brain function and the speed of thinking can be diminished. Thinking can be more difficult and go slower. In the next section you will read examples of changes in thinking that occur frequently, together with some tips.

- Forgetfulness: It is not possible to remember everything as you used to do. Information from the past is often remembered well. In contrast, remembering new information has become more difficult.

Tip: Use a diary. This will unburden your brain and prevents you from forgetting things.

- Slowness: Thinking goes slower and daily activities take more time and energy.

Tip: Make sure to plan enough time for the things you want to do. Daily activities take more time than before. It might not be possible to do everything you want. Make choice and try to say 'no'.

- Distraction: It is difficult to focus your attention. Tip: Try to work in a quiet environment without other people present. Turn off the radio or television. This will prevent you from being distracted and will improve your performance.

- Difficulties in doing two things at once: It has become difficult to do two things at the same time, such as cooking and talking.

Tip: Plan your activities one after the other in stead of at the same time.

- Planning: Planning, organizing and keeping an overview is more difficult now.

Tip: Plan beforehand how you are going to execute your activities, write this down and look at it regularly. A diary or notebook can help you.

- Fatigue: Activities which were easy before will now take more energy. You will feel tired more quickly.

Tip: Try to break your activities into smaller ones and take regular breaks.

- $\quad$ Agitation: You can feel exhausted more easily because everything takes more energy. This can lead to irritation or agitation.

Tip: The tips above will help you to prevent an overload of your brain. The chance of becoming agitated or irritated will diminish this way.

\section{Changed feelings}

A cardiac arrest has a high impact and can change the way you feel.

After a cardiac arrest many people become anxious. The memories of the cardiac arrest itself are rare, but the fact that it happened and that there was no control over the situation is a scary thought and can make people insecure.

Often people are afraid of a second cardiac arrest. This can lead to avoiding certain activities. Avoidance can lead to more fear and insecurity. It is better to pick up your activities gradually which gives you more confidence in your own functioning.

Also the way you feel can be changed after a cardiac arrest. Some people experience things more intensely; others become less emotional. Feelings of depression are also common and can emerge even after a few months. It is important to find out whether this is the case for you. Treating a depression is possible and can consist of psychotherapy and/or medication.

\section{Changes in behavior}

Brain damage can also lead to changes in behaviour, which can be very diverse. Some people become impulsive, easily agitated or disinhibited while others become more somewhat passive and show lack of initiative. Sometimes the person is not aware of these changes which can be a burden to the family members and other caregivers.

\section{Searching for balance}

It is important to find a balance (again) between activity and rest. To create a balance you have to take into account that activities might cost more mental

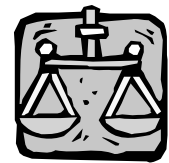
energy than before the cardiac arrest. It is important to set goals which are attainable and will not lead to stress. Take care that you do not try to do too much. It can be necessary to learn to say ' $n o$ ' in some situations. It is also essential that you schedule periods of relaxation. There are several ways to relax: physical activity is a form of relaxation for many people because it makes them feel fit. In addition, physical activity has a positive influence on your endurance and health. Other people relax by making music or perform another leisure activity. It can also help to just do nothing for a while. 


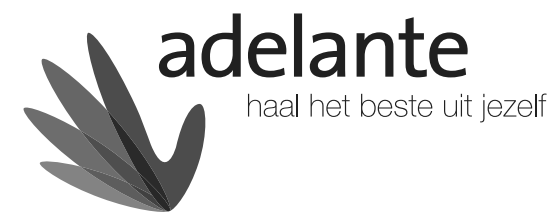

\title{
A CARDIAC ARREST DOES NOT ONLY INVOLVE YOU
}

\author{
Information for family members and other caregivers
}

A cardiac arrest can also be a shock to others in the environment such as a partner, parents, children or friends. The fact that your close relative survived a cardiac arrest can have a large impact on you. On the one hand you are happy that he/she survived the cardiac arrest; on the other hand there can be fear and grief about the things the cardiac arrest has changed.

\section{A different person}

A cardiac arrest can change your close relative. Some partners say 'I have another husband now' or 'She is not the same person anymore that she used to be'. This can indeed be the case when the cardiac arrest led to brain damage. Brain damage can change the way we feel, think and behave. This in turn can lead to changes in the relationship: maybe you have to do things which were normally done by your close relative before the cardiac arrest. This can be difficult. Sometimes changes occur within the relationship itself or in the area of intimacy or sexuality. It is important to talk about these changes and try to find solutions. A health care professional can help you with that.

\section{Building confidence}

Partners, family members and other caregivers can be worried. This is understandable as you want to prevent that such an event will ever occur again. Sometimes these worries become so pronounced that the person who had the cardiac arrest is never left alone anymore. This is not necessarily the best thing for all people involved. It is important to try and regain confidence which is not easy and might take some time.

\section{Take care of yourself}

Being a partner or close relative, it is important that you also take care of your own health. Your physical as well as your mental health are being challenged in the period after the cardiac arrest. Take care of yourself. This is important for both of you. Strain and depression are often seen in caregivers. Try to notice when you feel burdened and ask for help. Try to arrange some leisure time and relaxation for yourself. Finding a balance between activity and rest is also a challenge for caregivers.

\section{Asking questions can help}

Do you have any questions after reading this booklet? Talk about it with the health care professional that provided this booklet of your doctor. Do not hesitate to ask questions or discuss you problems. Sharing your situation with someone can ease your mind and can help you to get things back on track. 


\section{Colofon}

Authors: Véronique Moulaert, Caroline van Heugten, Jeanine Verbunt and Derick Wade

@ Copyright: 2013 Véronique Moulaert, Adelante Hoensbroek

This booklet can be reproduced freely for non-commercial use once agreement has been obtained from one of the authors.

This information booklet was developed for a research project called Activity and Life After Survival of a Cardiac Arrest (ALASCA). In this study the long term consequences of a cardiac arrest have examined and the effectiveness of an new early intervention service was evaluated.

This project is a collaboration between collaboration with Adelante, centre of expertise rehabilitation and audiology, and Maastricht University Medical Centre.

More information on this project: www.alasca.nl
Adelante

Health-care at Adelante focuses on research, treatment and advice relating to complex and general specialist rehabilitation for adults, children's rehabilitation, special needs education and home-training, audiology and communication, and employment reintegration. In the Adelante knowledge-centre research is carried out, and efforts made to modernise and improve health-care and treatment methods. Adelante employs over 1,000 professionals who work at our locations in Hoensbroek, Valkenburg a/d Geul, Heerlen, Maastricht, SittardGeleen, Roermond and Venlo. Adelante is also active in outpatient centres in hospitals and in community-based support.

More general information about Adelante: www.adelante-zorggroep.nl

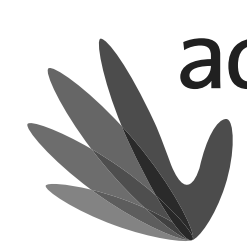

Zandbergsweg 111

6432 CC Hoensbroek, The Netherlands $\mathrm{t}+31$ (0)45- 5282828

www.adelante-zorggroep.nl 


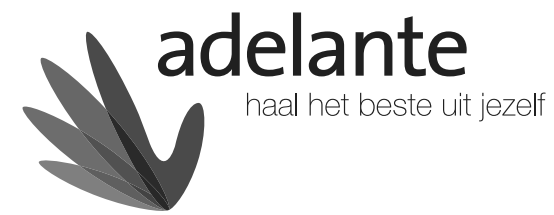

\title{
STILSTAAN... EN DOORGAAN
}

\author{
Leven na een hartstilstand
}

Deze informatie is bestemd voor mensen die een hartstilstand/circulatiestilstand overleefd hebben en hun naasten. Hierin wordt stilgestaan bij de mogelijke gevolgen van een hartstilstand op de functie van de hersenen wat kan leiden tot veranderingen in denken, voelen en gedrag, en de invloed daarvan op het dagelijks leven. $U$ krijgt informatie en tips die kunnen helpen om uw leven na de hartstilstand weer op te pakken. Misschien is niet alle informatie op u van toepassing, gebruik dan wat voor u relevant is.

Op vele vlakken een schok

Een hartstilstand is in meerdere opzichten een schok. Een hartstilstand is een schok voor het hart, een emotionele schok voor uzelf en uw naasten en een schok voor uw hersenen.

\section{Schok voor het hart}

Het hart is de motor van ons lichaam en pompt het bloed rond zodat het overal komt. Van top tot teen, en dus ook naar de hersenen. De bloedcirculatie zorgt voor aanvoer van zuurstof en voedingsstoffen naar het hele lichaam en voor de afvoer van afvalstoffen.

Tijdens een hart- of circulatiestilstand kan het hart geen bloed rondpompen en staat de bloedcirculatie tijdelijk stil. Dankzij reanimatie is, in uw geval, het hart weer op gang gebracht. Tijdens een reanimatie wordt er hartmassage gegeven en

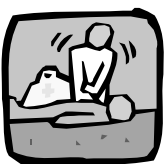
beademd. Meestal is er ook via een speciaal apparaat, een defibrillator (AED), een elektrische stroomstoot toegediend. Hierna is het hart weer gaan kloppen en is bloedcirculatie weer op gang gekomen.

\section{Schok voor uzelf en uw naasten}

Een hartstilstand is niet alleen een grote schok voor de persoon die het overkomt, maar ook voor de naasten. Het betekent dat $\mathrm{u}$ er bijna niet meer geweest was. Soms zijn uw naasten bij de hartstilstand en de reanimatie aanwezig geweest. Vaak is er een periode van onzekerheid geweest of $u$ het wel zou overleven. Dit brengt vaak gevoelens van onzekerheid en angst teweeg. En er zijn veel vragen, zoals: 'Waarom is dit mij overkomen?' of 'Hoe gaan we nu verder?'

\section{Schok voor de hersenen}

De hersenen vormen het regelcentrum van ons lichaam, ons denken en onze persoonlijkheid. De hersenen zijn vergelijkbaar met een computer: ze regelen alle processen die in ons lichaam plaatsvinden zoals bewegen, horen, zien, voelen en denken. Voor het functioneren van de hersenen is de aanvoer van bloed noodzakelijk. Tijdens de hartstilstand heeft de bloedcirculatie tijdelijk stilgestaan. Dit is een schok voor de hersenen omdat die hierdoor onvoldoende toevoer van bloed en zuurstof hebben gehad. Als een hartstilstand langer dan 5-6 minuten duurt zonder reanimatie, dan leidt dit vaak tot schade of sterfte van hersenweefsel. Hierdoor ontstaat hersenletsel.

\section{Hersenletsel}

De gevolgen van hersenletsel na een hartstilstand zijn divers en verschillen per persoon. Er kunnen veranderingen ontstaan in het bewegen, waarnemen,

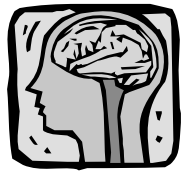
voelen en denken. Hieronder vindt $u$ informatie over veranderingen in denken, voelen en gedrag. $\mathrm{Na}$ een hartstilstand zijn er namelijk regelmatig problemen op deze gebieden. Dit worden ook wel de 'onzichtbare gevolgen' van hersenletsel genoemd. Voor buitenstaanders zijn die gevolgen namelijk niet direct te zien. Deze 'onzichtbare gevolgen' kunnen voor uzelf en uw omgeving echter heel lastig zijn.

In de eerste maanden vindt het meeste herstel plaats. $U$ merkt dan verbeteringen. Er kunnen echter ook blijvende gevolgen zijn. Het kan zinvol zijn om te kijken of $u$ bepaalde 'onzichtbare gevolgen' bij uzelf herkent. Dat is niet altijd gemakkelijk. Uw partner, naasten of een zorgverlener kunnen $\mathrm{u}$ helpen om helder te krijgen of er bij $\mathrm{u}$ iets veranderd is. We geven hieronder een aantal voorbeelden van de mogelijke gevolgen op dit gebied. 


\section{Veranderingen in denken}

Als er sprake is van hersenletsel door de hartstilstand, dan zijn de totale capaciteit van de hersenen en de snelheid van denken verminderd. Het denken gaat dan vaak lastiger en langzamer. Hieronder vindt $u$ voorbeelden van mogelijke veranderingen in het denken en een aantal TIPS om hier mee om te gaan.

- Geheugenproblemen en vergeetachtigheid: Het lukt niet meer om alles te onthouden zoals voorheen. Vooral het opslaan van nieuwe informatie gaat minder goed. Opvallend is dat informatie uit het verleden vaak nog wel goed herinnerd wordt.

TIP: Gebruik een agenda. Dit ontlast uw hersenen en voorkomt dat $\mathrm{u}$ afspraken vergeet.

- Traagheid: Het denken gaat langzamer en dagelijkse activiteiten kosten meer tijd en energie.

TIP: Plan voldoende tijd voor de belangrijke dingen die $\mathrm{u}$ wilt doen. Dagelijkse activiteiten kosten meer tijd. Het kan zijn dat u niet alles meer kan doen. Maak keuzes en zeg vaker 'nee'.

- Snel afgeleid zijn: Het is lastig om de aandacht ergens bij te houden.

TIP: Probeer in een rustige omgeving te werken zonder anderen in de buurt. Zet TV of radio uit. Dit alles voorkomt dat $u$ wordt afgeleid. Hierdoor lukt het beter uw taken uit te voeren.

- Moeite met twee dingen tegelijk doen: Het lukt niet meer goed om twee dingen tegelijk te doen, zoals bijvoorbeeld koken en tegelijkertijd een gesprek voeren. TIP: Probeer dagelijkse activiteiten na elkaar te doen in plaats van tegelijk.

- Moeite met plannen: Plannen, organiseren en overzicht houden kosten meer moeite.

TIP: Plan vooraf hoe u iets gaat ondernemen, schrijf dit op en lees het regelmatig na. Ook hierbij is een agenda een handig hulpmiddel.

- Moeheid: Zaken die voorheen automatisch gingen kosten nu meer energie. Hierdoor treedt vermoeidheid sneller op.

TIP: Deel uw taken op in kleinere porties en neem regelmatig een pauze.

- Prikkelbaarheid: Door vermoeidheid en overbelasting kan er sneller irritatie en prikkelbaarheid optreden.

TIP: Bovenstaande tips helpen $\mathrm{u}$ om overbelasting te voorkomen. Hierdoor vermindert de kans op irritatie en prikkelbaarheid.

\section{Veranderde gevoelens}

Een hartstilstand is een ingrijpende gebeurtenis en heeft invloed op uw gevoelens. Van de hartstilstand zelf kunnen de meeste mensen zich niet

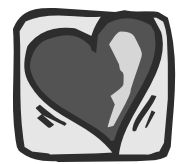
veel herinneren. Maar het feit dat dit hun zomaar is overkomen en dat er geen controle was over de situatie, is een eng idee en maakt mensen onzeker. Vaak is er ook de angst dat het nog eens zou kunnen gebeuren. Dit kan als gevolg hebben dat $u$ bepaalde activiteiten gaat vermijden. Vermijden leidt er echter toe dat de angst en onzekerheid groter worden. Beter is het om geleidelijk uw activiteiten weer op te pakken, zodat uw zelfvertrouwen weer kan groeien.

Ook het gevoelsleven kan veranderd zijn na een hartstilstand. Sommige mensen ervaren gevoelens intenser. Bij anderen zijn de emoties juist afgevlakt. Ook gevoelens van somberheid komen regelmatig voor. Soms ontstaan die sombere gevoelens pas na meerdere maanden. Er kan zelfs sprake zijn van een depressie. Het is belangrijk om na te gaan of dit bij $u$ het geval is. Behandeling van een depressie is mogelijk en bestaat meestal uit gesprekken en/ of medicijnen.

\section{Veranderingen in gedrag}

Er kan verandering van gedrag optreden. Dit kan zich op verschillende manieren uiten. Sommige personen worden impulsiever, sneller prikkelbaar of gedragen zich ontremd. Anderen gedragen zich juist erg rustig en worden passief. De persoon zelf is zich hiervan niet altijd bewust. Dit is dan vooral voor de omgeving heel lastig.

\section{Op zoek naar balans}

Het is belangrijk de balans te (her)vinden tussen activiteit en rust. Daarvoor is het nodig om er rekening mee te houden dat activiteiten nu meer energie kunnen kosten dan voorheen. Haalbare doelen

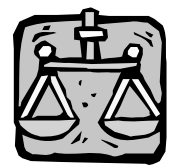
stellen is van belang om uzelf niet te overvragen. Zorg ervoor dat $\mathrm{u}$ niet te veel hooi op uw vork neemt. $\mathrm{U}$ moet daarom leren om op bepaalde momenten 'nee' te zeggen. Ook is het nodig om momenten van rust en ontspanning te zoeken. Er zijn verschillende manieren om te ontspannen. Bewegen, zoals fietsen of wandelen, geeft veel mensen een ontspannen en lekker gevoel. Bovendien is het goed voor uw conditie en gezondheid. Voor anderen kan muziek of een hobby helpen om tot rust te komen. Het is ook goed om soms gewoon even helemaal niets te doen. 


\title{
adelante \\ haal het beste uit jezelf
}

\section{EEN HARTSTILSTAND KRIJG JE NIET ALLEEN}

\author{
Informatie voor partner en naasten
}

Een hartstilstand is een grote emotionele schok voor de naaste(n) zoals echtgenoot, partner, ouder, kind of goede vriend. Het feit dat uw dierbare een hartstilstand heeft gehad, brengt veel gevoelens teweeg. Aan de ene kant bent $u$ blij dat uw dierbare er nog is. Aan de andere kant is er soms verdriet over de mogelijke gevolgen van de hartstilstand.

\section{Een ander mens}

Door een hartstilstand kan uw dierbare erg veranderen. Partners zeggen bijvoorbeeld: 'lk heb een andere man gekregen' of ' $\mathrm{Zij}$ is niet meer dezelfde persoon als voorheen'. Dit is het geval als er door de hartstilstand hersenletsel is ontstaan. Door hersenletsel kunnen namelijk het denken, gevoelens en gedrag veranderen.

Binnen een relatie kunnen er veranderingen plaatsvinden. $U$ moet bijvoorbeeld opeens taken op $u$ nemen die de ander voorheen deed. Dat kan heel lastig zijn. Ook op het relationele en seksuele vlak kunnen er veranderingen zijn. Het is belangrijk om hier open met elkaar over te praten en een oplossing te zoeken. Een zorgverlener kan hierbij helpen.

\section{Vertrouwen opbouwen}

Partners, familie en vrienden zijn vaak erg bezorgd. Dit is begrijpelijk omdat men niet wil dat hun dierbare nog eens iets dergelijks overkomt. Dit kan leiden tot overbezorgdheid. Men durft de ander dan soms niet meer alleen te laten. Dit is niet altijd het beste voor hem of haar. Het is belangrijk om weer vertrouwen op te bouwen. Dit is niet gemakkelijk en kost tijd en oefening.

\section{Zorg ook voor uzelf}

Als partner of naaste is het erg belangrijk dat $u$ ook op uw eigen gezondheid let. Zowel uw lichamelijke als mentale gezondheid worden in deze periode op de proef gesteld. Het is belangrijk dat $u$ ook goed voor uzelf blijft zorgen. Uw dierbare heeft er niets aan als $u$ het straks niet meer aan kunt. Let hier op, want overbelasting en depressie kan ook u overkomen. Geef daarom tijdig aan als het $u$ teveel wordt en zoek dan hulp, bijvoorbeeld bij familie, vrienden of uw huisarts.

Neem ook tijd voor $u$ zelf of ga er eens een dagje tussenuit. Dit kan helpen om weer energie te verzamelen. Voor partners en naasten is het een uitdaging om de balans te vinden en te behouden.

\section{Vragen helpt}

Heeft u na het lezen van deze informatiefolder nog vragen, bespreek die dan met degene die $u$ dit heeft verstrekt of met uw behandelend arts. Het is belangrijk niet rond te blijven lopen met vragen of problemen. Het lucht meestal op als u uw problemen met iemand deelt en het kan u verder helpen. 


\section{Colofon}

Auteurs: Véronique Moulaert, Caroline van Heugten en Jeanine Verbunt

(C) Copyright: 2013 Véronique Moulaert, Adelante Hoensbroek Deze uitgave mag verveelvuldigd en/of openbaar gemaakt worden uitsluitend na voorafgaande schriftelijke toestemming van de auteur.

Deze informatiefolder is ontwikkeld in het kader van een wetenschappelijk onderzoek met de titel 'Leven na een Hartstilstand'. De Engelse titel van dit onderzoek is: 'Activity and Life After Survival of a Cardiac Arrest', en wordt afgekort als ALASCA. In dit onderzoek werd gekeken naar de lange termijn gevolgen van een hartstilstand en de effectiviteit van een nieuw nazorgprogramma. Het onderzoek is een samenwerking tussen revalidatiecentrum Adelante in Hoensbroek, Universiteit Maastricht en het Academisch Ziekenhuis Maastricht. Voor meer informatie over dit onderzoek, zie www.alasca.nl.

Deze publicatie wordt inhoudelijk ondersteund door de Nederlandse Reanimatie Raad.

\section{ADELANTE}

Adelante ondersteunt volwassenen en kinderen bij het herstel of het leren omgaan met de gevolgen van een ziekte, aangeboren aandoening of ongeval. Het sportgezondheidscentrum maakt deel uit van Adelante volwassenenrevalidatie en arbeidsreïntegratie. Hier kunt $u$ terecht voor alle mogelijke vragen en behandelingen binnen de revalidatiegeneeskunde. Daarnaast richt de zorg van Adelante zich ook op kinderrevalidatie, speciaal onderwijs en wonen en audiologie en communicatie. In het kenniscentrum van Adelante wordt continu onderzoek verricht naar zorgvernieuwing en verbetering van behandelmethoden. De ruim 1.000 professionals van Adelante zijn werkzaam in Hoensbroek, Valkenburg a/d Geul, Heerlen, Maastricht, Venlo en Steijl. Daarnaast is Adelante actief in de poliklinieken van ziekenhuizen en in de ambulante begeleiding.

Meer algemene informatie over Adelante treft $u$ aan op: www.adelante-zorggroep.nl

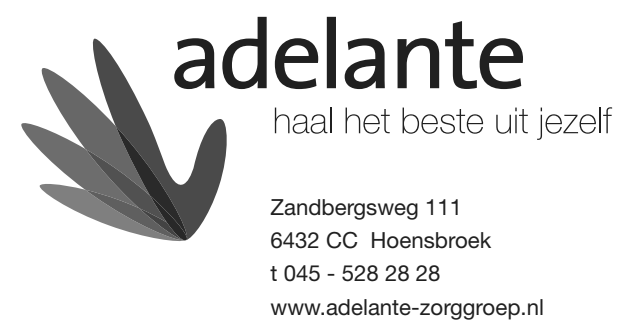


Dankwoord 
Wat een geluk heb ik gehad met mijn promotieteam: Jeanine Verbunt, Caroline van Heugten en Derick Wade. Uiteindelijk 100\% professoren. Dankbaar ben ik dat jullie me al die jaren begeleid hebben.

Jeanine, je gaf me de ruimte, was er altijd waar nodig en was op alle vlakken betrokken. Je bent een geweldige begeleider! Mooi hoe jij onderzoek en patiëntenzorg weet te combineren.

Caroline, jouw enthousiasme en kennis over hersenletsel zijn voor mij een bron van inspiratie. Fijn om met jou te mogen samenwerken.

Derick, it was an honour and a pleasure to work with you. I highly value your expertise and practical approach and have learned so much from you. Thank you for all your support.

Mijn begeleidingsgroep bestond uit enthousiaste experts uit verschillende vakgebieden: Ton Gorgels, Marc de Krom en Wip Bakx.

Ton, dank voor jouw cardiologische inbreng, want natuurlijk zijn toch ook de cardiale aspecten van een hartstilstand van belang. Ik bewonder jouw passie en inzet voor het bevorderen van reanimatie op de universiteit, op scholen en in buurten.

Marc, jouw scherpe opmerkingen en neurologische bril waren een belangrijke aanvulling voor ons team. Fijn om met jou hierover van gedachten te kunnen wisselen.

Wip, het idee voor dit onderzoek ontstond toen Jeanine Verbunt bij jou op de afdeling werkte. Eerst was je mijn supervisor, daarna opleider en intussen zijn we directe collega's geworden. Voor mij is het een eer dat ik daarbij naast je mag staan.

Betrokken adviseurs hebben mij en mijn onderzoek ondersteund.

Peter Heuts, bedankt voor jouw inbreng bij het ontwikkelen van de nazorginterventie. Fijn dat je nu weer in de buurt bent.

Jolanda van Haastregt, jij had een belangrijke rol in het bedenken en uitvoeren van de procesevaluatie. Jouw kennis was hierbij heel waardevol en je enthousiasme werkt aanstekelijk.

Mariëlle Goossens, bedankt voor jouw advies over hoe de kosteneffectiviteit van de interventie bepaald kan worden. Hier gaan we nog verder mee aan de slag.

Bjorn Winkens, veel dank voor je statistische adviezen en heldere uitleg.

Martine Moennekens, je was de onafhankelijke arts van dit onderzoek. Bij jou op de afdeling heb ik de eerste stappen in de revalidatie gezet. De hele weg heb jij me gevolgd, vaak onder het genot van een kop thee. Wij zijn nu directe collega's geworden en daar ben ik blij mee.

Graag bedank ik de beoordelingscommissie van dit proefschrift: Prof. dr. Rob Smeets, Prof. dr. van Oostenbrugge, Prof. dr. Ponds, Prof. dr. Visser-Meily en Dr. Koster.

Beste Rob, eerste vakgroephoogleraar revalidatiegeneeskunde in Maastricht en voorzitter van de beoordelingscommissie. Ik ben blij met jouw komst en wil je bedanken voor de steun die je me geeft om mijn onderzoek voort te zetten. 
Zeven ziekenhuizen hebben meegewerkt aan dit onderzoek en er zijn veel mensen die ik daarvoor mag bedanken. Van Zuid naar Noord:

- Mastricht Universitair Medisch Centrum, in het bijzonder Bas Bekkers, Dennis Bergmans, Jean Partouns, Chris Bout, Petra Erkens en Barbara Engelen.

- $\quad$ Atrium Medisch Centrum Heerlen, in het bijzonder J. Kragten, T. Lenderink, C. Punt, M. van der Woude, Jean-Pierre Geuskens, Irma Kremer, Caroline Jochems, Rob Lardinois, Harry de Leger, Simone Veldkamp, Ed Vondenhoff en de dames van de IC: Ien, Claudia, Linda en Phyllis.

- $\quad$ Orbis Medisch Centrum Sittard, in het bijzonder C. Hoorntje en M. van Daele.

- $\quad$ Laurentius Ziekenhuis Roermond, in het bijzonder Fleur Nooteboom en C. Werter.

- $\quad$ St. Jans Gasthuis Weert, in het bijzonder A. Lucassen en Will de Goey.

- $\quad$ Máxima Medisch Centrum in Veldhoven, in het bijzonder R. Verbunt, A. de Gooijer en Patric Dierckx.

- $\quad$ Catharina Ziekenhuis Eindhoven, in het bijzonder R. Michels, Harold Helmes, Antoinette Spierings en Peter van Leeuwen.

De nazorginterventie werd gegeven door enthousiaste verpleegkundigen: Brigitte Cobben, Marij Houben, Sandra ljselmuiden, Coby Vink, Marion van Kranen, Yvette Vuyk en Gusta Eekhof. Het was een plezier om met jullie samen te werken!

Ook wil ik grote dank uitspreken aan alle deelnemers aan het onderzoek. Uw inzet draagt bij aan verbetering van de zorg na een hartstilstand.

Ik wil al mijn collega's bij Adelante en de Universiteit Maastricht bedanken voor hun betrokkenheid. Een aantal mensen wil ik daarbij in het bijzonder benoemen:

Sita van Riet, jij maakte de database waarmee we goed overzicht konden houden over de hele logistieke kant van het project. Daar heb ik heel veel aan gehad.

Irma Nelissen, Nicole Driessens en Veronique van der Woude, bedankt voor jullie geweldige logistieke ondersteuning. Ook Jolanda Kerstges en Margareth van Krevel wil ik bedanken voor het organiseren van een goede en gezellige onderzoeksomgeving.

Dertien onderzoeksassistenten hebben Limburg en Brabant afgereisd om alle deelnemers thuis te bezoeken: Suzanne, Vera, Rob, Irene, Maroeska, Sanne, Famke, Lisanne, José, Magda, Anouk, Maud en Nienke. Heel erg bedankt voor jullie hulp.

Fijne kamergenoten maken het dagelijks werk leuker: Ananda, Annemie, Annick, Han, Hanne, Iris, Ivan, Carolien, Patrick, Ragma, Reni, Ryanne, Sascha, Thamar, Vera en Vera. Bedankt!

Esther Wachelder, ik vond het leuk om met jou onderzoek te doen, zowel tijdens jouw wetenschapsstage als tijdens onze opleiding tot revalidatiearts. Bedankt dat ik jouw artikel (hoofdstuk 2) heb mogen opnemen in dit proefschrift. 
Anneke, wij verdiepten ons samen in mixed model analyses, de moeilijkste statistiek van mijn hele onderzoek. En zo werd ik niet alleen vrienden met mijn data, maar ook met jou.

Peter Muris, mijn eerste stappen in de wereld van onderzoek deed ik bij jou. Samen met Björn heb je me laten ontdekken hoe leuk onderzoek is.

Maarten Verwijnen, begeleider van mijn wetenschapsstage van psychologie en geneeskunde. Ik ben je nog altijd dankbaar voor de manier waarop je me toen begeleid en gesteund hebt.

Ik vind alleen de rust om geconcentreerd te werken als ik weet dat er goed gezorgd wordt voor onze kinderen. Hiervoor wil ik Tamara Gabbano en de juffies van kinderdagverblijf Noach en de Bernard Lievegoed School bedanken. Een speciaal woord van dank voor Mariange Lemmens, voor jouw bijzonder liefdevolle zorg.

Michaël, Idwine en Lidewij, lieve paranimfen. Wij gaven als adviescommissie heel wat gevraagd en ongevraagd advies. Van Vleuten, Maastricht tot Zwitserland, fijn dat jullie er zijn.

Vrienden maken het leven mooi. Ik ben zo blij met alle vrienden die ik heb!

Lieve mama, wat fijn dat jij mijn mama bent. Ik ben dankbaar voor alles wat je me mee gegeven hebt en voor al je steun. Jij hebt de gave om van ieder mens 'het goede' te zien en dat bewonder ik. Mijn papa is er voor mij intussen al veel langer niet dan wel. Op zulke speciale momenten mis ik je meer.

Ik heb twee lieve grote zussen, Françoise en Brigitte, Swaas en Biche. Biche, bedankt ook voor je hulp met het ALASCA logo, teksten en het interview.

Lieve Danne, lieve Seppe. Wat een geluk dat jullie bij ons zijn. Door jullie ogen mag ik de wereld weer mee opnieuw ontdekken.

Zo zie ik 's ochtends als ik wakker word direct waar het écht om gaat...

Ward, mijn lief. Met jou deel ik mijn hart. 



\section{Curriculum Vitae}

List of publications 
174 | Curriculum Vitae 


\section{Curriculum Vitae}

\section{Véronique R.M. MOULAERT}

Date and place of birth: 16-09-1976 in Zeist, The Netherlands

Marital state:

Married, two children (born in 2009 and 2011)

Nationality:

Belgian

E-mail:

v.moulaert@adelante-zorggroep.nl

\section{Current work positition}

Consultant in rehabilitation medicine and researcher

- $\quad$ Adelante, Brain Injury Department/ Centre of Expertise in Rehabilitation and Audiology, Hoensbroek, The Netherlands

- $\quad$ Department of Rehabilitation Medicine, CAPHRI, Maastricht University

\section{Training \& education}

Trainee in rehabilitation medicine \& research (AIOSKO), Circuit Limburg/ Adelante, 2005 - 2012 Medical School, Maastricht University, 1999 - 2005 (artsexamen)

Master in Psychology, Maastricht University, 1995 - 2002

University College Utrecht, Pre-medical track, 1998 - 1999

Vrije Hogeschool, Driebergen, 1994 -1995

High School (VWO), Montessori Lyceum Herman Jordan, Zeist, 1988 - 1994

\section{Management experience}

Concilium VRA, National Educational Board, Rehabilitation Medicine, 2009 - 2011

Kerngroep VRA, Chair of association for trainees in Rehabilitation Medicine, 2009-2011

Exam Committee Faculty of Medicine, student member, 2000 - 2001

Educational Board Faculty of Medicine, student member, 1999 - 2001

MaasSAC climbing association, Board, Educational Board and Advisor, 1996 - 2001

International experience

Clinical rotations abroad (co-schappen):

Primary Health Care, Mexico City and jungle of Chiapas, Mexico, May - June 2005

Dermatology, Ghent, Belgium, August 2004

Gynaecology \& Obstetrics, Paramaribo, Suriname, April - May 2004

Psychiatry, Veterans Hospital, Syracuse, United States, June - July 2003

Traditional Chinese Medicine, Chengdu, China, May - June 2002 


\section{Invited lectures}

1. Moulaert VR. Systematic subacute intervention after cardiac arrest. World Federation of Neurological Rehabilitation, Istanbul, 09-04-2014. Presented at Symposium 'Cerebral anoxia: predictive factors, cognitive functions and functional outcome', organised in co-operation with A. Peskine (France), C. Luyt (France) and C. Hofgren (Sweden).

2. Moulaert VR. Gereanimeerd en dan? Nieuw nazorgprogramma verbetert kwaliteit van leven. 11e Nationale Reanimatie Congres, Nieuwegein, 12-03-2014.

3. Moulaert VR. New psychosocial intervention improves quality of life after cardiac arrest. Netherlands Society of Physical and Rehabilitation Medicine (VRA), Noordwijkerhout, 01-112013. Presented at symposium 'How to treat survivors of a cardiac arrest: from acute care to rehabilitation', organised in co-operation with P. Goossens (Rijnlands Revalidatiecentrum, Leiden).

4. Moulaert VR. Outcome of cardiac arrest survivors: cognition, daily activities and quality of life. Resuscitation, Vienna, 18-10-2012.

5. Moulaert VR. Quality of survival, first results of the ALASCA study. 7e Nationale Reanimatie Congres, Nieuwegein 02-06-2010.

\section{Awards}

1. Best of the Best abstracts: Resuscitation, Krakow, 26-10-2013. Invited to join the Editorial Board of Resuscitation

2. Young investigator Competition, runner-up: Resuscitation, Krakow, 26-10-2013.

3. Best presentation award: Moulaert VR \& Wachelder EM. Life after survival. Netherlands Society of Physical and Rehabilitation Medicine (VRA), Ermelo, 12-11-2010.

4. Poster award: Moulaert VR, Schrander JJP, Dunselman GAJ, Scherpbier AJJA. The new curriculum of Maastricht University. Network Congres, Bahrain, 21-10-2000. 


\section{List of publications}

1. Moulaert VR, van Haastregt JCM, Wade DT, van Heugten CM, Verbunt JA. 'Stand still ..., and move on', an early neurologically-focused follow-up for cardiac arrest survivors and their caregivers: A process evaluation. (2014). BMC Health Services Research, 14:34.

2. Duvivier RJ, van Dalen J, Muijtjens AM, Moulaert VR, van der Vleuten CP, Scherpbier AJ. The role of deliberate practice in the acquisition of clinical skills. (2011). BMC Medical Education, 11(1):101.

3. Moulaert VR, Verbunt JA, Bakx WG, Gorgels AP, de Krom MC, Heuts PH, Wade DT, van Heugten CM. 'Stand still ..., and move on', a new early intervention service for cardiac arrest survivors and their caregivers: Rationale and description of the intervention. (2011). Clinical Rehabilitation, 25 (10), 867-879.

4. Moulaert VR, Wachelder EM, Verbunt JA, Wade DT, van Heugten CM. Determinants of Quality of Life in Survivors of Cardiac Arrest. (2010). Journal of Rehabilitation Medicine, 42 (6), 553-558.

5. Wachelder, EM, Moulaert VR, Verbunt JA, van Heugten CM, Bekkers SCAM, Wade, DT. Life After Survival: Long Term Daily Functioning and Quality of Life after an Out-of-hospital cardiac arrest. (2009). Resuscitation, 80 (5), 517-522.

6. Moulaert VR, Verbunt JA, van Heugten CM, Wade DT. Cognitive Impairments in Survivors of Out-of-hospital Cardiac arrest: a Systematic Review. (2009). Resuscitation, 80 (3), $297-$ 305.

7. Moulaert VR, Verbunt JA, van Heugten CM, Bakx WG, Gorgels APM, Bekkers S, de Krom MC, Wade DT. Activity and Life After Survival of a Cardiac Arrest (ALASCA) and the effectiveness of an early intervention service: design of a randomised controlled trial. (2007). BMC Cardiovascular Disorders, 7(1):26.

8. Middelkamp W, Moulaert VR, Verbunt JA, van Heugten CM, Bakx WG, Wade DT. Life after survival: long term daily life functioning and quality of life of patients with hypoxic brain injury as a result of a cardiac arrest. (2007). Clinical Rehabilitation, 21 (5), 425-431.

9. Rikers RMJP, Schmidt HG, Moulaert VR. Biomedical Knowledge: Encapsulated or Two Worlds Apart? (2005). Applied Cognitive Psychology, 19 (2), 223-231.

10. Moulaert VR, Verwijnen MGM, Rikers R, Scherpbier AJJA. The effects of deliberate practice in undergraduate medical education. (2004). Medical Education, 38, 1044-1052.

11. Muris P, Merkelbach H, Gadet B, Moulaert VR. Fears, worries, and scary dreams in 4- to 12-year-old children: Their content, developmental pattern, and origins. (2000). Journal of Clinical Child Psychology, 29 (1), 43-52.

12. Muris $P$, Kindt M, Bögels S, Merkelbach $H$, Gadet B, Moulaert VR. Anxiety and threat perception abnormalities in normal children. (2000). Journal of Psychopathology and Behavioral Assessment, 22 (2), 183-199.

13. Muris P, Merckelbach $H$, Moulaert VR, Gadet B. Associations of symptoms of anxiety disorders and self-reported behavior problems in normal children. (2000). Psychological Report, 86 (1), 157-162. 
14. Muris P, Merkelbach H, Gadet B, Moulaert VR, Tierney S. Sensitivity for treatment effects of the Screen for Child Anxiety Related Emotional Disorders. (1999). Journal of Psychopathology and Behavioral Assessment, 21 (4), 323-335.

15. Muris $P$, Gadet B, Moulaert VR, Merckelbach H. Correlations between two multidimensional anxiety scales for children. (1998). Perceptual and Motor Skills, 87 (1), 269-270.

16. Muris P, Merckelbach H, Mayer B, van Brakel A, Thissen S, Moulaert VR, Gadet B. The Screen for Child Anxiety Related Emotional Disorders (SCARED) and traditional childhood anxiety measures. (1998). Journal of Behavior Therapy and Experimental Psychiatry, 29 (4), 327-339.

\section{Contributions to books}

1. Moulaert VR, van Heugten CM, Verbunt JA. Book chapter: Hypoxisch Hersenletsel na een reanimatie. Handboek voor Revalidatiepsychologie. Uitgeverij Boom. Submitted.

2. Scherpbier AJJA, Crebolder HFJM, Daemen MJAP, Damen JL, Dunselman GAJ, Farla PB, Hillen HFP, Kolle LFJThM, Leiner T, Moulaert VR, Nijhuis JG, Oosterhof I, Rosing J, Schrander JJP, Snellen HAM, Snoeckx, LHEH, Verwijnen GM, van der Vleuten CPM, Wesseling GJ. (2000). Voorstel voor het Nieuwe Maastrichtse Curriculum. Maastricht. 


\section{Interview met Véronique}

door Brigitte Moulaert 
180 | Interview met Véronique 


\section{Verwisseling}

Het leven van Véronique begon wat verwarrend. 'Bij mijn geboorte ben ik in het ziekenhuis verwisseld geweest met een ander meisje, precies even oud, even zwaar en even lang. Mijn moeder werd niet geloofd toen ze zei dat het meisje in haar armen haar kind niet was. Gelukkig heeft mijn moeder volgehouden en kwam ik snel bij mijn eigen ouders terug.' Dit voorval geeft aanleiding tot speculatie hoe dingen anders hadden kunnen lopen. Het leven wordt enerzijds bepaald door toeval, de mogelijkheden die op je pad komen, het gezin waar je geboren wordt en dat wat je overkomt. Anderzijds hangt het ervan af wat je met die kansen doet.

\section{Leer het mij zelf te doen}

De schoolperiode van Véronique begon op een kleine katholieke basisschool in het bos. 'De leraren namen daar ook de tijd om met ons te kijken naar de vogels en eekhoorntjes in de bomen.' Voor de middelbare school maakte Véronique haar eigen keuze, ze ging naar het Montessori Lyceum Herman Jordan in Zeist. Op de muur stond geschreven: 'Leer het mij zelf te doen'. En dit paste heel goed bij haar.

Voordat Véronique ging studeren heeft ze een jaar de Vrije Hogeschool in Driebergen gedaan. 'Misschien is dit wel de belangrijkste opleiding die ik heb gehad. Het was een jaar met ruimte voor creativiteit en een jaar waarin ik uit heb uitgezocht wat ik nu echt wilde worden. Lang had ik me verzet om geneeskunde te willen gaan doen, want mijn vader was kindercardioloog en mijn zus was ook al arts. Maar het bleek toch te zijn wat ik echt wilde doen.'

Groot was de teleurstelling toen ze vervolgens werd uitgeloot voor geneeskunde. Het duurde uiteindelijk 4 jaar voor ze met geneeskunde kon beginnen. 'Dat heeft me behoorlijk op de proef gesteld, maar nu ben ik dankbaar dat het zo gelopen is.'

\section{Lekker lang leren}

In afwachting van haar inloting begon Véronique met de studie psychologie in Maastricht. 'Het Maastrichtse onderwijssysteem sprak me aan en er startte daar een nieuwe opleiding; dat leek me wel een interessant experiment voor een jaartje.' Het werden er vier en uiteindelijk heeft ze de studie psychologie afgemaakt. 'Eigenlijk ligt daar een belangrijke basis voor wat ik nodig heb in mijn huidige werk als revalidatiearts en onderzoeker. Ik leerde over hersenen, emoties, gedrag en leren.' Ze deed ook al snel zelf ervaring op met onderzoek als student-assistent. 'Op basisscholen interviewden we kinderen over hun angsten en dromen. We werden volledig bij het onderzoek betrokken en zo ontdekte ik dat ik onderzoek leuk vind.'

Tijdens haar studie geneeskunde heeft Véronique veel gereisd. De co-schappen brachten haar naar China, de Verenigde Staten, Suriname en Mexico. 'Ik heb veel van de wereld mogen zien. Zo leer je met andere ogen te kijken.'

$\mathrm{Na}$ haar studies koos Véronique voor revalidatiegeneeskunde. 'Het is een mooi vak omdat er aandacht is voor de mens als geheel. Met een heel team proberen we revalidanten te begeleiden om weer vooruit te komen. Hierin komen mijn beide studies mooi samen.' 


\section{Buiten werktijd}

Moeder, vrouw, arts en onderzoeker. 'Mijn leven met werk en gezin is vol en rijk. Mijn kinderen Danne en Seppe helpen me om prioriteiten te stellen. Het is leuk en bijzonder om de wereld weer opnieuw te zien door de ogen van de kinderen. Ook maak ik met hun weer tijd voor creativiteit, muziek en lezen. Zo groei ik met ze mee.'

Om te ontspannen gaat ze het liefste naar buiten. 'Ik heb beweging nodig om me goed te voelen.' In vakanties zoekt ze met Ward en de kinderen het buitenleven op. Maar ook in Maastricht zijn natuur en rust altijd dichtbij. 'En we wandelen in het weekend graag even naar België.'

Daar liggen namelijk de roots van Véronique. 'Mensen zijn verbaasd als ze horen dat ik Belgisch ben. Ik voel me daarom vaak een Belg in vermomming.' Ze heeft duidelijk van beide culturen wat meegekregen en lijkt dat ook te koesteren.

\section{Le petit prince}

Op de achterkant van dit proefsschrift staat een bijzondere zin: 'I'essentiel est invisible pour les yeux'. Deze zin komt uit het boek Le petit prince. 'Toen mijn ouders in 1967 voor een periode met de boot naar Amerika gingen was dit één van de twee boeken die mijn moeder meenam.' Le petit prince gaat over een kleine prins van een verre planeet die een reis maakt door het heelal. Op die reis verwondert hij zich met open ogen over de mensen die hij tegenkomt. Zo komt hij er steeds meer achter wat echt belangrijk is en besluit hij terug te keren naar waar zijn hart echt ligt.

\section{L' essentiel est invisible pour les yeux}

Extra reden dat deze zin uit Le petit prince een plek kreeg op de kaft van dit proefschrift is omdat het ook goed past bij het thema van het onderzoek dat Véronique gedaan heeft. Dit proefschrift laat zien dat een hartstilstand gevolgen heeft voor hart én hersenen. Zo blijkt dat cognitieve en emotionele problemen na een hartstilstand vaak voorkomen. Dit worden ook wel de 'onzichtbare' gevolgen van hersenletsel genoemd. Deze 'onzichtbare' gevolgen bleken een grote impact te hebben op de kwaliteit van leven. 'Wij ontwikkelden daarom een nieuw nazorgprogramma met speciale aandacht voor die gevolgen. Het blijkt dat deze nieuwe aanpak werkt en dat daarmee de kwaliteit van leven na een hartstilstand aanzienlijk verbetert.'

\section{De kracht van combineren}

Tijdens haar opleiding tot revalidatiearts en klinisch onderzoeker heeft Véronique patiëntenzorg en onderzoek afgewisseld en gecombineerd. 'Deze combinatie was best pittig maar ook heel afwisselend en inspirerend.'

Véronique is nu revalidatiearts op een klinische afdeling voor patiënten met niet-aangeboren hersenletsel bij revalidatiecentrum Adelante in Hoensbroek. 'Regelmatig nemen we mensen op die een hartstilstand overleefd hebben en dat motiveert me om verder te blijven gaan met mijn onderzoek. Ik ben er namelijk nog lang niet klaar mee.' 


\section{Klaar voor de toekomst}

Het onderzoek dat Véronique gedaan heeft krijgt veel aandacht. De nieuwe manier waarop zij kijkt naar reanimatiepatiënten blijkt ook anderen aan te spreken. Zo ontving ze recent twee prijzen op een internationaal reanimatiecongres en werd ze gevraagd voor de editorial board van tijdschrift Resuscitation. Ook wordt ze regelmatig uitgenodigd om lezingen te geven in binnenen buitenland.

'Voor mij is mijn promotie geen eindstation. Ik wil mijn werk als revalidatiearts blijven combineren met wetenschappelijk onderzoek.' Dankzij het Kootstra Talent Fellowship, een beurs die zij net gekregen heeft van de Universiteit Maastricht, heeft ze nu ook de mogelijkheid om haar eigen onderzoek verder uit te gaan bouwen. 



\section{Life after survival of a cardiac arrest \\ The brain is the heart of the matter}

Een hartstilstand is een ingrijpende gebeurtenis voor patiënten en hun naasten. Dit proefschrift toont aan dat een hartstilstand gevolgen heeft voor hart én hersenen. Zo bleek dat cognitieve en emotionele problemen vaak voorkomen na een hartstilstand. Deze 'onzichtbare' gevolgen bleken ook een grote impact te hebben op de kwaliteit van leven.

Wij ontwikkelden daarom een nieuw nazorgprogramma waarin speciale aandacht was voor die 'onzichtbare' gevolgen van een hartstilstand. Deze nieuwe aanpak bleek te werken en zorgde voor een betere kwaliteit van leven. 